\title{
Plate Tectonic Evolution and Mineral Resource Potential \\ of the Lancang River Zone, Southwestern Yunnan, People's Republic of China
}

\author{
Dissertation \\ zur Erlangung des Doktorgrades \\ der Mathematisch-Naturwissenschaftlichen Fakultäten \\ der Georg-August-Universität zu Göttingen
}

\author{
vorgelegt von \\ Klaus Heppe \\ aus Warstein (NRW)
}

Göttingen 2004 
D 7

Referent: Prof. Dr. B. Lehmann

Korreferent: Prof. Dr. D. Bannert

Tag der mündlichen Prüfung: 9. Juni 2004 


\section{Abstract}

The geology of West Yunnan plays a key role in understanding the tectonic development of Southwest China and bordering countries. In the scientific literature, not only the Himalayan (cf. Tapponier et al., 1982, 1986; Dewey et al., 1988, 1989; Houseman and England, 1993; Leloup et al., 1995; Wang and Burchfiel, 1997), but also the Late Paleozoic and Mesozoic geodynamic evolution of South and West Yunnan is the subject of heated debate. In every case, there is general agreement that the present geological situation is primarily attributable to the evolution of the Tethys (Hsü and Bernoulli, 1978, Sengör, 1979, 1981, 1982) and the assumption that Southeast Asia constitutes a mosaic of Gondwana-derived terranes (e.g. Bunopas and Vella, 1978; Mitchell, 1981; Sengör, 1985; Hutchison, 1989; Metcalfe, 1988, 1996, 1998). Although investigations constraining the timing of rift, drift and collision have been of prime importance within the last two decades (e.g. Helmcke and Lindenberg, 1983; Helmcke, 1984, 1985; Huang et al., 1984; Metcalfe, 1993, 1995; Zhong et al., 1999; Zhong et al., 2000; Chonglakmani et al., 2001), the crucial question of how many micro-continents split off from Gondwana, drifted in the Tethys and collided with Eurasia, has not been satisfactorily answered. In this debate, the Lancang River Zone (Lancangjiang) is believed to hold a key position in tracing the major divide between Gondwana and Eurasia and has been the subject of a range of interpretations since the early 1980's. This study re-evaluates the existing data and presents an integrated tectono-sedimentological, geochronological and geochemical approach to the Lancang River Zone. The Late Paleozoic and Mesozoic geodynamic evolution and its mineral resource potential can be summarized as follows:

[1] A near-shore continental rift or back-arc basin with strong bathymetric variation must have existed from the Upper Devonian to the middle Lower Permian along the present Lancang River Zone. The extension phase, which led to the creation of the basin, is in time and facies related to the expanding continental margin of the Yangtze Platform in the Devonian and Lower Carboniferous (Feng and Helmcke, 2001, Heppe, 2002). During the rifting phase, basic to acid volcanic rocks were extruded in a submarine environment to form small-scale Kuroko-type volcanogenic massive sulfide (VMS) deposits. They form a belt along the central and southern Lancang River. Deposits of this type are Sandashan, Yinzishan, Dapingzhang and Xincun.

[2] Characterized by an eastward progressing deformation front, closure of the basin began in the Upper Carboniferous and progressed from the present west to east (Feng et al., 2001). This closure was associated with the formation of an accretionary wedge on the west side, in which the volcanogenic-hosted massive sulfide deposits were sheared. The stockworks of the Dapingzhang and Sandashan deposits are strongly tectonized and lie within the zone of the weakly- or unmetamorphosed accretionary wedge. From this belt to the present west, the deformation increases parallel to the gradual change from greenschist- (Phyllite Belt) to lower blueschist facies (Lancang Group) documenting a large-scale thrust belt or accretionary wedge (in terms of Sengör and Okurogullari, 1991).

[3] The closure of the basin led to the exhumation of the blueschist- and greenschistmetamorphosed rocks and the formation of a land area on the western edge of the 
Yangtze Platform up to the Middle Permian. The mineral resource potential related to this stage is estimated to be low.

[4] Late Paleozoic orogenesis was followed by marine ingressions, post-orogenic bimodal rift volcanism and continental sedimentation. The volcanism is an expression of a regional thermal event causing crustal anatexis and the formation of the Lincang Granite. The petrology and geochemistry of the basalts along the Lancang River are identical to the continental flood basalts of the Emeishan Large Igneous Province (LIP), which are proposed to be mantle-plume related (Xu et al., 2001; Chung, 1998). Hence, the new plate tectonic model excludes a Mesozoic island-arc setting and expectations of finding large-scale Au-bearing porphyry copper deposits cannot be met (Heppe and Helmcke, 2003). Nevertheless, a close correlation between the volcanic rocks along the Lancang River and the Emeishan flood basalts (and rhyolites) opens up a new perspective: Ore deposits in relation to large scale continental rifting, such as 1] Native Cudeposits of Keweenaw-type (Keweenaw rift, Precambrian, Superior Province, Canada), 2] Ni-Cu-PGE deposits of Norilsk-Talnakh-type, Siberian Traps, or 3] Volcanic red-bed Cu-deposits. The mineral deposit potential of the Lincang Granite is low. Although the Lincang Granite has the chemistry of prospective tin granites, the similarity to the North Thai Granite Province discourages a high mineral potential.

[5] In the Upper Triassic, weak compression and basin inversion took place along the Lancang River Zone. The cause of this compression is unclear but could be associated with the collision of the Tengchong micro-continent further to the west. No mineralizations are known in relation to this event along the Lancang River Zone.

[6] A regional extensional phase took place from the Upper Jurassic to the Paleogene, and the exhumation of the Lincang Metamorphic Core Complex controlled the deposition of massive sequences of continental red-beds in the Simao Region. The geometry of the basin can best be explained by a retreating plate boundary (in the sense of Royden, 1993) to the west of the Tenasserim-Mogok Belt causing extension and the formation of a retro-arc basin in the hinterland. Extension was accommodated along predisposed anisotropies of the Late Paleozoic accretionary wedge and led to the formation of west-dipping low-angle normal faults, along which cool lithospheric mantle material was progressively replaced by hot asthenospheric mantle causing or enhancing a plateau-like uplift to the east of the Doi-Inthanon-Lincang Unit and a depression in the Yunxian-Lanpang Unit (Min et al., 2001). In contrast to Yano et al. (1994), who relates the source of the continental red-beds to the emplacements of granites in the Mogok-Tenasserim Belt, this study regards the depositional features to be primarily controlled by the exhumation of the Lincang Metamorphic Core Complex and the uplift of the Doi-Inthanon Lincang Unit. In relation to this stage sediment-hosted stratiform Cu- or red-bed Cu-deposits evolved.

[7] If the mechanics forming the Simao Basin are fundamentally correct, the local consequence for western Yunnan is that a middle Cenozoic inversion of the Simao Basin must have been largely accommodated by the readjustment of formerly extensional allochthons, which progressively led to a complex interplay of thrusting, folding, faulting and rotation. During this period a whole spectrum of mineralization developed as a 
result of the high fluid flow in the transtensional settings of the India-Asia collision in West Yunnan. Copper porphyries occur in addition to polymetallic vein mineralization and Au-quartz veins.

The results of this study refine and corroborate the regional geodynamic model as postulated by Helmcke $(1985,1986)$, Helmcke et al. (1993), and Ingavat-Helmcke and Helmcke (1994). A differentiation between an "eo-" or "pre-Indosinian" (Late Paleozoic) stage of mountain-building, that was related to high-pressure/low temperature metamorphism and convergence, and an Indosinian (Late Paleozoic) stage of low-pressure/hightemperature metamorphism, that was related to extension and crustal anatexis, is demonstratively recorded along the Lancang River Zone. On a regional scale, the cyclic Cordilleran character of the evolution is further stressed by the Late Triassic accretion of the Tengchong continental fragment, and the Jurassic to Early Tertiary exhumation of an extensive N-S-striking belt of metamorphic core complexes with accompanying red-bed basins (e.g. Simao Basin, Lanping Basin). The process that facilitated extension is speculated to be primarily controlled by a retreating active plate-boundary to the west of the Jurassic to Miocene Mogok-Tenasserim Belt (continental island arc, Barley et al., 2003), which parallels the core complexes and red-bed basins throughout Southwest Yunnan, the eastern part of the Union of Myanmar (Burma), West Laos and northern Thailand. As far as the Cretaceous development is concerned, the plateau-like uplift of the DoiInthanon-Lincang Unit and the depression of the Yunxian-Lampang Unit may be further traced to circum-Himalayan regions. 
Contents

1. Introduction 1

1.1. Study Objectives $\quad 1$

1.2. Preliminary Work by the Research Group in Yunnan 1

1.3. Location of the Study Area, Morphology, Vegetation and Climate 2

2. Geodynamic Evolution of Southwestern Yunnan 4

2.1. Introduction $\quad 4$

2.1.1. Model A: Large-scale Nappe Tectonics 4

2.1.2. Model B: "Two-Tethys Ocean System" and "Archipelagic-Ocean Model" 6

2.1.3. Model C: Permo-Triassic (Late Variscan) Cordillera with Exotic Terranes 7

2.2. Major Tectonic Elements in Southwestern Yunnan 8

2.2.1. Tengchong Block 11

2.2.2. Nujiang Fault Zone 12

2.2.3. Baoshan Block 12

2.2.4. Changning-Menglian Zone 13

2.2.5. Lincang Region 14

2.2.6. Lancangjiang Fault Zone 14

2.2.7. Lanping-Simao Block 15

2.2.8. Ailaoshan-Red River Zone 15

2.2.9. Yangtze Paraplatform $\quad 15$

2.3 Integration within the Geodynamic Evolution of Southeast Asia 16

3. The Lancang River Zone (LRZ) 19

3.1. Introduction $\quad 19$

3.2. Metamorphic Evolution $\quad 22$

3.2.1. Damenglong and Chongshan Group 22

3.2.2. Lancang Group $\quad 29$

3.2.3. Lancang River Phyllite Belt $\quad 39$

3.3. Magmatic Evolution $\quad 41$

3.3.1. Lincang Granite 41

3.3.2. Lancang River Volcanic Rocks $\quad 47$

3.4. Sedimentary Evolution 56

3.4.1. Profiles along the Lancang River (North to South) 56

3.4.1.1. Wennai, East of Lancang River and Nanguan 56

3.4.2. Profiles Parallel to the Lancang River (West to East) 58

3.4.2.1. Dapingzhang 58

3.4.2.2. Yunxian 58

3.4.2.3. Manbie 60

3.4.2.4. East of Jinghong 61

3.4.2.5. East of Xiaodingxi 62

3.4.2.6. Reshuitang 62

3.4.3. Jurassic to Paleogene Evolution of the Simao Basin 65 
$\begin{array}{ll}\text { 3.5. Discussion } & 77\end{array}$

3.5.1. K-Ar Geochronology along the Lancang River Zone 77

3.5.2. The Lancang Paired-metamorphic Belts 83

3.5.3. A Note on Terrane Analysis 89

3.5.4. Mountain Building Processes $\quad 91$

3.6. Summary of the New Geodynamic Model and Mineral Resource Potential 94

3.6.1. Devonian - Lower Carboniferous Marginal Basin Evolution 94

3.6.2. Late Paleozoic Accretionary Wedge Tectonics 94

3.6.3. Upper Permian - Triassic Post-collisional Rifting 94

3.6.4. Late Triassic - Early Jurassic Basin Inversion 99

3.6.5. Late Jurassic to Paleogene MCC Evolution and Basin Formation 99

3.6.6. Himalayan Adjustment 99

$\begin{array}{lr}\text { 4. Acknowledgements } & 100\end{array}$

5. References 102

6. Appendix
A. Analytical Techniques
A-1. Major- and Trace Elements by XRF and ICPMS
A-2. Sm-Nd / Rb-Sr Isotope Geochemistry
A-3. K-Ar Geochronology and Illite Crystallinity (IC) Measurements
A-4. Ar-Ar Geochronology
A-5. Electron Microprobe Analysis
B. Tables
C. Stereonets
D. Stratigraphic Table
E. List of Abbreviations 


\section{Introduction}

\subsection{Study Objectives}

Within the framework of the science and technology collaboration between Germany and the People's Republic of China (Ministry of Land and Natural Resources), the Bundesanstalt für Geowissenschaften und Rohstoffe (BGR), Hannover, in collaboration with the Yunnan Bureau of Geology and Mineral Resources (YBGMR), Kunming, P. R. of China, externally awarded a contract to study the relationships between plate tectonics and ore formation in the central and southern Lancang River Zone in Yunnan. BGR awarded the contract to the University of Göttingen, and the overall supervision was by Prof. Dr. D. Helmcke, Applied Geology Department.

This PhD. thesis is part of the project and covers the southwestern Sanjiang Zone in Southwest Yunnan comprising the rivers Jinshajiang (Yangtzekiang), Lancangjiang (Mekong) and Nujiang (Salween). This N-S striking zone, squeezed between the Himalayas in the west and the Yangtze Platform in the east, is characterized by major fault zones. The central part of Southwest Yunnan on either side of the Lancang River has formed the highly-mobile continental margin of the Yangtze Para-platform since at least the Upper Devonian / Carboniferous. The geodynamic model previously elaborated for West Yunnan revealed some promising potential for VHMS- and SEDEX-type in the area associated with the development of Late Paleozoic back-arc basins. The objective of this thesis is to integrate and refine the overall geodynamic model as well as to investigate the petrogenetic and geotectonic position of the associated mineralization. The main research area was the Lancang River Zone covering an area up to $300 \mathrm{~km}$ long and up to $50 \mathrm{~km}$ wide.

\subsection{Preliminary Work by the Research Group in Yunnan}

The first investigations as part of the scientific and technical co-operation between BGR and the Yunnan Bureau of Geology and Mineral Resources took place in 1993 with the study on the "Location of the Paleoeurasian / Gondwana Boundary in Western Yunnan". This study was based on the postulated existence of a major suture and a Triassic island arc with possible Cu-porphyry mineralization along the Lancang River Zone. In 1996, this earlier work was supplemented by a BGR university external contract entitled "Study on mineral resources related to the plate-tectonics of the middle and southern Lancangjiang-Zone in Yunnan, P.R. China" and was increasingly influenced by the concepts derived from the geology of northern Thailand (e.g. Helmcke and Lindenberg, 1983, Helmcke et al., 1993). Numerous scientists have been involved in the studies over the years. At the BGR, this involved Prof. Dr. D. Bannert, Dr. V. Steinbach, Dr. D. Leifeld and Dr. T. Oberthür. The project manager of YBGMR was Prof. Dr. Yifei Zhang (former Vice Director YBGMR) for a long time and most recently Dr. Gang Bao. Both did all they could to support the work, as did a large number of geologists from Kunming. Today's Geoscience Center (GZG), Göttingen University (former IGDL, Göttingen), was represented by Prof. Dr. D. Helmcke, and Dr. B. Wagner, whereas TU Clausthal was represented by Prof. Dr. B. Lehmann, Dr. E. Gierth and cand. geol. R. Artmann. 


\subsection{Location of the Study Area, Morphology, Vegetation and Climate}

The study area covering approximately 15,000 square kilometers (Fig. 1-1) in the southwestern part of Yunnan province (People's Republic of China) is part of the southern Sanjiang zone and is bordered in the east by the Ailaoshan and in the west by a hypothetical line between Fengqing, Shuangjiang, Lancang and Manyan. In the south, the area is bounded by the border with Myanmar and Laos, and in the north by the summit of the Wulianshan between the Red River (Hong $\mathrm{He}$ ) and the towns of Manyan and Fengqing. The biggest river flowing from north to south through the study area is the Lancangjiang (Lancang River) which flows out of the Tibetan highland. This river divides the study area into the eastern Simao Basin and a small mountain chain (Wulianshan to Bangmashan) in the west. The main towns in the study area are Mojiang, Pu'er, Simao, Yunxian, Fengqing, Lincang, Lancang, Menghai and Jinghong. Unlike the deeply-incised densely-packed mountain ridges and gorges in the northern Sanjiang area, the landscape becomes increasingly gentle to the south. The difference in height between Litang in the north of the Sanjiang area to Menglian in the south is almost 3000 meters, which highlights the continuous drop in elevation of the mountains.

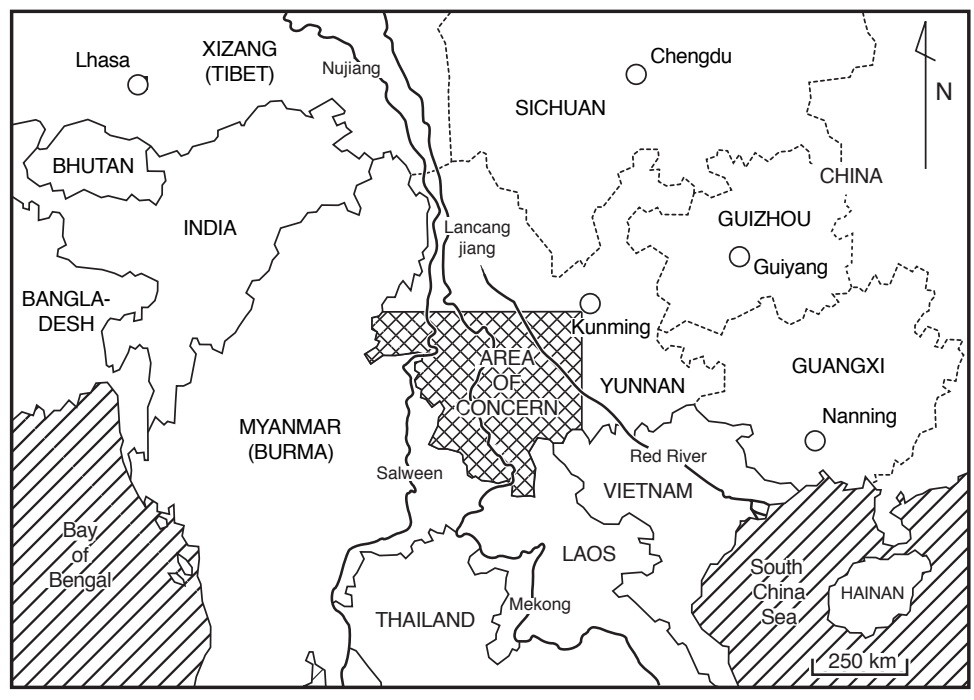

Fig. 1-1: Location of the study area in the south-westernmost part of the People's Republic of China.

Satellite pictures reveal an associated differentiation of the river system from north to south: in the north, all major rivers flow parallel in a north-south direction with virtually no lateral branches. In the south, there is an increase in the number of lateral branches to create a tectonically-controlled trellis drainage pattern in the area of Menglian, Simao and Mojiang. A major morphological feature is the fanning out of the main mountain ranges of the Laobie Shan, Bangma Shan, Wuliang Shan and Ailaoshan towards the south. The change in strike direction of the mountain ridges from NE - SW in the west in Laobi Shan to NNE - SSW in the east in Ailao Shan is clearly observable. The vegetation highlights the transition from a humid subtropical climatic zone to the tropical climatic zone at a latitude of approx. $23^{\circ}$ North (Zhao, 1986). In the study area, this transition corresponds to the zone from Gengma to Mojiang. The climate of South Yunnan is primarily controlled by the topographic height of the region between the major climatic zones of the cool Tibetan plateau and the subtropical monsoon climate in the south and 
east. The enormous difference in elevation between the valleys and mountain chains is responsible for the formation of micro-climates and floral zoning. Tropical monsoon forests in the broad valleys in the south give way northwards with increasing height to semi-arid, subtropical bush savannah below 2000 meters, to pine forests between 2000 -3000 meters and forests of fir trees above 3000 meters. Huge areas of primary vegetation below 2500 meters were deforested in the 1960's and 70's and only replaced by secondary vegetation in parts. The removal of vegetation led to enormous erosion in the rainy season between May and October and to the destruction of wide areas by the removal of nutrient-rich soil (acrisols, gleysols). The average annual precipitation is 1000 $-2500 \mathrm{~mm} / \mathrm{a}$ and increases inland and towards the south. Because of the monsoon climate, the period from February to April is extremely dry and therefore the optimum time for fieldwork. Temperatures at this time are pleasant and lie between 10 and $20{ }^{\circ} \mathrm{C}$ depending on the elevation. 


\section{Geodynamic Evolution of Southwestern Yunnan}

\subsection{Introduction}

South and West Yunnan is situated to the east of the eastern border of the Himalayas and incorporates the units linking the Tibetan geological domain and those characterizing the geological structure of the Southeast Asian subcontinent (Fig. 2-1; Bannert and Helmcke, 1981). The geology of Yunnan therefore plays a key role in understanding the tectonic development of China and bordering countries. The Late Paleozoic and Mesozoic geodynamic evolution of South and West Yunnan is the subject of heated debate in the scientific literature. The present geological situation is primarily attributable to the evolution of the Tethys (Hsü and Bernoulli, 1978; Sengör, 1979, 1981, 1982) and the assumption that Southeast Asia constitutes a mosaic of Gondwana derived terranes (e.g. Bunopas and Vella, 1978; Mitchell, 1981; Sengör, 1985; Hutchison, 1989; Metcalfe, $1988,1996,1998)$. Although investigations constraining the timing of rifting, drifting and collision have been of prime importance within the last two decades (e.g. Helmcke and Lindenberg, 1983; Helmcke, 1984, 1985; Huang et al., 1984; Metcalfe, 1993, 1995; Zhong, 1999; Zhong et al., 2000; Chonglakmani et al., 2001) the crucial question of how many micro-continents split off from Gondwana, drifted in the Tethys and collided with Eurasia, has not been satisfactorily answered. In this debate, the region between the Tengchong Block and the Yangtze Platform plays a key role inasmuch as many geoscientists believe that it harbors the major tectonic divide between the Gondwanan and Eurasian continents. Over the years, three rather contrasting models, which focus on the interpretation of the Late Paleozoic and Mesozoic history, were presented. Due to the strong intracontinental deformation by the Himalayan orogenesis (e.g. Molnar and Tapponier, 1975; Tapponier et al., 1982, Dewey, 1988, Dewey et al., 1989; Holt et al., 1991; Leloup et al., 1995; Wang and Burchfiel,1997), the efforts to substantiate or refute these models were rather painstaking. Though only marginally affected, and basically bypassed by the Indian indenter, the region is characterized by a dominant intracontinental style of transpressional and transtensional deformation. Large strike-slip faults, with lateral strain-partitioning on thrust systems, made the correlation of the various preHimalyan stratigraphic units a difficult venture. For the time being, no generally accepted proposal for the Late Paleozoic and Mesozoic has been agreed upon and three prominent models compete for attention.

\subsubsection{Model A: Large-scale Nappe Tectonics}

The mountains of West Yunnan and Thailand are considered to be part of a major Alpine foldbelt stretching from Asia Minor to Indonesia (cf. figures in Hahn et al., 1986). The eastern front of this orogen ranges from Yunnan to Nan-Uttaradit in northern Thailand. From west to east, the rocks are successively divided up into the following main zones: 1] Shan-Thai Para-platform, 2] Yunnan-Malay Mobile Belt (with Sukhothai Foldbelt and Loei Foldbelt) and 3] the Khorat Kontum Platform. Ophiolite zones are shown to the west of the Shan Thai Para-platform (Bhamo-Myitkyina ophiolite) along the boundary between the Sukhothai Foldbelt and the Loei Foldbelt (Uttaradit-Nan ophiolite) and at the western margin of the Khorat Kontum Platform. According to this interpretation, Alpine orogenesis affected the Shan-Thai Para-platform and the Sukhotai Foldbelt. 


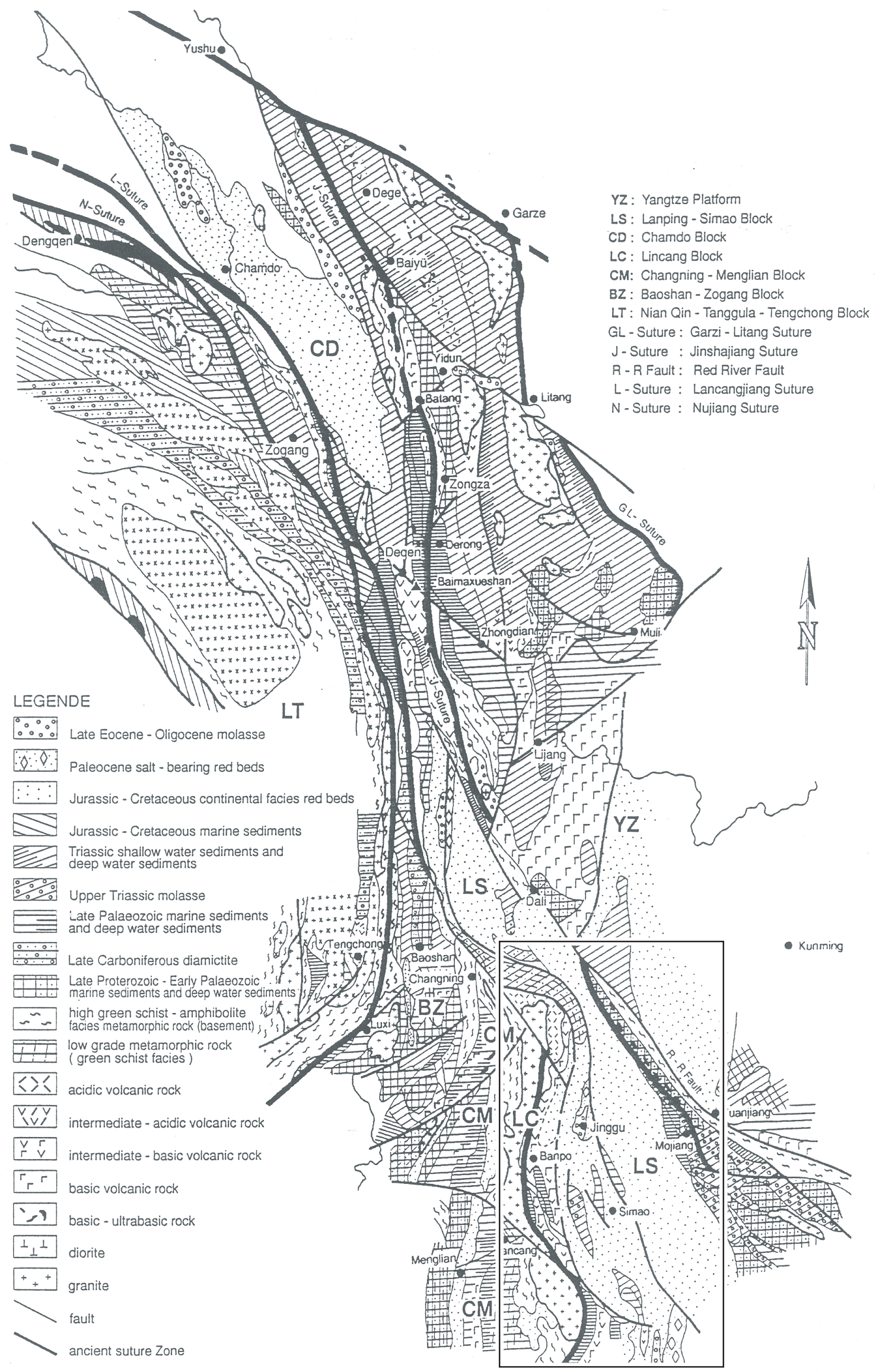

Fig. 2-1: Simplified geological map of the Sanjiang Area (Southwest China) with the location of the study area in Southwest Yunnan (Wang et al., 1997). 
Unfortunately, the published data on which this model is based are sparse and decisive questions such as on the significance of the allochthonous units and the aforementioned ophiolites were not raised. Nevertheless it appears justified to assume that Hahn et al. (1986) perceive the presence of a large-scale Alpine nappe. Baum et al. (1970) indicate that there is tectonic contact between the Precambrian of the Shan-Thai Paraplatform and the series of Paleozoic sedimentary rocks (e.g. Geol. Map 1:200 000, Sheet: Chiang Mai, Baum et al., 1982). They depict westerly nappe transport. Largescale nappe transport of Alpine age is also supported by Ahrendt et al. (1993) and is based on contrasting cooling histories within the Sukhothai Foldbelt. Geo-isotopic investigations carried out by this working group showed that the "Precambrian" of the ShanThai Para-platform is attributable to younger metamorphic overprint, which gives rise to the postulation that the area has been formed by large-scale Alpine nappes (Mickein, 1997). Unlike Baum et al. (1970), the given transport directions involve thrusting to easterly directions. The problems discussed are demonstrated in areas such as the "Omkoi Cliffs" between Hot and Mae Sariang in North Thailand or at Samoeng to the north of Chiang Mai. MacDonald et al. $(1991,1993)$ and Dunning et al. (1995) explained the tectonic structures in the vicinity of Doi Inthanon with the formation of a metamorphic core complex. To date, this concept has not been rigorously applied to Yunnan. Although tectonic contacts of Eocene age are frequently found on detailed Chinese maps, there are no reports on these separate findings being linked together to provide evidence for a major nappe orogen. Interpretations of the possible allochthony of the Lincang Batholith have been published, but they are described as "Indosinian" by Wu (1996). Wang and Burchfiel (1996) show the Lincang Granite to be thrust onto the Simao Basin, but they neither advocate large-scale nappe tectonics nor account for a uni-directed eastward thrusting to be the dominant mode of compression. They regard the Lincang Granite to oppose the movement along the Red River fault thus inverting the Jurassic-Cretaceous Simao Basin (pers. com. B. C. Burchfiel, 2002).

\subsubsection{Model B: "Two-Tethys Ocean System" and "Archipelagic-Ocean Model"}

This concept arose from differences between plate tectonic reconstructions (Carey, 1958; Bullard et al., 1965; Smith, 1973), which showed a Permo-Triassic wedge-shaped ocean opening to the east between Eurasia and the southern continents, and field observations in the Tethyan mountain belt, which revealed the existence of an early Jurassic (cf. Neumayr, 1885, Suess 1893, 1901), but apparently no Permo-Triassic ocean. Solving the differences, which were generally referred to as the Tethys Paradoxon (cf. concise treatment of the problem in Sengör, 1998), Hsü and Bernoulli (1978) and Sengör (1979) postulated a second, older Tethys ocean, the so-called Paleotethys of Hsü and Bernoulli (1978) or the Paleo-Tethys of Sengör (1979), which existed during PermoTriassic times and accounted for the configuration of the continents as required by the plate tectonic reconstruction of Pangea. According to Hsü and Bernoulli (1978) and Sengör (1979) the older Tethyan ocean closed by the collision of a Gondwana-derived, elongate continent, the so-called "Cimmerian Continent" of Sengör (1979), in the Late Triassic along a zone that can be traced by Permo-Triassic pelagic sediments and andesitic volcanic rocks from Dobrogea to Crimea to the Caucasus, into the Kopet Dagh Range and the Pamirs, and finally through the northern part of the Tibet Plateau into 
Indochina. Applied to Yunnan and Southeast Asia, this concept requires that West Yunnan and the western parts of the Southeast Asian subcontinent were formerly part of Gondwana, that they drifted across the Paleotethys in the form of a micro-continent ("Cimmerian Continent" of Sengör, 1979, in Southeast Asia known as "Shan-Thai Craton", Bunopas and Vella, 1978, "Sibumasu" of Metcalfe, 1996) and collided with the former northern continents in the Mesozoic. This gave rise to an Upper Triassic to Lower Jurassic collision orogen with a suture between Gondwana-type and Eurasia-type terranes in Southeast Asia.

To date, from the wide range of discussed possibilities, most authors of the international scientific community have agreed that the line of the Paleotethys suture runs from the Songpan-Ganzi triangle in West Sichuan, via Yunnan (along the Lancang River) into the Nan-Uttaradit suture zone in North Thailand, and finally into the Bentong-Raub suture in Malaysia. This interpretation has been put forward and developed in a large number of publications by A. M. C. Sengör in particular (e.g. Sengör, 1979, 1984, 1989) until it finally became incorporated in paleo-geographic maps (Scotese and Golonka, 1992). The publications of Chinese scientists in particular in recent years have tended to modify this concept by frequently referring to the "Paleotethys" as an "archipelagic-ocean system" (Wu, 1999, Zhong et al., 1999 and other authors, for Tibet also Hsü et al., 1995). In this interpretation, the triangular Permian "Paleo-Tethys" is described as an ocean hosting a large number of small micro-continents, where Zhong et al. (1999) distinguish between "intercontinental" and "intracontinental oceans" as well as "intracontinental troughs or rifts". The authors estimate that the "intercontinental oceans" had a width exceeding 1000 kilometers and a lifetime of more than 100 million years, while "intracontinental oceans" had a width of several 100 kilometers and a lifetime only extending to 10 s of million years (cf. Zhong et al., 1999, their Table 1). During the application of the Tethys Concept in Southwest Yunnan, the "intercontinental ocean" or in other words, the main ocean of the "archipelagic-ocean system" of the Paleotethys has moved a long way to the west of Yunnan into the area of the Changning-Menglian suture (cf. Wu, 1975; Duan and Zhao, 1981; Fan, 1982; Wang, 1983; Wang et al., 1997). The location of the main branch of the Paleotethys in the Changning-Menglian Belt is presently favored by most Chinese scientists (Zhong et al., 2000). This places the suture along the Lancang River in the zone of the "Yangtze-affinity blocks" and marks it as a formerly intracontinental ocean.

\subsubsection{Model C. Permo-Triassic (Late Variscan) Cordillera with Exotic Terranes}

Field observations in central Thailand and data from the literature on the development of the Permian in North Thailand form the basis for the hypothesis that a late-Variscan continental margin orogen (Cordillera) formed West Yunnan and West Thailand. The eastern deformation front of this orogen was first described in the area around Phetchabun and similarly derived from the Late Paleozoic of the Nan-Uttaradit suture (Helmcke and Lindenberg, 1983). In addition, paleontological evidence from North Thailand (Toriyama et al., 1978) gave rise to the postulation that the Shan-Thai Craton was not part of Gondwana; i.e. that the Nan-Uttaradit suture cannot have arisen from the closure of a major Paleotethys ocean. The observed Triassic and younger deformation 
in North Thailand was attributed to intracontinental deformation (Helmcke and Lindenberg, 1983). In the years that followed (Helmcke, 1985, 1986), the concept was extended to Yunnan and the docking of exotic terranes onto the cordillera was recognized (Helmcke et al., 1993, Ingavat-Helmcke and Helmcke, 1994). The accretion of continental fragments gave rise to inversion of the Triassic basins in the hinterland of the Cordillera during the Indosinian period. Additionally, other periods of intracontinental deformation must have also occurred during the remainder of the Mesozoic (Mouret, 1994).

In the Tertiary, the collision between India and Asia, which started at about 50 Ma ago (Rowley, 1996), resulted in a complex superimposition of Cenozoic intracontinental deformation. It has been rarely possible to clearly separate each post-collisional deformation phase in Tibet, Sichuan and Yunnan, and the alternative views of the research groups around Tapponier and Dewey have been at odds for many years. Tapponier et al. $(1982,1986)$ and Avouac and Tapponier (1993) promote the idea that the collision between India and Asia caused the south-eastward extrusion of continental fragments along major strike-slip faults such as the Ailaoshan-Red River shear zone in central Yunnan (Leloup et al., 1995). In their interpretation, the extrusion of Tibet is thought to have accommodated 50 percent of the stress induced by the Indian/Asian collision with relatively little internal deformation. In contrast, Dewey et al. (1988, 1989), England and Houseman (1989) and Houseman and England (1993) favor a more complex scenario and consider the extrusion process as barely relevant or minor. They postulate that the enormous continental convergence of about 2000 kilometers between India and Eurasia primarily gave rise to a homogeneous, ductile and N-S aligned deformation of the lithosphere to the north of the Indian sub-continent. The result was intense overprinting of the Himalayas and Transhimalayas and the uplift of the Tibetan Plateau. Southeast Asia to the east of the eastern syntaxis was primarily overprinted by transtensive and transpressive tectonism exhibiting a more than $700 \mathrm{~km}$-wide right-lateral accommodation zone extending from western Indochina to the Tibetan Plateau. Holt et al. (1991) emphasize clockwise block rotation within this zone and Wang and Burchfiel (1997) draw attention to the oblique shear that was partitioned into strike-slip faults and thin-skinned shortening in the fold- and thrust belts during Middle Eocene to Pliocene time.

\subsection{Major Tectonic Elements in Southwestern Yunnan}

Notwithstanding the working groups which interpret the mountain chains in this region as a large-scale nappe structure of Himalayan age, most researchers in recent decades have concentrated on the following questions: [1] Which parts of this region could feasibly consist of exotic terranes which originated from Gondwana; [2] Where is the position of the Paleotethys suture; [3] which parts of Yunnan shall be interpreted as the former northern continental margin of Tethys, i.e. which of the blocks had Yangtze affinities. Four different zones in West Yunnan are discussed in the literature as potential locations for the Paleotethys suture and are marked in the following in italics. From west to east the major tectonic elements, which are unfortunately termed "blocks" or "massifs" (e.g. YBGMR, 1990; Liu et al., 1991, Fang et al., 1994; Wang et al., 1997, Ueno, 1999; Wang et al., 2001) comprise: [1] the Tengchong Block, [2] the Nujiang Fault Zone, [3] the 
Baoshan Block, [4] the Changning-Menglian Zone, [5] the Lincang Block, Massif or Region, [6] the Lancangjiang Fault Zone, [7] the Lanping-Simao Block or Massif, [8] the Ailaoshan / Red River Zone, and [9] the Yangtze Paraplatform (Fig. 2-2).

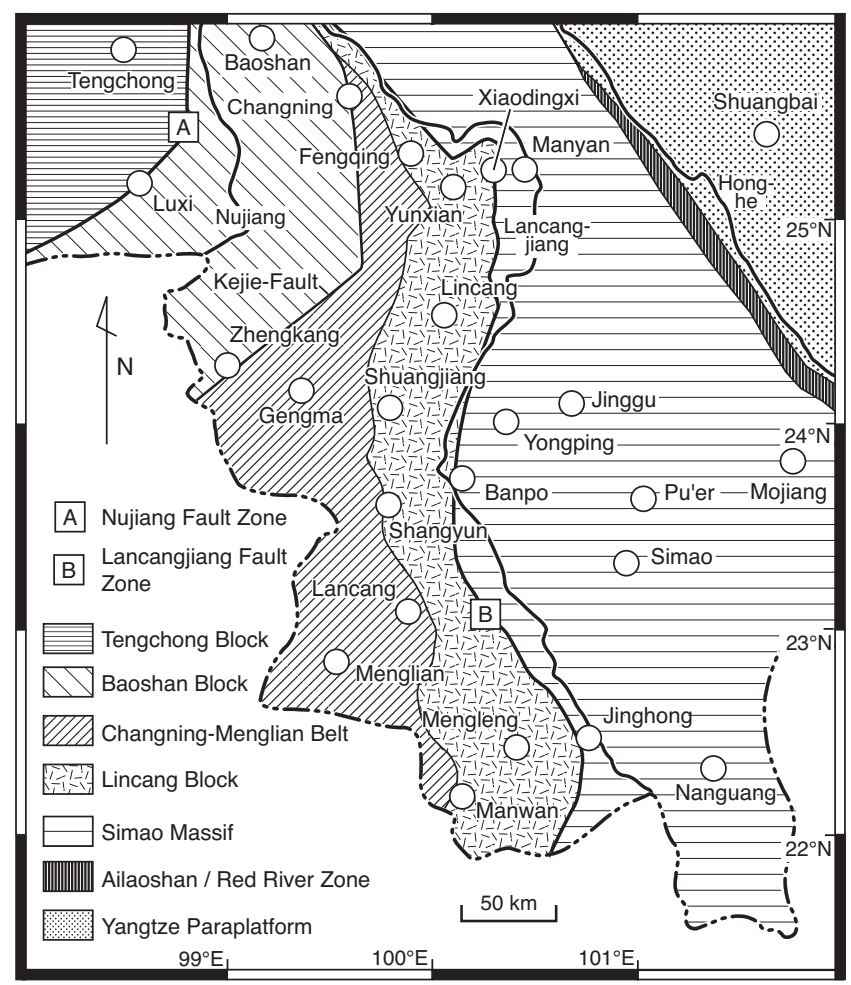

Fig. 2-2: Tectono-stratigraphic subdivision of southwest Yunnan (i.e. Wang et al., 1997).

Despite the range of possibilities, according to Min et al. (2001), locating the boundary between Eurasia and Gondwana terranes has basically already been determined primarily from the distribution of climatically-sensitive fauna, flora and sediments of Upper Carboniferous to Lower Permian age (Fig. 2-3). The remaining differences are very minor and the border lies either to the east or west of the Baoshan Block but definitely to the west of the Simao-Lanping Block. This interpretation is the subject of some heated debate in the international geoscientific literature (cf. Metcalfe, 1999). Further, paleomagnetic data, which are presented by Fang et al. (1989) and Huang and Opdyke (1991) are difficult to interpret. Fang et al. (1989) compared the paleomagnetism of Devonian sequences from the surroundings of Kunming on the Yangtze-Paraplatform with data obtained from localities around Baoshan and Shidian on the Baoshan Block. Huang and Opdyke (1991) concentrate on Upper Carboniferous strata from localities around Baoshan and Yongde on the Baoshan Block. These strata have been assigned to be of Lower Permian age recently (Wang et al., 2001). In both publications it is assumed that the primary Paleozoic remanence is still preserved. Therefore, Fang et al. (1989) conclude that the Devonian strata of the Yangtze Paraplatform and Baoshan Block are marked by very different paleo-latitudes. While the Yangtze Platform was at the paleoequator, the Baoshan Block was situated at approximately $42^{\circ}$ southern latitude. Their data, however, require a former "upside down" orientation of the Baoshan Block. In other words the Baoshan Block was attached with its present western side to Gondwana 


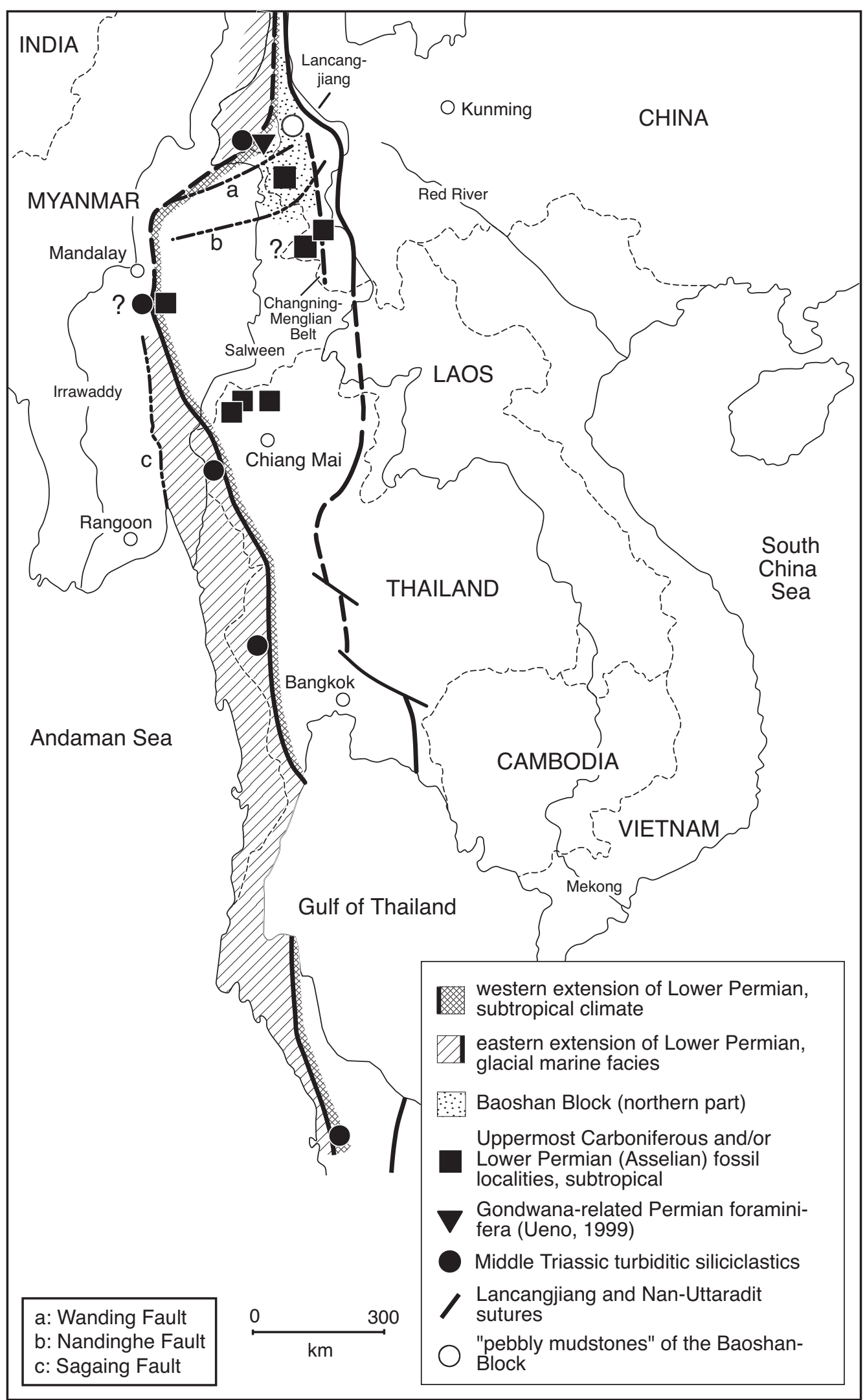

Fig. 2-3: Position of Gondwana-derived micro-continents and possible location of the Paleotethys suture in Thailand, Burma, Laos and Yunnan (People's Republic of China). Slightly modified from Min et al. (2001) 
(Fang et al., 1989, p. 949 and their Fig. 12). Huang and Opdyke (1991) report a similar paleo-inclination from the Lower Permian (formerly upper Carboniferous) Woniusi Formation, but the paleo-declinations are different by $170^{\circ}$ and therefore almost opposed. Confusingly, in their text, Huang and Opdyke (1991) write that the Baoshan Block should be attached with its present eastern side to Gondwana, but depict a situation where the Shan-Thai Malay Block is attached with its present western side to Gondwana (cf. Huang and Opdyke, their Fig. 7). However, the strange "reversal" of $170^{\circ}$ is difficult to accept. Wopfner (1996) suggests that the basalts of the Woniusi Formation mark the initial rifting of the Baoshan Block from Gondwana. Therefore, the question arises how much of the observed $170^{\circ}$ difference in paleo-declination from the Devonian to lower Permian was caused by a) the rotation of the Baoshan Block as part of Gondwana (from the Devonian to Carboniferous), b) the drift of the Baoshan Block during a short period after separation from Gondwana (lower Permian), and finally c) tectonic rotations between the sampling sites during collision and later intra-plate deformations. All three points are difficult to quantify and Huang and Opdyke (1991, p. 333) conclude that "extreme caution should be exerted when trying to establish an apparent polar wander path for, and to reconstruct the paleo-geographic position of, the Shan-ThaiMalay microplate". They further give the disenchanting estimation that "a reconstruction of the tectonic evolution of SE Asia requires abundant paleomagnetic results of high quality and an expansion of sampling to rocks of Cenozoic age" (Huang and Opdyke, 1991, p. 342). I do interpret Huang and Opdyke (1991) in the sense that the data put forward so far are not sufficient enough to make a reliable case for the drift history of the Baoshan Block as part of the Shan-Thai-Malay Block (same as Shan-Thai Craton of Bunopas and Vela (1978), the Cimmerian continent of Sengör (1979) and the Sibumasu Block of Metcalfe (1993).

Finally, it may also seem possible that the samples from the Baoshan Block underwent strong or even complete remagnetization associated with the collision between India and Asia similar to the samples studied by Chen and Courtillot (1989) in Thailand and Richter et al. (1999) on Peninsular Malaysia. If the reported complex deformational patterns of Wang and Burchfiel (1997) for southwest Yunnan are taken into account, the judgement of Huang and Opdyke (1991, p. 340) that the characteristic remanent magnetization directions were acquired "prior to the Mesozoic" becomes uncertain. In addition, this estimation is somehow at odds with the widespread remagnetization observed from the relatively undeformed Khorat Plateau (Chen and Courtillot, 1989). If plate tectonic reconstructions intend to rely on the above mentioned results, an answer to the question of why the remagnetization is observable in northern Thailand and not in Southwest Yunnan is highly desirable.

\subsubsection{Tengchong Block}

The basement of the Tengchong Block consists of Middle-Proterozoic gneiss, granulite, mylonite, slate and marble with a thickness of up to 6000 meters. The Tengchong Block is assigned to Gondwana on the basis of the glacio-marine nature of the Upper Carboniferous to Lower Permian Menghong Group/Zizhi- and Kongshuhe Formations (Wang et al., 1997., cf. their Fig. 4). The sedimentary record of pebbly mudstone, mud- 
stone and siltstone is largely comparable to the sequences on Phuket (South Thailand) and is characterized by clasts indicating a crystalline source (Heinemeyer, 1996; Jin, 1994). This is an important difference to the pebbly mudstones of the Dingjiazhai Formation of the Baoshan Block. Between basement rocks and the Menghong Group, Silurian and Lower Devonian terrestrial to shallow marine interbeds consisting of limestone, dolomite and marl occur. They are the oldest sedimentary rocks in the Tengchong Block. In upper parts of the section a thick carbonate sequence of the Dadongchang Formation occurs. Fan and Zhang (1993) report Triticites sp. from this section and estimate an age of Upper Carboniferous. Analysis by Prof. Dr. D. Meischner (Institute for Geology and Paleontology, University of Göttingen) revealed that the carbonates were deposited in a high-energy, warm shallow-water environment (open platform) and the analysis of large foraminifera by Dr. R. Ingavat-Helmcke (University of Göttingen) and Prof. Dr. K. Ueno (University of Fukuoka, Japan) indicate that they are slightly younger than Upper Carboniferous (pers. com. Ingavat-Helmcke 2003). A more detailed stratigraphic account of the Tengchong area is given by Prof. Zetong Nie and Prof. Jianjun Jiang in Zhong et al. (2000).

\subsubsection{Nujiang Fault Zone}

The Nujiang Fault Zone is the tectonic boundary between the Tengchong and Baoshan Block. Interpretation of this fault zone is the subject of controversy. In a narrow area along this fault zone between Luxi and Ruili (Nujiang valley, Western Gaoligong Mountains) turbiditic siliciclastic rocks occur. Chinese sources give their age as Middle Triassic (YBGMR, 1990). This zone also contains a small outcrop of radiolarites and serpentinites (Luxi, Santaishan). Although its age has not so far been determined on the basis of radiolaria specimens, according to Prof. Dr. D. Helmcke (University of Göttingen), the black color is taken to indicate a younger Paleozoic age because radiolarites of Triassic age in Southeast Asia generally tend to have a red or, less commonly, a green colour. Precise dating of these radiolarites is very important because it is postulated in the Chinese literature that the Nujiang Fault Zone is the suture of a former shortlived Mesozoic ocean (Bitu ocean, Zhong et al., 2000, p. 99). The above mentioned siliciclastic rocks are referred to flysch in some Chinese publications. By way of comparison, it should also be mentioned that Permian to Middle Triassic radiolarites and turbiditic siliciclastics are also found in the area around Mae Sariang in northern Thailand. They have been interpreted by Töfke et al. (1993) as unequivocal syn-orogenic sediments. If the situation in Nujiang can be interpreted in an analogous way to North Thailand, then the sediments along the Nujiang Fault Zone must be seen as indicating an Indosinian collision between the Tengchong and the Baoshan Block. However, not until there is more precise biostratigraphic information on the Nujing Fault Zone, the correlation remains speculative.

\subsubsection{Baoshan Block}

The Baoshan block lies to the east of the Nujiang Fault Zone. The geological observations and analysis carried out so far are contradictory and provide no clear evidence of whether this unit should be interpreted as a Gondwana fragment or whether it is a former part of the northern continent (Fan and Zhang, 1994, or summary by Ueno, 2002). 
A great deal of weight is placed in the literature on the possible glacio-marine nature of the Dingjiazhai Formation (Upper Carboniferous - Lower Permian, Wang, 1983; Jin, 1994), although opposite opinions exist (Zhou and Fang, 1990; Zhou et al., 1999). The discovery of Pseudoschwagerina sp. and the onset of oolite formation in a limestone sequence of the Yongde Formation in the southern part of the Baoshan Block indicates the presence of warm-water conditions (classification: Dr. R. Ingavat-Helmcke, pers. com. 2003). Another important finding is that unlike the clasts in the Tengchong Block, the clasts of the Dingjiazhai Formation largely consist of oolitic limestones with an identical or only very slightly different micro-facies to the oolitic limestones of the underlying Pumenquian Formation, which is interpreted as a lower Carboniferous carbonate platform. The transition is usually marked by a hiatus encompassing the entire Late Carboniferous. The Pumenquian Formation often contains the coral Kweichophyllum sp. which is considered to be a typical faunal element of Cathaysia. However, Fontaine et al. (1994) point out that the Tournaisian in Northwest Australia is also characterized by oolitic limestones with Kweichophyllum sp.. On top of the Dingjiazhai Formation a 450meter-thick-sequence of basalts and basaltic clastic rocks occur, which are considered to be continental rift tholeiites (Cong et al., 1994) and related to the separation from Gondwana (Wopfner, 1996). Based on analysis of the Late Paleozoic foraminiferal biogeography, Ueno $(1999,2002)$ proposes that the boundary between the Gondwana and non-Gondwana crustal fragments runs along the Keijie Fault in South Yunnan, which means that the northern Baoshan Block belongs to Gondwana. However, the presence of Pseudoschwagerina sp. referred to above is inconsistent with this interpretation. The assumption that the Tengchong and Baoshan Block are both Gondwana-derived continents would further imply that although the two blocks were derived from different parts of Gondwana (Jin, 1994), they both accreted at around the same time.

\subsubsection{Changning-Menglian Zone}

The Changning-Menglian Zone is currently favored by most Chinese scientists as the location of the Paleotethys (main branch). The Upper Carboniferous to Middle Permian volcanic rocks occurring in this zone are interpreted by numerous authors as ophiolites at Shuangguo, Tongchangjie and to the south of Menglian (e.g. Zhang et al., 1985, 1988). The interpretations often refer to the Tethys as a "polyisland ocean" or as an "archipelago" (Zhang et al, 1985; Li et al., 1986; Liu et al. 1991; Liu and Feng, 1993; Wu et al. 1995; Zhang et al. 1996a,b; Fang and Feng, 1996; Mo et al., 1988; Zhong et al., 2000) where most volcanic rocks have originated in seamount (He and Liu, 1993) or oceanic plateau environments (Fang and Niu, 2003). Despite the numerous publications, the interpretation of the volcanic rocks is still considered to be inadequate. For example, Yang et al. (1994) characterize the basic volcanic rocks as alkali basalts of intra-continental affinity and advocate the Changning Menglian Zone to host a former back-arc or rift basin in relation to the subduction of the Paleotethys along the Lancang River. The model of a rift for the Changning-Menglian Zone is shared by others, such as Fan (1982, 1985), YBGMR (1990), Yang and Mo (1993), Mo et al. (1993) and Wang (1997). The stratigraphic relationships are very complicated within this zone (Feng, 2002). Radiolarian ribbon-cherts with a wide stratigraphic range are present (Feng, 1992). It does appear certain, however, that the calcareous sequences of Upper 
Carboniferous/Lower Permian age are always characterized by carbonates of warm water origin, and that the foraminiferal fauna reveals typical Tethyan characteristics. Similar relationships are also found in some parts of northern Thailand. Caridroit (1993), for instance, describes a similar situation in the area around Chiang Dao to the north of Chiang Mai. However, this zone lies well to the east of the most western known occurrence of non-Gondwana carbonates in Northern Thailand. With the possible exception of the recent publication by Fang et al. (1998) the research on this zone provides no indication of the presence of Triassic siliciclastics deposited by turbidites and which could therefore be interpreted as flysch deposits. In contrast, this situation is common in Mae Sariang, Northwest Thailand, as well as in West Malaysia.

\subsubsection{Lincang Region}

The most distinctive unit in South and West Yunnan is the major Lincang Granite which is believed to form a composite granitic batholith of Late Permian and Triassic age (Liu et al., 1989). According to current geological maps, the intrusion is usually surrounded by metamorphic rocks of Proterozoic age (Damenglong and Chongshan Group, Lancang Group) and followed by sedimentary series of Paleozoic and Mesozoic age further to the west. In many publications, this major intrusion is associated with the postulated Triassic subduction along the Lancang River Fault to the east or west of the Lincang Granite. High-pressure metamorphic rocks have also been described from localities to the west of the batholith. Zhang et al. (1993) report the occurrence of a pairedmetamorphic belt in the Lincang region and along the Lancang River Fault Zone with a low-P/T belt to the east and a high-P/T belt to the west. Chinese publications also infer that the Lincang Granite could be allochthonous (Wu, 1996). However, the key to understanding this region is certain to lie in the following observations. According to the interpretation presented on large-scale geological maps, the surrounding metamorphic rocks host mylonite zones striking over long distances, and there are numerous places where the batholith or the metamorphic rocks are apparently disconformably overlain by red conglomerates and clastic rocks of Jurassic age. This surely indicates that the granite had already been exposed by uplift and erosion in the uppermost Triassic and lowermost Jurassic before the Jurassic clastics could have been deposited. New geochronological and petrological data, and the integration of this region within the overall interpretation indicate the presence of a metamorphic core complex. A detailed analysis of this zone will be presented in Chapter 3 .

\subsubsection{Lancangjiang Fault Zone}

The Lancangjiang Fault Zone is considered by some Chinese authors to be an important suture which they interpret to have been formed by the Triassic subduction of the Paleotethys (e.g. Fan and Zhang, 1994). This interpretation is published in numerous paleo-geographic reconstructions (e.g. Scotese and Golonka, 1992). However, younger tectonic overprinting implies that the geotectonic relationships are difficult to unravel. The following arguments are often presented to support the aforementioned interpretation. A thick Middle Triassic volcanic sequence is often found along the Lancang River and interpreted as a volcanic arc. Other indicators of a suture are seen in questionable ophiolites (e.g. at Banpo) and synorogenic sedimentary series. However, this data and interpreta- 
tions should be considered with a great deal of scepticism. Merely the fact that typical warm-water carbonates of Upper Permian age which bear characteristic Tethyan large foraminifera lie well to the west of the Lincang Granite clearly confirms that the Lancangjiang Fault Zone cannot be a subduction zone of the former Paleotethys (main branch). Chinese geologists of the Yunnan Geological Survey regard the questionable ophiolites as basic intrusives of Jurassic age. A detailed analysis of the ultramafic rocks is highly desirable. Moreover, the so-called synorogenic sediments have not been adequately investigated or stratigraphically classified. According to Fan and Zhang (1994) they are dated as Middle Permian. The recent results of our working group (Feng et al., 2001) and my own investigations will be presented in Chapter 3.

\subsubsection{Lanping-Simao Block}

Large parts of the Lanping-Simao Basin are formed by red clastic sequences (continental red-beds) of Jurassic to Eocene age. Paleozoic and Triassic series are only exposed in a few anticlines. The Permian sedimentary sequences have analogous facies and fossils analogues to the Yangtze Platform. The nature of the Triassic sequences is subject to marked variation at a regional scale and indicates very rapidly changing lateral conditions - probably attributable to the presence of half-graben systems. Triassic syn-sedimentary extension and subsequent inversion was revealed by Wagner et al. (2001) further north on the Yangtze Platform. The continental sedimentary rocks of Jurassic to Eocene age (Yano et al., 1994) of the Lanping-Simao Block are well over 10,000 meter thick and indicate subsidence over a considerable length of time. A marine ingression in the Middle Jurassic is confirmed by fossil evidence (e.g. to the west of Simao, YBGMR, 1990). Chapter 3.4.3. discusses in detail the development of the Simao Basin and its connection to the Lancang River Zone.

\subsubsection{Ailaoshan-Red River Zone}

The Ailaoshan-Red River Zone has an extremely complex structure and is therefore subject to a wide range of interpretations. One undisputed fact is that it has a lengthy history. Up to only a few years ago, outcrops in the Ailaoshan were interpreted as indicating the presence of the Paleotethys suture (Duan and Zhao, 1981) overprinted by Tertiary strike-slip faulting. The development of a mantle-rooted shear zone during the Tertiary with the formation of mylonite and high temperature gradients is further proposed by Leloup et al. (1995), while Wang and Burchfiel (1997) regard the Ailaoshan shear zone to be detached from the lower lithosphere above an easterly-dipping subhorizontal intracrustal shear zone. They stress that the motion above the subhorizontal detachment zone has been partitioned into horizontal SW-NE shortening in the Simao Basin and left-lateral shear on the steeply to gently dipping Ailaoshan shear zone (cf. Wang and Burchfiel, their Fig. 16.)

\subsubsection{Yangtze Paraplatform}

To the east of the Ailaoshan - Red River Fault Zone lies the Yangtze Platform. Zhang et al. (1984) consider that this block, which is part of the former northern continent, is largely made up of a Proterozoically consolidated craton with some minor Late Archean elements. The oldest sedimentary cover rocks are Vendian to Cambrian black shales, 
carbonate rocks and pyroclastics. They are discordantly overlain by Devonian clastic rocks and Permo-Carboniferous shallow water limestones containing basic extrusive rocks such as the Emeishan basalts (e.g. Chung et al., 1998; Xu et al., 2001). The basic volcanism within the carbonate platform indicates extensional tectonics and incipient rifting and is interpreted to be associated with the aborted break-up of Pangea at the end of the Permian. The Triassic contains shallow-water carbonate rocks, sandstone and marlstone. The depositional environment changed in the Jurassic and the whole area became arid with the deposition of red sandstone (continental red-beds) typical of the Yangtze Platform with thicknesses of up to ten kilometers (cf. "Central Yunnan Basin" in Yano et al, 1994). Terrestrial sedimentation of continental red-beds continued into the Eocene. Young intracontinental tectonism, which is clearly associated with linear zones, indicates that the platform cannot be compared with cratonic zones such as the Baltic shield. Special features are zones of intensively faulted continental red-beds alternating with flat-bedded units typical of strata overlying a craton.

\subsection{Integration within the Geodynamic Evolution of Southeast Asia}

For the various political and infrastructural difficulties, which hinder the southward delineation of the tectonic elements into Myanmar and Laos, a regional discussion can only be resumed in North Thailand. The scientific discussion of this area in recent years was dominated by the hypothesis that the Nan-Uttaradit suture in Northeast Thailand is evidence of the subducted Paleotethys. The western parts of North Thailand were interpreted as a micro-continent ("Shan-Thai Craton" of Bunopas and Vela, 1978), which separated from Gondwana in the Upper Paleozoic and drifted northwards to collide in the Upper Triassic with the Indosinian Craton, which is purported to form the eastern part of Thailand. This interpretation is contradicted by the work of Helmcke and Lindenberg (1983) for various reasons, including that it has been known since the first detailed paleontological work on the Permian in North Thailand that there are also Lower Permian sedimentary rocks to the west of this "suture" which have no Gondwana affinities. In addition, other findings indicate that the Nan-Uttaradit suture had already closed by the Upper Permian (Ingavat-Helmcke and Helmcke, 1994). In recent years, some authors attempted to localize the southern extension of the Paleotethys suture along the socalled Chiang Rai suture. Zhong et al. (1999), Chonglakmani (1998) and Fang et al. (1998) are of the opinion that the Changning-Menglian Zone in Yunnan may extend into the Chiang Dao area. They refer in their interpretations to the findings of Caridroit (1993). However, this interpretation does not take into consideration the extensive outcrop of Lower Permian carbonate rocks in North Thailand (Konishi, 1953; Baum, 1982), which also lie to the west of this important suture. Not to mention that the extensive areas of granite at Kentung in the Northern Shan States of the Union of Myanmar (link between the Lincang Granite of Yunnan with the Doi Inthanon complex of North Thailand) crosses the postulated connection between the Changning-Menglian Zone in Yunnan and the Chiang Mai suture. This is only feasible if these granites were of younger age (e.g. Cretaceous intrusions) or if large-scale Himalayan nappe formation was present in this area (Ahrendt et al., 1993, Mickein, 1997). Hence, an extension of the suture must be sought to the west of the Doi Inthanon complex. Until recently, no boundary zone to the west of the Doi Inthanon complex could be identified in North Thailand, which might be 
interpreted as the potential suture between the Gondwana and non-Gondwana crustal fragments. Only a re-interpretation of the area around Mae Sariang revealed evidence capable of contradicting the current map interpretation (Baum et al., 1982). A concise treatment is given by Min et al. (2001). Ueno (1999) also placed the boundary with the Gondwana terranes in this area. A correlation of the tectonostratigraphic units of Thailand and Yunnan is given in Fig. 2-4.

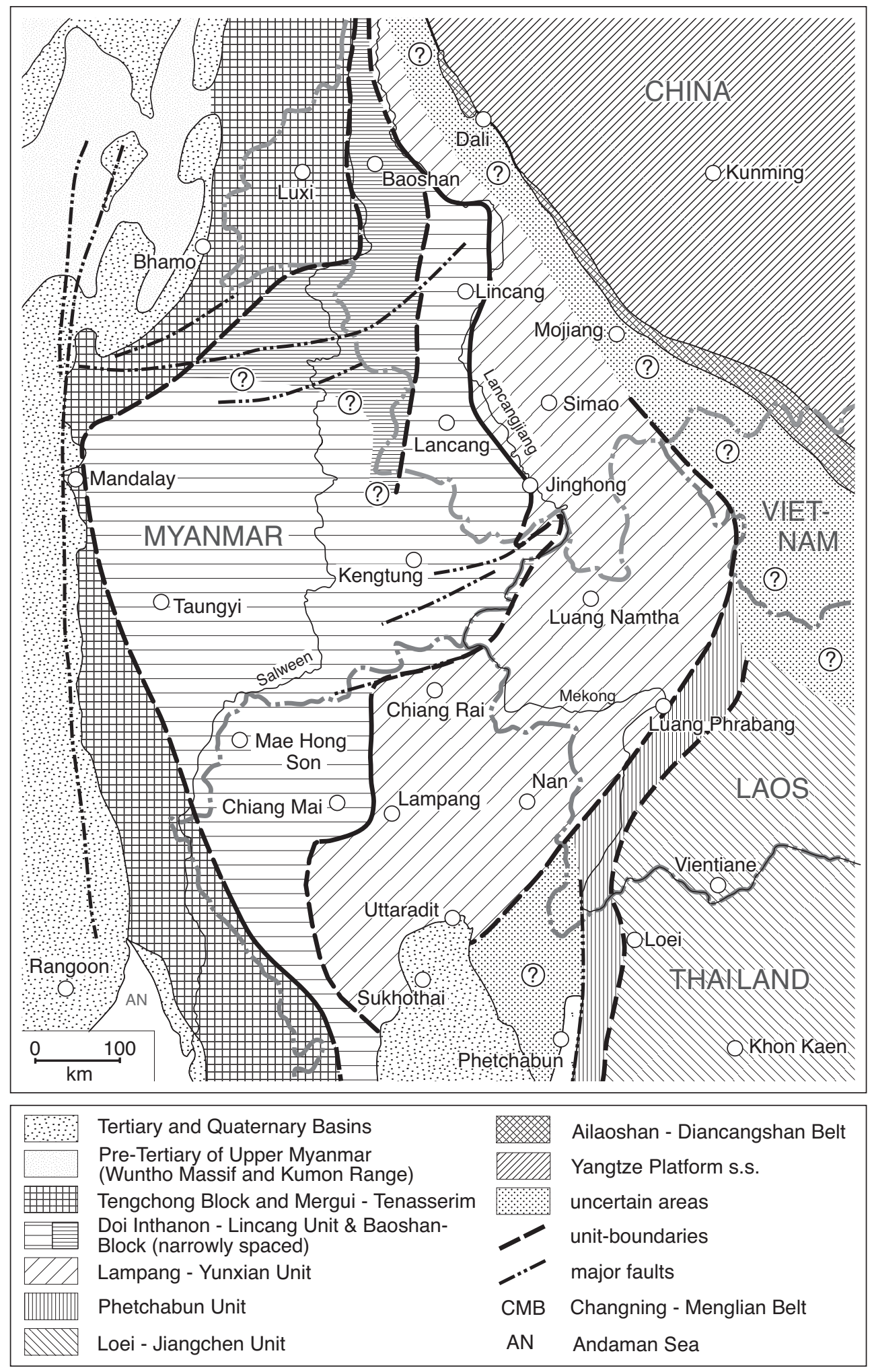

Fig. 2-4: Correlation of the tectonostratigraphic units in Thailand and Yunnan, People's Republic of China (from Chonglakmani et al., 2001) 
Finally, to the north of the central and southern Lancang River Zone, a very large number of publications report that the northern extension of the Paleotethys suture should be sought in the large triangular Songpan-Ganzi area in West Sichuan and Tibet. This interpretation was questioned by Helmcke $(1985,1986)$, who regards that this suture must be sought further to the west, and the Songpan-Ganzi triangle should be considered as a Triassic rift structure within the continental crust of the northern continents. 


\section{The Lancang River Zone (LRZ)}

\subsection{Introduction}

The area immediately to the east and west of the Lancang River is believed to hold a key position in deciphering the complex geological evolution of West Yunnan, and has been the subject of a range of interpretations since the early 1980's.

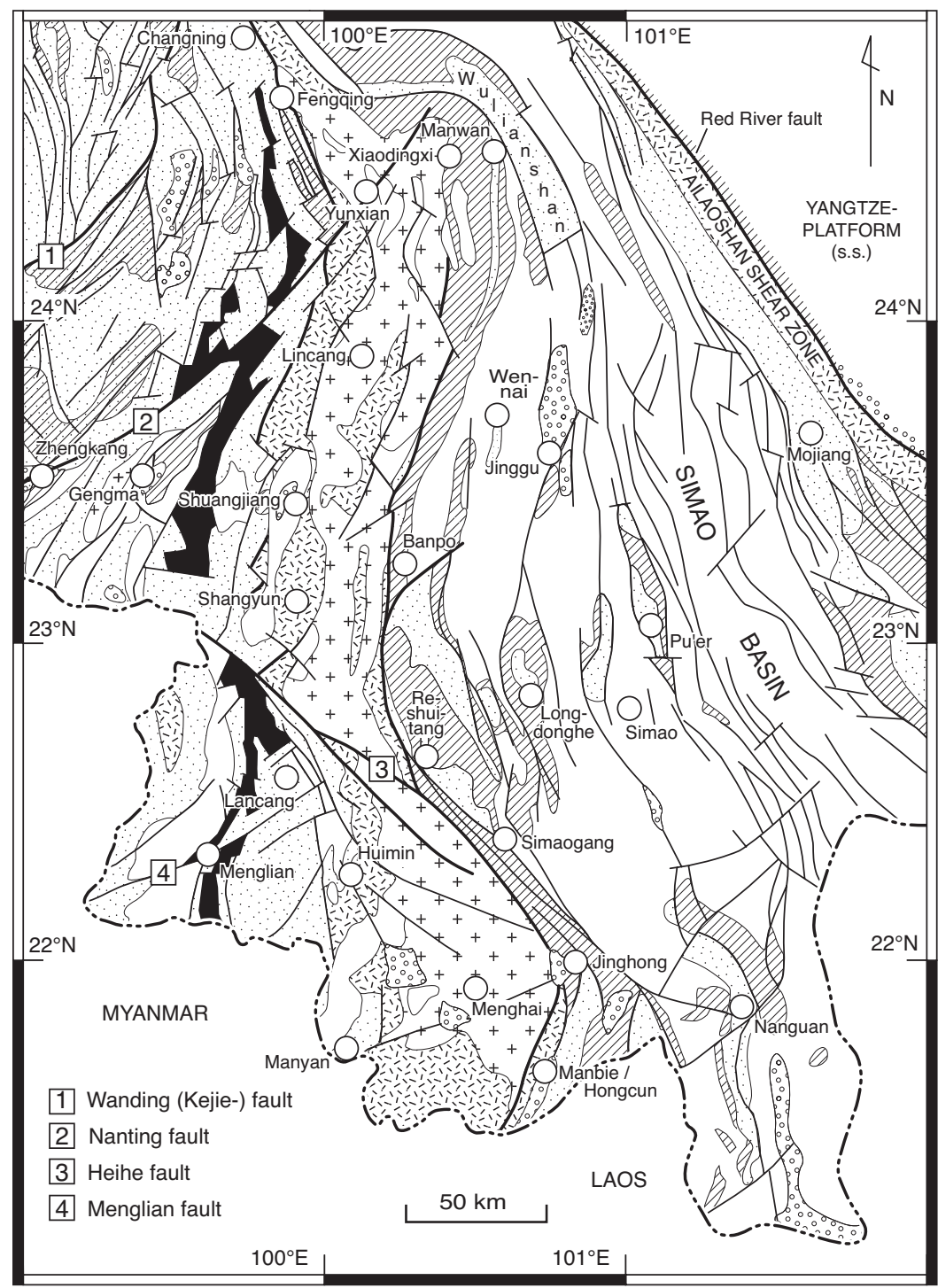

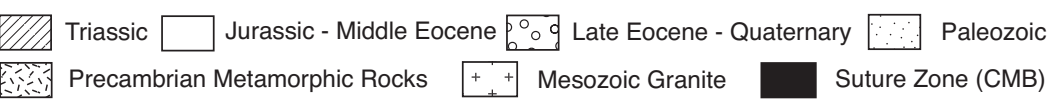

Fig. 3-1: Simplified geological map of Southwest Yunnan. CMB: Changning Menglian Belt (compiled from Wang and Burchfield, 1997 and YBGMR, 1990).

Though intensive efforts were undertaken to establish a reliable stratigraphy for the numerous metamorphic, magmatic and sedimentary formations, no consensual agreement has been reached upon the geodynamic evolution. To date, two interpretations based on the Paleotethys concept (Chapter 2.1.2.) occupy prominent positions in the literature:

Model A) The area along the Lancang River (cf. Lancangjiang Fault Zone, Chapter 
2.2.6.) is believed to host the immediate suture of the Paleo-Tethys between a Gondwana-derived micro-continent (Lincang Block) and the Yangtze-continental plate (Fan and Zhang, 1994). Closure of the ocean is estimated to have taken place in the "late Hercynian-early Indosinian (P-T)". Carboniferous to Permian volcanic rocks along the Lancangjiang are interpreted to document an island arc, which was progressively raised by the west-dipping subduction of the Paleo-Tethys beneath the Lincang Block. This interpretation has been incorporated in numerous geotectonic reconstructions and paleogeographic interpretations (see e.g. Scotese and Golonka, 1992).

Model B) The area bordering the Lancang River is part of a high-T/low-P-belt comprising the Lincang Granite, the Precambrian high-grade metamorphic rocks of the Damenglong and Chongshan Group, and the Permo-Triassic volcanic rocks along the Lancang River (Zhang et al., 1993; Zhong et al., 2000). The volcanic rocks are interpreted as a product of island-arc volcanism analogous to Model A. Unlike Fan and Zhang (1994), the arc was caused by the consumption of an "intracontinental ocean" of the Paleotethys along an eastward-dipping subduction zone postulated to lie on the west side of the Lincang Granite. The argument for an opposite vergence is derived from a blueschist belt, that is known from the Lancang Group and lead Zhang et al. (1993) to propose a paired-metamorphic belt for the region. The proposed Gondwana-derived continent, closing the Paleo-Tethys in the Late Triassic, is the hitherto enigmatic Baoshan Block to the west of the Changning-Menglian Zone.

Given the poor chronostratigraphic dating of the formations and the apparently complex metamorphic, magmatic and sedimentological history of the region, a definition of single tectono-stratigraphic units as presented in Chapter 2.2. is a precarious approach. It certainly meets up with efforts required in the light of plate tectonic theory and is naturally a process of ongoing refinement, but I have gained the impression that the adaptation of the terrane concept in Yunnan has produced more problems than solutions (cf. the criticism of Sengör and Dewey, 1990).

Hence from this point, I will leave the aforementioned subdivision, break it down to its smallest comprehensible units, discuss similarities and differences, and reassemble the fragments to a modified and new approach. For this reason, I will define the area along the Lancang River as a purely territorial entity (Lancang River Zone) covering a N-S trending stripe to the east of the Lincang Granite, where Late Paleozoic and Triassic sedimentary rocks crop out in the vicinity of the Lancang River (Fig. 3-1). The term "zone" is further preferred to the term "tectono-stratigraphic unit" or "terrane", as I was not able to see a prominent change in the Late Paleozoic and Early Mesozoic facies that would justify a delineation of the area to the east. This becomes especially true, if further Late Paleozoic profiles are taken into account that were acquired from anticlines in the western part of the Simao Basin. These profiles convey a situation that is connected to the development along the Lancang River itself. Surprisingly, similar conclusions can be drawn for the areas to the west of the Lincang Granite. Although the transition is marked by a Himalayan mylonitic fault zone, various similarities in the tectono-metamorphic evolution exist across the area and show a tight relationship between the Late Paleozoic evolution of the Lancang Group and the development along the Lancang River. Due to 
these similarities I have extended my investigation to the east of the Lancang River and will therefore include a discussion on the origin and genesis of the Lincang Granite, Lancang, Damenglong and Chongshan Group as well. 


\subsection{Metamorphic Evolution}

\subsubsection{Damenglong and Chongshan Group}

The rocks of the Damenglong and Chongshan Group occur inside and to the east of the Lincang Granite and consist of banded gneiss, quartzo-feldspathic mica schist, amphibolite, migmatite and marble. In some gneisses and pelitic schists, garnet, cordierite and andalusite occur as porphyroblasts, and in zones close to the Lincang Granite fibrous sillimanite is abundant. In rocks of the Chongshan Group migmatitic gneisses with clinopyroxene-bearing melanosomes and felsic quartzo-feldspathic leucosomes were formed. The mineral paragenesis, as presented by Zhang et al. (1993), documents an increase in metamorphic grade from lower amphibolite to lower granulite facies (Fig. 3-2, 3-3). Due to poor outcrop conditions a precise mapping of metamorphic isograds has not been obtained, but Zhang et al. (1993, p. 608) report that the metamorphic grade increases from east to west in northern and southern exposures (Fig. 3.2).

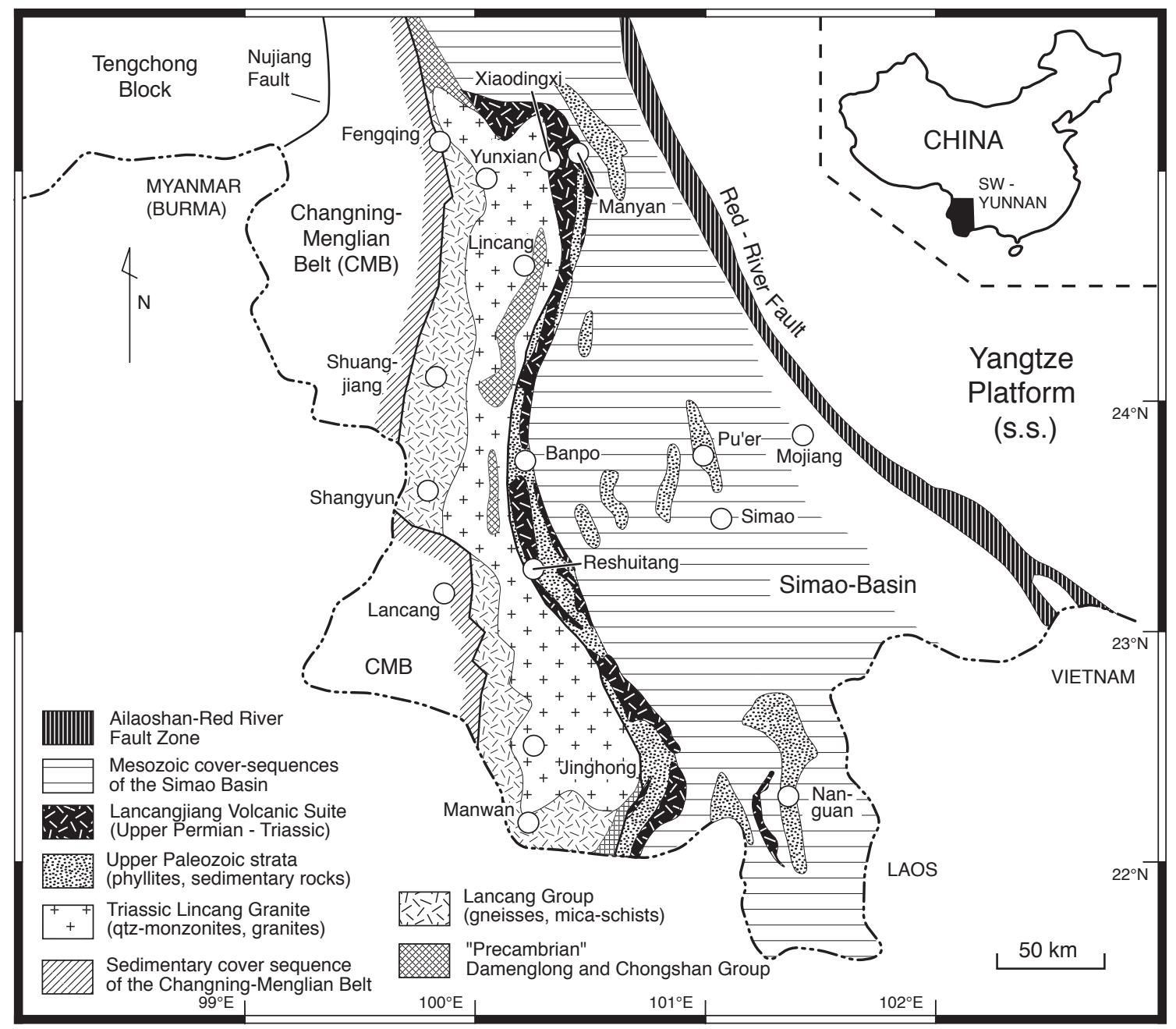

Fig. 3-2: Overview and main geological units of the Lancang River Zone, southwestern Yunnan, People's Republic of China

In the eastern part of the Chongshan and Damenglong Group, metabasaltic rocks contain low-amphibolite-facies assemblages of oligoclase + green hornblende \pm epidote \pm biotite, and pelites contain andalusite with muscovite and biotite. Further to the west and 
close to the Lincang Granite, high-amphibolite facies assemblages including clinopyroxene + brown hornblende + andesine appear in metabasic rocks, whereas in metapelites cordierite + garnet and garnet + sillimanite occur. Finally, a retrograde greenschist facies is documented by the replacement of clinopyroxene by actinolite, and hornblende and mica by chlorite.

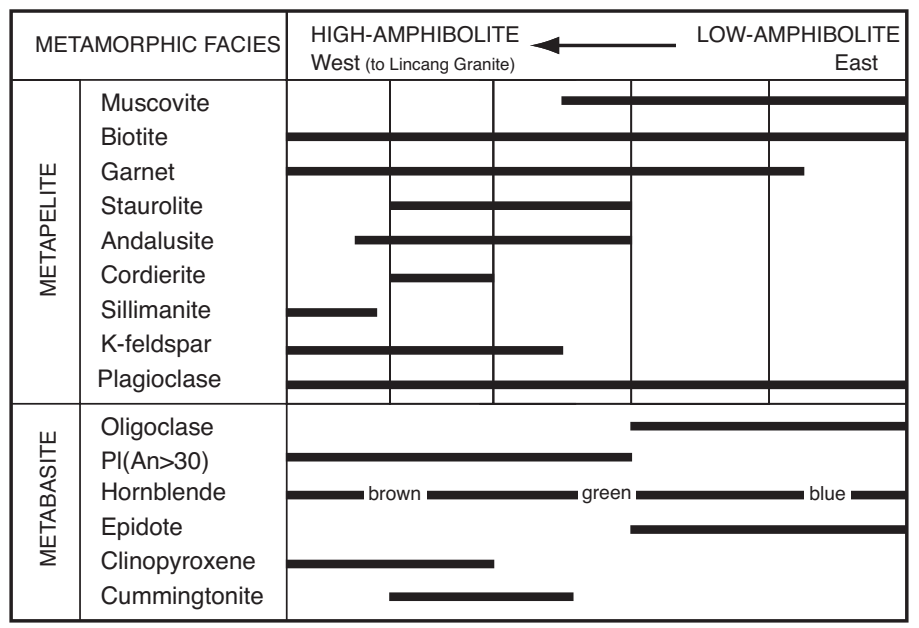

Fig. 3-3: Mineral paragenesis (+Qtz) of the Damenglongand Chongshan Group (low-P/T metamorphic belt after Zhang et al., 1993).

Geochemical and geochronological data of the zone are sparse and no English paper is known to me that is entirely dealing with the geochemistry or geochronology of the Damenglong and Chongshan Group. Zhang et al. (1993) report that the metavolcanic rocks of the Damenglong Group show moderately LREE-enriched patterns, $(\mathrm{La} / \mathrm{Yb})_{\mathrm{CN}}$ ratios between five and eight, and a depletion in HFS-elements and compatible elements, such as $\mathrm{Cr}, \mathrm{Ni}$, and $\mathrm{Co}$. They point out that much of the reported data is based on work by the Institute of Geology, Academia Sinica, and the Bureau of Geology and Mineral Resources, Yunnan Province (YBGMR, 1990). On the grounds of these results they suggest that the metavolcanic rocks are calc-alkaline.

Geochronological and isotopic data are rather inconclusive as well. Metavolcanic rocks from the Damenglong Group gave a whole-rock Sm-Nd isochron age of $1437 \pm 17 \mathrm{Ma}$ (Zhai et al. 1990a), and from a gneiss, a whole-rock Rb-Sr age of $716 \mathrm{Ma}$ is published by YBGMR (1990). Some Sm-Nd model ages of granitic gneisses (Damenglong and Chongshan Group) and amphiboles (Damenglong Group) are available and range between 1.7 and $1.9 \mathrm{Ga}$, whereas the K-Ar age of hornblende from amphiboles of the Damenglong Group yielded a young age of $188 \mathrm{Ma}$. Geological maps of the region indicate that both groups are believed to be entirely of Precambrian age and constitute the host of the Lincang Granite intrusions.

Zhang et al. (1993) conclude that the Damenglong and Chongshan Group reflect a possibly Early Precambrian arc environment with a regional metamorphic event that was later overprinted by low-P/T metamorphism during the emplacement of the Lincang Granite. The intrusion of the Lincang Granite was followed by post-Triassic retrograde metamorphism. In their view, two stages of arc emplacement are documented along the 
Lancang River Zone, one in the Precambrian and the other in the Permo-Triassic. They point out that: "Details of thermal metamorphic zones around the intrusives and possible pre-intrusive recrystallization require further studies. Because of heavy vegetation and poor exposure, differentiation of these two metamorphic events has not been accomplished." (Zhang et al., 1993, p. 607).

Cong and Zhai (2000) relate the Damenglong and Chongshan Group to the Early MidProterozoic active continental margin of the Yangtze continental block. They reason that the age of the Damenglong metavolcanic rocks (1436 Ma, Cong and Zhai, 2000, p. 26) is similar to amphibolites of the Ailaoshan. "These data represent the ages of amphibolite facies (metamorphism)." (Cong and Zhai 2000, p. 26). Further, they point out that a typical metamorphic belt of high-P/T- (Lancang Complex) and low-P/T- (Lincang Granite, Damenglong and Chongshan Group, Permian-Triassic volcanic rocks) metamorphism was developed along the Lancang River Zone in the Late Paleozoic to Early Mesozoic. Being a co-author in the publication of Zhang et al. (1993), Prof. Bolin Cong advocates a paired-metamorphic belt in this area, and from his synopsis in Zhong et al. (2000) I infer that his current ideas have not changed since 1993: a possible amphibolite-facies metamorphism of Mid-Proterozoic age was overprinted by low-P/T metamorphism in the Late Paleozoic/Early Mesozoic.

As pointed out by Zhang et al. (1993), the coexistence of biotite and andalusite, almandine and cordierite or sillimanite in metapelitic rocks as well as oligoclase, clinopyroxene and calcic plagioclase in metamafic rocks indicates that the rocks metamorphosed to amphibolite/lower-granulite-facies conditions along a low-P/T path. A low-P/T path is essentially advocated by the presence of andalusite (see KFMASH-diagram in e.g. Winter, 2001, p. 580), and therefore a path below the triple point of the $\mathrm{Al}_{2} \mathrm{SiO}_{5}$-phase diagram. In this respect, the documented index minerals and facies variations favor a Buchan facies- (Miyashiro, 1961, 1973) or low-P/T series metamorphism (Miyashiro, 1994). Further assemblages of lower granulite facies document a transition to lowerBarrovian-facies series at medium pressures.

Although I am aware that an older metamorphic event had possibly shaped the Damenglong and Chongshan Group, I will start discussing the youngest stage of metamorphism and agree with Zhang et al. (1993), who regards this event to be dominant. Hence, the youngest stage of metamorphism should account for most of the observed petrologic features. - In my view, two conceivable end members for the cause of low-P/T metamorphism exist:

A] The metamorphism was accomplished by the intrusion of the Lincang Granite leading to thermal disturbances and contact metamorphism in the host rock (Damenglong and Chongshan Group).

B] Increased heat-flow within the crust lead to metamorphism and partial melting (anatexis) of predominantly pelitic rocks (Damenglong and Chongshan Group) and the formation of the Lincang Granite.

In this respect, migmatites of the Chongshan Group are interesting to discuss. Though there are various explanations on how migmatites form (Ashworth, 1985), one process 
is evident since the experiments of Winkler (1976): metasediments will begin to partially melt at temperatures a little above those of the sillimanite zone and this process can certainly be advocated to the formation of many migmatites (Yardley, 1996, p. 74).

In relation to the formation of the Lincang Granite the question arises whether the process of partial melting and migmatization has played a dominant role at the current level of exposure?

Zhang et al. (1993) underline that metamorphism ranges from lower amphibolite to lower granulite facies and explicitly report on the following assemblages in metapelitic host rock: 1] biotite + plagioclase + sillimanite + andalusite + garnet, 2] muscovite + staurolite + quartz + sillimanite + biotite + plagioclase, 3] plagioclase + biotite + cordierite + quartz \pm garnet, and 4$]$ biotite + quartz + garnet + sillimanite .

Knowing that metamorphism started along the low-P/T path with the occurrence of andalusite (Fig. 3-3 and 3-5), which high-temperature phase equilibria were likely to have formed with increasing temperature?

One of the key-processes involved in melting pelites is the release of water and the lowering of the granite solidus from the breakdown of hydrous minerals, such as muscovite and biotite. From Fig. 3-3 it is clear that breakdown of muscovite (there is no muscovite at high-amphibolite facies condition) must have occurred by the reaction muscovite + quartz $\rightarrow \mathrm{Al}_{2} \mathrm{SiO}_{5}$ (sillimanite, andalusite) $+\mathrm{K}$-feldspar $+\mathrm{H}_{2} \mathrm{O}$-rich vapor during upper amphibolite metamorphism. As there is a gap between the last occurrence of muscovite and the first appearance of sillimanite, the $\mathrm{Al}_{2} \mathrm{SiO}_{5}$-phase of the reaction was first andalusite and later sillimanite. To account for this observation a path below the univariant reaction line of muscovite + albite + quartz $->\mathrm{Al}_{2} \mathrm{SiO}_{5}+\mathrm{K}$-feldspar $+\mathrm{H}_{2} \mathrm{O}$-rich vapour and the andalusite/sillimanite transition was presumably followed. With increasing temperature, this path must have crossed the biotite $+\mathrm{Al}_{2} \mathrm{SiO}_{5} \rightarrow$ garnet + cordierite $+\mathrm{K}$ feldspar + melt - reaction line until it reached the minimum melting temperature of the granite system. At this point, vapor-saturated melting occurred by the reaction $\mathrm{K}$-feldspar + albite + garnet + cordierite + biotite + quartz $+\mathrm{H}_{2} \mathrm{O} \rightarrow$ melt (cf. Winter, 2001, his Fig. 28-21, p. 580 or Fig. 3-4 this study).

It is interesting to note that at low pressure muscovite- and biotite-breakdown is facilitated at significantly lower temperatures. At this stage muscovite-bearing rocks will first start dehydrating without forming a melt. Still within the subsolidus region, most fluids will not leave the rock due to low porosity. Reaching the minimum melting temperature of pelites, again, little melt is produced and not until biotite breakdown occurs, significant fractions of melt will occur. Hence, I will conclude that if partial melting of the Damenglong and Chongshan Group formed the Lincang Granites, biotite- and not muscovite-breakdown must have been the key-process.

However, whether biotite-breakdown has played a major role remains speculative, but typical high-grade pelites and migmatites contain an assemblage of garnet - cordierite K-feldspar (sample Dy06 and Dy10 of Zhang et al., 1993, p. 608), and indeed migmatites do occur. Direct evidence of this process is documented by the migmatitic gneisses of the Chongshan Group, which show cpx-bearing melanosomes and plagioclase/qtz-rich 


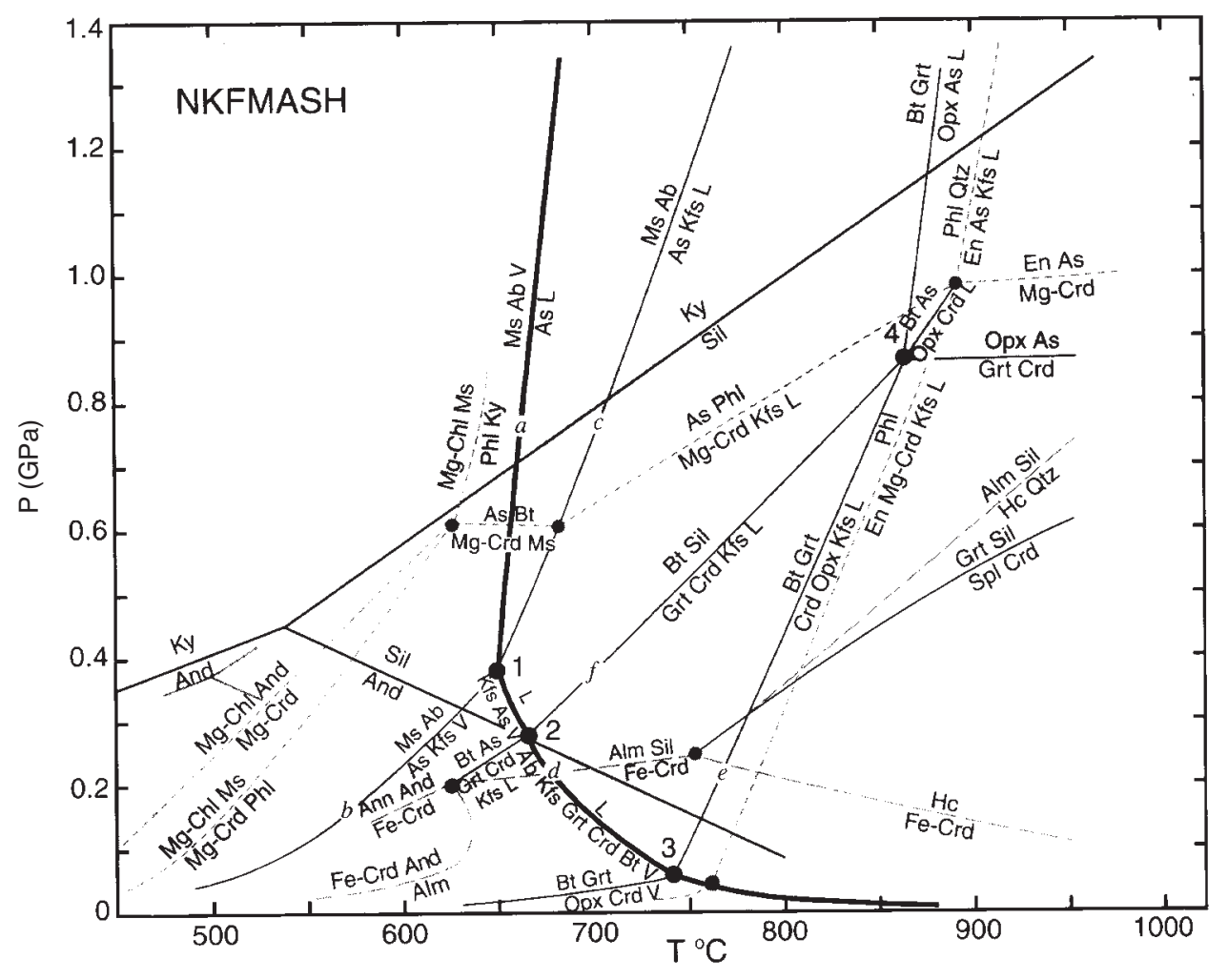

Fig. 3-4: High-temperature petrogenetic grid of pelititic rocks showing the location of selected melting and dehydration equilibria in the NKFMASHsystem. Some equilibria of the KFASH- (dotted) and KMASH (dashed) systems were added (from Winter, 2001, p. 580, after Spear et al., 1999). Reactions are not balanced and commonly leave out Ms and Qtz, which are considered to be present in excess. Typical medium and low-P/T metamorphic field gradients are included for comparative purposes. The $\mathrm{Al}_{2} \mathrm{SiO}_{5}$ triple point is shifted following the arguments of Pattison (1992). $\mathrm{V}=\mathrm{H}_{2} \mathrm{O}$-rich vapour, when present in fluid saturated rocks.

leucosomes. The occurrence of clinopyroxene can be attributed to the dehydration of amphibole to pyroxenes in metabasites at low pressures and high temperatures (Spear, 1981). Yardley (1996, p. 109) states: "At the highest grades of metamorphism, where temperatures exceed those of the Barrovian zones, hornblende in metabasites begins to break down and pyroxenes appear. At the same time, partial melting may occur to produce migmatitic metabasites with leucosomes of plagioclase and quartz."

Zhang et al. (1993) emphasize that estimated temperatures of plagioclase-amphibolite and garnet-biotite-geothermometers for amphibolites and garnet-bearing schists document temperatures up to $705-781^{\circ} \mathrm{C}$, and at such high temperatures partial melting of pelites would have occurred if $\mathrm{H}_{2} \mathrm{O}$-rich fluids were present (Winkler, 1976).

Indications of high- or even ultra-high-temperature assemblages are further documented from xenoliths within the granites. The xenoliths are biotite-rich and accessory minerals locally comprise a rather exotic assemblage of cordierite, sillimanite, spinell and sapphire. This assemblage points to abnormally high temperatures of the melt reaching 800 to $850^{\circ} \mathrm{C}$ (pers. communication Prof. P. O'Brien, Potsdam). If such high-temperature melts had occurred, an intrusion, rising from lower hotter to uppermost cooler parts of the crust (i.e. sedimentary cover sequence), is unlikely. 
In the field, I often had the impression that the Lincang Granite was actually formed "in-situ" or without a distinct vertical displacement of the melt body. I was never able to find an outcrop, where a typical contact metamorphism is documented and plutons never intrude the phyllites along the Lancang River or any sedimentary cover sequences. The granites are coarse-grained (partially megacrystic), unfoliated and undeformed. As to my knowledge, there is no indication of any kind of macroscopically observable emplacement mechanism. The boundary between Lincang Granite and the metamorphic basement seems to be a broad transition of several kilometers ranging from qtz-mica-schists to gneisses to migmatites and finally to the granite itself. This situation is especially well documented from a section at Manyan (Burmese border, Fig. 3-1). Here, within the Lancang Group, I was very much reminded of the situation described by Mehnert (1968) for the Kirchzarten area in the Black Forest.

It can be concluded that an abnormally high geothermal gradient was progressively established during the Late Permian and Triassic along the Lancang River Zone. The increase in temperature lead to crustal anatexis making the formation of the granite a very likely scenario. Due to the occurrence of migmatites and upper-amphibolite- to lower-granulite-facies rocks with estimated temperatures of $705-781^{\circ} \mathrm{C}$ at about $5 \mathrm{kbar}$ (13-15.5 km depth; high(!) geothermal gradient: $45-60^{\circ} \mathrm{C} / \mathrm{km}$ ) neither a shallow intrusion level nor a significant vertical emplacement of the Lincang Granites is indicated. Due to the restricted exposure of basement rocks in the area, a good estimate on the spatial distribution of migmatites and granulites is difficult to obtain. This is on the one hand related to poor outcrop conditions and on the other hand due to a limited amount of basement rocks that were exhumed along the Lancang River. However, the residuum remains a problem. From experimental works of pelite melting (Winkler, 1976) it is known that the unmelted residuum, which is left after forming a granitic melt, contains biotite, cordierite, sillimanite, and excess quartz. This is exactly the assemblage that occurs in the gneisses of upper amphibolite facies (see Zhang et al., 1993, p.608, his Fig. 3.) Further, I would like to draw attention to the work by Bohlen and Metzger (1989), who oppose the long held view that granulite-facies rocks do entirely represent the dehydrated roots of the deep continental crust. Bohlen und Metzger (1989) have shown that many granulite facies rocks have mid-crustal and not deep-crustal origins!

Discussing the metamorphic evolution of the Damenglong and Chongshan Group alone, Zhang et al. (1993)'s perception of an island-arc environment is a logical platetectonic scenario. And indeed, the high geothermal gradient could be explained by a strong mantle influence as typical for high-temperature magmas in island-arc settings (high-heat flow orogenic belts). In later chapters we will see whether this conclusion is sustainable if further parameters, such as the petrology and geochemistry of the granites and volcanic rocks along the Lancang River are taken into account. The low-pressure or Buchan-facies series as described by Miyashiro (1994) is not only characteristic of high-heat flow orogenic belts (Buchan or Ryoke-Abukuma type), but also for other tectonic environments, such as rift zones (cf. Winter, 2001, p. 500).

It shall finally be noted that the Precambrian age of both units is rather disputable and reflects a general debate on the occurrence of Precambrian basement rocks in mainland 
Southeast Asia (Mickein, 1997; Ahrendt et. al., 1994). As far as the Precambrian basement along the Lancang River Zone is concerned, geochronological data, as well as the metamorphic evolution of the area, unequivocally document a Proterozoic basement as part of the Damenglong and Chongshan Group. There is general agreement on the age by all scientists working in the area and Zhong et al. (2000) relate both groups to the Yangtze basement (Yangtze-Affinity Block) of the South-China micro-continent. Nevertheless, crustal melting had not only played a major role in forming the Triassic Lincang Granite but probably also in metamorphosing and partially melting the Damenglong- and Chongshan Group. As for the age of the migmatites, and certainly for the high-amphibolite- and lower ganulite rocks in the vicinity of the granites as well, a Precambrian age is misleading. Though the protolith is Precambrian, the metamorphic age of the rocks, which were influenced or completely metamorphosed, are distinctly younger and contemporaneous to the formation of the Lincang Granite. As noted earlier, Zhang et al. (1993) point out, that the differentiation of these two metamorphic events is rather difficult.

I therefore speculate that this difficulty is basically related to high-T/low-P metamorphism and local anatexis which largely destroyed the Precambrian metamorphic history.

A remaining problem related to the low-P/T metamorphism is why the estimated $\mathrm{P} / \mathrm{T}-\mathrm{t}$ path of Zhang et al. (1993) shows an almost isothermal pressure increase of $2 \mathrm{kbar}$ at 750-800 ${ }^{\circ} \mathrm{C}$ (Fig. 3-5, Fig. 3-6).

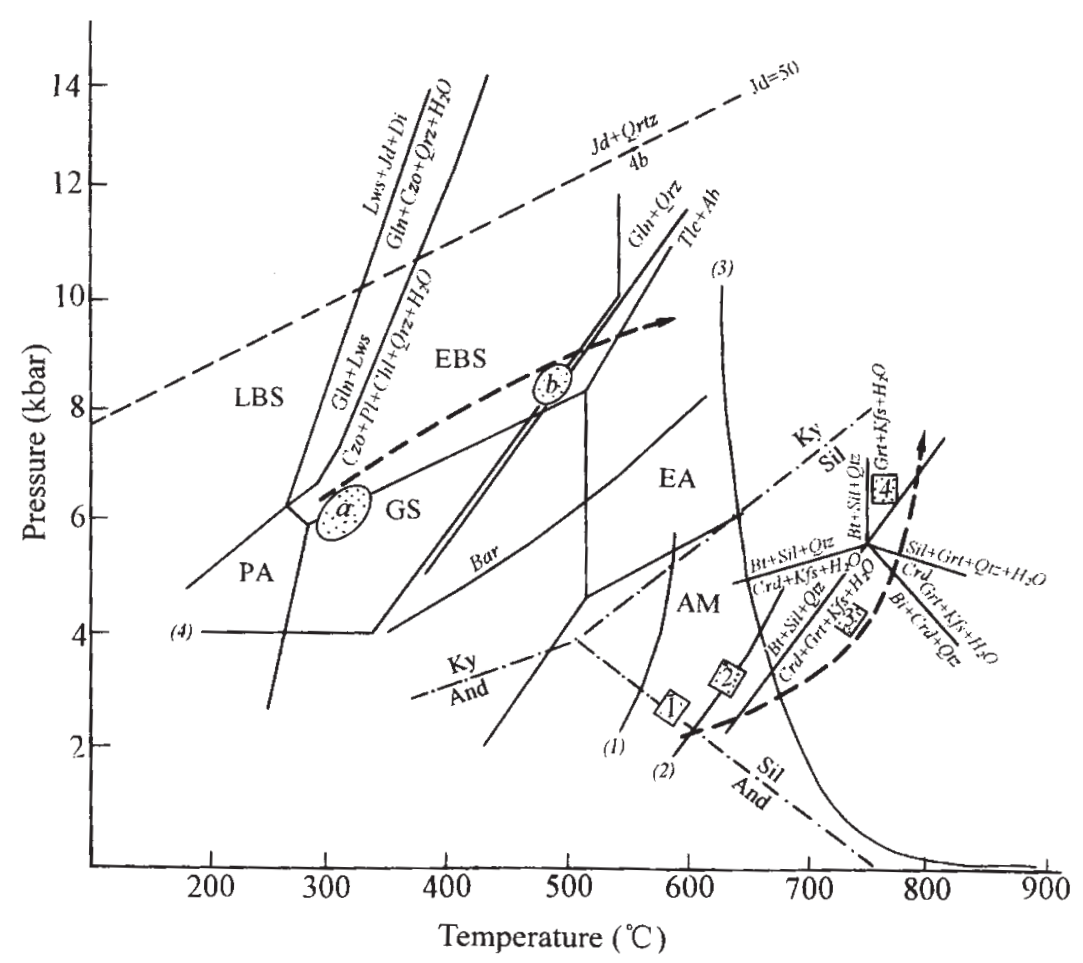

Fig. 3-5: P-T conditions of the Lancangjiang paired metamorphic belts (from Zhang et al., 1993). AM - amphibolite facies; EA - epidote facies; EA - epidote amphibolite facies; EBS - epidote-blueschist facies; GS - greenschist facies; PA - pumpellyite actinolite; LBS - lawsonite blueschist field; $a$ and $b$ are estimates for blueschist from Zone II and III; 1, 2, 3 and 4 are estimates for the low-P/T belt. 
A logical explanation could be given in relation to the widespread volcanism at the Permo-Triassic boundary, where new material was rapidly added to the uppermost part of the crust. A pressure increase of 1-2 kbar at depth of granite formation could have been caused by "overplating" volcanic and sedimentary material in a basin-and-rangetype rift environment. That the eruptions of volcanic material was not a local feature is depicted in Fig. 3-31. Similar to this mechanism, Bohlen $(1987,1991)$ pointed out that counter-clockwise P/T-t paths (Fig. 3-5) typically occur in high-grade gneisses and granulite-facies terranes, and are believed to result from intrusion of relatively large quantities of usually mafic magma into the lower and middle crust. This addition in mass leads to a pressure increase below the mafic intrusion levels. Hence, both mechanisms, the addition of volcanic and clastic material by extrusion of the Emeishan basalts and the intrusion of mafic magmas, such as at Banpo (cf. Chapter 2.2.6), are a logical deduction and can account for the 2-3 kbar isothermal pressure increase depicted by Zhang et al. (1993, Fig. 3-5).

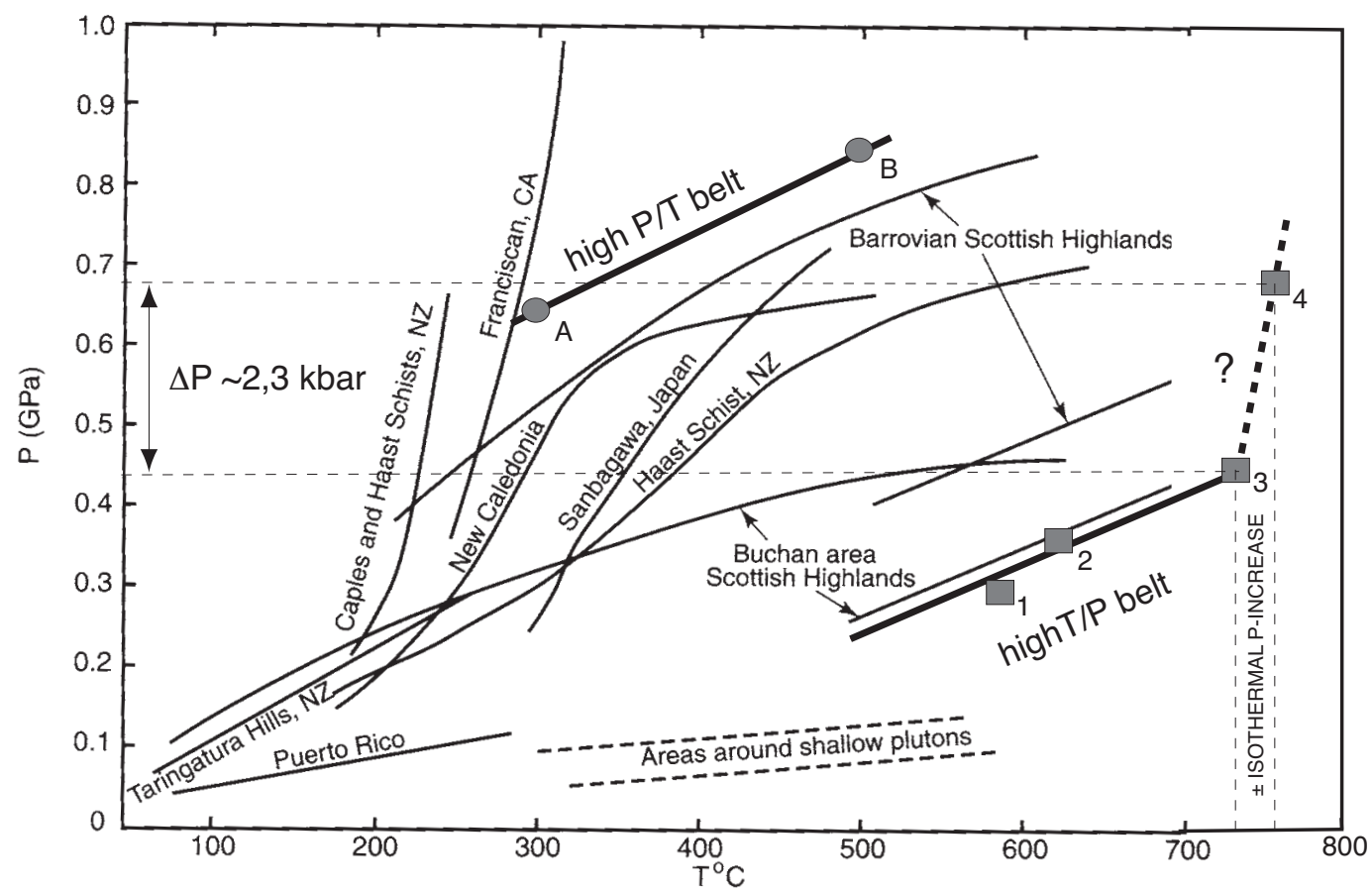

Fig. 3-6: Metamorphic field gradients (estimated P-T conditions along surface traverses directly up metamorphic grade) for several metamorphic areas (after Turner, 1981; modified figure from Winterer, 2001, p. 413). Field 1, 2, 3, and 4 are P-T estimates for the low P/T- and field A and B are for the high-P/T belt of Zhang et al. (1993, p. 614, cf. Fig. 3-5).

However, not until more precise geochronological data is available, a further alternative remains: the depicted P/T-t-path by Zhang et. al. (1993) might actually be a composite "pseudo"-path of two separate events and the observed mineral assemblage does not solely document the evolution of the low-P/T belt alone.

\subsubsection{The Lancang Group}

The Lancang Group, originally named by the Yunnan Bureau of Geology and Mineral Resources for an assemblage of Proterozoic metamorphic rocks to the west of the Lincang Granite (YBGMR, 1990), has been the focus of considerable debate over the 
last decade and several new sets of data have shown that the formation of the rocks was more complex than previously suspected. Substantial work has been done on the petrology, and the available papers and reports are partially contradicting and confusing.

Zhang et al. (1993) divide the Lancang Group into three fault-bounded units depending on their difference in lithology (Fig. 3-7).

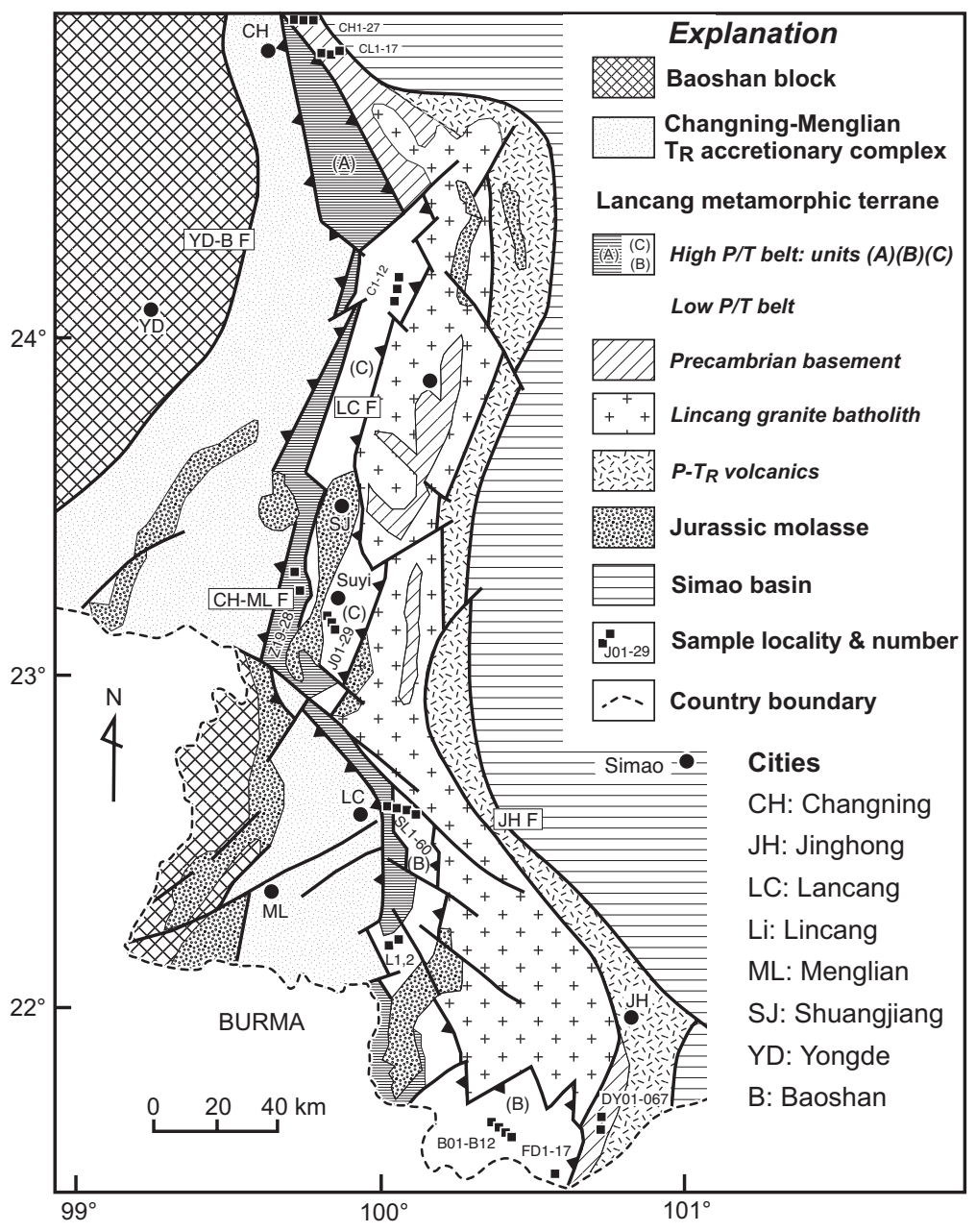

Fig. 3-7: Geological map of the Lancang paired metamorphic belts (redrawn from Zhang et al., 1993).

The westernmost unit (A) consists of sandstones, mudstones, slates, phyllites, and minor chlorite schists and blueschists. This estimation is shared by Zhong et al. (2000). The blueschists are less developed in respect to unit (B) and (C) and range from tens to more than 100 centimeters in thickness. In some metabasites crossite, ferroglaucophane, chlorite, and albite appear. Zhang et al. (1993) suspect that the possibly high $\mathrm{CO}_{2}$-content of the metamorphic fluid prohibited the crystallization of characteristic $\mathrm{Ca}$ Al silicates, such as lawsonite, pumpellyite and epidote. Characteristic mineral assemblages of metamorphosed rocks include 1] phengite, quartz, chlorite, and albite, 2] phengite, chlorite, quartz, stilpnomelane, and 3] quartz, phengite, calcite, and clinozoisite for metapsammitic rocks. Metabasites are characterized by assemblages such as 1] crossite, calcite, chlorite, and albite, and 2] crossite/glaucophane, phengite, quartz, chlorite, and albite. Zhang et al. (1993) relate the lithological unit (A) to Chlorite Zone I (Fig. 3-8). 


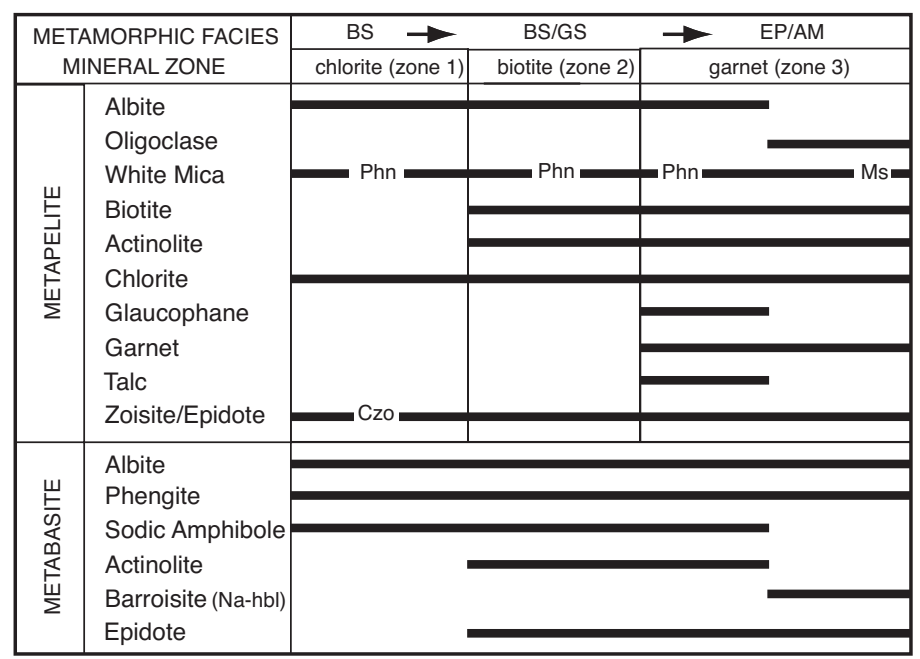

Fig. 3-8: Mineral paragenesis of the Lancang Complex (high-P/T metamorphic belt after Zhang et al., 1993). BS: blueschist facies, GS: greenschist facies, AM: epidoteamphibolite field; Phn: phengite, Czo: clinozoisite.

The stratigraphic age of the formation is disputable and estimations range from EarlyMiddle Proterozoic (Zhong et al., 2000, p. 28) to Devonian (Zhao, 1991). The age of metamorphism, as indicated by an Ar/Ar-plateau age of 279 Ma for crossitic amphiboles (Zhao, 1991), was advocated to be Late Paleozoic (Zhang et al., 1993). In this respect, I would like to stress that the age of $279 \mathrm{Ma}$ is presumably of limited geological significance, inasmuch as the Ar/Ar analysis by Zhao (1991) is further cited by Zhong et al. (2000, p. 178), and actually documents a staircase-pattern with plateaus at $279 \pm 1.6 \mathrm{Ma}$, $214 \pm 0.9 \mathrm{Ma}$, and 111.9 Ma. In this study, an attempt to date a typical blueschist (02/143) form the western Lancang Group by means of the Ar-Ar laser ablation technique (Hodges, 1998) has shown that the potash-content of the glaucophanes (crossites) is too low (<0.1 wt\%) to obtain a reliable age (see EMS-Analysis, Fig. 3-9, and Table 5 in Appendix). Hence, paragenetic phengites were chosen and obtained a concordant "age spectrum" and a plateau age of $294 \pm 1$ Ma (Fig. 3-10, Table 6 in Appendix).

Geochemical data for the unit (A) are sparse as well (Zhong et al., 2000, p. 28-31). Metabasites are low in $\mathrm{TiO}_{2}$ and show a variable ratio of $\mathrm{FeO} / \mathrm{MgO}$ from 1.8 to 2.5. $\mathrm{Zr}$ content ranges from 110 to $190 \mathrm{ppm}$. In the Ti/100-Zr-3Y-diagram (Pearce, 1982), the samples plot in the field for volcanic-arc basalts (Zhong et al. 2000, p. 29, their Fig. 3.2 and 3.3). $\varepsilon N d-$ and $\varepsilon S r-v a l u e s$ range between -8 to -17 and 100 to 325, respectively. In the Th/Yb diagram after Pearce et al. (1984) the meta-basalts still plot in the field of continental active-margin-/alkaline island-arc basalts (CAM, AOA), but almost on the boundary to the field of within-plate basalts (WPB). MORB-normalized incompatible element data show enrichment in $\mathrm{Rb}, \mathrm{K}, \mathrm{Ce}$ and $\mathrm{Ta}$ and depletion in $\mathrm{Ni}$ and $\mathrm{Ti}$. The most prominent feature is a strong Sr-depletion with respect to $\mathrm{K}, \mathrm{Rb}, \mathrm{Ce}$ and $\mathrm{Ta}$.

Zhang et al. (1993) present the "Huimin Greenschist Series" as a calc-alkaline volcano-sedimentary sequence. In contrast, Zhao (1991) reports on a passive continentalmargin sequence stressing the occurrence of well-bedded Devonian "flysch" deposits. It is obvious that some of the geochemical data, such as the multi-incompatible element plots, are rather suspicious or even contradictory. 

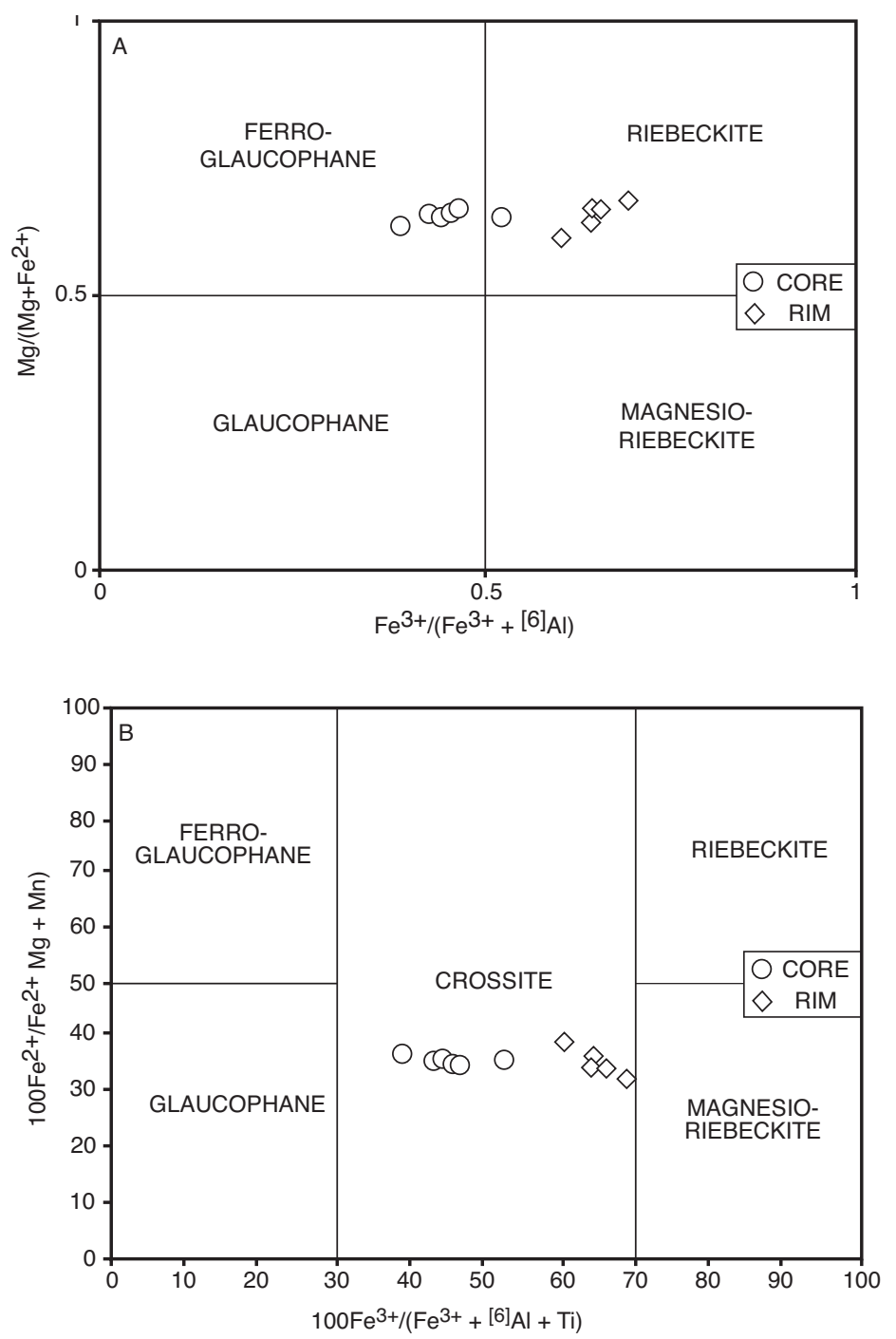

Fig. 3-9: Classification of amphiboles from sample 02/143. Amphibole-classification (A+B) after Deer et al. (1992).

A further complication is that the "Huimin Greenschist Formation" of Zhong et al. (2000, p. 28) is the unit (A) of Zhang et al. (1993). But during the last years, geological formations, which were formerly believed to belong to the Lancang Group, have been revised to Devonian and Carboniferous strata (pers. comm. Prof. Feng Qinglai 2003, Univ. of Wuhan). Hence, the stripe between the Lancang Complex and the DevonoCarboniferous sedimentary rocks are more likely related to the Late Paleozoic evolution of the Changning-Menglian Belt than to the Lancang Group.

During my own field observations, I have gained a completely different perception of the rocks, which were mapped as the Huimin Formation. The rocks that crop out as $\mathrm{P}_{\mathrm{t}} \mathrm{h}^{1}$ or $\mathrm{AnO}^{\mathrm{Xq}}$ are schists and mylonites of higher metamorphic grade. It is true though that a fault separates the Huimin Formation from the sedimentary cover sequences of the Changning-Menglian Belt at various locations (i.e. to $\mathrm{Cnn}_{1}$, Nanduan Formation, west of Shuangjiang, cf. Fig. 3-38). But this fault is only evident because of the distinct metamorphic gap between both units. I suspect that at least some parts of the unit (A) belong to the sedimentary sequence of the Changning-Menglian Zone, and no fault can be drawn unless there is a strong gap in metamorphic grade between both units. It sounds illogi- 
cal to me, that a 180-kilometre-long, single sharp fault could have possibly been mapped between the "flysch"-type Devonian sedimentary rocks of unit $(A)$, and the sedimentary sequence of the Changning-Menglian Zone. This argument is even more true, if the Changning Menglian Belt is regarded to be an accretionary complex (see Zhang et al., 1993, p. 607, Fig. 3-7).

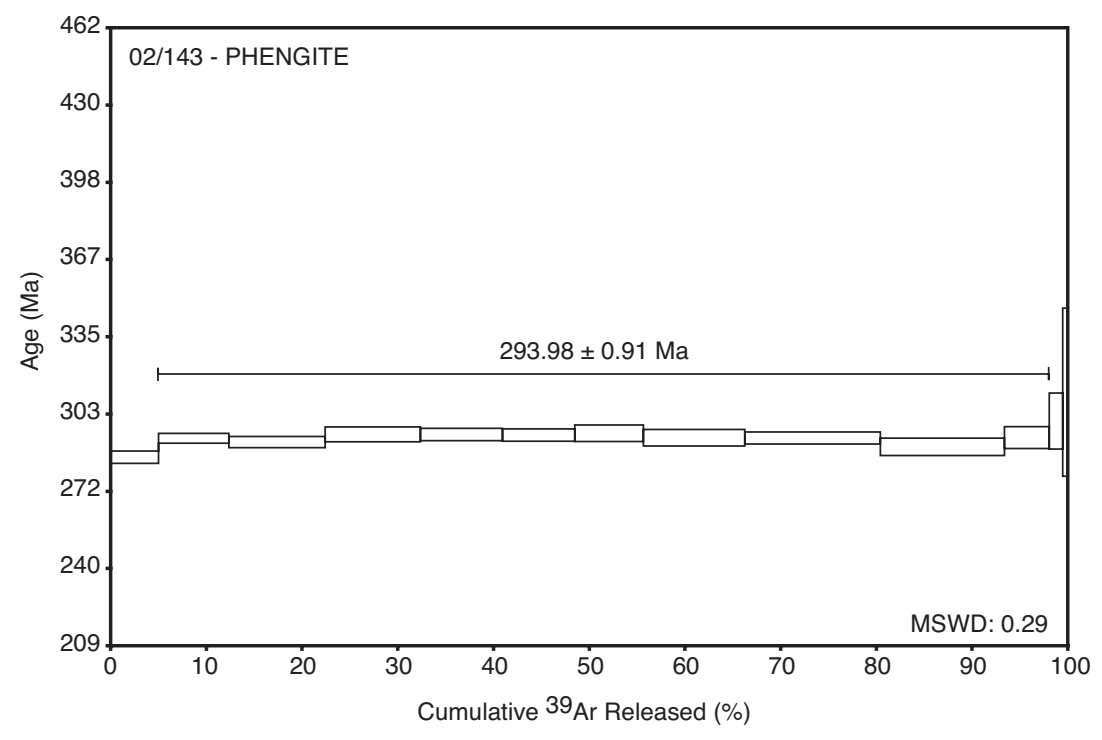

Fig. 3-10: Results of $40 \mathrm{Ar} / 39 \mathrm{Ar}$ phengite dating from the blueschistbelt west of Lincang Granite (sample 02/142, measured and irradiated at MIT, Cambridge, USA). Sample located on Fig. 3-43 as point S.

Unit (B), situated southeast of unit (A), consists of mica-schists, pelitic schists, greenschists, and some blueschists. Zhang et al. (1993) report that metasediments appear to be former platform-type deposits, where a mid-Late Proterozoic microflora is reported by Xue et al. (1989). Interlayered greenschists and blueschists contain abundant actinolite, sporadically sodic amphibole, chlorite, epidote, and albite. Sm-Nd model ages of 1000$1300 \mathrm{Ma}$ are advocated to document a Middle to Late Proterozoic protolith (Peng and Luo, 1982; Zhai et al., 1990b). Zhou and Lin (1982) report Rb-Sr ages on phengites ranging between 260-240 Ma for mica schists. Further, Zhai et al. (1990b) describe metaandesites with geochemical features typical of island-arc volcanics: high Ba/La: 30-40, $(\mathrm{La} / \mathrm{Yb})_{\mathrm{CN}}$ : 15-19, low $\mathrm{TiO}_{2}$-content: 0.57-1.01 wt\%), and a depletion in HFSEs.

Unit $(C)$, is situated to the northeast of unit $(A)$ and is the northern equivalent of $(B)$. Unit $(C)$ is similar to $(B)$ and hosts the best outcrops for blueschists in the region. It comprises phengite schists, graphite schists, few marbles, and sodic-amphibole-bearing metavolcanic rocks. Geochronological data has not been obtained for the unit and the geochemical analyses are contradictory. Zhang et al. (1993) note that the protoliths of the metavolcanic rocks were mostly "alkaline basalts of island arc affinity". Zhong et al. (2000, p. 28) report that the meta-volcanic rocks of the unit (B) show geochemical characteristics of island-arc basalts, whereas unit $(C)$ of within-plate basalts. They further stress that the protolith of the blueschist was mainly "oceanic island alkaline basalts", containing a higher content of $\mathrm{TiO}_{2}$, a high $(\mathrm{La} / \mathrm{Yb})_{\mathrm{CN}^{-}}$-ratio, and an "abundance of highfield strength elements". The metavolcanic rocks have high $87 \mathrm{Sr} / 86 \mathrm{Sr}$-ratios $(0.709$ 0.720 ) and low ${ }^{143} \mathrm{Nd} /{ }^{144} \mathrm{Nd}$-ratios $(0.51175-0.51250)$ showing "isotope geochemical 
characteristics of island arc and active continental margin" (Zhong et al., 2000, p. 31).

Zhang et al. (1993) relate the geological units $(B)$ and $(C)$ to a Biotite Zone II in the western part of $(B)$ and $(C)$ and a Garnet Zone III in the eastern part of $(B)$ and $(C)$ (Fig. 3-8). Due to poor outcrop conditions the boundary between Zone II and Zone III is not clearly defined in both units. Further, another fault is proposed to separate unit (B) and (C) from the Lincang Granite. To make it clear, after Zhang et al. (1993), unit (A) is faultbounded to the Changning-Menglian accretionary complex of Triassic age. The contact between unit $(A)$ and unit $(B)$ and $(C)$ is not exposed. Further, the contact or transition between Zone II and III is not clearly defined as well, and finally, a theoretical fault, of which there is no evidence, is required to separate the high-P/T (in this case unit (C)) from the high-T/P belt (in this case the Lincang Granite).

In Biotite Zone II, sodic amphiboles become more abundant than in Zone I, and typical mineral assemblages are 1] biotite, phengite, quartz, albite, chlorite, calcite, and 2] phengite, chlorite, quartz, and carbonaceous material for metapsammitic rocks. Representative assemblages for greenschists are 1] actinolite, epidote, phengite, albite, quartz, and chlorite; 2] albite, quartz, chlorite, phengite, epidote, calcite, biotite, and for blueschists: 1] crossite, albite, epidote, chlorite, phengite, quartz, and 2] glaucophane, epidote, actinolite, chlorite, quartz.

Garnet Zone III, to the east of Zone II, shows blueschists with typical assemblages of 1] glaucophane, talc, phengite, garnet, epidote, quartz, and dolomite. Garnet-bearing oligoclase-mica schists contain an assemblage of 2] biotite, muscovite, oligoclase, garnet, and quartz. The high-grade blueschists show coarse-grained almandine and glaucophane porphyroblasts in a matrix of talc, phengite, chlorite, glaucophane, quartz and rare epidote. High-T blueschists of Chopin (1981) are documented by an assemblage of glaucophane, talc, almandine, and phengite. Further, amphibolites occur in the southeastern part of unit (B) with an assemblage of chlorite, albite, barroisite, and epidote.

The best developed blueschists are developed in Zone II and III. They are generally intercalated with greenschists and mica schists having a variable thickness from a few to about 50 metres.

Estimated P-T conditions for Zone II blueschists are $300-350^{\circ} \mathrm{C}$ at $5-6 \mathrm{kbar}$ based on the suggestion by Maruyama et al. (1986) that the glaucophane component of sodic amphibole coexisting with epidote + actinolite + chlorite + albite + quartz decreases with decreasing pressure. A decreasing pressure of $4-5 \mathrm{kbar}$ is estimated from the rim of zoned sodic amphiboles.

Zone III blueschists are proposed to be called high-T blueschists (Chopin, 1981), possibly reaching temperatures between $400-500^{\circ} \mathrm{C}$. Using the garnet-muscovite geothermometers of Hynes and Forest (1988), Zhang et al. (1993) estimate a temperature of $440^{\circ} \mathrm{C}$ and a pressure of $8 \mathrm{kbar}$ with reference to the equilibrium curve of glaucophane + quartz = talc + albite. Further, the occurrence of barroisite-bearing epidote amphibolites and garnet-bearing oligoclase mica schist point to high-grade conditions of the epidote amphibolite facies. 
Zhang et al. (1993) conclude that the Lancang Group documents a high-P/T metamorphism following the high-P intermediate facies series from blueschist (Zone I) through transitional blueschist/greenschist (Zone II) to the epidote amphibolite facies (Zone III). The Lancang Group is proposed to be the western belt of the Lancang paired-metamorphic belt during Permian and Triassic.

The structural evolution of the Lancang Group is complex as well. Prof. Chuanheng Zhang reports in Zhong et al. (2000) that the Lancang basement metamorphic complex (Lancang Complex, previously called the Lancang Group) is located to the east of the Changning-Menglian Belt. On the basis of detailed structural studies, he regards the Huimin Formation (unit (C) of Zhang et al., 1993) to be a different entity, and separates it from the Lancang Group. From west to east the former Lancang Group was therefore split up into two new units, the Huimin Formation and the Lancang Complex (unit (B) and (C) of Zhang et al., 1993). The contact between both units has been mapped as an eastdirected thrust displacing the Huimin Formation on top of the Lancang Group (Zhong et al., 2000, p. 43, their Fig. 3.15).

The Lancang Complex is believed to document a Yangtze-type Precambrian basement similar to the Ailaoshan-Diancangshan-Shigu metamorphic belt and contrasts with the Pake Complex, which crops out to the west of the Changning-Menglian Belt and is regarded to represent a Gondwana-type basement (Zhang et al., 2000, p. 38). Three generations of structures are proposed for the Lancang Complex:

1] $D 1$ shows a strong replacement of $S 0$ by a penetrative foliation $S 1 . S 1$ is reported to be the axial plane cleavage of the $\mathrm{f1}$ folds, which are SSW-vergent, isoclinal-tight folds. Fold-hinges strike WNW-ESE. The foliation is either defined by segregation of $0.5 \mathrm{~mm}$ thick layers of phyllosillicates interbedded with quartz-rich layers or by flow cleavage of orientated micas and chlorite. D1 is related to upper-greenschist facies metamorphism. F1 faults are mostly south-directed thrust showing corresponding S-C fabrics. D1 is attributed to the: "Jinningian tectonothermal event" that shaped the Yangtze basement at about $900 \mathrm{Ma}$.

2] D2 structures are characterized by a penetrative crenulation cleavage S2. The f2folds, taking S2 as their kinematic surface, form tight to open folds, whose fold-hinges coincide with D1 and strike east to west. F2 faults, on the contrary, are north-directed imbricate thrusts. D2 is accompanied by low-grade greenschist metamorphism and is attributed to the "Hercynian orogeny" as Prof. Chuanheng Zhang writes: "The two earlier generations of folding which can be obviously observed in the Yangtze-type basement are related to Jinningian (900 Ma) and Hercynian, respectively." (Zhang et al., 2000, p. 40).

The structures of the third, and last, generation D3 show cross folds, isopachous folds, box folds and kink bands. Folding is east-vergent and the hinge-lines trend north to south, with a preferred orientation of $15^{\circ}$ and $195^{\circ}$. They are perpendicular to the hinges of D1 and D2. No further generation of structures is reported for the Lancang Group, suggesting that the Himalayan overprint has been of brittle nature.

3] D3 is related to the closure of the Changning-Menglian Belt. Prof. Chuanheng 
Zhang writes: "Regionally D3-structures can be compared with those in the pre-Mid Jurassic stratigraphic sequences, suggesting that this generation of deformation is relevant to the evolution of the Paleotethys orogeny." (Zhang et al., 2000, p. 40).

In the Huimin Formation, on the contrary, only one generation of structures is developed. Unfortunately, the Fig. 3.14 in Zhang et al. (2000, p. 42), that refers to this question, is rather imprecise. At Huimin village, presumably the type-locality of the Huimin Formation, the signature of the Lancang Group is indicated and a thrust separates the Nanwanghe Group from the Lancang Group. No Huimin Formation is depicted at all. I therefore conclude that the Nanwanghe Group is actually meant to be the HuiminFormation. If this argumentation is valid, the Huimin Formation is characterized by northsouth trending, east-vergent folds similar to D3.

Up to this stage one key-problem is whether the Huimin Formation is a Late Paleozoic, partially metamorphosed sequence in relation to the Changning-Menglian Belt or a higher grade metamorphic unit related to the Lancang Complex. From my experience in the field, I regard the Huimin Formation to be the latter, and the Nanwanghe Formation to be the former. All rocks, which I have sampled from the Huimin Formation, are mica schists, and in the area to the north of Shuangjiang, a distinct gap in metamorphism from the Huimin Formation to the Nanduan sandstones $\left(\mathrm{Cnn}_{1}\right)$ can be observed. The geological maps clearly show that the Huimin Formation comprises schists and no low-grade metasedimentary rocks! This is certainly not a rule throughout the length of the Lancang Group. In respect to Fig. 3.14 in Zhang et al. (2000, p. 42), I would repeat the notification by Prof. Feng Qinglai that a range of formations, formerly believed to belong to the Lancang Group, have recently been re-assigned to Late Paleozoic rocks. I presume that this is especially true for the Nanwanghe Formation.

The reason for discussing this complex situation is related to the generation of the socalled D3 structures. Investigations of the structural evolution of a belt of phyllites (Lancang River Phyllite Belt), to the east of the Lincang Granite, have shown that there is a striking similarity between both belts (Fig. 3-11, Fig. 3-12). Stage D1 in the Phyllite Belt coincides with D3 in the Lancang Group and D1 in the Huimin Formation or Nanwanghe Formation (in the sense of Prof. Chuangeng Zhang). Further, Zhong et al. (2000, p. 40) state that the D2 structures in the Lancang Complex are similar to a first generation in the Upper Paleozoic sequences of the Reshuitang Formation (Lancang River Zone). I will come back to these observations in Chapter 3.4.2.

Reviewing the metamorphic evolution of the Lancang Group alone, the argumentation of Zhang et al. (1993) for a high-P/T temperature belt is convincing. Nevertheless, there are some substantial uncertainties related to the aerial extent of the Lancang Group (Huimin Formation, Nanwanhe-Group), its protolith (passive or active continental margin), and the age of metamorphism. Further, the various episodes of deformation and metamorphism have not been arranged into a logical temporal order and the spatial connection and transition to other units remains a severe problem. A fundamental contradiction is why Prof. Zhang Chuangheng relates greenschist metamorphism to D1 and D2, whereas Zhang et al. (1993) relate transitional blueschist-greenschist facies metamorphism to Prof. Zhang Chuanhengs phase D3? 
A model, that seems to account for some of these problems, has been put forward by Zhang et al. (1993). In analogy to the Sangabawa/Ryoke Belt in Japan they regard the Lancang Group to be the high-P/T segment of a paired-metamorphic belt. In later chapters we will see, whether this conclusion is sustainable when further parameters, such as new geochronological, isotopic and structural data, are taken into account.

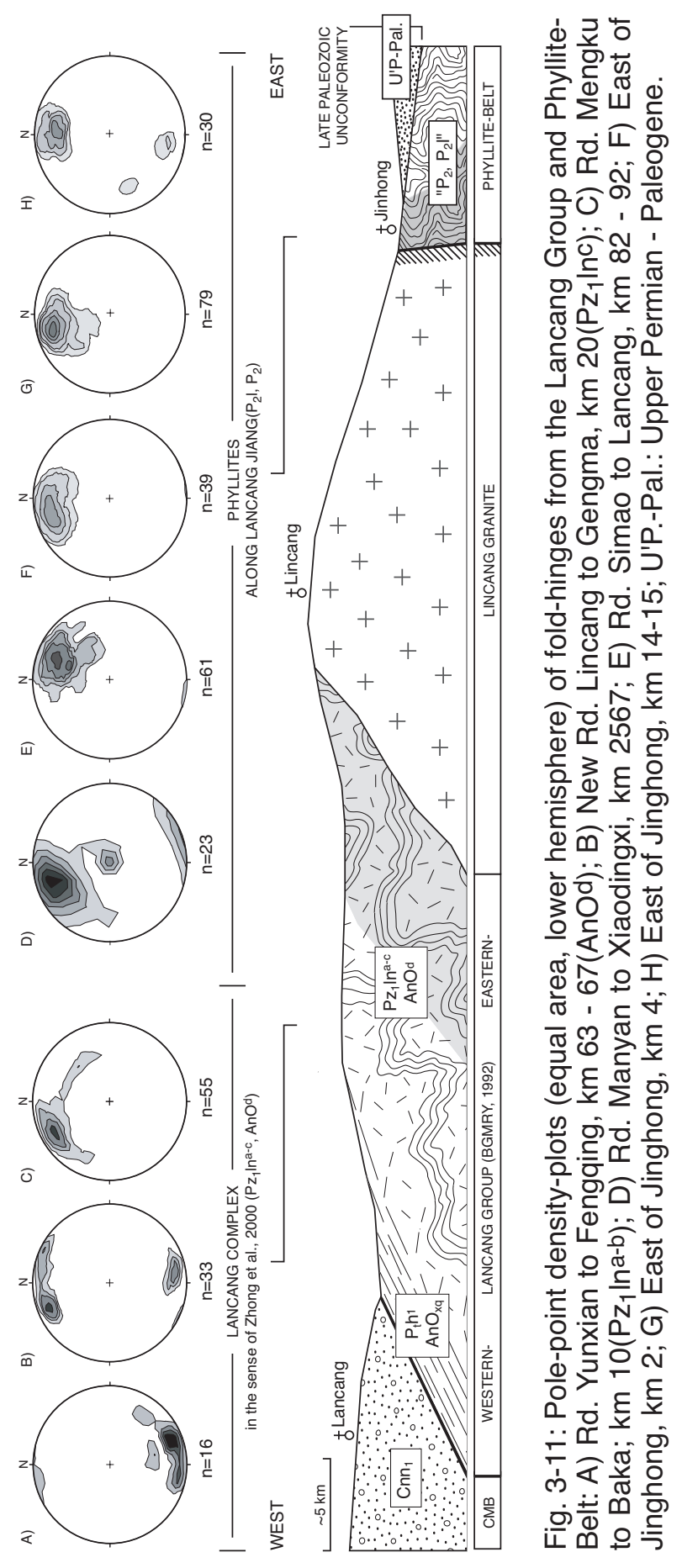


West of Lincang Granite

(Lancang Group)

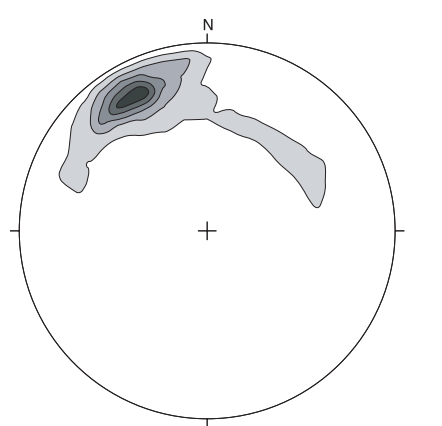

Rd. Yunxian to Fengqing, km $63-67, \mathrm{n}=28$

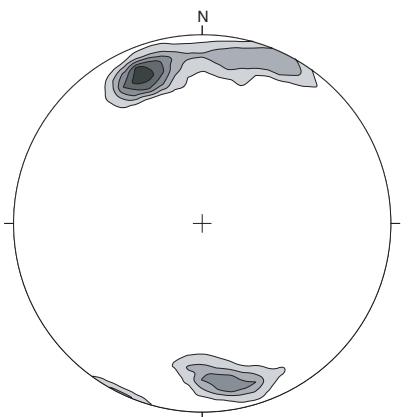

New Rd. Lincang to Gengma, km 20, n=33

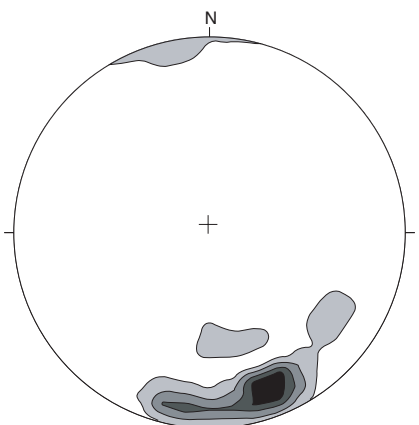

Rd. Mengku to Baka, km 10, n=16
East of Lincang Granite

(Phyllite Zone)

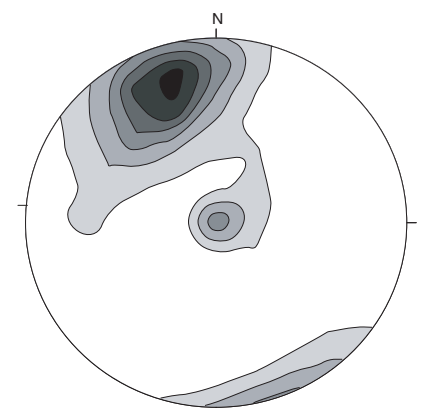

Rd. Manyan to Xiaodingxi, km 2567, n=23

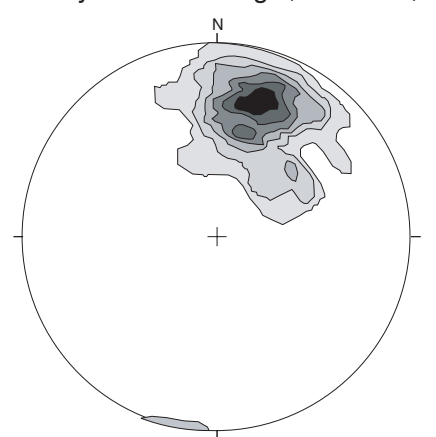

Rd. Simao to Lancang, km 82 - 92, n=61

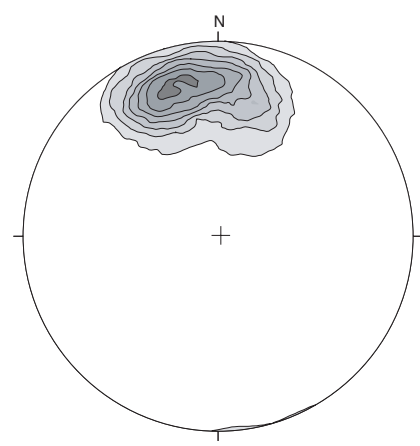

East of Jinghong, $\mathrm{km} \mathrm{2,} \mathrm{n}=39$

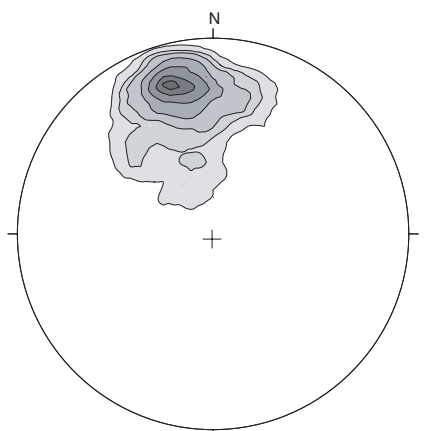

East of Jinghong, $\mathrm{km} \mathrm{4,} \mathrm{n=79}$

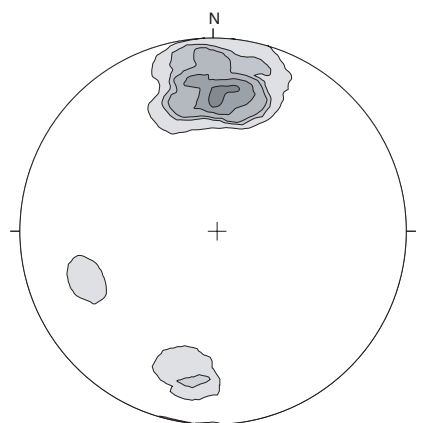

East of Jinghong, $k m$ 14-15, $n=30$

Fig. 3-12: Comparison of density-plots showing the orientation of fold-hinges from the Lancang Group (D3, after Zhong et al., 2000) and eastern Phyllite-Belt (D1). 


\subsubsection{The Lancang River Phyllite Belt}

Detailed geological maps of the Yunnan Bureau of Geology and Mineral Resources show a stripe of late Paleozoic rocks to the east of the Lincang Granite. From its northernmost tip slightly to the north of a small town called Manyan (Fig. 3-1 and 3-2) the belt extends for about 200 kilometers to Jinghong and farther to the south crossing the border into Myanmar (Burma).

Within this stripe of Late Paleozoic rocks a distinct metamorphic belt can be separated, which has hardly been mentioned in the literature. The belt is generally mapped as the formation $\mathrm{P}_{2}$, implying a Permian age, and constitutes severely folded partially quartz-remobilizing phyllites. No geochronological age data are available for this zone. The metamorphic rocks are separated by a fault to the Lincang Granite and at a few locations, such as Reshuitang, the phyllites are replaced by unmetamorphosed siliciclastic sedimentary rocks of Late Paleozoic age (detailed discussion in Chapter 3.4.2.). As a rule, the degree of metamorphism and the intensity of deformation decreases from west to east, where the quartz-remobilizing phyllitic rocks of higher greenschist facies gradually change into unmetamorphosed Late Paleozoic siliciclastic and calcareous turbidites, radiolarites and bioclastic limestones. Due to this observation, I regard the protolith of the phyllite belt to be the infill of a Late Paleozoic highly structured marginal basin. A more detailed account on the Late Paleozoic sedimentary evolution of the Lancang River Zone will be given in Chapter 3.4.

As the structural evolution is concerned, at least two distinct episodes of deformation can be separated from outcrops along the Lancang River:

The deformation phase D1 shows disharmonic, tight- to gently-open folds and wavelengths generally ranging between ten and thirty centimeters. Fold hinges dip slightly to the north. The folds are isoclinal, upright and seldomly chevron-like. Subordinately eastvergent and rarely west-vergent folds occur. Schistosity is perpendicular to the documented east - west compression and well-developed where the degree of metamorphism decreases below greenschist facies. In these areas folding becomes more widespanned and transforms into sub-greenschist facies sedimentary rocks of the Late Paleozoic (cf. Stereonets 1-8 in Appendix). The simultaneous decrease of metamorphism and deformation indicates that the greenschist-facies metamorphism was originally related to the compressional event. I conclude that D1 documents a phase of west-toeast tectonic transport and can best be related to an eastward-propagating deformation front closing a Late Paleozoic basin. The exact age of the tectono-metamorphic event is difficult to pinpoint from these observations alone, but as a Late Paleozoic protolith is evident, an Early Paleozoic age can be excluded.

The deformation phase D2 is represented by east-directed faults, north-south striking strike-slip faults and kink-banding. The measurement of cleavage from various outcrops has revealed a locally varying deformation pattern, whereas in young magmatic bodies a more consistent northwest - southeast cleavage has been acquired. D2 is unequivocally related to the locally varying transpressive deformation as part of the Himalayan dextral accommodation zone (i.e. Dewey et al., 1989, Wang and Burchfiel, 1997). 
It is obvious that the deformational phase D1 in the phyllite belt is the same as the D3 phase in the Lancang Group (compare Fig. 3-12 and Zhong et al., 1993, p. 40). All documented features that occur in the Lancang Group do occur in the Phyllite Belt. Although a similarity has been observed by Professor Chuangheng Zhang in Zhang et al. (2000) for the sedimentary rocks in Reshuitang, an explanation for this observation has not been given. However, it is a major contradiction to the existing models based on having two joint "blocks" such as the Lincang Block and the Simao Massif in the area. In the perception of Fan and Zhang (1994), this new observation may not be of such a surprise, but Zhang et al. (1993), who perceive a paired-metamorphic belt, can hardly explain, why the area in which subduction takes place exhibits the same style of deformation as the area beyond the contemporaneous volcanic arc.

Moreover, it is striking that the degree of metamorphism does not only decrease from greenschist facies in the west to unmetamorphosed sedimentary rocks in the east of the Lancang River Zone, but also extends further: If the Lancang Group is incorporated and considered in relation to the Lancang River Zone, a wedge-shaped sucession from unand slightly unmetamorphosed sedimentary rocks, to greenschist- and finally to blueschist-facies rocks is recorded. If one conceives the resulting geometry, its formation may best be explained by successively accreting the infill of a Late Paleozoic basin by means of folding and thrusting.

In order to determine the metamorphic age of the phyllite belt several samples have been processed for $\mathrm{K}$-Ar geochronology on mineral fine-fractions along this zone (Table 2, 3 and 4). The resulting ages do not only document the tectono-metamorphic episode that lead to the formation of the Phyllite Belt, but also record various other processes, such as a thermal event resetting the K-Ar system during Triassic times (see low-P/T metamorphism of Chapter 3.2.1.). I have chosen to postpone a detailed discussion of the geochronological data to a following chapter as more information is needed to understand the apparent spread of data. As for this chapter, I will antedate my conclusion and report that the reliable age for the tectono-metamorphic event is Late Carboniferous (Sample No. J, Table 3). This conclusion is in line with the postulated age of the protolith and a set of profiles (Chapter 3.4.1. and 3.4.2.) documenting an angular unconformity between the phyllites and Upper Middle Permian rocks. 


\subsection{Magmatic Evolution}

\subsubsection{Lincang Granite}

The dominant plutonic unit in Southwest Yunnan is built up by a N-S trending elongate body of granitic intrusions to the west of the Lancang River. Though uncertainty exists about its single batholithic nature, the unit was named "Lincang Granite ( $\left.\mu^{3-4}\right)$ " by the Yunnan Bureau of Geology and Mineral Resources (YBGMR, 1990).

The Lincang Granite consists of an assemblage of megacrystic potash-feldspar-bearing, biotite-quartz monzonites, granites, and subordinately granodiorites (Fig. 3-13).
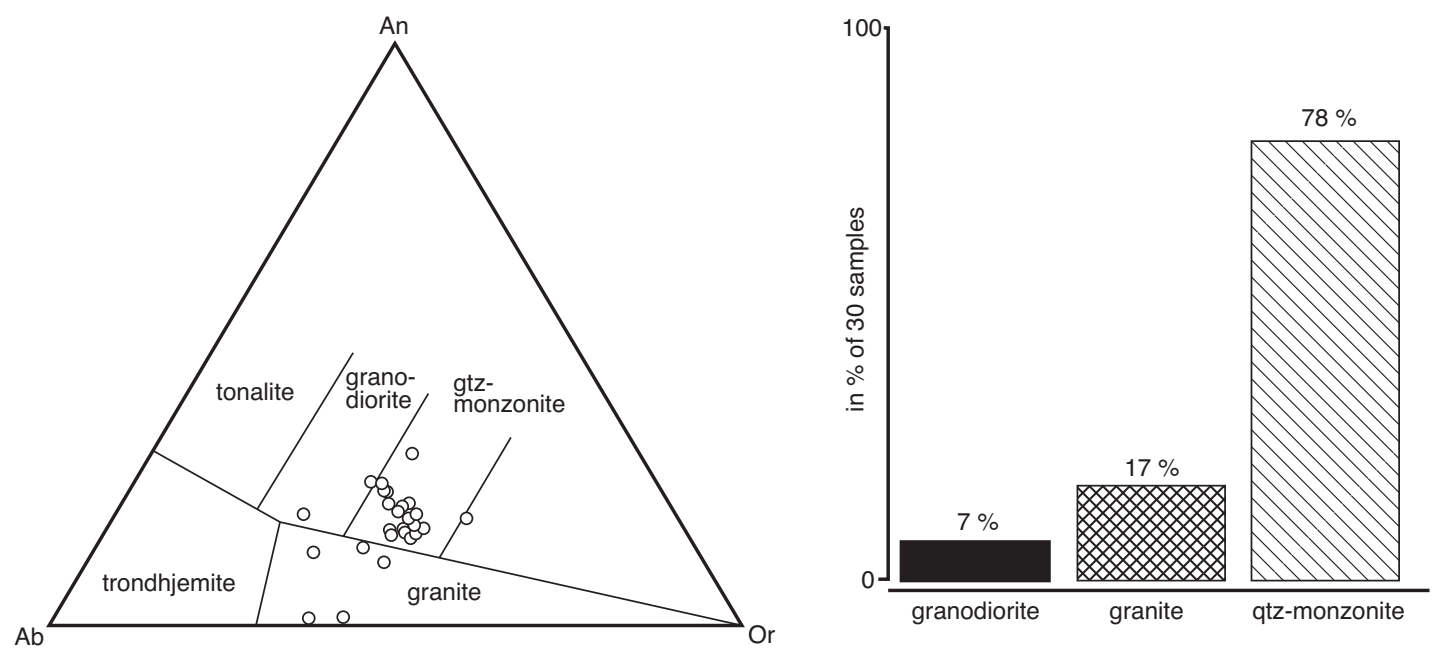

Fig. 3-13: Modal classification (A) and distribution (B) of the Lincang Granite after Barnes (1979). CIPW-Norm was calculated as outlined in Best (2000). Samples are taken from Zhong et al. (2000) and own data.

Accessory minerals are muscovite, apatite, monazite, zircon and a few opaque minerals such as ilmenite. Numerous, up to fist-sized, dark, unzoned and metasedimentary xenoliths occur regularly spread throughout the intrusions. Showing biotite as the main component, on rare occasions, the enclaves exhibit a remarkable high-temperature paragenesis of biotite, quartz, spinell, cordierite and sapphire. In a few samples, relics of a crenulation cleavage can be observed which also occurs in the country rock (Lancang Group). In general, the texture of the xenoliths is characterized by the parallel alignment of biotite. Muscovite is only subordinate.

The Lincang Granite is surrounded by the Lancang Group, the Damenglong and Chongshan Group and by a Himalayan mylonitic fault next to the Lancang River Zone. Due to poor outcrop conditions, the nature of the contact is disputable and has already been discussed in Chapter 3.2.1. In addition, detailed geological maps show Middle Jurassic rocks in discordance to the Lincang Granite.

The age of the Lincang Granite is considered to extend from Permian to the Triassic. Whole-rock Rb-Sr ages are reported by Chen (1987) having a peak around 297 to 279 Ma, but showing a considerable total spread between 348 and 236 Ma. More reliable $\mathrm{U} / \mathrm{Pb}$-ages from zircons have yielded Triassic magmatic ages between 254 and $212 \mathrm{Ma}$ 
(Liu et al., 1989). A Triassic age of the intrusions is further supported by ongoing $\mathrm{U} / \mathrm{Pb}-\mathrm{SHRIMP}$ studies on the Lincang Granite by Chung Sunlin from the University of Taipei (pers. com. 2003).

On the basis of Chapter 3.2.1. the depth of formation can be deduced from the mineral paragenesis of the accompanying lower-granulite- and amphibolite-facies rocks in the Damenglong and Chongshan Group. Zhang et al. (1993) have estimated a pressure of $5 \mathrm{kbar}$, which equals a depth of 13-15.5 kilometers (with 2.7 and $3.1 \mathrm{~kg} / \mathrm{m}^{3}$ as average values for the density of the crust).

In contrast to this estimation, a shallow depth of the intrusion is advocated by geoscientists favoring an Indosinian orogeny (Model B, Chapter 2.1.2.) along the Lancang River. This interpretation is based on the following assumption: the Lincang Granite was exhumed to such an extent at the end of the Triassic that - as the former root zone of an island arc - it was exposed to erosion. In the post-orogenic stage, the Lincang Granite was discordantly overlain by continental red-beds of Middle Jurassic age. According to this theory, exhumation took place in the Lower Jurassic between 212 and $180 \mathrm{Ma}$. This interpretation would require rapid uplift during a relatively short time span in the lower Jurassic and the massive erosion of a 15-kilometer-thick stack of crustal rocks. - In my view, the accompanying molasse sediments neither equate the amount of redistributed sedimentary and metamorphic rocks nor do they reflect the required granitic and metamorphic influx within the middle Jurassic sediments. If such deep crustal levels had already been exhumed, a different kind and a regional distribution of massive molasse deposits is expected. A discussion on how the Lincang Granite was possibly exhumed, will be outlined when dealing with the evolution of the Late Mesozoic and Tertiary evolution of the Simao Basin (Chapter 3.4.3.).

Furthermore, none of the outcrops, which I have visited, reveals a macroscopically observable magmatic foliation or fabrics, and no publication is known to me dealing with the emplacement mechanism or its detailed magmatic evolution. Crystals are oriented with no preferred alignment; pegmatites, greisenization or magmatic differentiation (magmatic layering) was neither observed in any of the outcrops nor reported in any of the literature.

Apart from the mylonite zone of Zhang et al. (1993), which I could sporadically retrace from outcrops along its eastern side, the deformation of the Lincang Granite is of brittle nature. In addition to weak jointing there are NW-SE and NE-SW striking transcurrent faults of Himalayan age (Fig. 3-1). They show sinistral offsets in the south and dextral offsets in the north, reflecting the rotational displacement of the body during the Tertiary.

The metasedimentary xenoliths and the lithology with the sporadic presence of muscovite point to a peraluminous character of the intrusions. This observation is furthermore reflected by the classification of Shand (1947) showing a distinctive dominance of peraluminous over metaluminous rocks (Fig. 3-14a). Calculations of the CIPW-Norm have - as expected - shown a normative corundum excess between 0.9 and $3.9 \mathrm{wt}-\%$. The mol. A/CNK-ratio varies from 0.9 to 1.3 with a maximum at 1.1. The $\mathrm{SiO}_{2}$-content covers a spectrum between 68 and 73 wt- $\%$ and the $\mathrm{CaO}$-content between 1.1 to 3.3 

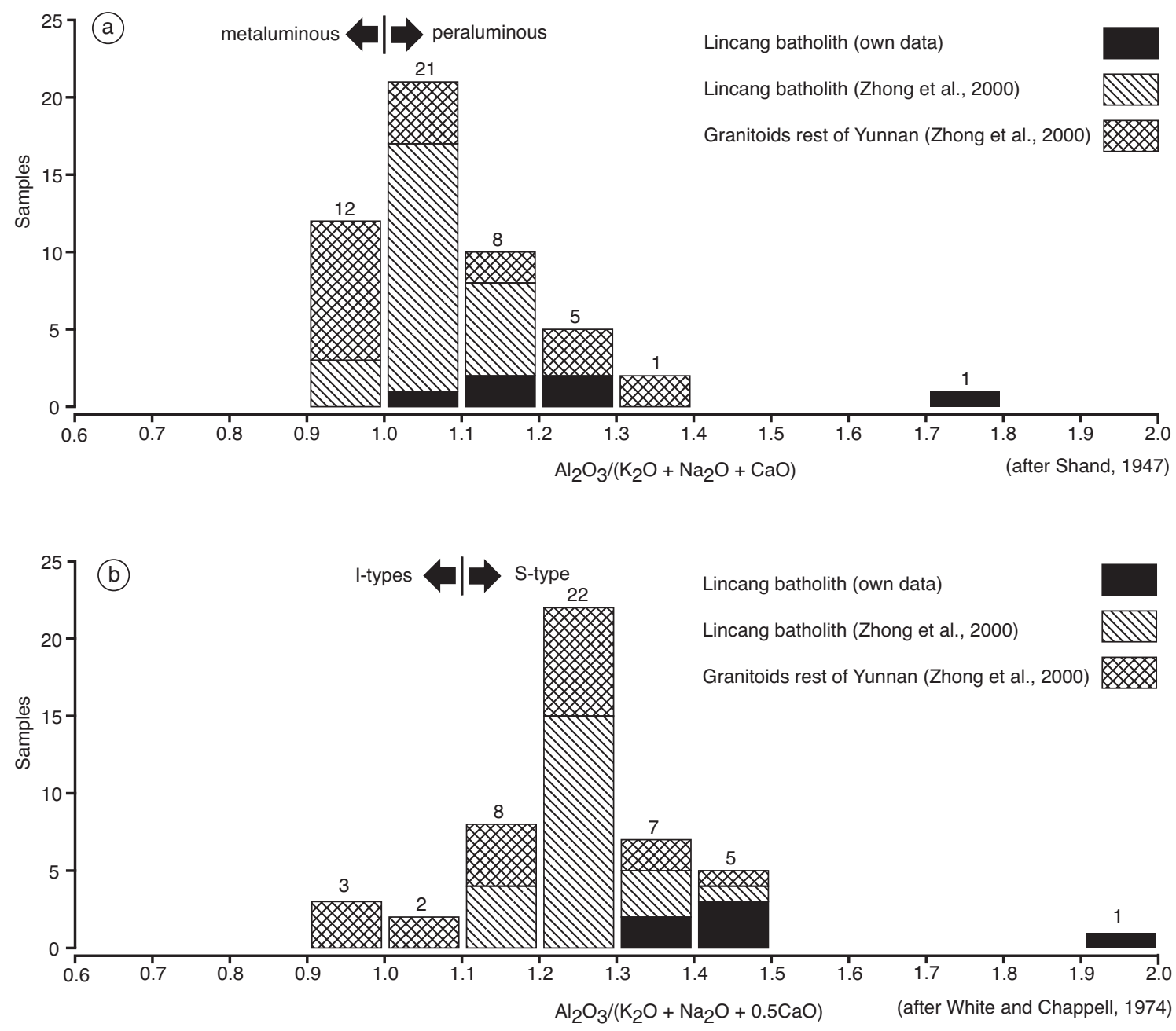

Fig. 3-14: Chemical classification of granitic rocks in southwest Yunnan after a) the aluminasaturation (Shand, 1947), and b) the presumed origin (I-S scheme by White and Chappell, 1974).

wt- $\%$. The $\mathrm{Na}_{2} \mathrm{O}$ - and $\mathrm{K}_{2} \mathrm{O}$-contents are high, whereas the $\mathrm{Na}_{2} \mathrm{O} / \mathrm{K}_{2} \mathrm{O}$-ratio varies from 0.4 to 1.2 with a maximum between 0.6 and 0.7 (alkali feldspar). Discrimination diagrams characterize the rock spectrum to comprise undifferentiated, syn- to post-tectonic, anatectic alkali-granites and syenodiorites (Fig. 3-15 to 3-19).

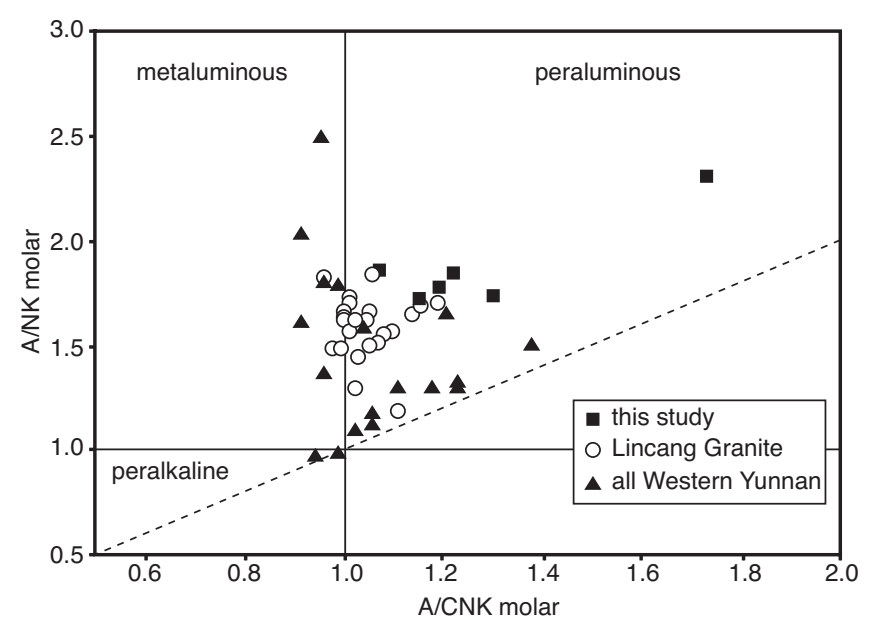

Fig. 3-15: Alumina saturation of granitoids in western Yunnan (after Shand, 1947). 


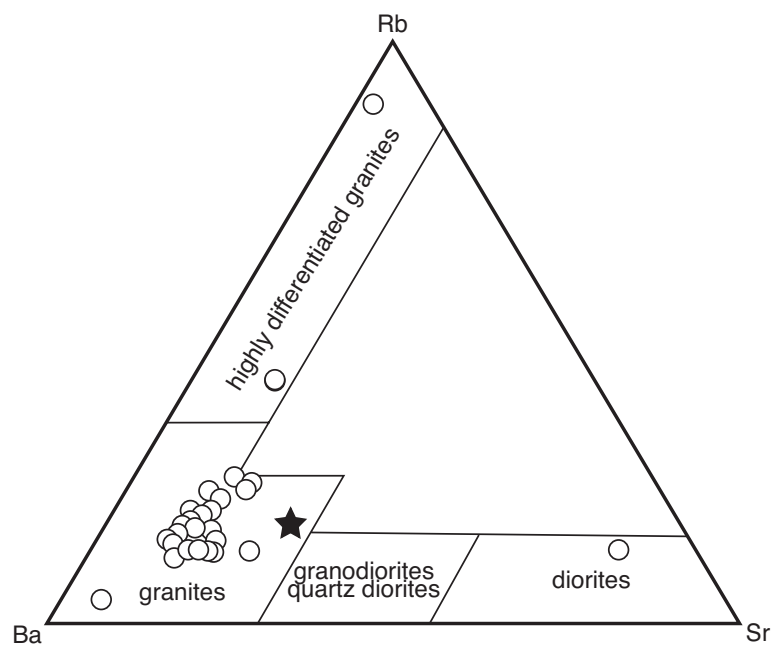

Fig. 3-16: Rb-Ba-Sr triangle plot of the Lincang Granites. Petrological classification according to El Bouseily and El Sokkary (1975). World average of granites is marked by the star.

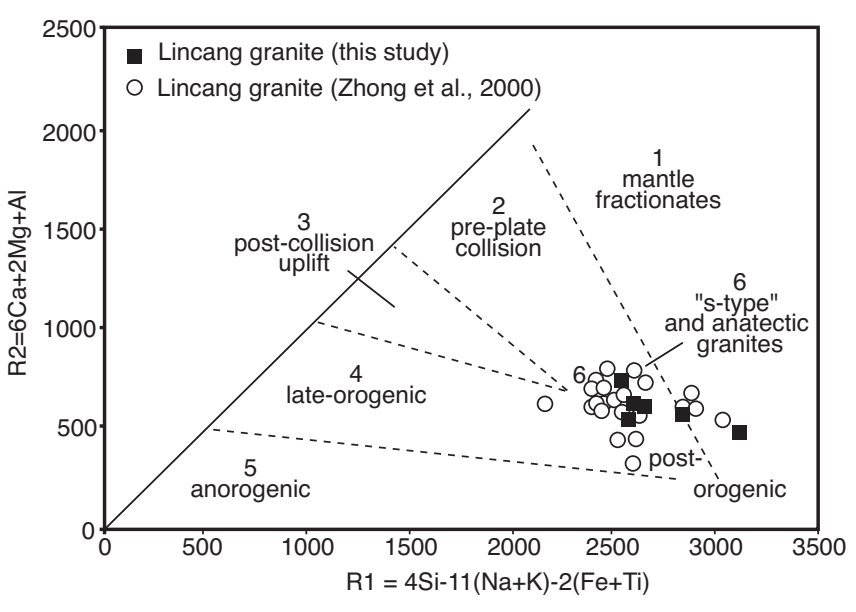

Fig. 3-17: Tectonic discrimination diagram for granitoid rocks using major element compositions after Batchelor and Bowden (1985).

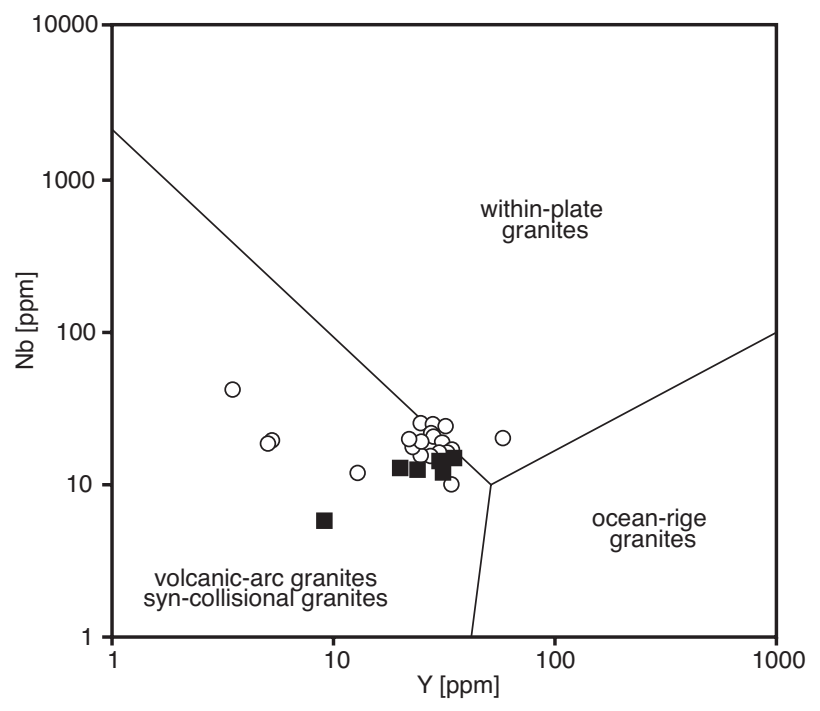

Fig. 3-18: Nb-Y diagram after Pearce et al. (1984).

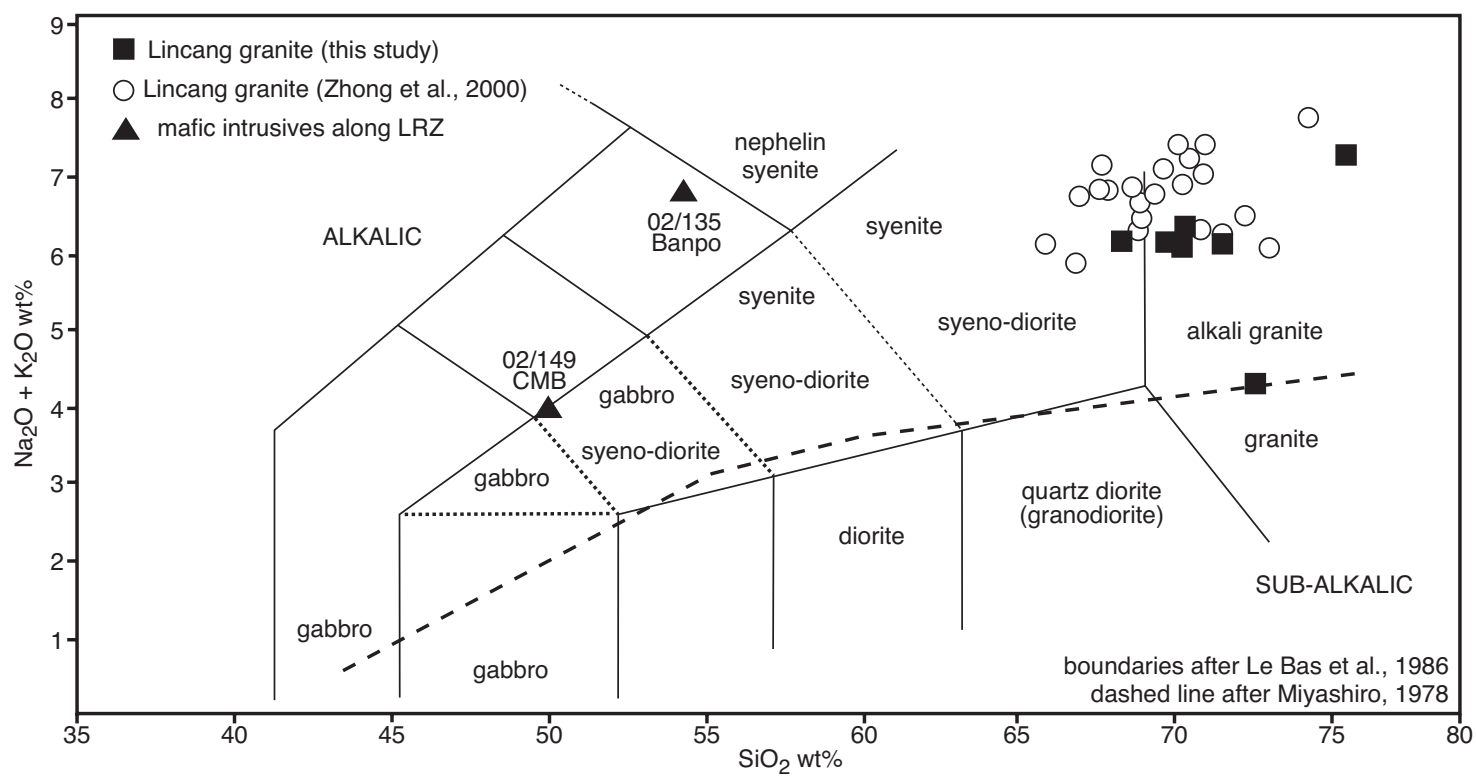

Fig. 3-19: TAS-Harker variation diagram of the plutonic rocks along the Lancang River Zone. 
Two isotope chemistry analyses (Table 11 ) have yielded high ${ }^{87} \mathrm{Sr} / \mathrm{Sr} 86$ initial-values between 0.7455 and 0.7545 and ${ }^{143} \mathrm{Nd} /{ }^{144} \mathrm{Nd}$-values of 0.511768 and 0.511893 . These data translate into $\varepsilon \operatorname{Sr}(\mathrm{T}=220 \mathrm{Ma})$-values of 527 and 400 , and $\varepsilon \mathrm{Nd}(\mathrm{T}=220 \mathrm{Ma})$ of -12.3 and -14.5 , respectively. Sm-Nd model ages, calculated in respect to the evolution of a depleted mantle, range from 1.9 to $2.1 \mathrm{Ga}$ (Fig. 3-20).

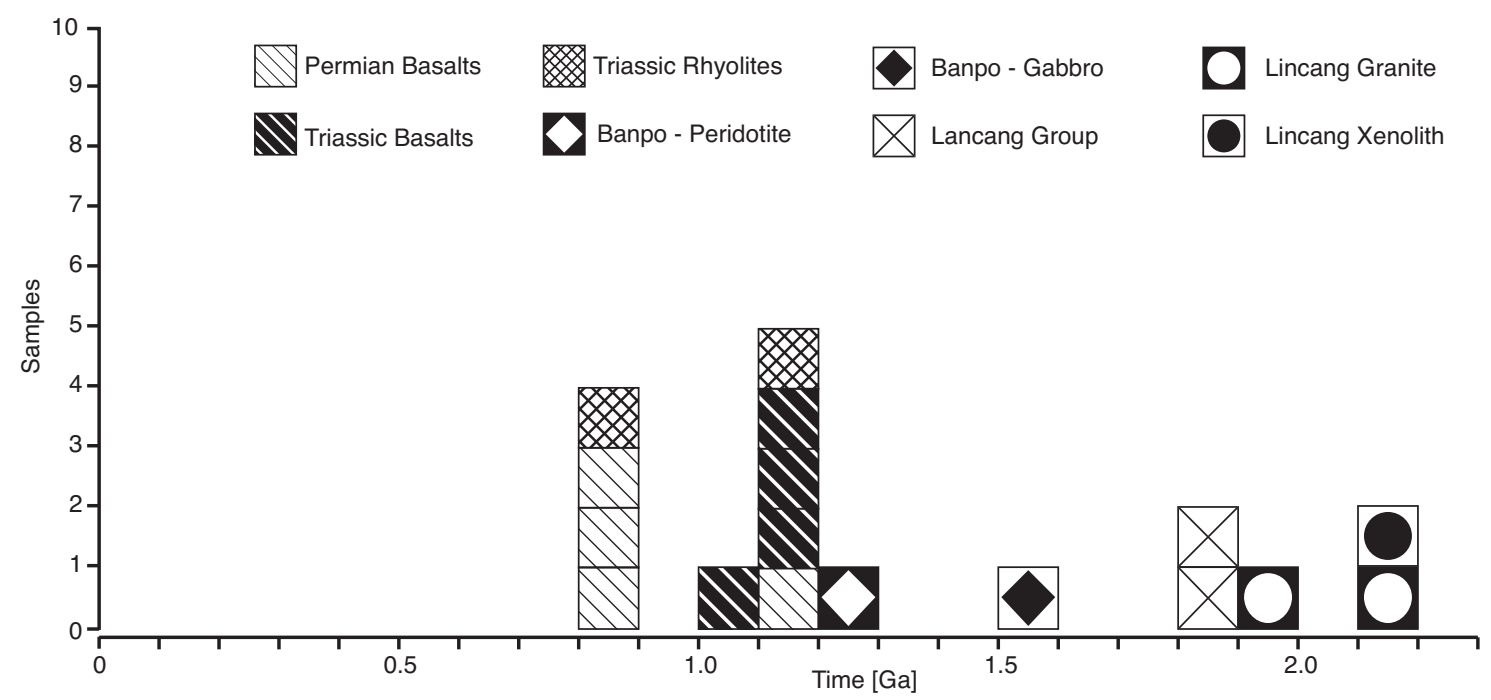

Fig. 3-20: Histogram of (Nd)-T Zone.

Commonly applied granite classifications of Chappell and White (1974) and White and Chappell, (1983) show typical S-type granites (Fig. 3-14b) belonging to the IImeniteSeries (Fig. 3-21) after Ishihara (1977).

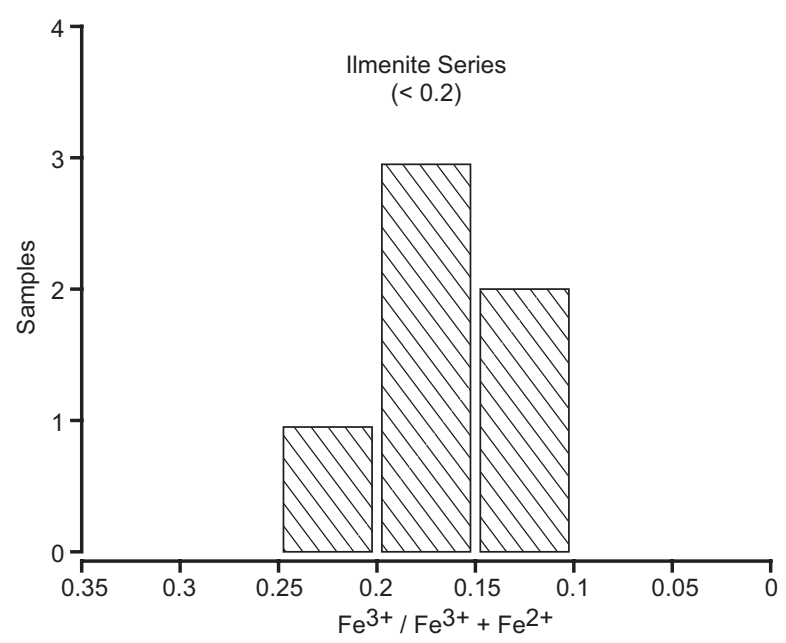

Fig. 3-21: Granite-series after Ishihara (1977). $\left.\mathrm{Fe}^{3+} / \mathrm{Fe}^{3+}+\mathrm{Fe}^{2+}\right)<0.2$ are Ilmenite-series granites.

\section{Interpretation}

The above mentioned features determine a post-orogenic granitic assemblage largely formed from the melting of Proterozoic continental crust. No geochemical signature of any mantle influence is observable that would indicate the existence of an island arc. The 
age of the assemblage is disputable. The only reliable data available so far comes from the $\mathrm{U}-\mathrm{Pb}$ dating of zircons. The results of the $\mathrm{Rb}-\mathrm{Sr}$-(whole-rock) analysis must be treated with caution when not combined with individual dating of specific minerals such as biotite and potash feldspar (Dickin, 1997). Because the U-Pb ages fall into the Triassic, this must indicate a main anatectic episode in Early Mesozoic, in other words, after the Late Paleozoic orogenic development.

Neighboring Regions

In comparison to neighboring granite provinces, age, mineral composition and chemistry reveal considerable similarity with the Central Granite Province (Main Range and North Thailand Granite Complex) of the Southeast Asian tin belt. In terms of mineral composition, Cobbing et al. (1986) and Pitfield (1988) divide the granites of the Central Province into two broad groupings:

a) Peraluminous S-type granites with high-Al biotite \pm muscovite \pm garnet \pm sillimanite \pm ilmenite \pm tourmaline \pm monazite; these include the Southeast Peninsular- and Central Thailand granites, such as Songkhla and Rayong, and the North Thai granites of Fang as well as the Central Belt granites, such as Chiang Dao and Om Koi.

b) Metaluminous to mildly peraluminous S-type (and IS) granites and quartz monzonites with low-Al biotite \pm actinolitic hornblende \pm sphene \pm allanite \pm ilmenite; these include the sodi-potassic Kaochong batholith of southwestern Peninsular Thailand and the Mae Sariang batholith of the Western Marginal Belt of northern Thailand.

Apart from its mineral composition, Pitfield (1988) states that the North Thai Granite Province has experienced a more protracted granite-producing event, than the main Range from syn-late kinematic precursor granites to post-kinematic batch melt granites and their derivatives. The North Thai Granites are associated with regional migmatitic complexes and are typically less differentiated and exhibit greater uniformity in the batch melt intrusions. They further exhibit a greater ${ }^{87} \mathrm{Sr} / 86 \mathrm{Sr}$-ratio of $>0.725$ and plot in a tight grouping at the ternary minimum melt composition. In contrast to the syn- to post-tectonic nature, I regard the Lincang Granite to be merely post-tectonic. The age of the Main Range granites in Malaysia was determined by $\mathrm{Rb}-\mathrm{Sr}$ and $\mathrm{U}-\mathrm{Pb}$ (zircon) geochronology and ranges between 220 and $200 \mathrm{Ma}$ (Liew and McCulloch, 1985; Liew and Page, 1985). As for the Northern Thai Granite province, Triassic U-Pb ages are reported from zircons of a gneisses at Umphang (202 $\pm 3 \mathrm{Ma})$, Larn Sang (197 +2/-3 Ma, $190 \pm 3 \mathrm{Ma})$, and Mae Sariang (200 $\pm 3 \mathrm{Ma}$, see Mickein, 1997). He further reports on a Triassic U$\mathrm{Pb}$ age from zircons of the Tak Granite $(208 \pm 16 \mathrm{Ma})$.

Due to the similarity of the Lincang Granite to the Northern Thai Granite Province, I postulate that the Central Granite Province can be traced into Southwest Yunnan. The Lincang intrusions, as well as the granites of the Northern Thai Granite Province, do not show any kind of island-arc affinity and are at odds with the perception of a paired-metamorphic belt along the Lancang River Zone (Zhang et al., 1993). Unlike the geochemical, a structural relationship with a distal, active continental margin far to the west cannot be excluded. Such a scenario could derive from slab-rollback (rate of subduction > rate of convergence) with extension in the hinterland of a cordillera (e.g. Royden, 1993). 


\subsubsection{Lancang River Volcanic Rocks}

Major element analysis from representative sites of the Permo-Triassic volcanic rocks reveal a clear bimodal distribution. The rocks include basalts, alkali basalts, hawaiite (trachybasalts), andesitic basalts, rhyolites, ignimbrites and coarse, acid pyroclastics (Fig. 3-22). Over time, there is a progression from exclusively basic magmas in the Upper Permian to subordinate basaltic and mainly acid extrusives in the Lower and Middle Triassic.

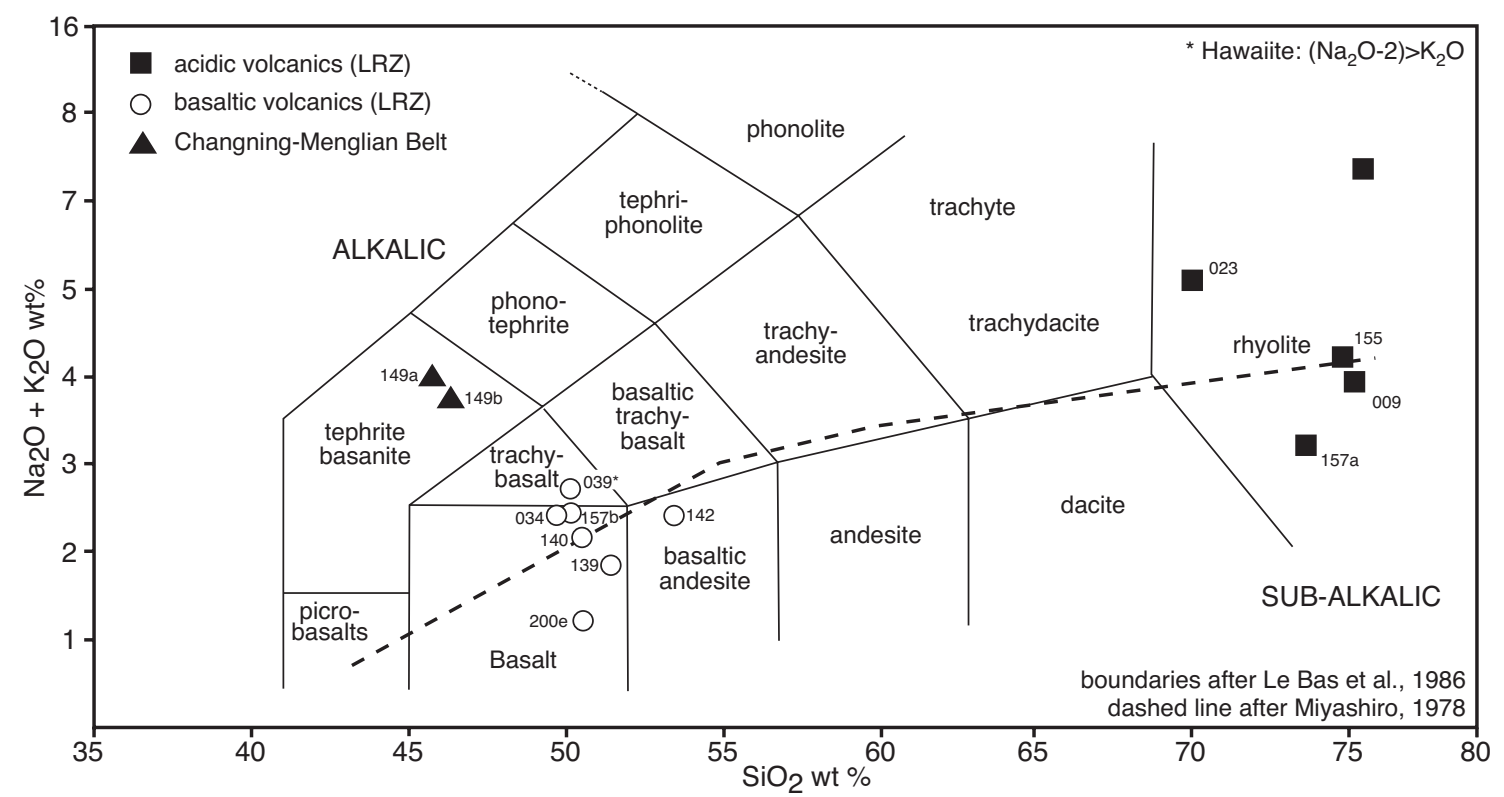

Fig. 3-22: Total-Alkali-Silica (TAS) diagram of basic and acidic volcanic rocks from the Lancang River Zone. Numbers, such as 034, represent samples of Table 7 and 8 . Number 149a and 149b were sampled from the Changning-Menglian Belt.

In the AFM-diagram (Fig. 3-23), the analyzed basalts show a distinct FeO enrichment and hence a tholeiitic trend. $A$ tholeiitic series is further supported by low $\mathrm{Al}_{2} \mathrm{O}_{3}$ concen-

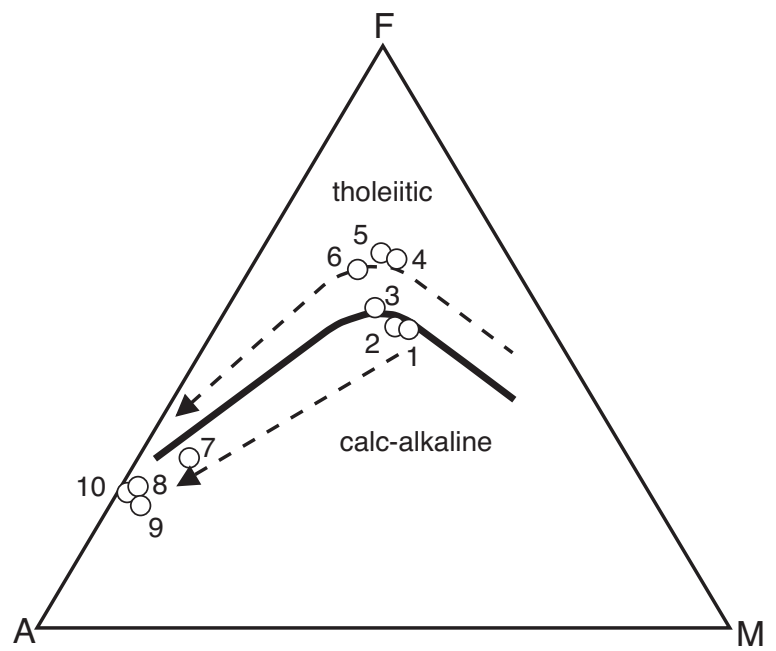

Fig. 3-23: AFM - diagram of basic to acidic volcanic rocks along the Lancang River Zone. 1: alkali basalt; Upper Permian 2: hawaiite $\left(\mathrm{T}_{2} \mathrm{~m}_{2}\right)$; 3: basaltic andesite, upper Middle Permian; 4: basalt, Upper Permian; 5: alkali basalt, Upper Permian; 6: alkali basalt $\left(\mathrm{T}_{2} \mathrm{~m}_{2}\right)$; 7-10: rhyolites $\left(\mathrm{T}_{2} \mathrm{~m}_{2}\right) \cdot \mathrm{A}: \mathrm{Na}_{2} \mathrm{O}+\mathrm{K}_{2} \mathrm{O} ; \mathrm{F}$ : total $\mathrm{Fe}$ as $\mathrm{Fe}_{2} \mathrm{O}_{3} ; \mathrm{M}$ : $\mathrm{MgO}$. 
trations of less than $16 \mathrm{wt}-\%$, which is untypical of calc-alkaline series that usually range between 16-20 wt-\% (cf. Wilson, 1997, p. 9). After Middlemost (1975), the basalts occurring in the Upper Permian and Triassic are transitional basalts and clearly fall within the continental rift- and flood basalt reference field (Fig. 3-24a-d).
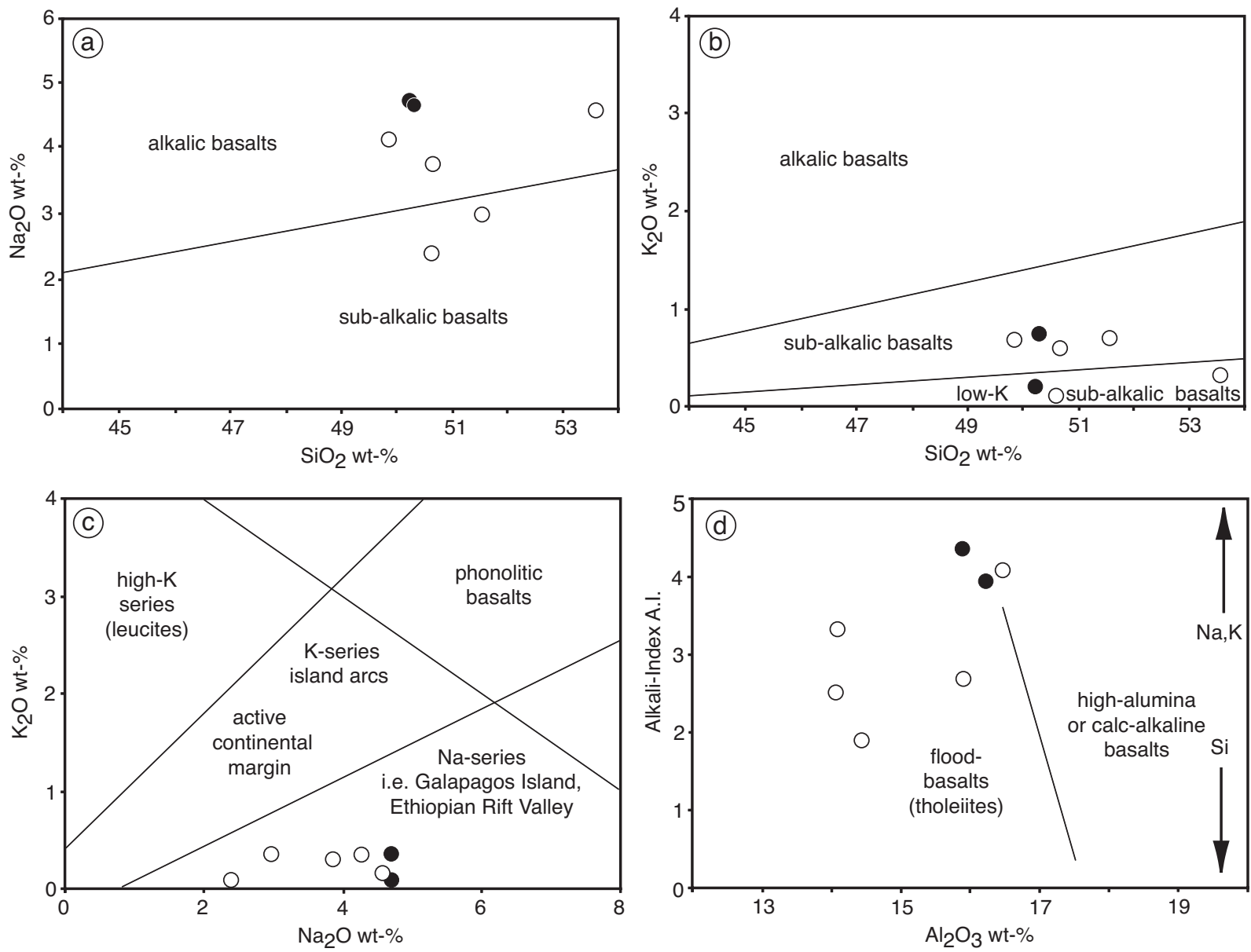

Fig. 3-24: Major element classification of basaltic volcanic rocks from the Lancang River Zone (Classification scheme after Middlemost, 1975). Filled circles are Triassic and open circles Permian basalts. Alkali Index (A.I.): $\left(\mathrm{Na}_{2} \mathrm{O}+\mathrm{K}_{2} \mathrm{O}\right) /\left(\mathrm{SiO}_{2}-43\right) \times 0.17$.

The chondrite-normalized distribution patterns of rare earth elements (REE) in Fig. 325a-e show generally high REE levels, and particularly high enrichments in the light rare earth elements. A weak Eu-anomaly is also identifiable. A comparison with tholeiitic basalts overlying oceanic hot spots (Fig. 3-26 to 3-28) highlights the spiked pattern of the immobile elements, which can be explained by contamination with crustal material. And although the relative deficiency of high-field-strength elements (HFSE), which is typical for island-arc volcanic rocks, is partially shown, it is only weakly developed (Fig. 3-29). Wilson (1997, p. 307) pointed out that a weak Ta and Nb trough also occurs in typical continental flood basalts like the Deccan or Paraná: "Its occurrence in many CFB spider diagram patterns could reflect the existence of a residual $\mathrm{Nb}$-Ta bearing phase during the partial melting process. However, it is more likely to be the consequence of crustal contamination." Here M. Wilson refers to various authors, including the work of Cox and Hawkesworth (1985) on the Deccan Traps in India.

There is also a marked correspondence of the ocean-island-tholeiite(OIT)- normalized, incompatible elements (after Thompson et al., 1984) with continental flood basalts of the 

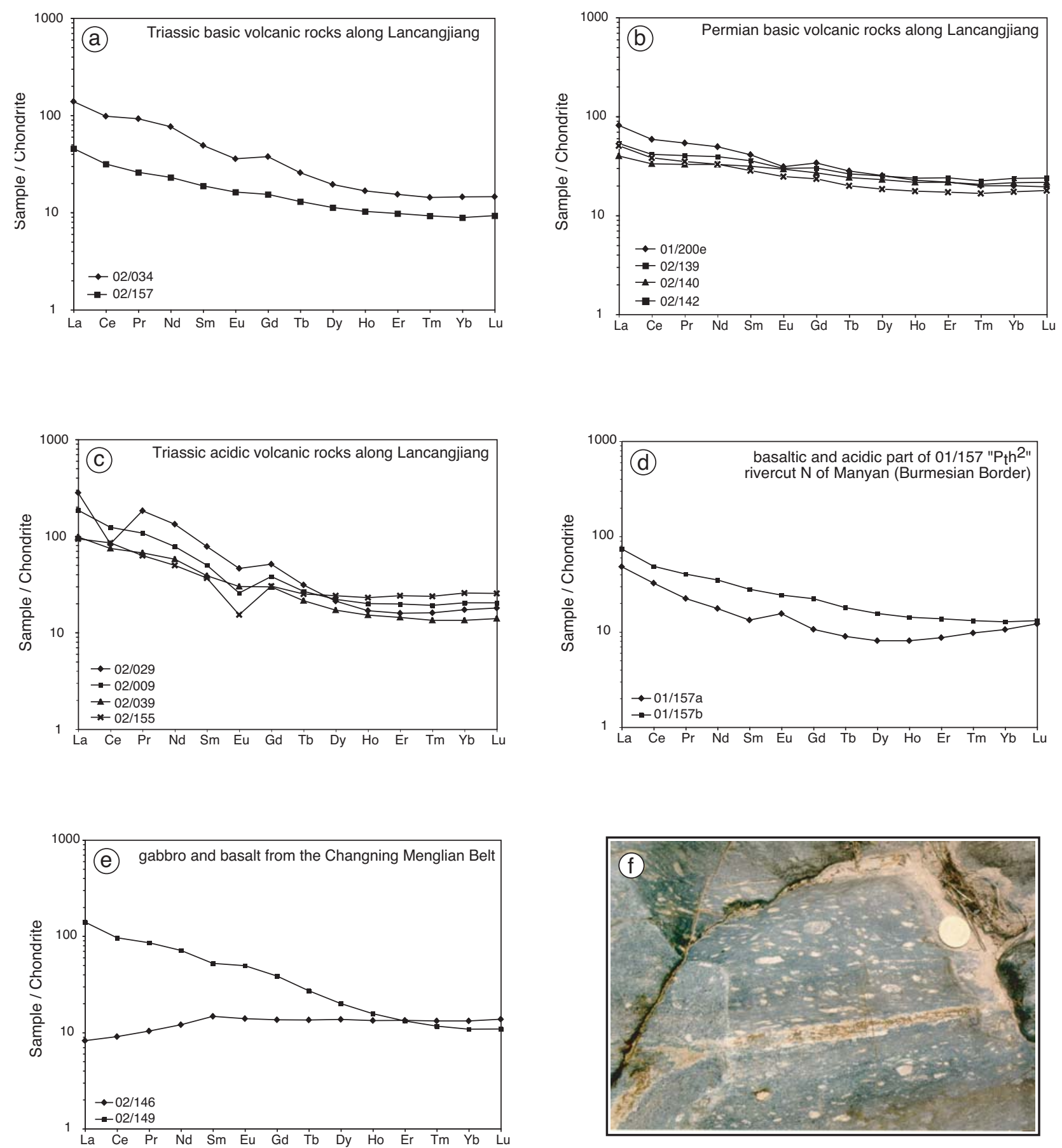

Fig. 3-25: Chondrite-normalized REE-spiderdiagrams of the Lancang River Zone (a-c) and from the Changning Menglian Belt (e). Diagram (d) depicts a rock which is mapped as a gneiss from the formation $\mathrm{P}_{\mathrm{t}} \mathrm{h}^{2}$. According to Table 7, these rocks document a composite volcanic sequence of acidic (rhyolite) and basaltic volcanic rocks (alkali basalt) of presumably Triassic age. Assimilation of anatectic acidic melts by tholeiitic basalts of Triassic age is likely to have caused the flow texture of (f). Normalizing values after Nakamura (1974). 
Emeishan Large Igneous Province, Paraná, Deccan and Snake River (cf. the relative deficiency in $\mathrm{Ti}$ and $\mathrm{Nb}$ and relative enrichment of Large lon Lithophile Elements (LILE), Th and $\mathrm{Ce}$ ). This relationship is shown in Figs. 3-26 and 3-28 and further supports my

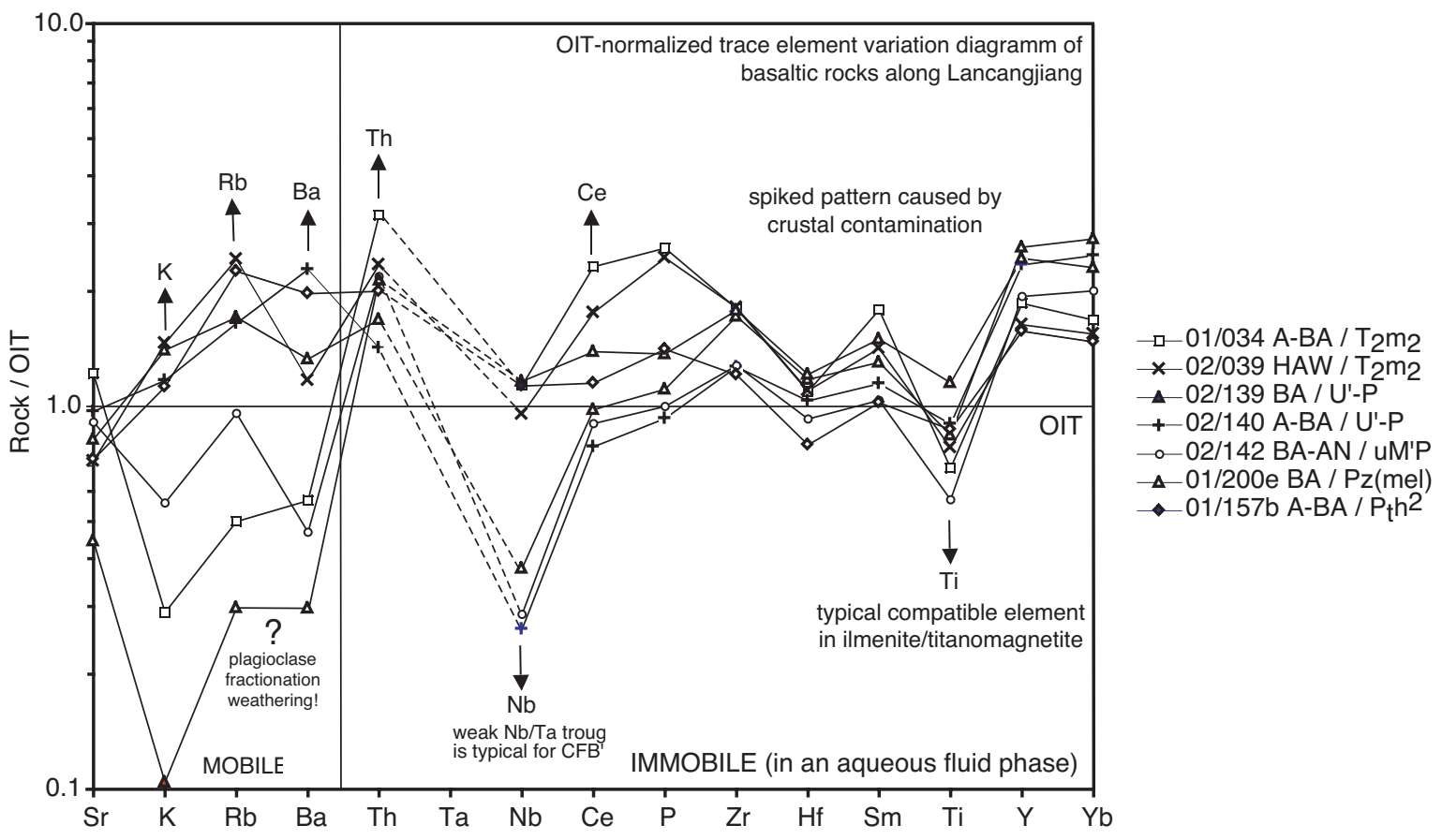

Fig. 3-26: OIT-normalized trace element variation diagram for basaltic rocks along the Lancangjiang (after Thompson et al., 1984; and in reference to Wilson, 1997, her Fig. 10.18). Normalization factors are: $\mathrm{Sr} 368 ; \mathrm{K} 0.48 \%, \mathrm{Rb} 8.4$; $\mathrm{Ba}, 125 ; \mathrm{Th}, 1.14 ; \mathrm{Ce} 36.5 ; \mathrm{P} 0.27 \%$; $\mathrm{Zr} \mathrm{141}$; Hf 4.47; Sm 5.55, Ti 2.61\%, Y 22; Yb 1.00. Ta: not calculated. A-BA: alkali basalt, HAW: hawaiite, BA: basalt, BA-AN: basaltic andesite. T2 $\mathrm{m}_{2}$ : Middle Triassic, U'-P: Upper Permian; uM'-P: upper Middle Permian; $\mathrm{Pz}(\mathrm{mel})$ : Paleozoic rock from melange zone to the East of Jinghong (cf. chapter 2.4.2.4).

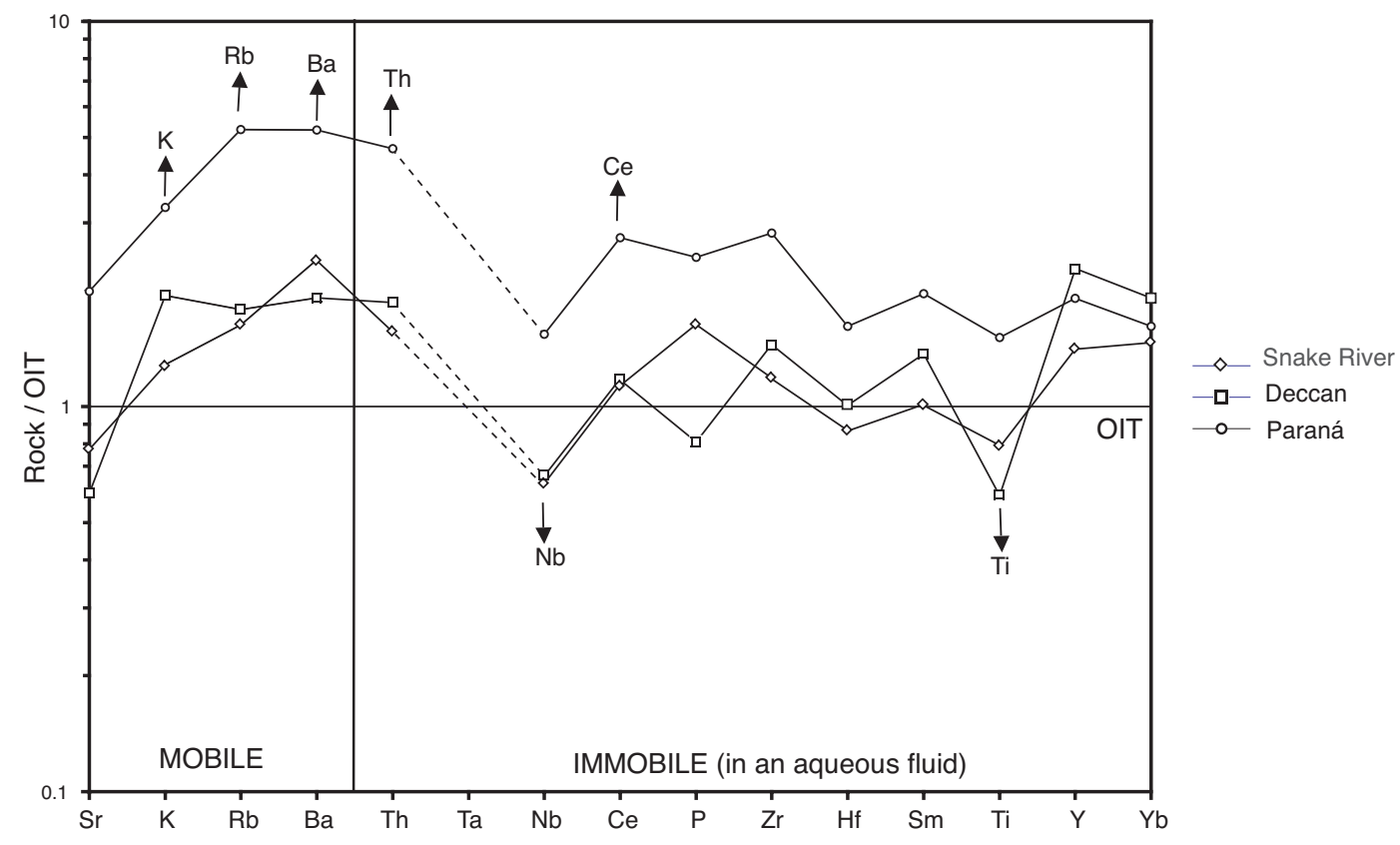

Fig. 3-27: OIT-normalized trace element variation diagram for recognized continental flood basalt provinces (after Thompson et al. 1983, 1984; and in reference to Wilson, 1997, her Table 10.3). Normalization factors are: Sr 368; K 0.48\%, Rb 8.4; Ba, 125; Th, 1.14; Ce 36.5; P 0.27\%; Zr 141; Hf 4.47; Sm 5.55, Ti 2.61\%, Y 22; Yb 1.00. Ta: not calculated. 


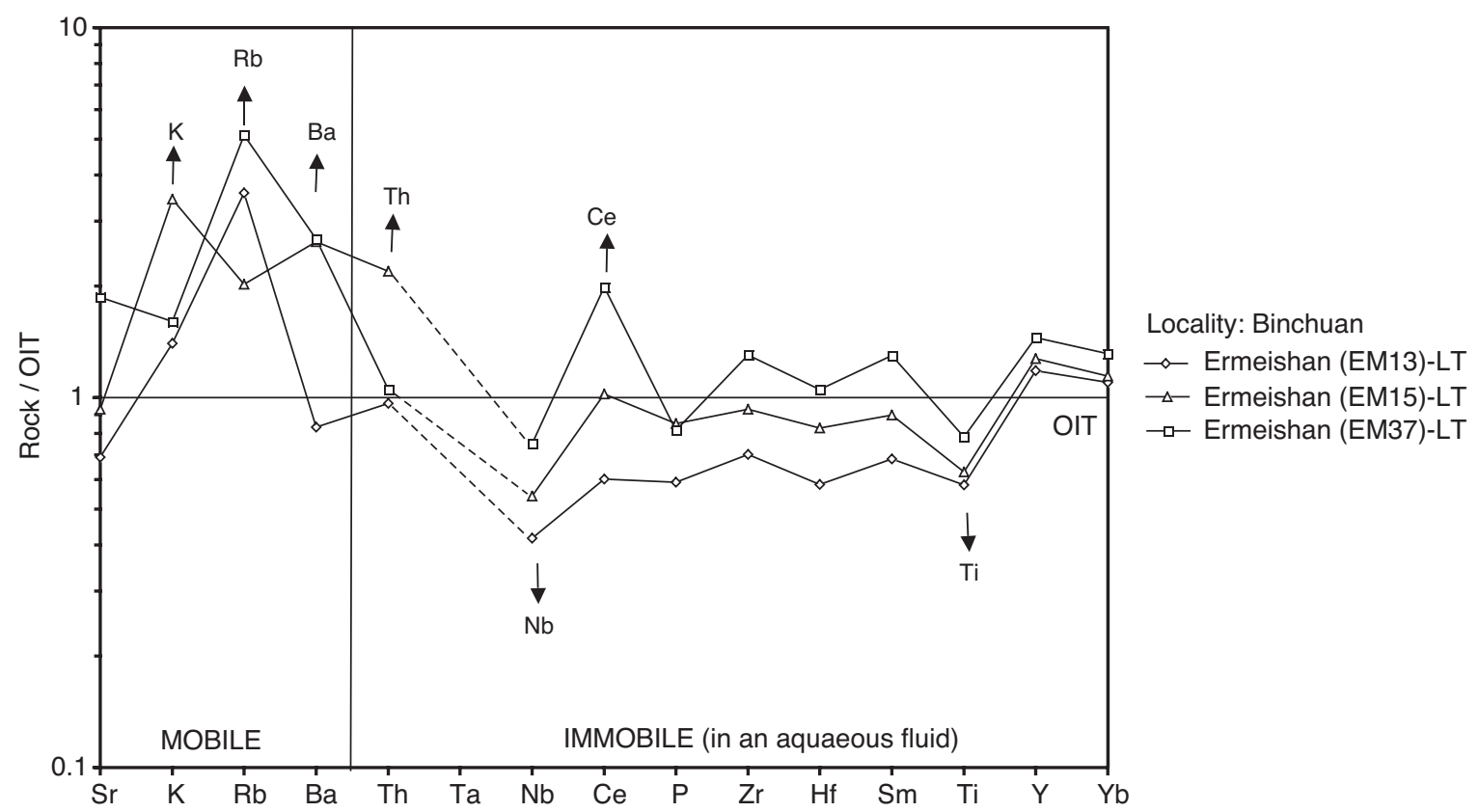

Fig. 3-28: OIT-normalized trace element variation diagram for Emeishan continental flood basalts from Binchuan (after Xu et al., 2001). Normalization factors after Thompson et al. (1984): Sr 368; K 0.48\%, Rb 8.4; Ba, 125; Th, 1.14; Ce 36.5; P 0.27\%; Zr 141; Hf 4.47; Sm 5.55, Ti 2.61\%, Y 22; Yb 1.00. Ta: not calculated; LT: low Titanium.

hypothesis that the Permo-Triassic volcanism along the Lancang River is unlikely related to an island arc but rather to an intracontinental rift.

The Permo-Triassic basalts reveal a shift in Nd isotopic composition from the Upper Permian to the Triassic. The initial $\varepsilon N d$-values from Upper Permian basalts are 6.4, 5.5, 4.5 and 3.0, whereas the Lower and Middle Triassic basalts are -0.7, - - -9, - -1.1 and -1.4. (Table 11 in Appendix). Positive initial $\varepsilon N d$-values show that melts were separated from a depleted mantle, whereas negative values indicate that they were derived from enriched mantle sources and/or contaminated by continental crust. The data suggest that the source of the Permo-Triassic basalt magmatism changed from a depleted to enriched mantle reservoir \pm mafic continental crust with time.

As the isotopic and chemical composition of the subcontinental lithosphere is a matter of debate and may exhibit extreme heterogeneities and isotopic compositions (cf. Allégre et al., 1981 or Zindler and Hart, 1986), it is difficult to distinguish between basalts being partial melts of an enriched subcontinental mantle reservoir from those that have undergone crustal contamination. In Chapter 3.2.1 and 3.3.1 I have deduced that during the Late Permian and Triassic the crust was subjected to an anomalously high heat flow leading to partial melting, migmatization and the formation of the Lincang Granite.

In this context, I conclude that crustal contamination has more likely played a dominant role and accounts for most of the isotopic variability. ${ }^{143} \mathrm{Nd} /{ }^{144} \mathrm{Nd}$ values, which primarily lie above the CHUR, are lowered by mixing with crustal material having lower ${ }^{143} \mathrm{Nd} /{ }^{144} \mathrm{Nd}$ values and fall beneath the curve with increasing crustal contamination.

Although no absolute age can be determined, a relative comparison of the data may reveal a chronology of events. The $\varepsilon N d$ systematics is also reflected (by definition) in depleted mantle model ages. Fig 3-20 shows that the Permo-Triassic basalts can be 

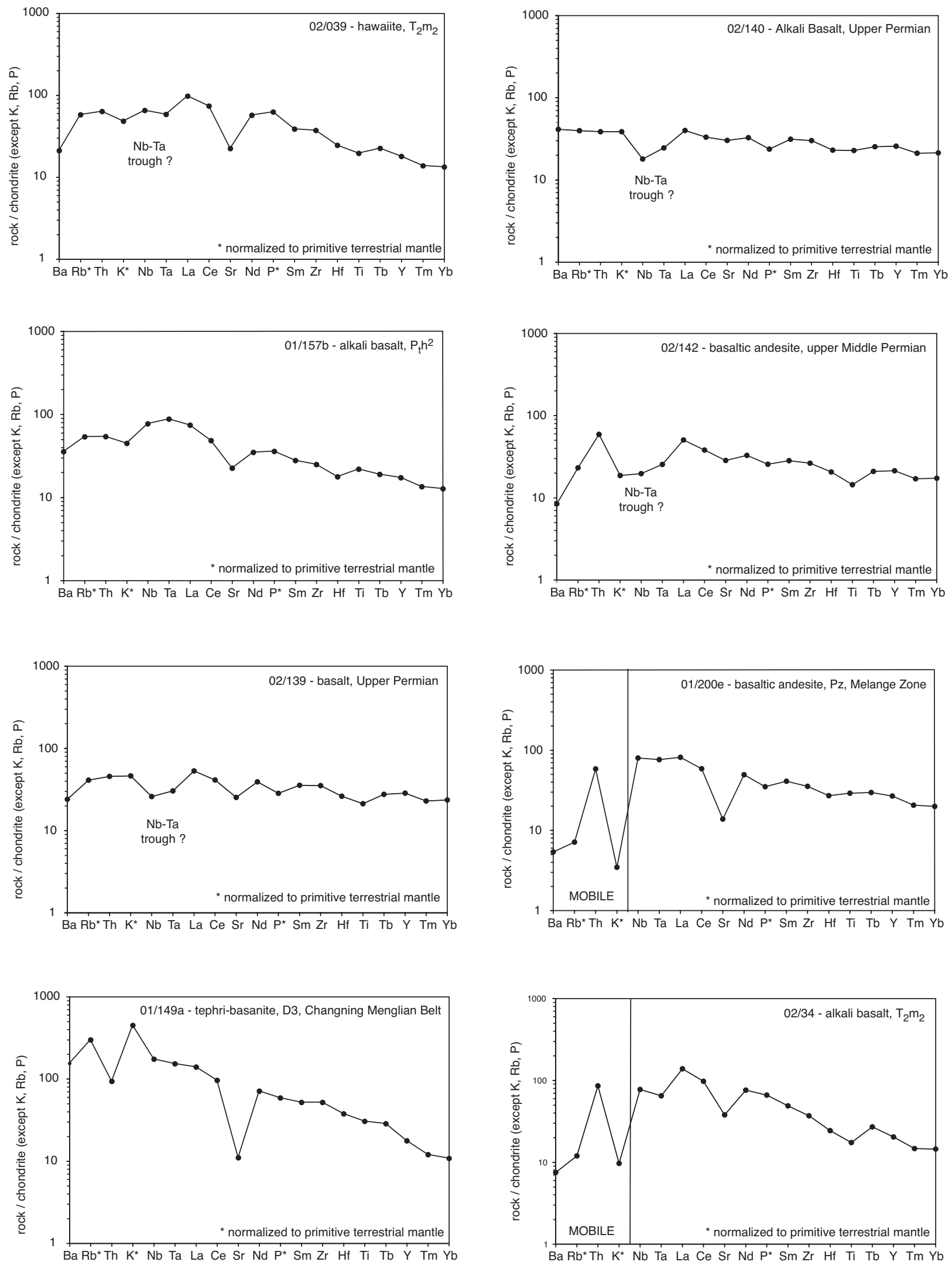

Fig. 3-29: Chondrite-normilized spiderdiagrams of Permotriassic basaltic rocks along the Lancang River Zone. Rock names are taken from the TAS - Harker diagram of Fig. 3-20. In respect to the postulated island arc, no distinct $\mathrm{Nb}-\mathrm{Ta}$ depletion or $\mathrm{Sr}$ enrichment is observable. Normalizing values are according to Thompson et al. (1984): Ba 6.9; Rb 0.35; Th 0.042; K 120; Nb 0.35; Ta 0.02; La 0.328; Ce 0.865; Sr 11.8; Nd 0.63; P 46; Sm 0.203; Zr 6.84; Hf 0.2; Ti 620; Tb 0.052; Y 2.0; Tm 0.034; Yb 0.22. 
divided into two groups: a) Permian basalts with $\mathrm{T}_{(\mathrm{DM})}$ model ages between: 0.8 to 0.9 $\mathrm{Ga}$ and $\mathrm{b}$ ) Triassic basalts with $\mathrm{T}_{(\mathrm{DM})}$ model ages between: 1.0 to $1.1 \mathrm{Ga}$.

As for the ${ }^{143} \mathrm{Nd} /{ }^{144} \mathrm{Nd}$-values, there are various possibilities to explain these results. The old model ages may indicate that: a) the mantle, which melted, was less depleted than model depleted mantle b) that partial melts, which separated from the depleted mantle approx. $1 \mathrm{Ga}$ ago, crystallized in the lower crust (magmatic underplating) to form a reservoir for the Permo-Triassic basalts; $\mathrm{c}$ ) crustal assimilation has played a significant role, particularly for the Triassic basalts.

It is likely that both enriched mantle sources and crustal contamination have played a role. Due to this conclusion it is neither applicable to further constrain the nature of the subcontinental lithosphere nor to determine the volume of crustal contamination.

In the Nd-Sr isotope diagram (Fig. 3-30), the data plots on the right-hand side of the MORB-OIB array ("mantle array"). Note, however, that the ${ }^{87} \mathrm{Sr} / 86 \mathrm{Sr}$ values of the Triassic und Permian basalts have unrealistically high values probabaly due to alteration by seawater. The position of the data to the right of the mantle array is also typical of other flood basalt provinces, where the dilemma of the extent to which the isotope distributions are primary, i.e. already existed in the mantle, or whether they first developed their signatures as a result of crustal assimilation has also been stressed (cf. Menzies at al., 1984, Cox and Hawkesworth, 1985, Hawkesworth et al., 1986). They further show a yet unnoticed similarity to the Emeishan basalts.

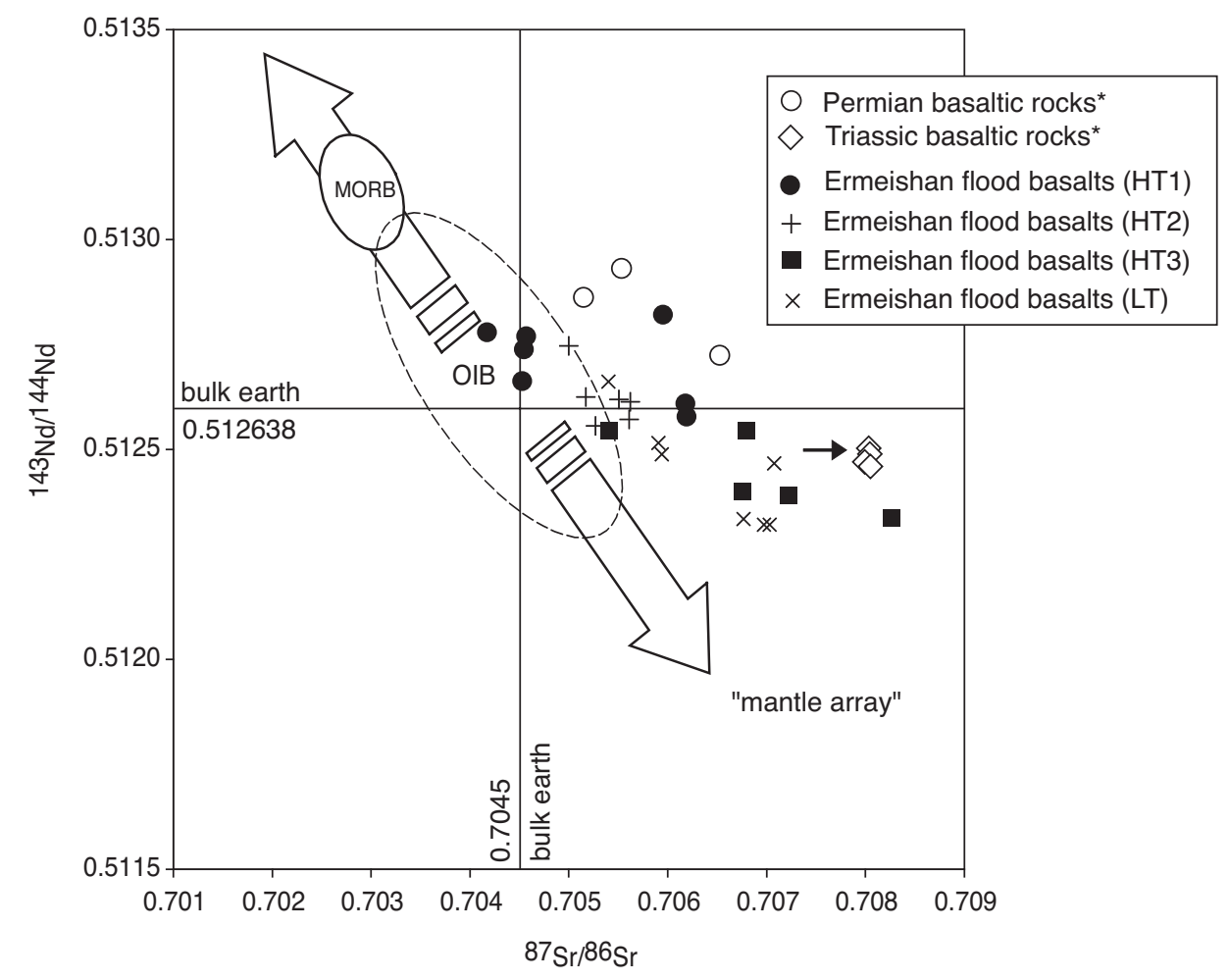

Fig. 3-30: Comparison of the Sr-Nd isotopic composition of Permotriassic basalts of the Lancang River Zone with basalts from the Ermeishan large igneous province. HT1-3 and LT are data from Xu et al. (2001). * all Permian and Triassic basalts are Na-series transitional basalts and plot in the floodbasalt field with high A.I. indexes after Middlemost (1975), (cf. Fig. 3-22). The high $87 \mathrm{Sr} / 86 \mathrm{Sr}$-values of the Permotriassic basalts along Lancangjiang are caused by seawater alteration (shift is indicated by black arrow). 
The higher ${ }^{86} \mathrm{Sr} /{ }^{87} \mathrm{Sr}$ values of the Triassic basalts may be explained by stronger crustal assimilation. U-Pb dating of zoned zircons in the Triassic rhyolites reveal upper intersections with the Concordia at ages of approx. 1.2 to $1.8 \mathrm{Ga}$ (Fig. 7 in Helmcke et al., 1999). These higher ages resemble the model ages of the Lancang Group and the Lincang Granite (Fig. 3-20, Table 11 in Appendix). Mixing of anatectic acidic and "primary" basaltic magma is observable at Manyan (cf. Fig. 3-1 and 3-25f).

An interesting aspect in this context is that the Permian-Triassic basalts of the Emeishan Large Igneous Province on the border to Sichuan are considered to be associated with a mantle plume or continental hot spot at the Permian-Triassic boundary ( $\mathrm{Xu}$ et al., 2001). In my opinion, this idea opens up a fourth option: small volumes of crustal material are subducted with the oceanic plate at an active continental margin, they sink to the deeper parts of the mantle (i.e. below $660 \mathrm{~km}$ boundary layer into the less depleted OIB source reservoir), are heated up, and return in hot spots as basaltic material with a crustal signature (cf. other possibilities in Winterer, 2001, p. 291, his Table 15.14).

Finally, a point is reached, where the applicability of the geochemical methods to separate and quantify the various petrogenetic processes becomes questionable. Despite the different opinions regarding their genesis, the presence of acid volcanic rocks (Triassic rhyolites and ignimbrites) and the strong regional-scale crustal anatexis in the Triassic (Lincang Granite) reveal that the assimilation of continental crust must have played a major role in (at least) the Triassic. Deductions on the nature of the subcontinental mantle lithosphere or the amount of crustal contamination cannot be drawn.

\section{Interpretation}

The results presented here indicate that volcanism along the Lancang River cannot be classified as island-arc type. Similar to Chung et al. (1998) and Xu et al. (2001), who consider the Permo-Triassic continental flood basalts in the area bordering Sichuan to be associated with a mantle plume, the development of a Permo-Triassic failed rift along the Lancang River can be postulated and should be seen as marginal to the development of the Emeishan Large Igneous Province. If the pre-Himalayan position is assumed by restoring the movement along the Red-River Fault (Leloup et al., 1995), the volcanic rocks along the Lancang River lie directly adjacent to the Emeishan Large Igneous Province (Fig. 3-31). This also applies, if the Red-River Fault would only have minor amounts of movement (Wang and Burchfiel, 1997).

It is interesting to note that although extrusion of the Permo-Triassic Emeishan continental flood basalts is restricted to a relatively short period around the Permian-Triassic boundary (10 Ma, according to Boven et al., 2002), the regional rift phase lasted considerably longer. From the Upper Permian, shallow marine limestones in the sequence underlying the basalts near Nanguan (Fig. 3-1) are known with a relative age of approx. $260 \mathrm{Ma}$. The youngest rhyolite, which has been dated so far, is $218 \mathrm{Ma}$ years old (Helmcke and Wagner, 2000). Hence, rifting precedes and succeeds the Emeishan LIP formation! 


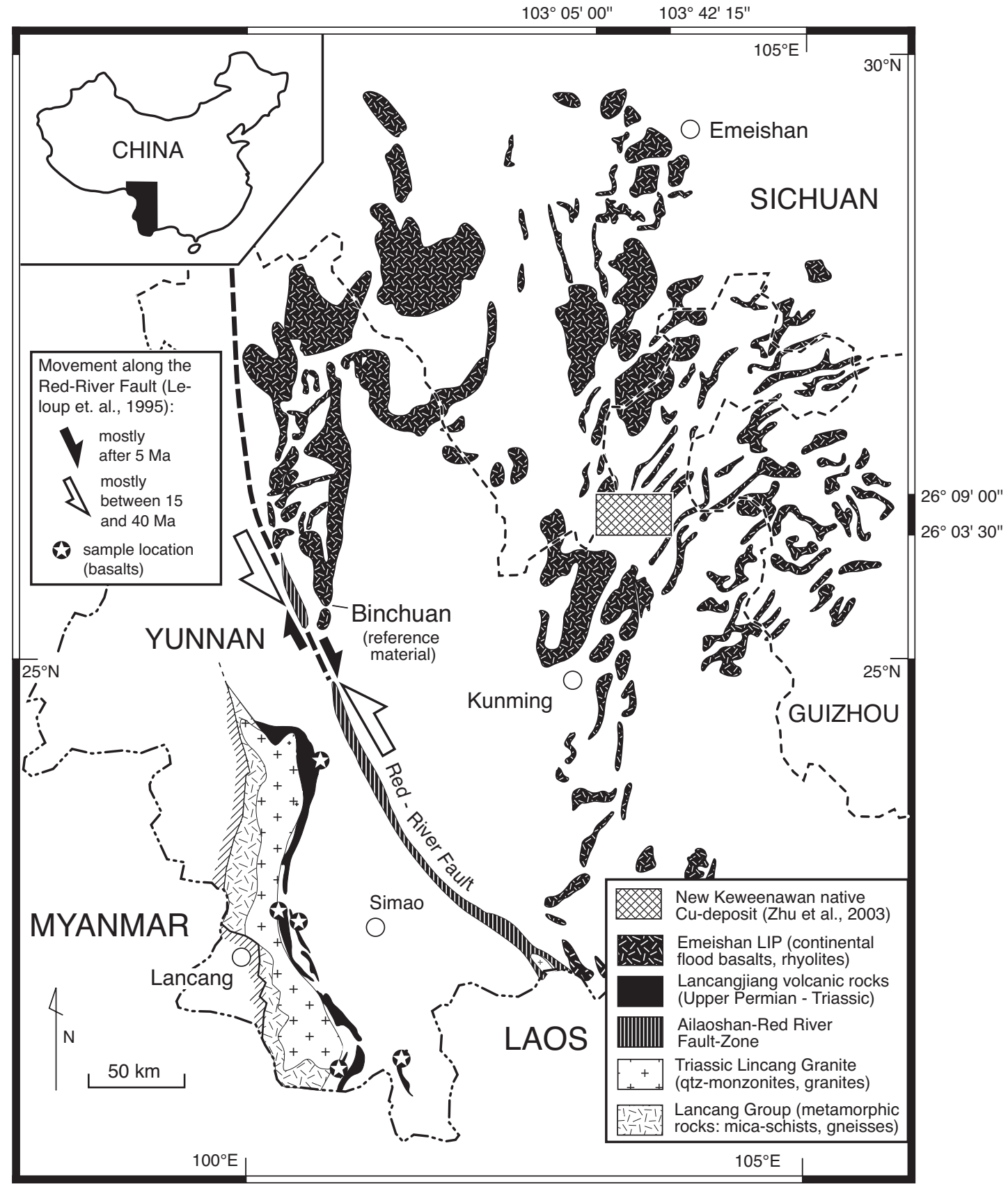

Fig 3-31: Distribution of Permotriassic volcanic rocks of the Lancang River Zone and Ermeishan Large Igneous Province (Emeishan data after Xu et al., 2001). The Red River Fault is regarded as a transform boundary (Ailaoshan-Red River Shear Zone) with a left-lateral offset of several hundred kilometres during the late Eocene to early Miocene time by Leloup et al. (1995). The view of having large sinistral offsets is challenged by various authors, including Wang and Burchfiel (1997). 


\subsection{Sedimentary Evolution}

\subsubsection{Profiles along the Lancang River (North to South)}

Detailed maps from the Yunnan Bureau of Geology and Mineral Resources (YBGMR) reveal three dominant geological units along the Lancang River: 1] quartz-phyllites and phyllites $\left(\mathrm{P}_{2}\right.$, cf. Chapter 3.2.3.), 2] a series of Middle Triassic red continental sandstones $\left(T_{2} m_{1}\right)$ with interbedded acid volcanic rocks $\left(T_{2} m_{2}\right.$, cf. Chapter 3.3.2), and 3] largely acid, pyroclastic and subordinate basic volcanic rocks of the Upper Triassic $\left(\mathrm{T}_{3} \mathrm{X}\right.$, cf. Chapter 3.3.2.).

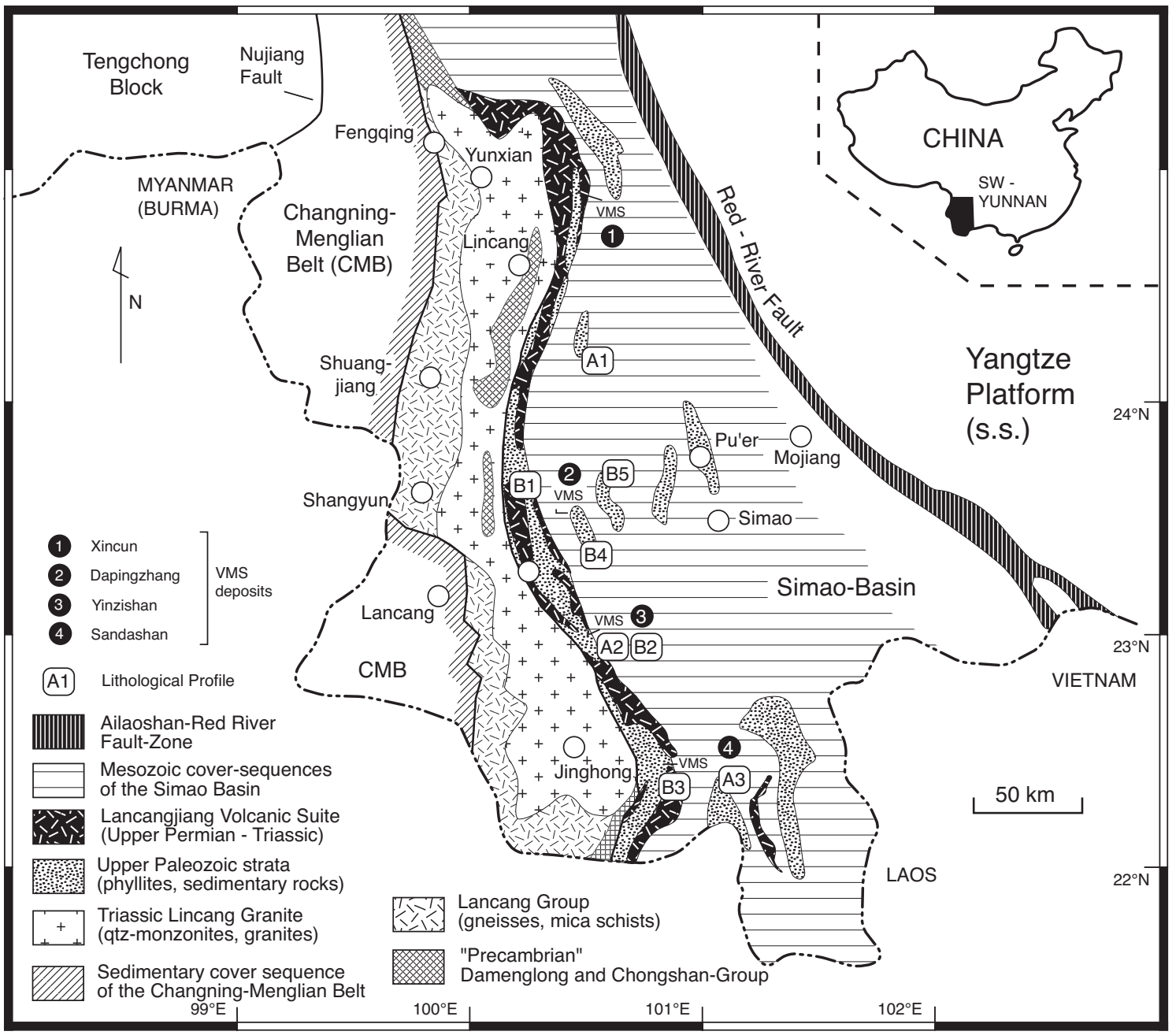

Fig 3-32: Geological sketch map of Southwest Yunnan with the position of the lithological profiles and VMS deposits discussed in the text.

\subsubsection{Wennai, East of Lancang River and Nanguan Profiles}

The Wennai profile (Fig. 3-32 and 3-33) shows an angular unconformity between the phyllites $\left(\mathrm{P}_{2}\right)$ and the Middle Triassic continental red-beds $\left(\mathrm{T}_{2} \mathrm{~m}_{1}\right)$. Outcrops showing this angular unconformity were mapped in several profiles along the Lancang River during the 2001 fieldwork and are shown in Fig. 3-33. The lithological development of the profiles along the Lancang River are similar, albeit with some differences to the Nanguan profile (Xiong et al., 1984), which indicates the Middle Permian transgression of a shallow sea from present southerly directions. In addition, pebbles of shallow marine lime- 
stone with a foraminiferal fauna of upper Middle Permian age (pers. com. Dr. IngavatHelmcke, Univ. of Göttingen) are also present in the basal conglomerate of the Wennai profile and unequivocally constrain the tectono-metamorphic event to be pre-upper Middle Permian. The occurrence of carbonate pebbles reveals the erosive reworking of Middle Permian limestones which must have been associated with the exposure of the carbonate platform. Furthermore, and in relation to a sequence of shallow platform carbonates, basalts with geochemical features similar to the Emeishan LIP occur (cf. Chapter 3.3.2).

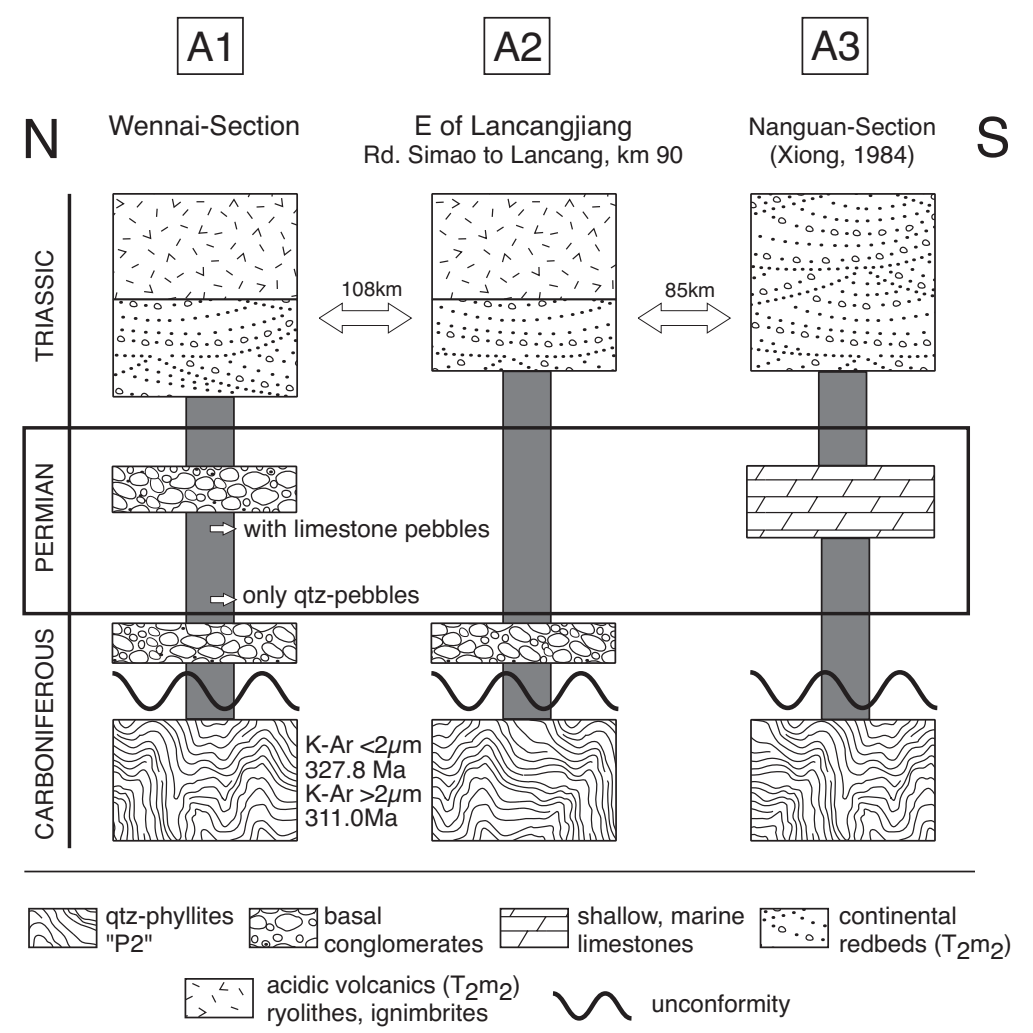

Fig. 3-33: Lithostratigraphic profiles from north to south along the Lancangjiang (compare Fig. 3-30 for the exact location of the profiles).

K-Ar dating carried out in collaboration with Dr. Klaus Wemmer of the GZG (University of Göttingen) reveals that the phyllites in Wennai were formed by a tectono-metamorphic event, which took place at the earliest in the Upper Carboniferous (Viséan-Westfalian, see $\mathrm{K}$-Ar analysis, Table 4, sample J, and Feng et al., 2001). Unlike the clear time constraints determined by biostratigraphy, the K-Ar geochronology along the Lancang River Zone has generated a whole spectrum of ages documenting various events such as the thermal disturbance of the geothermal gradient during the Late Permian and Triassic. The problems and possibilities opened up by the interpretation of the K-Ar data are discussed in Chapter 3.5.1. U-Pb dating of zoned zircons in the acid volcanic rocks of the formation $\mathrm{T}_{3} \mathrm{x}$ revealed an age between 1.2 to $2.0 \mathrm{Ga}$ for the core and 250 to $220 \mathrm{Ma}$ for the outer rims (Feng et al., 2001). The acidic volcanic rocks (see Chapter 3.3.2.) are of Middle to Upper Triassic age.

Hence, classifying the Phyllite Belt as a Middle Permian formation $\left(P_{2}\right)$ is incompatible with both the biostratigraphic and the geochronological data. In fact, the new results 
reveal a tectono-metamorphic event that triggered uplift and formed a landmass in the Upper Carboniferous. This landmass was marked by continental red-bed sedimentation, extrusion of basic and acidic volcanic rocks and temporal transgression of shallow marine seas in the Late Permian and Middle Triassic. At this point credit shall be given to Xiong (1984), who back in the early 80's, published a paper in the Journal of the Regional Geology of China and referred to a Late Paleozoic unconformity and a "Variscan orogenesis" in the Nanguan section. Presumably, because it was published in the Chinese language, the paper became hardly known und utterly undervalued while deploying the Tethys Concept in Yunnan.

\subsubsection{Profiles Parallel to the Lancang River (West to East)}

\subsubsection{Dapingzhang Profile}

The marked similarities among the profiles do not continue perpendicular to strike or in the anticlinal structures of the Simao Basin. Lower Carboniferous to Lower Permian marine-clastic sedimentary rocks and radiolarites with interbedded basic to acid volcanic rocks occur in the Dapingzhang anticline (Fig. 3-34/B4 Dapingzhang profile). Feng et al. (2001) interpreted the profile as a rift basin with high sedimentation rates. It contains a series of claystones, sandstones, radiolarites and interbedded, allodapic limestones. The lithology of the Carboniferous is similar to the Hercynian facies of the Rheinisches Schiefergebirge or the Harz Mountains being part of the Variscan mountain belt in Germany. The Paleozoic series are discordantly overlain by Middle to Upper Triassic clastic and calcareous formations and reveal another major change between the Late Paleozoic and the Triassic. Though poorly exposed, the Dapingzhang profile is of particular interest because volcanic-hosted massive sulfide (VHMS) orebodies are present. The orebodies were dated as Lower Carboniferous (Viséan, pers. com. Prof. Qinglai Feng, CUG, Wuhan) from radiolaria in cherts in the stratigraphically higher part of the massive sulfide lenses. The geology directly surrounding the orebodies and the genesis of the sulfides is being looked at by Prof. Dr. B. Lehmann from the Technical University of Clausthal, Clausthal-Zellerfeld. The data, which has been gathered on the petrology and geochemistry of the volcanic rocks so far, support the interpretation of a marine back-arc basin (pers. com. Prof. B. Lehmann, 2004). Preliminary discussions and orepetrographic analyses are given in Helmcke and Wagner (2001) and a concise treatment will soon be published by Prof. B. Lehmann. Field descriptions of the cores analyzed during the joint field work by BGR, TU Clausthal and GZG revealed that the stockwork and the massive sulfides are strongly sheared. There are serious doubts about whether a continuous profile from Lower Carboniferous to Lower Permian is observable in Dapingzhang. However, it is clear though, that a connection with the Yunxian profile described in the following is certain (Feng at al., 2001).

\subsubsection{Yunxian Profile}

The Yunxian profile (Fig. 32/B5, and Feng et al., 2001, their Fig. 3) provided important information on the Late Paleozoic and Triassic evolution of the Lancang River Zone. The oldest rocks cropping out in the Yunxian area are spilitized basalts, dacites, rhyolites and acid tuffs with interbedded radiolarian cherts of Lower Carboniferous age. The sequence 


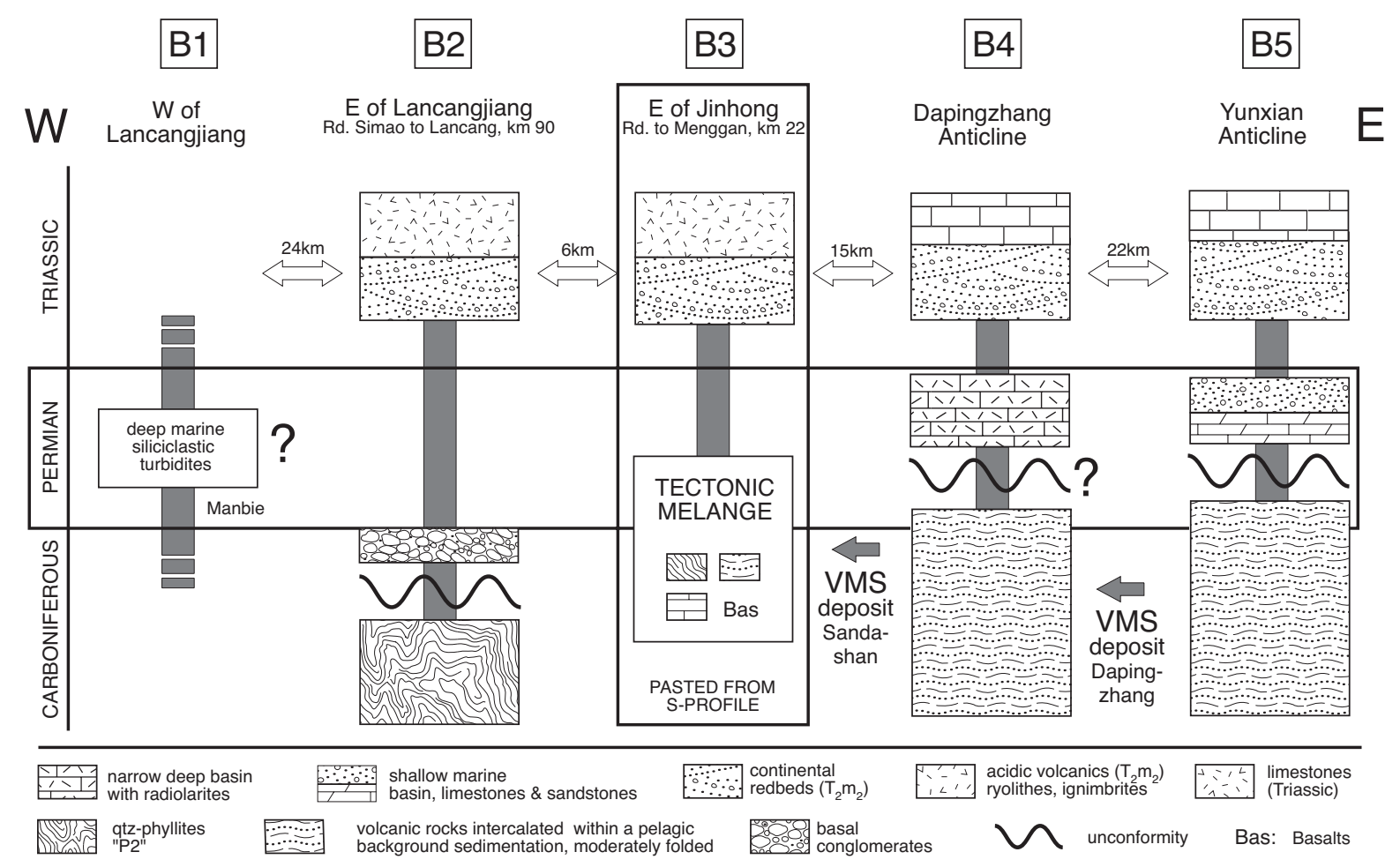

Fig. 3-34: Lithostratigraphic profiles from west to east along the Lancangjiang (compare exact po-sition of the profiles in Fig. 3-32).

also contains blocks, presumably olistoliths of Lower Devonian carbonates, and Upper Devonian sequenced clastics (up to $80 \mathrm{~m}$ ), which were dated by conodonts and radiolaria (Feng et al., 2000). This unit, in which the VHMS orebodies are located in Dapingzhang, still has no official name and was only recently separated from the younger Upper Carboniferous to Lower Permian Longdonghe Formation. The lower part of the Longdonghe Formation consists of bioclastic limestones, micritic limestones, claystones and fine-grained sandstones. In the middle part, there are interbeds of allodapic limestones (turbidites consisting of limestone clasts) and tuffs, and in the upper part, there are interbeds of rhyolites and trachybasalts. This profile is interpreted as a multiply reactivated deep rift basin characterized by deposition of siliciclastic and calcareous turbidites by Feng et al. (2000). This would indicate proximity to an area of carbonate erosion consisting of Lower Devonian rocks. An angular unconformity with a hiatus from upper Lower Permian to middle Middle Permian is observable between the Longdonghe Formation and the overlying Lazhuhe Formation. The following Lazhuhe, Yangbazhai and Naqing Formations, starting with a basal conglomerate show the development of a littoral-neritic basin which forms at the beginning of the upper Middle Permian. The lithology primarily consists of clastic sedimentary rocks such as claystones and sandstones, fine conglomerates and thin sparry limestone beds with typical Tethyan fusulinids: Yabeina sp., Verbeekina sp., Schwagerina sp., Neoschwagerina sp.. There is also a Late Paleozoic Cathaysian flora with Gigantopteris nicotianaefolia, Lepidodendron acutanguta. Another hiatus is reported between the Naqing and Xiapotou Formations. There are slight differences in the deformation of the upper and lower sequences. The Xiapotou Formation begins with a Middle Triassic conglomerate followed by a shallow marine basinal environment in which massive carbonates were deposited in the upper Middle Triassic. 
The Yunxian profile is extremely important inasmuch as it is the first area in which the stratigraphy (Feng and Helmcke, 2001) of the most important orogenic events shaping the region to the west of Simao was revised. The Yunxian anticline clearly demonstrated that the deformed Carboniferous and Lower Permian sediments - which were deposited in a relatively deep basin - are separated from the overlying shallow marine sediments of upper Middle Permian and Upper Permian age by an angular unconformity. This profile reveals that a Late Paleozoic orogenesis took place in the Lancang River Zone - as do the profiles discussed in the previous chapter. A late Paleozoic angular unconformity can frequently be inferred from outcrops of Paleozoic sequences in other areas. However, the problem with these profiles is the unfortunate variation in stratigraphic classification on different geological maps and the lack of published paleontological data.

(Comment: Outside of our study area in the eastern part of the Simao Basin near Mojiang and Jiancheng, there is another well documented intra-Permian angular unconformity (Feng and Helmcke, 2001): the hiatus lies between the Xiamidi Formation (Pseudoschwagerina moelleri zone, Asselium) and the Xianrendong Formation (Misellina ovalis zone, Kubergandian). The uppermost part of the Permian here is dominated by andesites, andesitic breccias and tuffs which are overlain by Late Triassic sediments of the Weigucun Formation.)

On the grounds of the good stratigraphic subdivision in Yunxian, it can be demonstrated that with respect to the Dapingzhang orebody, a multiply reactivated nearshore rift or back-arc basin of considerable depth must have existed from the Upper Devonian to the middle Lower Permian (at least in the western part of the Simao Basin). Because the Lower Devonian in Southwest Yunnan and on the Yangtze Platform consists of calcareous sediments - from evidence including the Lower Devonian blocks (olistoliths) in the Yunxian profile - Dapingzhang must have been part (in terms of age, and particularly, facies) of the Upper Devonian to Carboniferous extensional development of the carbonate platform on the southern edge of the Yangtze Platform. The Dapingzhang orebody would therefore have formed in a narrow, submarine rift or back-arc basin during the Visean within the large-scale rifted continental margin of the Yangtze plate.

\subsubsection{Manbie Profile (West of Lancang River)}

It was not previously possible to relate the deformed Middle Permian radiolarian cherts and basalts (Daxingshan Formation) in the Manbie region southwest of Jinghong to the Lancang River Zone (see Fig. 3-1 and Fig. 34/B1). Outcrops shown to me by Prof. Qinglai Feng in spring 2002 were strongly weathered. Radiolarian cherts and basalts crop out sporadically in road and river cuttings. However, none of the outcrops could clarify the relationship between the two units. In the west, there is a tectonic contact between the Daxinshan Formation and the Damenglong Group. In the east, the unit is bounded by the Phyllite Belt (former $\mathrm{P}_{2}$ ), which also crops out to the east of Jinghong along the Lancang River. The red radiolarian cherts are assigned to a continental margin basin by Feng et al. (2001). The basalts are interpreted as tholeiitic basalts of a midoceanic ridge (N-MORB). However, this interpretation contradicts the evidence from a sample that I have analyzed (see 02/142 in Table 7). Feng et al. (2001) reported LREE- 
depleted basalts whilst sample 02/142 from the same location (Hongcun, N 21 $37^{\prime} 58^{\prime \prime} \mathrm{E}$ $\left.100^{\circ} 44^{\prime} 56^{\prime \prime}\right)$ revealed an andesitic basalt with strong LREE enrichment and a similarity with continental flood basalts. The interpretation of these rocks as MORB needs to be reviewed. Consideration of the geochemical analyses $\mathrm{HN}-2$ and $\mathrm{HN}-4$ in Table 1 in Feng et al. (2001) puts the analytical results into question: if the weight percentages given are added up and LOI (loss on ignition) is included, then $\mathrm{HN}-2$ does not result to be 99.36 but to 95.2 (including LOI of 2.28); in the case of $\mathrm{HN}-4$, the weight percents plus LOI add up to 94.0 (including LOI of 3.00). It is probable here that strongly altered basalts were analyzed. Another aspect of the Manbie region, which requires further discussion, is whether the basalts were extruded in an epicontinental marginal basin - as also indicated by analysis of the radiolarites. This would explain the similarity of our analyses to other Upper Permian basalts (02/139 and 02/140), which crop out in the stratigraphically higher sequence of an Upper Permian shallow-marine limestone platform (Changxinnian) in the Nanguan area (Jinghong to Nanguan road, km 44).

\subsubsection{East of Jinghong Profile (East of Lancang River)}

The road from Jinghong to Mengan up to kilometer post 22 intersects outcrops of quartz phyllite, phyllite, strongly folded sandstone-claystone sequences of $P_{2}$, and finally, a N-S striking, at least 80-90-meter-wide melange zone with various dislocated slices (Fig. 34/B3). Because the river intersects this zone obliquely from the northwest, the outcrop of this unit is up to 170 meters wide. The contact with the overlying sequence is not exposed. To the east, the sequence is followed by continental red-beds of Jurassic and Cretaceous age. The melange zone consists of typical dark-blue micritic Permian limestones, numerous sheared, four-to-five-meter-long basalt lenses (analysis 02/200e), pyroclastics with lapilli and bombs (individual wedges seven to eight metres), basalts with pyroclastic xenocrysts, and numerous up to 50-60-centimeter-sized lensoidal sheared dislocated slices consisting of bedded sandstone-siltstone sequences which appear very similar to the outcrops further to the west (e.g. kilometer 16). Imbricated sandstone packages show marked alteration by fluids, and the sporadically occurring phyllites are strongly mylonitized in places along shear planes. Phyllites with quartz and a few slates are also present.

It is not completely clear whether this zone is purely tectonic or as a result of the slumping of variably consolidated sediments also synsedimentary in part. Further, I frequently gained the impression that in addition to the strong shearing, deformation also occurred in a semi-consolidated state. However, this is difficult to confirm because of the strong overprinting. The individual slices are regularly aligned and strike N-S (Stereonet: $8 \mathrm{~A}$ in Appednix) and usually dip steeply to the west or northwest. Numerous southwesterly dipping flat and probably young fault planes can be seen in the road outcrop. Slickensides indicate thrusting of the upper units towards the east/southeast (Stereonet: 8 B-F in Appendix).

The orientation of the dislocated slices in the melange (north-south) does not match the position of the thrusts (southeast direction) nor the jointing in a major basalt lens in the northwest of the outcrop. It is assumed that the southeasterly thrusting is younger and may be part of the Himalayan deformation phase. 
An age range can be interpreted with the help of the components within the melange: the presence of phyllites indicates that the melange must be younger than the age of approximately $311 \mathrm{Ma}$ (see Table 4 in Appendix). The imbricated pelagic sediments are almost certainly the protolith of the phyllites, as can already be derived from the decreasing metamorphism of quartz phyllites to phyllites and finally to strongly deformed but unmetamorphic turbiditic siliciclastics. Hence, these imbricated slices cannot be older than Lower Carboniferous. The blue color of the carbonates resembles that of Permian limestones (analysis still incomplete), while the geochemistry of the basalts has a similarity with the Upper Permian basalts of Manbie and Menglun. It is therefore concluded that this melange was created in the Upper Permian at the latest and was reactivated by younger deformation.

These interpretations correspond with the information derived from the description of outcrops at the Sandashan ore body directly to the north of the outcrop. Helmcke and Wagner (2001) reported in a BGR study that the Sandashan area was deformed by a northwest - southeast striking fault zone. My opinion is that the Sandashan orebody reflects the following genesis: The VHMS orebody developed in the same tectonic setting as Dapingzhang and is thus of Carboniferous, probably Lower Carboniferous age. At the end of the Paleozoic at the latest, the orebody was then sheared up in a melange zone and finally overprinted by the Himalayan deformation phase. Cores looked at in spring 2002 by TU Clausthal reveal strong shearing of the massive sulfide ore and the stockworks as in Dapingzhang.

\subsubsection{Outcrop East of Xiaodingxi}

In addition to this zone, another N-S striking melange zone occurs to the north between Nanjian and Xiaodingxi ( $\mathrm{km} 2562-2563$, Rd. Manwan to Xiaodingxi), which is again to the east of the Phyllite Zone. The outcrops are much worse and again on the banks of a small river (Luozhahe). Observable wedges consist primarily of sand- and claystones, arkoses, some calcite-banded, dark-blue carbonate rocks, and conglomerates. Some of the wedges are up to 15 meters long. The carbonates are similar to those in the Wennai profile and brachiopods and crinoid segments are recognizable from micritic carbonates. The wedges strike in a north-south direction and dip gently to the west. Due to poor outcrop conditions, a detailed tectonic description of the outcrop was not possible in this case.

\subsubsection{Outcrop at Reshuitang Village, $\mathrm{km} 121-122$, (Rd. Simao to Lancang)}

The rocks cropping out to the west of Reshuitang consist of Late Carboniferous to Middle Permian massive feldspathic graywackes, fine-grained quartz-sandstones, muddy slates with minor intercalated limestones (cf. Liu et al., 1991, 1993 and Fang et al., 1994). The detritus of the graywackes is interpreted to consist of mainly intermediate to acid volcanic rocks constituting 50 to 70 percent of the matrix. Plotted in a Q-F-L diagram after Dickinson and Suczek (1979) a magmatic-arc provenance is indicated (Liu et al., 1991). Paleocurrent directions indicate a redistribution of sediments and volcanic rocks from a volcanic arc to the east. The arc is constrained to lie in the "Jiufang Fracture Zone", which sedimentary sequence has been represented by the Dapingzhang profile 
of 3.4.2.1. Liu et al. (1994) regard the volcano-sedimentary sequence of Reshuitang to be the fore-arc basin, and the Dapingzhang profile to constitute a volcanic arc with its back-arc depositional environments in the Longdonghe valley at Jinggu (Xiong, 1984).

From the last preceding paragraphs the interpretation by Liu et al. (1994) is supported inasmuch as the provenance of the graywackes is related to the volcanism in the Jiufang Fracture Zone. The volcanic rocks at Dapingzhang are identical to the detritus of the graywacke in Reshuitang. But, I cannot agree on the fore-arc setting, because no volcanic arc is recorded in the area around Dapingzhang. I consider the sedimentary volcanic sequence at Reshuitang to be part of a bathymetrically structured basin-and-swell facies of a narrow, submarine rift or back-arc basin within the Yangtze plate. The redistribution of sediments from original swells and progressively inverted domains of the basin sufficiently accounts for the observed features at Reshuitang. In this context I will draw attention to the Upper Carboniferous to Permian Laba Group (cf. Feng et al., 1996), which is recorded to the west of the Lancang Group. In terms of its depositional environment this formation is still enigmatic and I would speculate on a possible relationship to Reshuitang inasmuch as the facies and tectonic setting is concerned.

\section{Interpretation}

The profiles described enable three main tectonic domains to be differentiated from west to east: 1] the Phyllite Belt, 2] the Melange Zone, and 3] the folded Simao region. The intensity of deformation decreases from west to east and is paralleled by a gradation from tightly folded vertical to slightly west-vergent small-scale folding to large-scale folding. The decrease in deformation is also paralleled by a decrease in the degree of metamorphism of the greenschist facies from dark-grey-lustrous phyllites with strong quartz remobilisation, to phyllites and slates with silky lustre, and finally, to non-metamorphosed melange zones and sedimentary sequences of the Late Paleozoic basin. In the reported angular unconformities, the age of the hiatus becomes increasingly younger from west to east which indicates an eastwardly-progressing deformation front occurring between the Viséan and Middle Permian. This migration of the orogenic front can be interpreted as a westwards movement of the Lower Devonian to Upper Carboniferous rift or back-arc basin within the Yangtze Platform. The resulting tectonic structure could be interpreted as an accretionary wedge or a wedge-shaped thrust belt.

Tectonism in the Late Palaeozoic is clearly demonstrated in profiles parallel to and along the Lancang River. Less clear is a deformation phase occurring in the Late Triassic which is documented by the inversion of a Triassic continental basin in a basin-and-swell facies to the south of Menghan. As already described by Wagner et al. (2001) for northerly parts of the Sanjiang area, this indicates that the Late Paleozoic compression was followed by a second weaker episode within the Mesozoic development of the Yangtze Platform. The compressive event at the end of the Triassic is indicated by a disconformity between the Triassic and Jurassic, and the presence of Middle Jurassic conglomerates. Many Chinese scientists interpret the disconformity and the conglomerates $\left(J_{2} h_{1}-\right.$ Huakaizu Formation) as signs of an intense Indosinian tectonic phase related to the closure of the Paleotethys along the Changning-Menglian Belt (Chapter 3.1., Model A) or the Lancang River (Model B). The results of our working group place the "Indosinian" 
development in a new light. Because a land area developed from west to east starting in the Upper Carboniferous, and the zone along the Lancang River was above sea level at the latest by the later Middle Permian, all of the subsequent deformation must be considered as intracontinental. This rules out a Triassic continent-continent collision, leading to the closure of the Paleotethys. The nature and distribution of the so-called molasse sediments also support the idea that the compressional event at the end of the Triassic was only weak and intracontinental. The Jurassic conglomerates consist almost exclusively of supracrustal sedimentary formations (Fig. 3-36, next chapter). Metamorphic rocks or granites pointing to the presence of basement within the erosional area are extremely scarce. On the contrary, the acid volcanic rocks of $T_{3} a$ and $T_{3} b$, which have been interpreted as an island arc, are interbedded with marine carbonates in the south of Yongping (e.g. km 2784 on the Lincang to Yongping road). Moreover, no widespread distribution of these conglomerates is observed. The conglomerates only locally reach considerable thicknesses. The $\mathrm{J}_{2} \mathrm{~h}^{1}$ is usually marked by sandstones, siltstones and claystones of continental red-bed facies (cf. Yano et al., 1994). Finally, the picture is complicated by a younger, transpressive deformation of Himalayan age which offsets the different sedimentological and "tectonic" facies zones along N-S transcurrent faults, and sometimes even thrusts the different units over one another. This makes the facies of strongly tectonized and poorly exposed profiles such as Manbie (Chapter 3.4.2.3.) difficult to interpret. It further stresses the difficulty of interpreting the Jurassic conglomerates on top of the Lincang Granite. How easily can juxtaposed sequences of Jurassic sediments containing continental red-bed facies rocks be misinterpreted and depicted as an unconformity?

In conclusion, the tectonic development of the Lancang River Zone is very complex and the local deformation patterns associated with transcurrent faulting during the Himalayan intracontinental deformation complicates the interpretation of the earlier phases. Nevertheless, it is possible to identify the main stages of plate tectonic development in Southwest Yunnan. Up to this point, these stages are summarized in Fig. 3-35.

Fig. 3-35: Summary of the geological evolution of the Lancang-River-Zone (LRZ) between the Upper Devonian and Late Cretaceous.

\begin{tabular}{|c|c|c|c|c|c|}
\hline PHASE & TIME & $\begin{array}{l}\text { CORDILLERAN } \\
\text { CYCLE }\end{array}$ & $\begin{array}{l}\text { DOMINANT } \\
\text { TECTONIC REGIME } \\
\text { (upper crust) }\end{array}$ & $\begin{array}{l}\text { CHARACTERISTIC } \\
\text { FEATURES }\end{array}$ & $\begin{array}{c}\text { PLATE BOUNDARY } \\
\text { CONDITION a } \\
\text { (further west of CMB) }\end{array}$ \\
\hline V & $\begin{array}{l}\text { M.-JURASSIC } \\
\text { U.-CRETACEOUS }\end{array}$ & $\begin{array}{l}\text { RETRO-ARC FORMATION } \\
\text { (in relation to Mogok-Belt) }\end{array}$ & EXTENSION & $\begin{array}{c}\text { LOCAL MYLONITIZATION } \\
\text { SIMAO BASIN- \& MCC- } \\
\text { EVOLUTION }\end{array}$ & $\begin{array}{l}\text { ACTIVE : } \\
\text { CONVERGENCE }< \\
\text { SUBDUCTION }\end{array}$ \\
\hline IV & L.-JURASSIC & $\begin{array}{l}\text { BASIN INVERSION } \\
\text { (due to collision of } \\
\text { Tengchong Microcontinent) }\end{array}$ & COMPRESSION & $\begin{array}{l}\text { STRATIGRAPHIC GAP, } \\
\text { INVERSION TECTONICS } \\
\text { RED-BED SEDIMENTATION }\end{array}$ & TRANSITION \\
\hline III & $\begin{array}{l}\text { U.-PERMIAN - } \\
\text { TRIASSIC }\end{array}$ & $\begin{array}{l}\text { POST-COLLISIONAL } \\
\text { RIFTING }\end{array}$ & EXTENSION & $\begin{array}{l}\text { HIGH-T/LOW-P-METAM. } \\
\text { BASIN \& SWELL, } \\
\text { S-TYPE GRANITES, } \\
\text { RIFT -VOLCANISM }\end{array}$ & $\begin{array}{l}\text { PASSIVE or } \\
\text { CONVERGENCE < } \\
\text { SUBDUCTION }\end{array}$ \\
\hline II & $\begin{array}{l}\text { U.-CARBON. - } \\
\text { U.-M.-PERMIAN }\end{array}$ & $\begin{array}{l}\text { WEDGE-SHAPED THRUST BELT } \\
\text { ACCRETIONARY BELT b }\end{array}$ & COMPRESSION & $\begin{array}{l}\text { HIGH-P/ LOW-T- METAM. } \\
\text { MELANGE-ZONES } \\
\text { UNCONFORMITY }\end{array}$ & $\begin{array}{l}\text { ACTIVE : } \\
\text { CONVERGENCE > } \\
\text { SUBDUCTION }\end{array}$ \\
\hline 1 & $\begin{array}{l}\text { L.-CARBON. - } \\
\text { DEVONIAN }\end{array}$ & $\begin{array}{l}\text { BACK-ARC BASIN or } \\
\text { EXTENDED MARGIN } \\
\text { (Yangtze Paraplatform) }\end{array}$ & EXTENSION & $\begin{array}{c}\text { PLATFORM CARBONATES, } \\
\text { "STEINMANN-TRINITY", } \\
\text { VMS DEPOSITS }\end{array}$ & $\begin{array}{l}\text { PASSIVE or } \\
\text { CONVERGENCE < } \\
\text { SUBDUCTION }\end{array}$ \\
\hline
\end{tabular}




\subsubsection{Jurassic to Paleogene Evolution of the Simao Basin}

The Jurassic to Eocene continental red-beds of western Yunnan were firstly described by Saurin (1933), Young (1940) and Bien (1941). Later, and in more detail, stratigraphic investigations were conducted by the Yunnan Bureau of Geology and Mineral Resources, Kunming, and published in a concise treatment of the regional geology in 1990 (cf. YBGMR, 1990). In the early 90's, additional investigation on the sedimentary facies, provenance and tectono-sedimentary evolution of Upper Jurassic to Paleogene strata were carried out by Wu (1991) and Yano et al. (1994), who propose the Western Yunnan and Central Yunnan basins (cf. Yano et al., 1994, their Fig. 1 and 2) to depict the evolution of a continental back-arc basin in relation to the Tenasserim-Gaoligong Belt (Kin, 1990, "Mogok Metamorphic Belt" of Barley et al, 2003).

Wang and Burchfiel (1997, p. 207) propose that the Jurassic to Paleogene infill of the Simao-Basin has been shortened in a general NW-SE direction. On the basis of undeformed Neogene rocks that superimpose deformed Eocene-Oligocene strata, Wang and Burchfiel (1997) infer that folding began in Middle to Late Eocene time and - apart from active strike-slip faults - was completed by the Pliocene. Strata of Late Miocene age appear to be generally missing in southern Yunnan.

The Upper Jurassic sedimentary rocks of the Simao-Lanping Basin (Western Yunnan Basin of Yano et al., 1994) consists of a 700-1800-metre-thick, monotonous sequence of red mudstones, which sporadically intercalate with fine-grained sandstones. The unit is known as the Bazhulu Formation and interpreted to be of lacustrine facies (cf. Yano et al., 1994, their Fig. 3 and 4). A drastic loss of red color introduces the Jingxing Formation (800-2100m) of Lower Cretaceous, where white-colored coarse-grained to pebbly sandstones and conglomerates intercalate with red mudstones. The facies is characterized by channel lag deposits and interpreted to have accumulated in sandy meandering rivers. The uppermost part of the Jingxing Formation is dominated by red mudstones and is interpreted to have a fluvio-lacustrine facies. Except for its uppermost part, the Jingxing Formation is the only Cretaceous formation that is recorded from a few areas to the east of the Lincang Granite in Yunnan (cf. Yano et al., their Fig. 2). This is equally true for the Paleogene, Eocene and Oligocene formations. Only in the westernmost part of the Simao Basin, an unconformity between the lower Lower Cretaceous and upper Lower Cretaceous strata occurs. The following uppermost Lower Cretaceous Mangang Formation (600-1200m) shows mainly conglomerates and sandstones with interbeds of mudstone. All rocks show a reddish color and Yano et al. (1994) interpret this sequence as a braided river facies. The Upper Cretaceous comprises red sandstones, mudstones and conglomerates. The thickness of the Manghuai Formation (3000 $\mathrm{m}$ and plus) increases to easterly directions, where more argillaceous sediments and marls occur. At the earliest Paleogene, an angular unconformity with a basal conglomerate to the Yunlong $(270-2280 \mathrm{~m})$ and the Guolang Formation $(300-1620 \mathrm{~m})$ is documented. The strata of the Yunlong and Guolang Formation are represented by red-colored argillaceous sediments, thicken to the east and are bound by another angular unconformity to the Upper Eocene and Lowest Oligocene Baoxiangsi Formation $(820 \mathrm{~m})$. The Baoxiangsi Formation contains "boulder-bearing conglomerates which grade upward 
into reddish sandstones" (cf. Yano et al., 1994). The angular unconformity is reported to cut down to the Triassic.

In addition, Yano et al. (1994) have studied the provenance of the sediments and their studies point to an increasing influx of granitic material and the change of facies in relation to uplift in the distant Tenasserim-Gaoligong Belt in Myanmar (Burma). Therefore, the Cretaceous to Eocene tectono-sedimentary development is grouped into four stages by Yano et al. (1994): 1a] A Late Jurassic lacustrine environment with low topography documenting terrigeneous clasts of the "stable craton interior" (methodology after Dickinson et al., 1983); 1b] An early Early Cretaceous fluvial system of meandering rivers documenting the import of clasts of continental interior to recycled orogen provenance from westerly directions. At the end of this stage a short transgressional phase shifted the shoreline and deltas landwards; 2] After a rapid regression a Late Early Cretaceous braided river system was established and changed downstream (i.e. to the present east) to meandering. Terrigeneous clasts are more coarse-grained and polycrystalline quartz particularly of A-type occurs. Yano et al. (1994) propose that "the uplift of the source area had intensified, and consequently the erosional level had been lowered to substrative coarse-grained polycrystalline rocks"; 3] Similar to 2] a fluvio-lacustrine environment with the strong influx of coarse-grained material and polycrystalline A-type quartz grains. Yano et al. (1994, p. 164) interpret "that this fact may imply the advancement of uplifting in the source area and the complementary subsidence of the sedimentary basins." 4] At the beginning of the Paleogene the sedimentation terminates and an unconformity occurs in the Western Yunnan basin. This unconformity is not reflected in the east (Central Yunnan Basin of Yano et al., 1994) and southeast (southernmost part of the Western Yunnan basin of Yano et al., 1994), where the basin continues to subside without gaps in the stratigraphic record. This observation is interpreted that "presumably (...) in the Middle Eocene the regional uplifting in and around the Tenasserim-Gaoligong Belt further advanced at that time (..) and that the concentration of K-Ar ages from granitic rocks into 70-50 Ma may imply that the remarkable advancement of regional uplifting during the Latest Cretaceous to early Paleogene could have been associated with thermal events at depth (...)." (Yano et al 1994, p. 164).

\section{Discussion}

As already mentioned in the previous chapter, I perceive the development of the Jurassic to Eocene Simao Basin to be tightly knotted with the exhumation of the Lincang Granite and surrounding metamorphic rocks. In order to convey my perception, I need to point to the magmatic and tectonic history of the Lincang Granite and its surrounding rocks inasmuch as it is the key for explaining the tectonic process of Jurassic to Eocene basin formation.

It is assumed by many Chinese geoscientists that the intrusions of the Lincang Granite are of shallow nature. This interpretation is based on the assumption that the Lincang Granites were exhumed by a strong Indosinian orogenesis to such an extent at the end of the Triassic that, as the former root zone of an island arc, they were exposed to erosion. Subsequently, in the post-orogenic stage, they were discordantly overlain by continental red-beds of Middle Jurassic age. According to this perception, exhumation took 
place in the Lower Jurassic between 212 and 180 Ma. There are several facts forwarded against this hypothesis:

1] The Lincang Granite is a barely differentiated and mainly mega-crystic granite of uniform grain size.

[2] There is no contact aureole. Instead, there is a transition to migmatised gneisses of upper amphibolite and lower granulite facies (cf. Damenglong, Chongshan, parts of the Lancang Group in Chapter 3.2.1 and 3.2.2.). Although the phyllites of the Lancang River Zone (Chapter 3.2.3.) were partially overprinted by a thermal event leading to the formation of the Lincang Granite, there is no sharp contact with the granites.

[3] The paragenesis of the xenoliths shows rare occurrences of biotite, cordierite, quartz, spinel and sapphire. Although I am uncertain on how to interpret this observation, there are clear indications of high-temperature contact metamorphism of the enclaves (no muscovite, large amounts of biotite, and in particular sapphire) with an extremely hot magma $800-900^{\circ} \mathrm{C}$. The question is at which depth the contact metamorphism had occurred and whether the xenoliths are actually the restites of anatexis. As for the $\mathrm{Nd}$ model ages ( $\left.\mathrm{T}_{\mathrm{DM}}\right)$ they reveal a clear relationship between granites, surrounding rocks and xenoliths (Fig. 3-20).

[4] Zhang et al. (1993) used plagioclase-amphibolite geothermometry (Blundy and Holland, 1990) and garnet-biotite geothermometry (Ferry and Spear, 1978) to analyse the development of the Damenglong gneisses of the low-T/high-P belt and determined a temperature of $735^{\circ} \mathrm{C}$ at $5 \mathrm{kbar}$ (upper amphibolite to local granulite facies). As deduced in Chapter 3.2.1., the metamorphism had caused crustal anatexis and the formation of the Lincang Granite.

[5] Since I do not consider that the Lincang Granite emplaced in the cover rock, several kilometers (about 13.5-15 kilometers, see Chapter 3.2.1.) of cover rock and basement must have been eroded during the Lower Jurassic. This concept of a Late Triassic-Early Jurassic exhumation does not marry with the Middle Jurassic conglomerates $\left(\mathrm{J}_{2} \mathrm{~h}^{1}\right)$ as they do not provide any evidence for an eroding granite (see Fig. 336). As far as it is seen from the English literature, Lower Jurassic rocks seem to be absent in Western Yunnan.

[6] Numerous outcrops, which were investigated in 2001 and 2002, show a tectonic contact between the granite and the Middle Jurassic, and when profiles further to the west are taken into consideration, the set of profiles reveal the presence of a low-angle westerly dipping normal fault (Low Angle Normal Fault, LANF, Fig. 3-37). The following locations may serve as examples:

A) Location Xiaohaguai Village and neighboring areas (Rd. Shuangjiang to Wumulong, Fig. 3-38): A north-westerly dipping normal fault transects disharmonically banded, partially garnet-bearing gneisses, qtz-sericite and sericite schists of the Lancang Group ( $\mathrm{P}_{\mathrm{t}} \mathrm{h}$, Huimin Formation) from a monotonously clastic, massive and nonmetamorphic section of the Nanduan Formation $\left(\mathrm{Cnn}_{1}\right)$. The foliation of the Huimin Formation dips moderately $\left(15-35^{\circ}\right)$ to the northwest and west, whereas the 


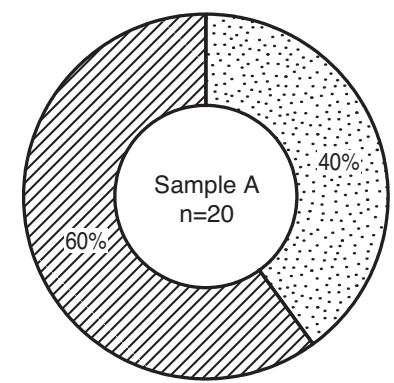

matrix- to component-supported

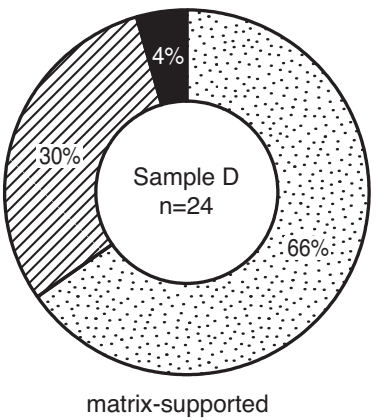

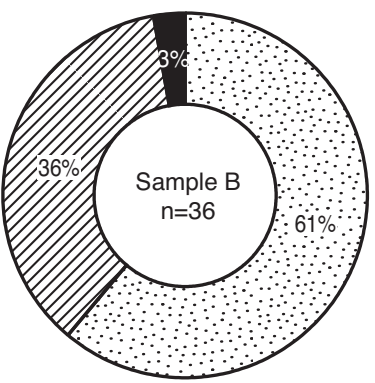

component-supported

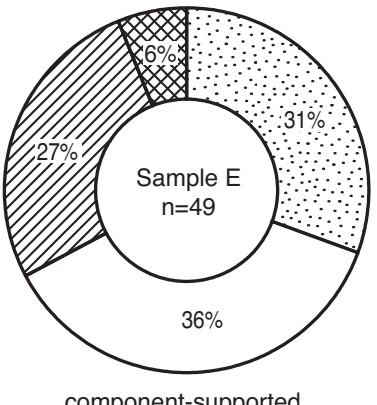

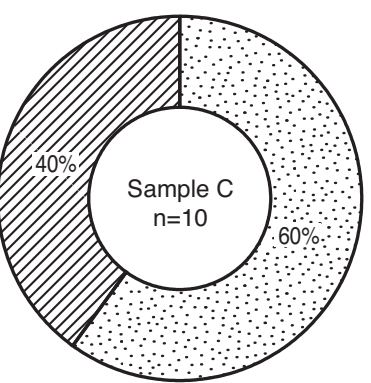

matrix-supported

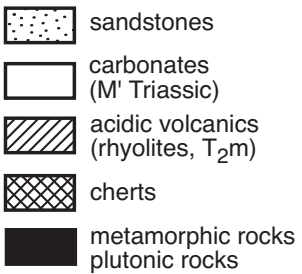

Fig. 3-36: Semi-quantitative pebble analysis of the $\mathrm{J}_{2} \mathrm{~h}_{1}$ conglomerates from locations along the Lancangjiang. Sample A: Representative sample of the outcrop at $\mathrm{km} 34-$ 35, Rd. Simao to Lancang; Samples B to E: Rd. Lincang to Shuangjiao, km 2784. Components of $>2 \mathrm{~cm}$ in diameter were counted within an area of two DIN A4 sheets directly from the outcrop. The analysis shall simply document a) the sparse occurence of metamorphic pebbles and $b$ ) the apparent difficulty to find massive molasse sediments of Middle Jurassic age along the Lancang River Zone.

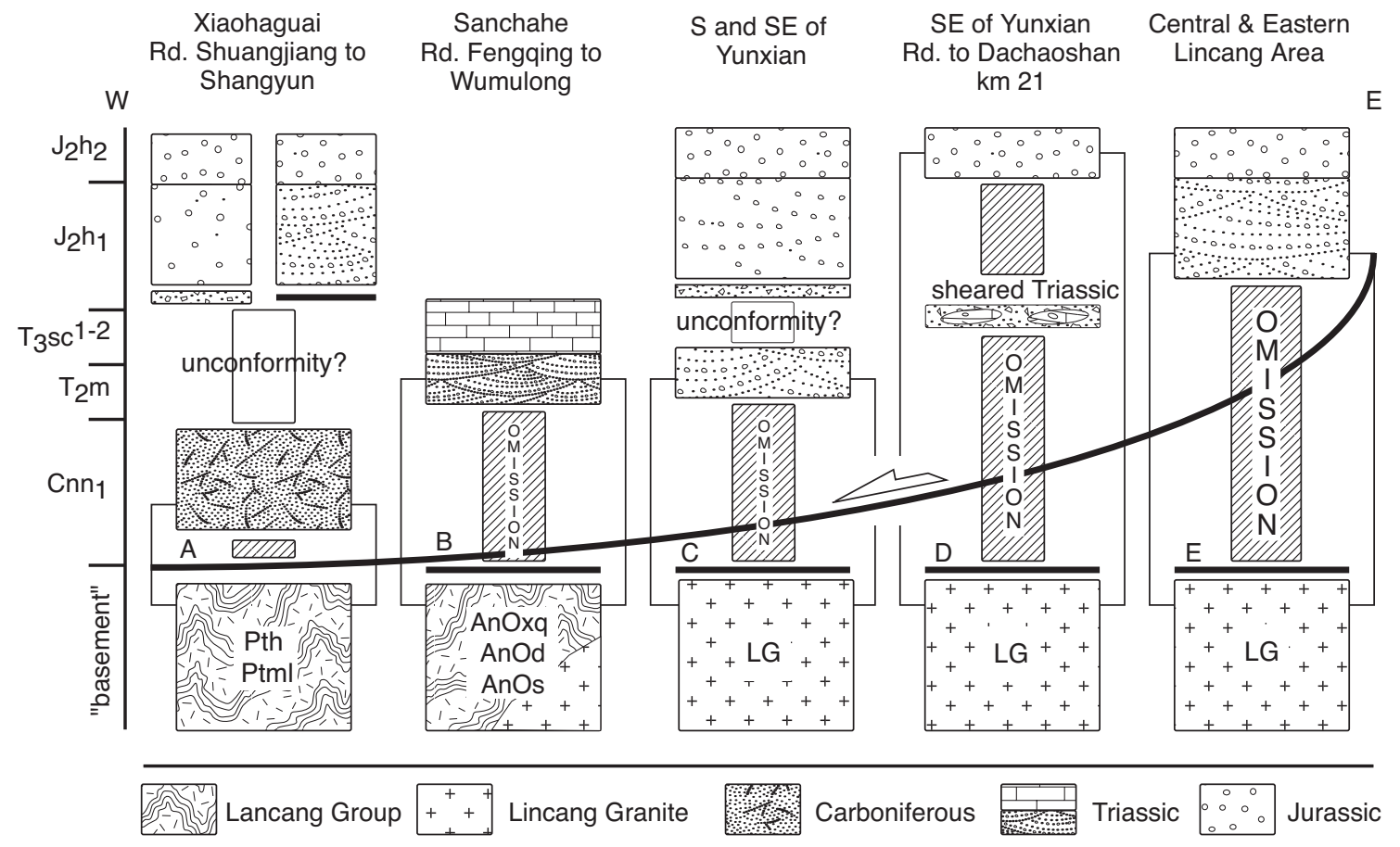

Fig. 3-37: A decreasing hiatus from east to west can best be explained by a westerly dipping low-angle normal fault (LANF) omitting (normal faulting) rather than repeating (reverse faulting) the sedimentary section on top of the Lincang Granite and Lancang Group (cf. "thin-skinned extensional tectonics" in Wernicke, 1981). Permian rocks, which do not crop out at Xiaohaguai, occur further to the west. Rd.: Road. Black horizontal line: tectonic contact. LG: Lincang Granite. 


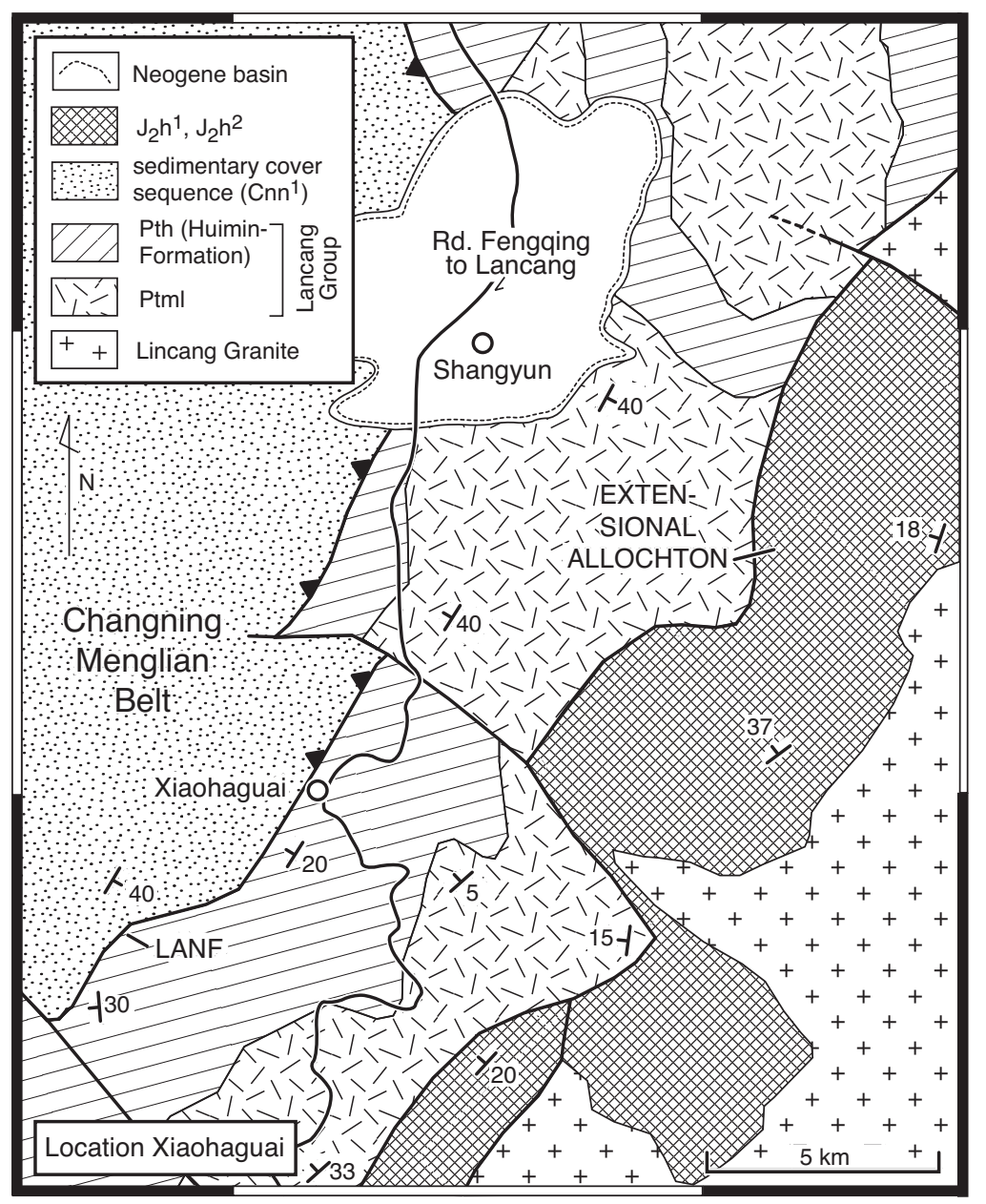

Fig. 3-38: Simplified geological map of the Xiaohaguai area. LANF: low-angle normal fault. Filled triangles indicate mapped thrusts (triangles on the down-faulted side), black thick lines are mapped faults. (after: YBGMR-Geological Map 1:200 000 Lancang. WNW-ESE striking faults are presumed to be of Himalayan age.

bedding of the Nanduan Formation dips moderately $\left(\sim 40^{\circ}\right.$, dip from Chinese geological map 1:200.000) to the east and east-south-east. The contact between Nanduan and Huimin Formation is not exposed but a cleavage pattern, resembling a pureshear deformation, is poorly preserved in the immediate vicinity of the mapped fault and within both sequences. Measured foliation planes in the Huimin Formation are $315 / 65,336 / 35,311 / 36,336 / 45,329 / 15$ and fold-hinges (lineaments): 273/14, $276 / 15,269 / 16,258 / 17$. Due to poor outcrop conditions, the direct fault plane between Huimin Formation and Nanduan Formation is not exposed in the area of Shangyun. Nevertheless, the 1:200.000 map of the Chinese Geological Bureau indicates a normal fault separating the Nanduan Formation in the hanging-wall from the Huimin Formation in the footwall at several locations such as at km 2, km 10 and km 15 following a line marked by the Xiaohei River to the NNW of Shangyun. Though several days were spent in searching for the direct contact, unfortunately this hard evidence was not detected. However, the following similarities are repeated from numerous locations: a) west- and northwest-dipping normal faults between Huimin Formation and Nanduan Formation are indicated on detailed geological maps, b) a significant metamorphic gap between both units and a deeply incising valley due to 
the differences in rock hardness is observable, c) bedding of the NanduanFormation predominantly opposes the foliation of the Huimin Formation, d) a pureshear deformation apparently parallel to the foliation of the Huimin Formation and parallel to the normal fault overprints both formations. (This becomes very obvious along the Rd. from Shuangjiang to Shangyun, e) there are no indications of a basal conglomerate between Huimin Formation and Nanguan Formation, f) though the massive sandstones of the Nanduan Formation behave as rather incompetent layers, folding seems to be of less importance.

B) Locations at Sanchahe (Rd. Fengqing to Wumulong, Fig. 3-39): Two parallel, 20 to 25 kilometer long, NNW-SSE striking stripes of Triassic sedimentary rocks evincing an overall fault-bounded contact to the adjacent metamorphic rocks of the Lancang Group. The lithology of the Lancang Group (AnOxq, $\mathrm{AnO}^{\mathrm{s}}$, AnOd) comprises qtz-mica schists, plagioclase schists, gneisses and granulites. The Middle

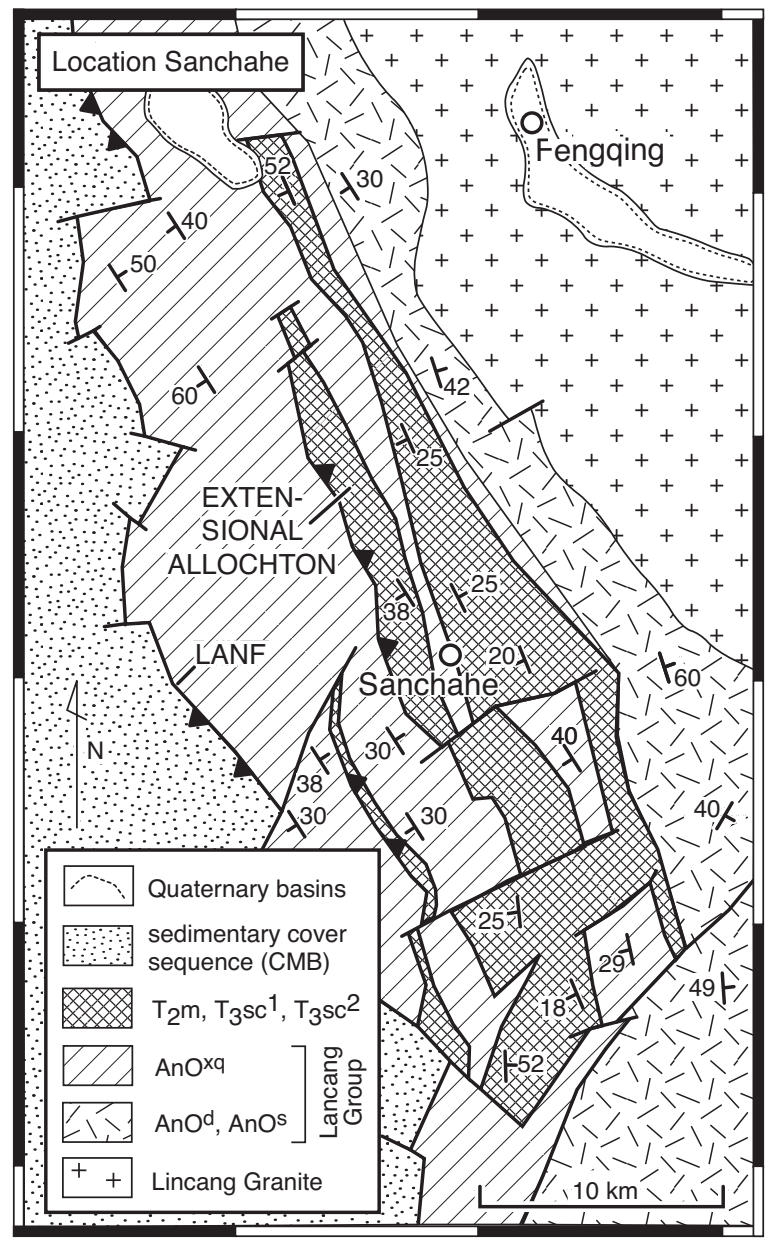

Fig. 3-39: Simplified geological map of the Sanchahe area. CMB: Changning Menglian Belt; LANF: Low angle normal fault. Filled triangles indicate mapped thrusts (triangles on downfaulted side), black thick lines are faults. (after: YBGMR-Geological Map 1:200 000 Fengqing.

Triassic sedimentary rocks contain acid volcanic rocks of the Manghuai Formation $\left(\mathrm{T}_{2} \mathrm{~m}\right)$, Upper Triassic fine- to medium-grained clastic sequence of mud- and sandstones of the Lower Sanchahe Formation $\left(\mathrm{T}_{3} \mathrm{sc}^{1}\right)$ and immature sandstones, con- 
glomerates and mudstones of the Upper Sanchahe Formation $\left(\mathrm{T}_{3} \mathrm{Sc}^{2}\right)$. The double stripe is cut by younger WSW-ENE trending faults and is terminated by a NW-SE and NE-SW trending fault in the south. The Triassic body is parallel to the length of the Lincang Granite and parallel to the observed foliation in the Lancang Group. Presumably, due to poor outcrop conditions, the nature of the tectonic contacts between cover and basement is only indicated for the north-westernmost end of the western stripe, where a NNW-SSE-striking normal fault with a dip-direction to the east is mapped. After visiting the area, the nappe character of the structure becomes evident due to the following reasons: a) The topography of the Triassic sedimentary sequence exhibits a strong positive relief in respect to the surrounding formations of the Lancang Group. All mountain peaks within the area are lined up and exhibit a low mountain range following the Triassic nappes in a NNW-SSE direction. Crossing the nappes from west to east, the shape of the range shows a shallow-dipping face on the west and a deep face to the east; b) The contact between the Lancang Group and the Triassic sediments of the west of Sanchahe reveals a one- to two-meterthick tectonic breccia that dips with $20-30^{\circ}$ to the west. The breccia contains red and white sandstones, acidic volcanics of the Triassic, schists of the Lancang Group as well as centimeter-sized clasts of unclear origin. Shear sense indicators are not observable. Slickenside along a fault planes of 164/78 and 188/55 within the overlying $\mathrm{T}_{2} \mathrm{~m}$-Formation revealed lineaments that shallowly dip to the east and are parallel to the foliation planes observed in the Lancang Group. c) The normal fault at the north-westernmost end of the western stripe can be interpreted as a detachment; d) Following the river from the dam to the south, the fault-plane of the western stripe between the Lancang Group and the Triassic cover bends by about the same amount as the river does. This indicates a shallow dip of the detachment as the slope of the river is low. - Taken the above criteria into account, a nappe structure of either extensional or compressional origin must be favored. Rare SW-NEdirected folding as well as WSW-dipping, high-angle normal faults account for both compression and extension. As far as the repetition of two, parallel stripes is concerned, it has unlikely been formed by means of thrusting and is merely the effect of an incising river.

C) Locations S and SE of Yunxian (Fig. 3-40): As depicted on the Yunnan geological Map 1:200.000 (YBGMR), Middle Triassic sedimentary and volcanic rocks of the Manghuai Formation $\left(\mathrm{T}_{2} \mathrm{~m}\right)$ concordantly overlie parts of the Lincang Granite south and southeast of Yunxian. In the field the depicted areas were inaccessible but another similar location to the NNE (e.g. Rd. Yunxian to Dachaoshan, km 21, before Daguokou-Village) was found. Cut by a small river, continental red-beds of the Middle Jurassic $\left(\mathrm{J}_{2} \mathrm{~h}^{1}\right)$ show an unequivocally tectonic contact to the Lincang Granite. Moreover, a brittle fault zone of ten to 15-meter thickness is exposed and completely recrystallized bluish limestones occur along the fault plane. I assume that these limestone lenses are the same as the "tectonized marbles" which have been described by the geological map from the above mentioned inaccessible areas. They must be older than Jurassic and are at least of Middle Triassic (Manghuai Formation, $\mathrm{T}_{2} \mathrm{~m}$ ) age. Besides the marbles, sub-angular up to fist-sized 


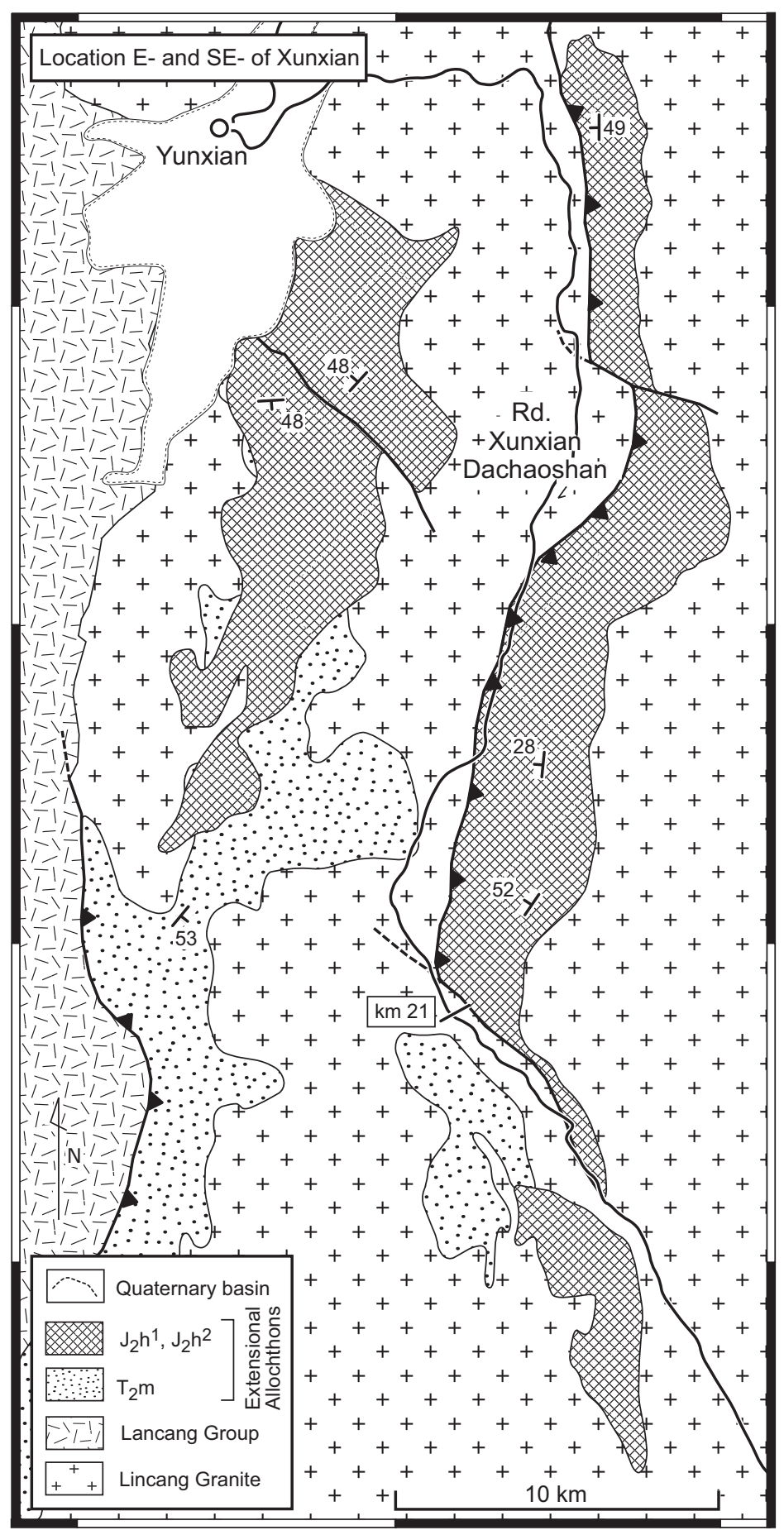

Fig. 3-40: Simplified geological map of the area to the southeast of Yunxian. Filled triangles indicate mapped thrusts (triangles on down-faulted side), black thick lines are mapped faults. (after: YBGMR-Geological Map 1:200 000 Jingdong), WNW-ESE striking faults are presumed to be of Himalayan age.

components of the Lincang Granite occur within a silty to fine-grained clastic matrix of Jurassic red-beds. Partially, flat-lying lenses of medium-grained Jurassic sandstones occur parallel to the fault-zone. Subordinate, the color of the matrix turns from a pale red to a typical red of the Jurassic red-beds. Closer to the granite, a greenish matrix (7-10 meters) is visible and can be termed a chloritized breccia. The 
fault plane dips moderately to the ESE or E, and from a few shear-sense indicators such as horsetails, a movement of the hanging wall to the WNW and SW can be inferred with some uncertainty.

D) As for location C, the intrusive contact between the Lincang Granite and the Middle Triassic rocks is questionable in other areas as well. Along the north-easternmost tip of the Lincang Granite a concordant contact is mapped in relation to the acidic volcanic rocks of the Middle Triassic Manghuai Formation $\left(T_{2} m_{2}\right)$ : An intrusion of the Triassic granites into the Triassic volcanics is implausible (cf. Fig. 3-1), and as a matter of fact this must have been recently realized by the Survey because a newly, yet unpublished geological map of the Lincang area treats these inconsistencies insofar as the discussed rocks become newly assigned as $\mathrm{P}_{\mathrm{t}}{ }_{\mathrm{DM}}$ (Damenglong Group). In this case, the Damenglong Group certainly served as a dustbin for disagreeable rock units. It is assumed that the field geologist, who had mapped the area, was able to distinguish between coarse-grained sandstones or acidic volcanic rocks of the Manghuai Formation on the one hand, and a mica schist or gneiss of the Damenglong Group on the other.

E) Further locations exhibiting a tectonic contact between the basement and sedimentary cover are: i) NW of Fengqing at Xiqian cement company (Xiqian Formation $\left(A n O^{X q}\right)$ to the Jurassic and Triassic); ii) Rd. Lincang to Simao, quarry at kilometer 2813 (Lincang Granite to Middle Jurassic, $\mathrm{J}_{2} \mathrm{~h}^{1}$; this is the only location which might record a clastic sequence documenting the erosion of the Lincang Granite during the Lower Jurassic, km 2813-2817); iii) Rd. Lincang to Shuangjiang, km 2784, best outcrop in river bed (Lincang Granite to Middle Jurassic, $\mathrm{J}_{2} \mathrm{~h}^{1}$ ); iv) SE of Shangyun, Rd. Shangyun to Lancang, km 2915 (Lancang Group to Middle Jurassic, $\mathrm{J}_{2} \mathrm{~s} ; \mathrm{v}$ ) small abandoned quarry close to the monastery at Manpa, Rd. Menghai to Manyan, km 43-44, N2145'56.2"; E100²'20.3" (Lincang Granite - Middle Jurassic, $\mathrm{J}_{2}$ ).

[7] The low-angle westerly dipping normal fault can be seen in the context of the exhumation of a metamorphic core complex. The extension beginning in the Jurassic led to the creation of half grabens and exposed the metamorphic basement and the Lincang Granite by the beginning of the Tertiary at the latest. Evidence in favor of this model includes:

A] There is a suspicious metamorphic gap between the Nanduan- and HuiminFormation (Lancang Group) all along the western side of the Lincang Granite;

B] A low-angle fault on the western side of the Lincang Granite reveals an increasing hiatus from west to east and documents omission rather than repetition. A normal sense of the fault is therefore indicated. (cf. Fig. 41, and Wernicke, 1981, 1985);

C] Chloritized breccias occurs in relation to the low-angle fault (e.g. Rd. from Yunxian to Dachaoshan, km 21);

D] Steeply dipping normal faults are associated with the cover sequence and folding is of subordinate importance;

E] The facies development in the Simao Basin to the west indicates an increasing steepening of the relief beginning in the Cretaceous with an increased contribution of granite clasts (Yano et al., 1994); 
A)
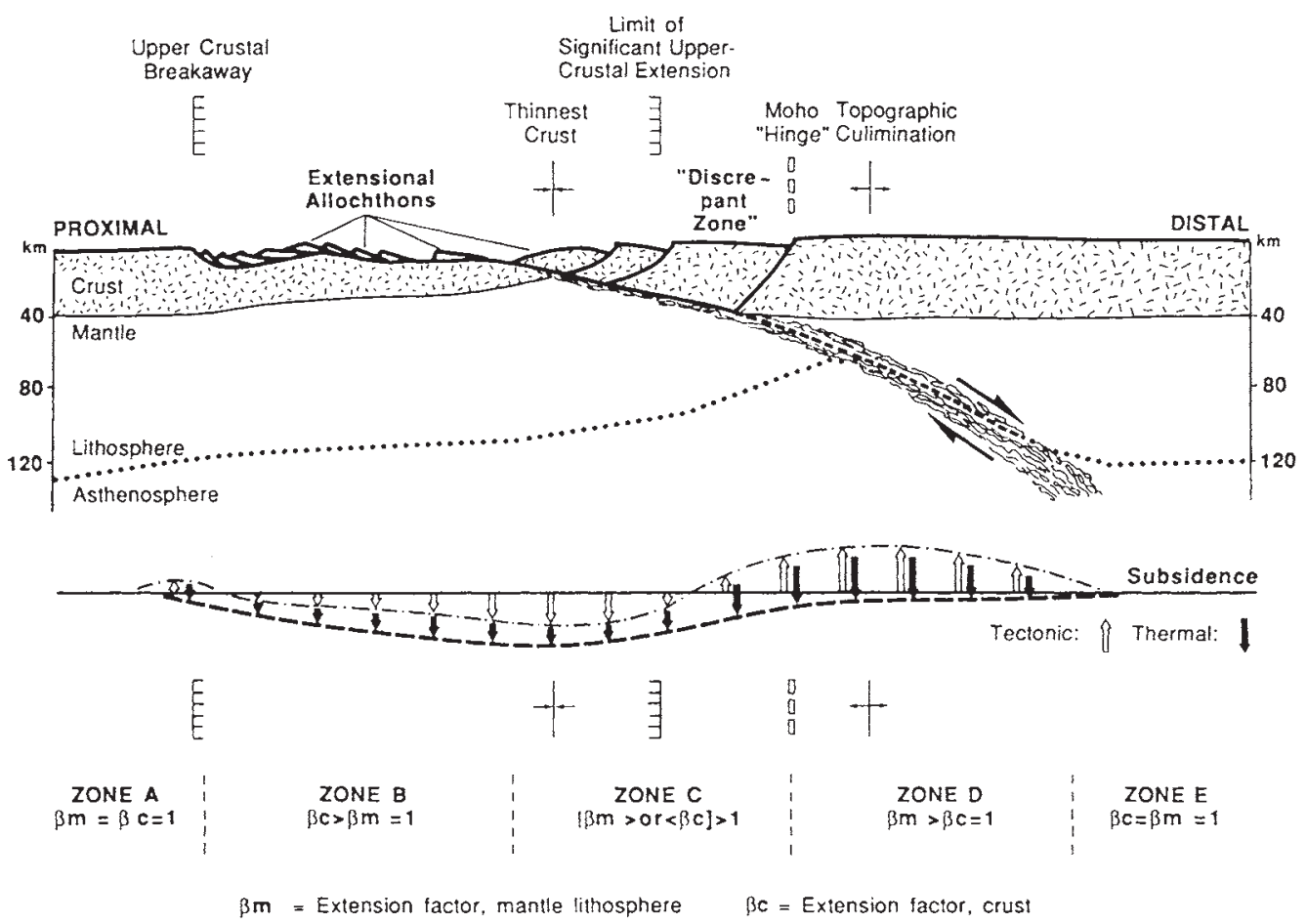

"Thinnest Crust"

future Lancang Fault Zone

B)

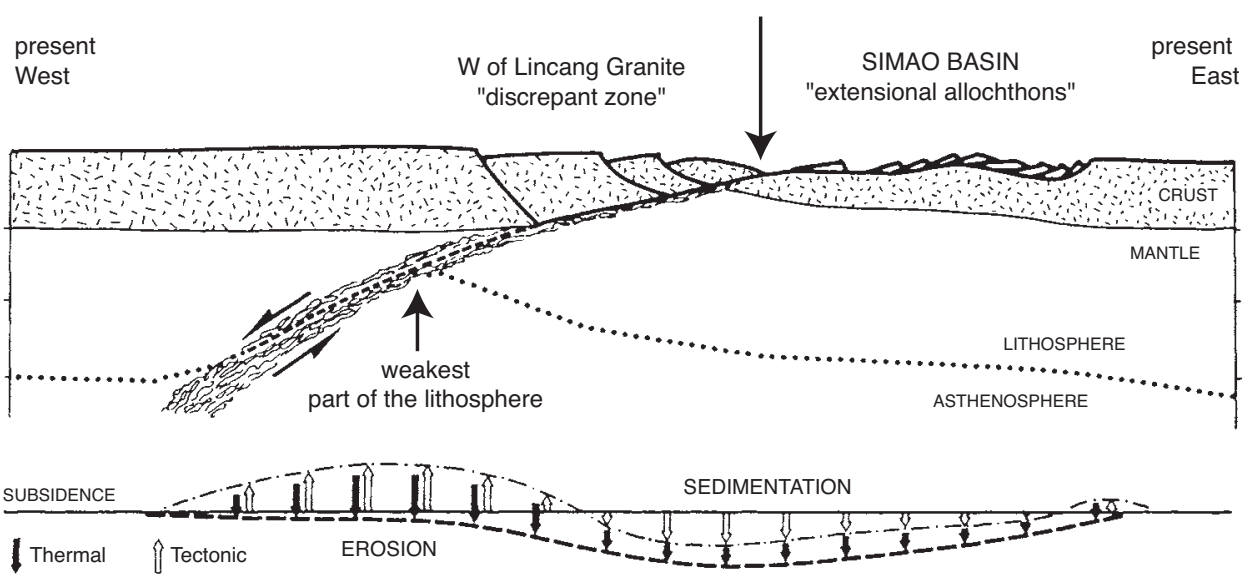

Fig. 3-41: The evolution of a metamorphic core complex after A) Wernicke (1985) and b) the model of Wernicke applied to the Lancang River Zone in west Yunnan.

F] Three unconformities of lower Lower Cretaceous / upper Lower Cretaceous, Early Paleocene and Upper Eocene/Lower Oligocene do only occur in the western part of the Simao Basin (Yano et al., 1994) documenting uplift and erosion to the west of the basin. Wang and Burchfiel (1997, p. 207) point out that "the low-angle unconformities between lower and upper Cretaceous strata, and lower Eocene rocks overlie both Lower and Upper Cretaceous rocks, but there is no significant folding associated with the unconformities."

G] Except for the Jingxing Formation there are no Cretaceous and Paleogene sediments in the area to the west of the Lancang River Zone. This indicates a stage of 
"thermal uplift" caused by the replacement of lithospheric by asthenospheric mantle along a low angle normal fault (cf. Wernicke, 1981, 1985; and the dependence of the relative thickness of the crustal versus the lithospheric thickness, $\mathrm{C}_{Z} / \mathrm{I}_{\mathrm{Z}}$-ratio as in Dewey et al., 1993);

$\mathrm{H}$ ] The K-Ar cooling ages on muscovites report a transgression through the $300-$ $350^{\circ} \mathrm{C}$ isotherm between 190 and $155 \mathrm{Ma}$ (Table 4, cf. $\mathrm{P}_{\mathrm{t}} \mathrm{h}^{1}$ and AnOxq) for the Huimin Formation;

I] The geometrical structure of the Simao Basin in the form of extensional allochthons, typical for a metamorphic core complex (MCC), and the half-graben development of the Jurassic on the west side of the Lincang Granite ("discrepant zone" after Wernicke, 1985), (Fig. 41);

J] the occurrence of Himalayan transcurrent faulting precisely in the area where the crust was thinnest and warmest after the MCC development in the Tertiary (Fig. 41, cf. Lancangjiang Fault Zone Chapter 3.2.6.);

K] A metamorphic core complex postulated by McDonald et al. (1993) in North Thailand which Min et al. (2001) consider to be the same tectono-stratigraphic unit as the Doi-Inthanon Lincang Unit (Fig. 2-4). The exhumation of the Doi-Inthanon metamorphic core complex is constrained to a period of approximately $50 \mathrm{Ma}$ between the Late Cretaceous and Miocene.

\section{Interpretation}

Though further investigations on the exhumation history are highly desirable, the available data reveal that doubts on the previously interpreted exhumation history of the Lincang Granite and surrounding metamorphic rocks are justified and that a development in the Upper Jurassic is more likely. From the above discussion, the evolution of the Simao-Lanping Basin must be seen in relation to the simple-shear model of basin formation (Wernicke, 1982), considered as a large-scale feature in Southeast Asia (Fig. 3-42), and related to the evolution of a Cordillera that is characterized by a retreating active plate boundary (as in Royden, 1993) to the west of the Mogok Belt (Barley et al., 2003) during the Late Jurassic to Paleogene. The new model agrees with Yano et al. (1993), who considers the Simao Basin to be a back-arc or retro-arc basin in relation to the Tenasserim-Gaoligong Belt, but regards the documented depositional features to be primarily controlled by a normal low-angle lithospheric detachment to the east of the DoiInthanon - Lincang Unit of Min et al. (2001). The process of progressively replacing cool lithospheric mantle material by hot asthenospheric mantle caused a plateau-like uplift in the Doi-Inthanon Lincang Unit and a depression in the Yunxian Lampang unit (cf. Min et al., 2001). If this interpretation is basically correct, the local consequence for western Yunnan is that a middle Cenozoic inversion of the Simao Basin was largely accommodated by the readjustment of allochthons (former extensional allochthons, see sub-point [7] - I), which progressively lead to a complex interplay of thrusting, folding, faulting and rotation. - That the Middle Cenozoic deformation within the Simao-Basin was rather complex is supported by the fact that a consistent vergence of the structures within the foldbelt (Wang and Burchfiel, 1997, p. 207) or a penetrative cleavage is lacking (see Leloup et al., 1995, their Fig. 4). - As far as the regional development is concerned, the plateau- 


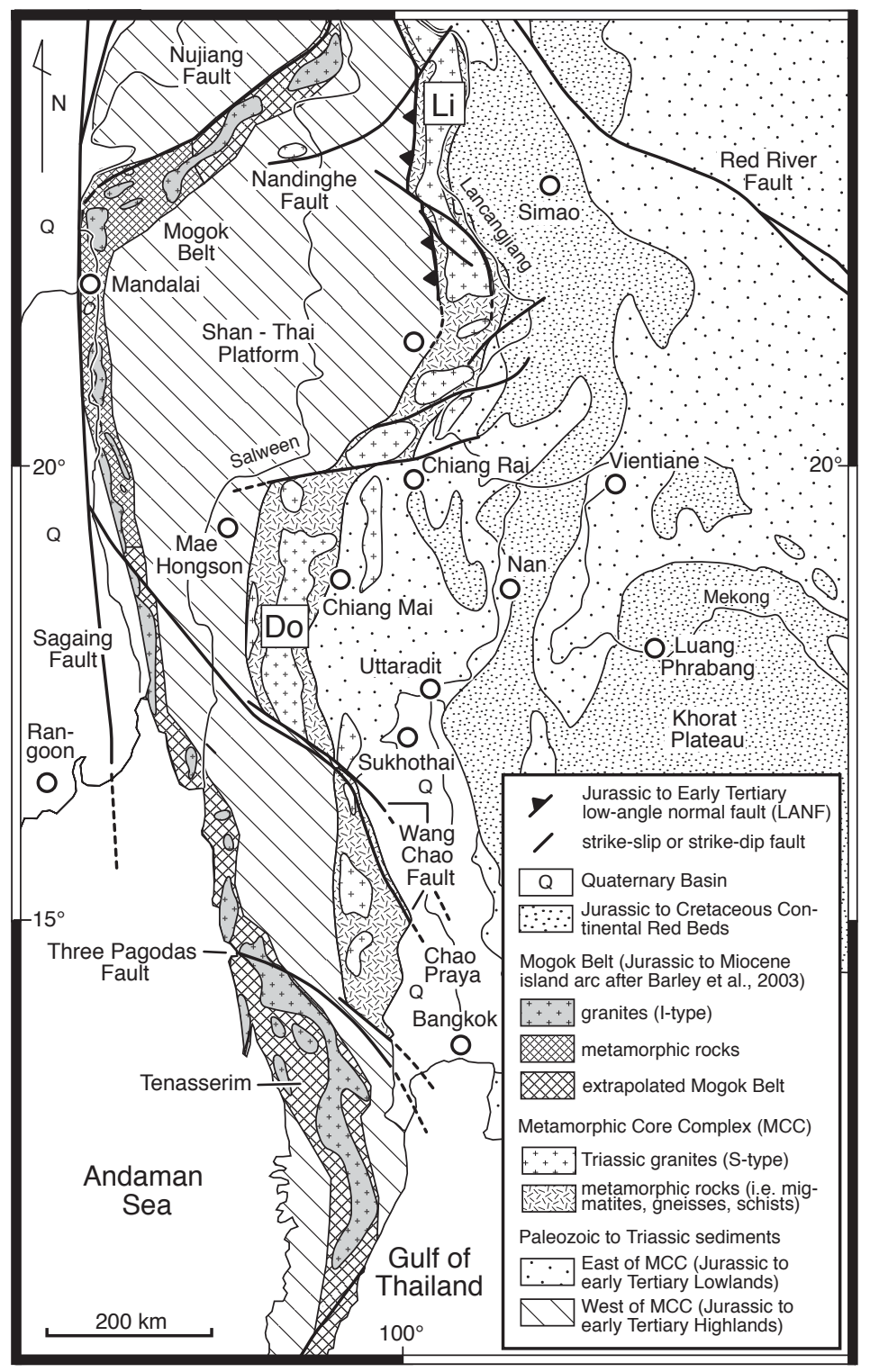

Fig. 3-42: Simplified geological map showing the continuation of the geological units from Yunnan into Southeast Asia (compiled after Lacassin et al., 1993, Bender, 1983, Cobbing et al., 1986, and Barley et al., 2003). Emphasis is placed on the Late Jurassic to Early Tertiary evolution. Li: Lincang Granite Metamorphic Core Complex, Do: Doi Inthanon Metamorphic Core Complex (after: McDonald et al., 1993). - Two signatures for the Paleozoic and Triassic sedimentary rocks were used in order to emphasize the idea of a Late Jurassic to Early Tertiary plateau-like area to the west of the LincangDoi-Inthanon Metamorphic Core Complex. While the western part was exhumed and eroded, the eastern part subsided and served as a basin for the continental red bed sedimentation. Note that except for areas to the north of the Nujiang fault there is only sparse Jurassic and no Cretaceous sedimentation recorded to the west of the Doi-Inthanon Lincang Unit (cf. Bender et al., 1981 and Lacassin et al.,

like uplift of the Doi-Inthanon Lincang Unit and the depression of the Yunxian-Lampang Unit may be traced to the circum-Himalayan region leaving a provocative question for further studies on the evolution of the Tibetan Plateau: Was there a Cretaceous/Paleogene plateau before the Tibet Plateau? 


\subsection{Discussion}

\subsubsection{K-Ar Geochronology along the Lancang River Zone}

In an attempt to constrain the Late Paleozoic tectono-metamorphic event along the Lancang River Zone, 18 samples were processed for K-Ar dating on mineral fine fractions and detrital muscovites (Table 2 to 4 in Appendix, Fig. 3-43). The samples included phyllites from the formation $\mathrm{P}_{2}$ along the Lancang River, mica schists, mylonites, gneisses and phyllites from the Lancang Group $\left(P_{t} h^{1}, A n O^{X q}, P_{t} \ln ^{a-b}, P_{t} n^{c}\right)$ and an Upper Triassic mudstone $\left(T_{3}\right)$ from the eastern Simao Basin (cf. Table 1). Micas were handpicked from schists exhibiting larger crystals (samples $O, P, Q$ ) as well as from the Upper Triassic mudstone (sample R). Sample J has been incorporated into Table 1 from Feng et al. (2001).

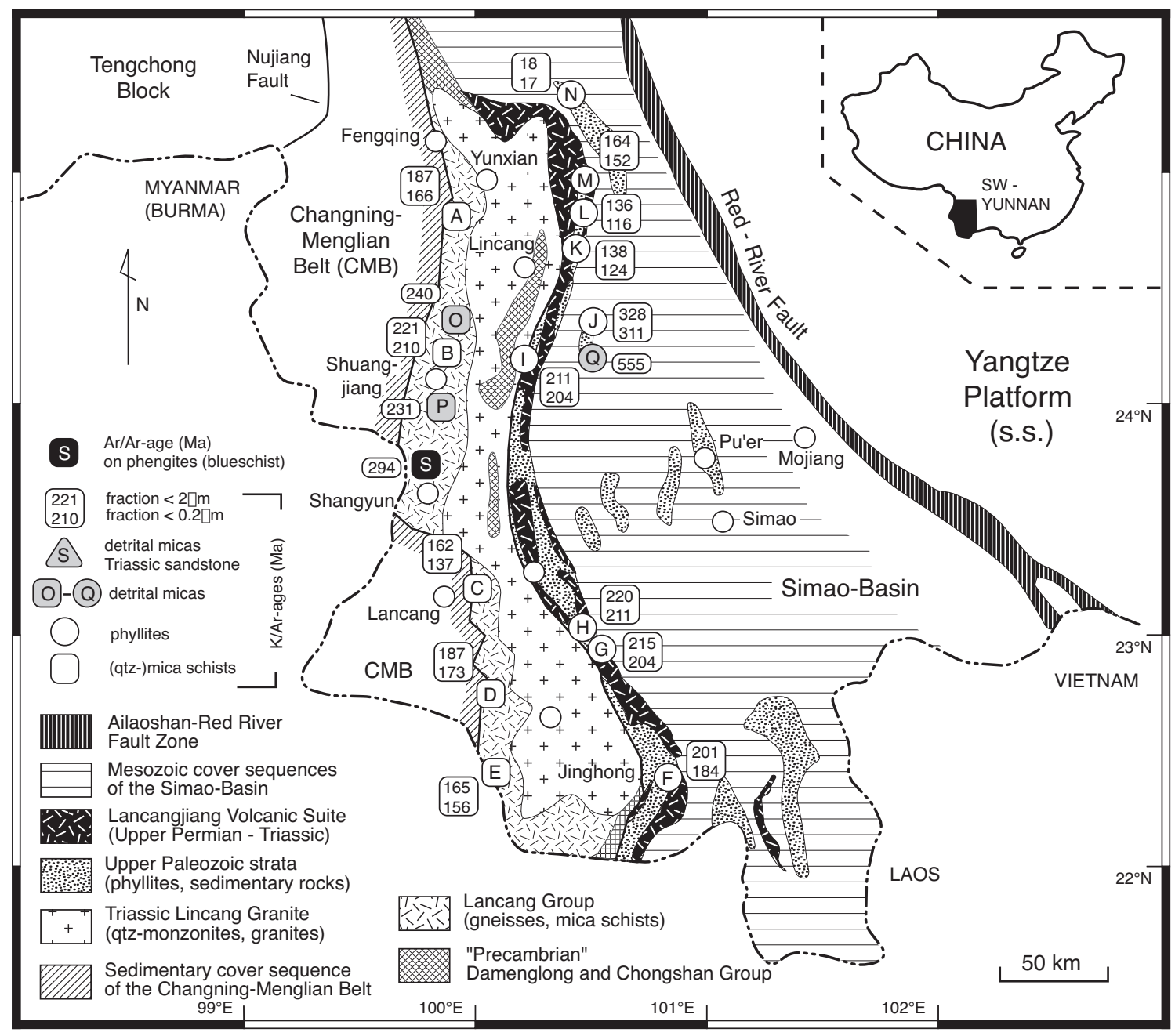

Fig. 3-43: Geological sketch map of Southwest Yunnan showing the position of the new geochronological data of the Lancang River Zone. Letters represent samples of Table 3 and 4.

The obtained results reveal a considerable spread and expectations, which were raised by a Late Carboniferous age of the tectono-metamorphic event at Wennai (Feng et al., 2001, cf. sample $\mathrm{J}$ in Table 1), are not met. Though disappointing at first, a critical discussion in respect to the tectonic evolution of the Lancang River Zone shows that the recorded cooling ages are of particular value: they accentuate the various tectono-metamorphic and thermal events that have shaped the Lancang River Zone. 


\section{Discussion}

Samples A to $\mathrm{N}$ of Table 2 show high IC-values (low crystallinity) in the fine fraction and can be classified to the epizonal part of metamorphism. Due to relatively high temperatures of the greenschist facies, illite was completely replaced by muscovite and in this respect, all ages are reliable and geologically meaningful. Coarse-grained muscovites, which were handpicked from samples $\mathrm{O}$ to $\mathrm{R}$ in Table 3, reveal cooling ages, and in the case of the Lancang Group, the age was set, when either the rocks were moving through the regional isotherm of the closure temperature (e.g. during exhumation) or, when the isotherm moved through the rocks (e.g. cooling after a thermal pulse). It has long been known, that in a strict sense K-Ar dates do not present the time of rock or mineral formation, but rather the time at which the temperature was low enough that Ar-diffusion was more or less zero (Dodson, 1973). Therefore, all presented dates refer to a certain temperature of the system at a time indicated by the isotopic age. In Fig. 3-44 all ages, except 01/008 from the eastern Simao Basin, are depicted on a sketched west-to-east profile across the western part of the Lancang River Zone. Additionally, the U-Pb geochronological data of the Lincang Granite intrusions (Liu et al., 1989; Chung Sunlin, pers. com. 2003) are annotated.

The obtained data can be clustered into five groups: 1] Paleozoic, and basically Late Paleozoic ages, 2] Triassic ages similar to the age of the Lincang Granite, 3] Middle Jurassic to Upper Cretaceous ages of the Huimin Formation $\left(\mathrm{P}_{\mathrm{t}} \mathrm{h}^{1 /} \mathrm{AnO} \times \mathrm{q}\right)$, and 4] Upper Jurassic to Tertiary ages reported from the Wulianshan Area.

Firstly, attention shall be drawn to the Mesozoic dates since the close relation between the intrusion of the Lincang Granites and the documented cooling ages of the eastern Lancang Group and western Phyllite Belt is conspicuous and deserves an explanation. With respect to the potential tectonic models of the zone, two explanations can be discussed:

1] The metamorphism was caused by bulk convergence along the Lancang River Zone. Hence, muscovites of the epizone document cooling ages of a waning regional greenschist facies metamorphism. If this is the case along the Lancang River Zone, the Lincang Granites are syn-collisional intrusions and a compressive tectonic regime should be documented during the Triassic (Indosinian Orogeny). This explanation complies with the tectonic Model B of Chapter 2.1.2.

2] The metamorphism was caused by post-collisional bulk divergence leading to a high regional geotherm. Potential processes might be seen in relation to thermal re-equilibration after orogenesis, post-orogenic rifting or a mantle plume. The emplacement of the Lincang Granite or crustal anatexis forming the Lincang Granite caused a local, thermally activated volume diffusion loss of radiogenic argon in neighbouring formations up to a distance of five to ten kilometers (Indosinian Thermal Pulse). This explanation would account for the tectonic Model C of Chapter 2.1.3.

As presented in Chapter 3.4., detailed maps show three characteristic units along the banks of the Lancang River: a] bimodal, but mainly acidic volcanic rocks $\left(\mathrm{T}_{3} \mathrm{x}\right.$ and $\left.\mathrm{T}_{2} \mathrm{~m}_{2}\right)$, b] continental red clastics $\left(\mathrm{T}_{2} \mathrm{~m}_{1}\right)$, and 3] phyllites $\left(\mathrm{P}_{2}\right)$. The age annotations imply a Late 


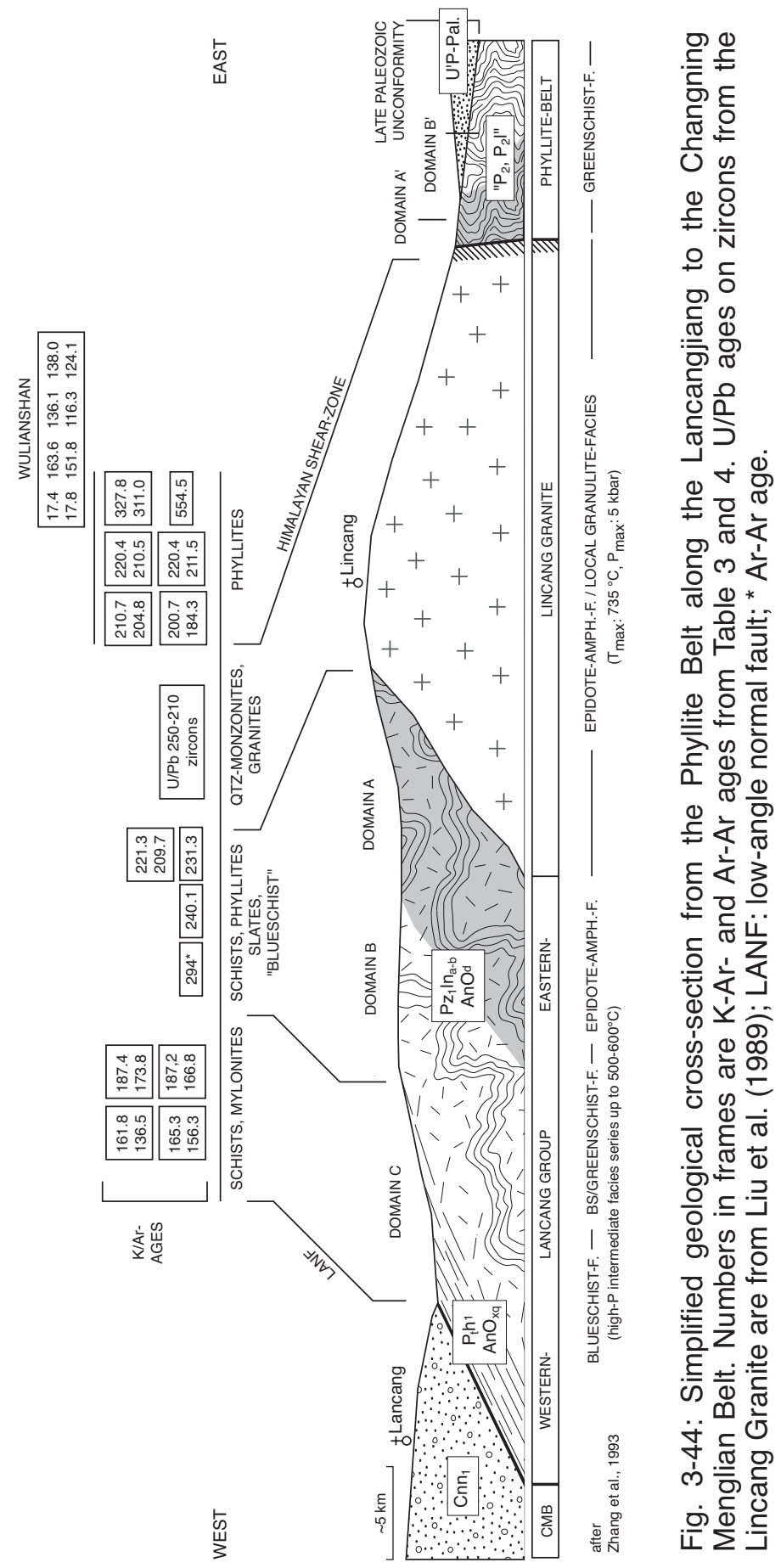


Paleozoic and Upper Triassic sequence with an unconformity between the phyllites and red sandstones. According to basic stratigraphic investigations along this zone, Feng et al. (2001) have started to question the Middle Permian stratigraphic age of the phyllites for the following reasons: a] the basal conglomerates above the phyllites contain pebbles of Middle Permian limestones at Wennai and b] a marine ingression of an UpperPermian marine sea is reported from Nanguan. Moreover, the greenschist metamorphism of the phyllites decreases in easterly directions and pelagic sediments of a Devonian to Carboniferous marginal basin crop out (cf. Chapter 3.4.). For these reasons, a pre-Middle-Permian tectono-metamorphic event forming an elevated landmass of regional extent in West Yunnan must be concluded from biostratigraphic considerations.

On the contrary, the K-Ar data from the phyllites of $\mathrm{P}_{2}$ (Table 3) reveal a considerable spread from 17.4 $\pm 1 \mathrm{Ma}(<2 \mu \mathrm{m}, 29 / 98)$ to $327.8 \pm 7.1 \mathrm{Ma}(<2 \mu \mathrm{m}, 24 / 099)$. These data do neither support a late Paleozoic nor Middle Triassic/Early Jurassic tectono-metamorphic event, but corroborate the fact that the age annotation " $\mathrm{P}_{2}$ " is utterly misleading. If the geochronological data do not single out a tectono-metamorphic event, how can they be interpreted?

In this respect it is noteworthy that muscovites exhibit a low closure temperature of approximately $350 \pm 50^{\circ} \mathrm{C}$ for the K-Ar system (Purdy and Jäger, 1976) and are hence sensible to thermal disturbances (Hart, 1964, Kübler, 1967a, 1967b, 1968). This is even more true, when the volume/surface ratio of the analyzed crystals is very low, such as for the presented phyllites of $\mathrm{P}_{2}$. For this reason, Hunziker et al. (1986) have argued that the closing temperature for very fine-grained muscovites is about $260 \pm 30^{\circ} \mathrm{C}$. For this reason, a thermally activated volume diffusion loss of radiogenic argon in the neighboring metamorphic rocks is advocated to account for the increase in age with an increase of distance from the Lincang Granite (Fig. 3-44 and 3-45). The age of the samples, which were taken at some distance from the Lincang Granite, comply with biostratigraphical constraints. Hence it is conclusive, that the Late Carboniferous ages account for the tectono-metamorphic event that triggered uplift along the Lancang River Zone, and the Triassic ages reflect a thermal event as outlined in point 1 of this chapter.

Secondly, ages documented for the Wulianshan area are difficult to understand at the present day. The Wulianshan has been interpreted to be a pop-up structure by Wang and Burchfiel (1997), where deformation and uplift of the zone is related to the Himalayan stage of intra-plate deformation. Although Upper to Lower Cretaceous ages are reported from the southern Wulianshan $(02 / 014,02 / 050,02 / 027)$, the explanation by Wang and Burchfiel (1997) is corroborated by the young Himalayan age of sample 98/029 (Table 3) from the central part of the oroclinal bend. At the moment, the information that has been gathered from the Wulianshan is too poor in order to speculate on the significance of the Upper-Cretaceous to Lower Jurassic dates, but a relation to the exhumation of the Lincang Metamorphic Core Complex is suspicious.

Thirdly, isotopic data from the Huimin area support the perception by Zhong et al., (2000, p. 42), that the Huimin Formation is a separate entity and unrelated to the Lancang Group or Lancang Complex. In their view, the Huimin Formation was thrust eastwards and onto the Lancang Complex, and the new cooling ages from the Huimin 


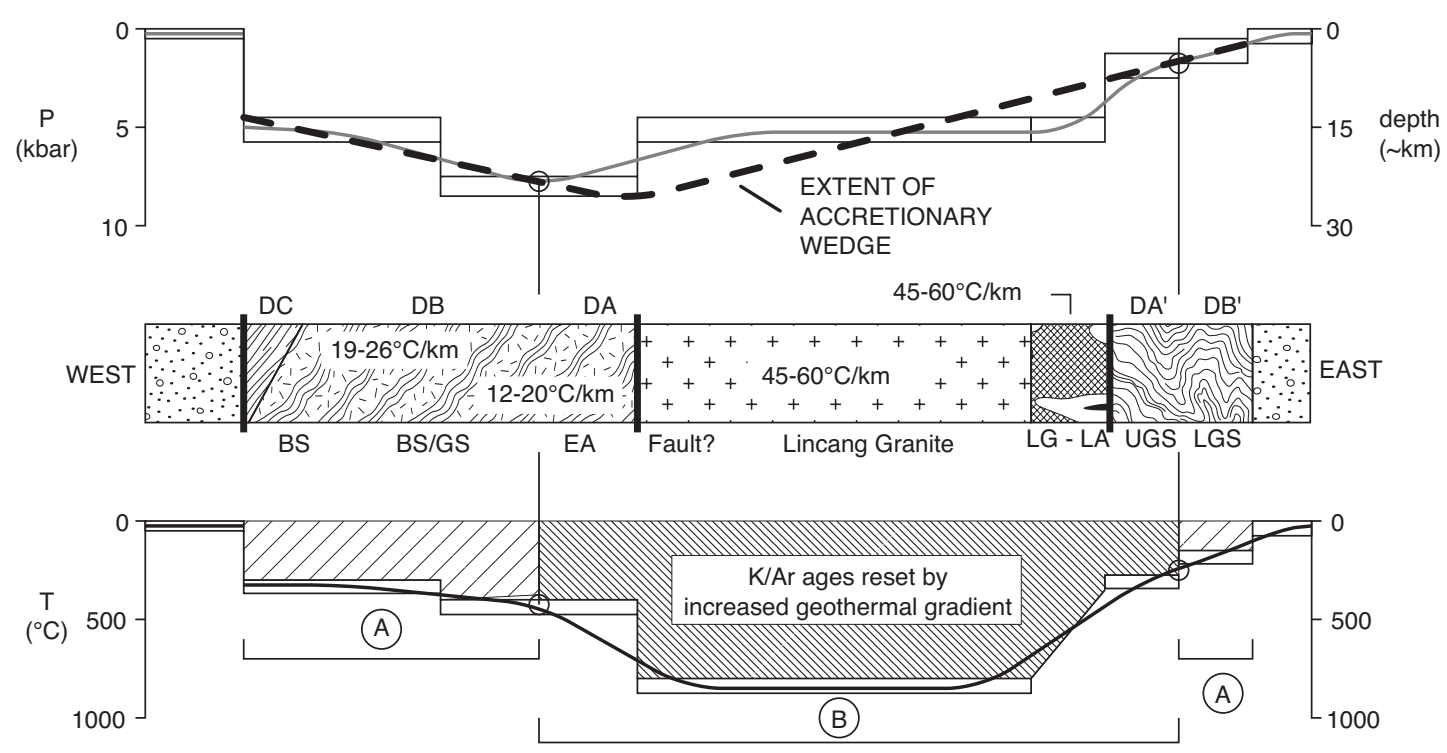

Upper Permian/Triassic Rifting (Indosinian) - A high-T/low-P Belt

"Eo"- or "Pre"- Indosinian (Paleozoic orogeny) - B high-P/low-T Belt

Fig. 3-45: Geological cross-section from the Phyllite-Belt in the east to the ChangningMenglian Belt in the west. In combination with the estimated P/T-conditions from Zhang et al. (1993), the new geochronological data indicate that the high-T/low-P Belt (B) postdates the high-P/low-T Belt (A). BS: blueschist, GS: greenschist, LG: Lincang Granite, UGS: upper greenschist facies (as indicated by the remobilization of quartz), LGS: lower greenschist facies (as indicated by lustrous schists and the absence of quartz remobilization). DA: Domain A of Fig. 3-44. - Geothermal gradients are calculated according to the estimations by Zhang et al. (1993). The following calculation may serve as an example: blueschist zone (BS): $300-350^{\circ} \mathrm{C}$ at $5 \mathrm{kbar}$ (after Zhang et al. 1993, p. 608) results in a range from: $350^{\circ} \mathrm{C} /(5 \mathrm{kbar} \times 2.7 \mathrm{~km})=26^{\circ} \mathrm{C} / \mathrm{km}$, and $300^{\circ} \mathrm{C} /(5 \mathrm{kbar} \times 3.1$ $\mathrm{km})=19^{\circ} \mathrm{C} / \mathrm{km}$.

Formation (Table 3, Fig. 3-43 and 3-44) would indicate, that the stage of thrusting had probably occurred sometime between the Upper Jurassic to Lower Cretaceous. Although eastward thrusting is conceivable, in relation to the contemporaneous extensional evolution of the Simao Basin (Yano et al., 1994), it is rather implausible. Therefore, the Huimin Formation is the sheared footwall of a low-angle normal fault constituting a key-feature within the extensional evolution of the Simao Basin.

Fourthly, detrital muscovites, which were handpicked from a phyllite of $\mathrm{P}_{2}$ at Wennai, revealed a Precambrian age of $554.5 \pm 12.8 \mathrm{Ma}(02 / 152)$. This sample was taken close to 24/99 (Fig. 3-43), which was advocated to support a Late Paleozoic tectono-metamorphic event by Feng et al. (2000) along the Lancang River Zone. As there is only sparse information on the Precambrian evolution of the zone, the age is difficult to interpret. Nevertheless, deposition of detrital micas with pan-African cooling ages during the Late Paleozoic further exemplifies the complex history of the zone and points to an eroding Gondwana-type basement in the region.

Noteworthy is further, that although a Late Paleozoic greenschist metamorphism is clearly recorded from the phyllite at Wennai, it is surprising, that these muscovites have not suffered a complete Ar-loss. 


\section{Conclusions}

In deciphering the geological evolution of the Lancang River Zone, the geological unit " $\mathrm{P}_{2}$ " is regarded to be a collective unit for an assemblage of low-grade metamorphic rocks, melanges, and pelagic sedimentary rocks that was difficult to map, differentiate, and classify by biostratigraphy. Although the K-Ar method is rather sensible and some error needs to be assumed, the new geochronological data is valuable in the respect that several geological processes must have played a role in shaping the unit " $\mathrm{P}_{2}$ ", and from the lithological profiles, I can demonstrate that one of the dominant processes was a stage of Late Paleozoic mountain building. Finally, the new data point to at least two dominant stages of metamorphism: 1] an "eo" or "pre"-Indosinian (Late Paleozoic) stage of metamorphism, that was related to high-pressure metamorphism and convergence and b) an Indosinian, basically upper Permian to Triassic stage of metamorphism, that was related to high temperature metamorphism and anatexis. A comparison of the $\mathrm{K}-\mathrm{Ar}$ geochronological data with the major tectono-stratigraphic, metamorphic and magmatic events along the Lancang River zone is given in Fig. 3-46.

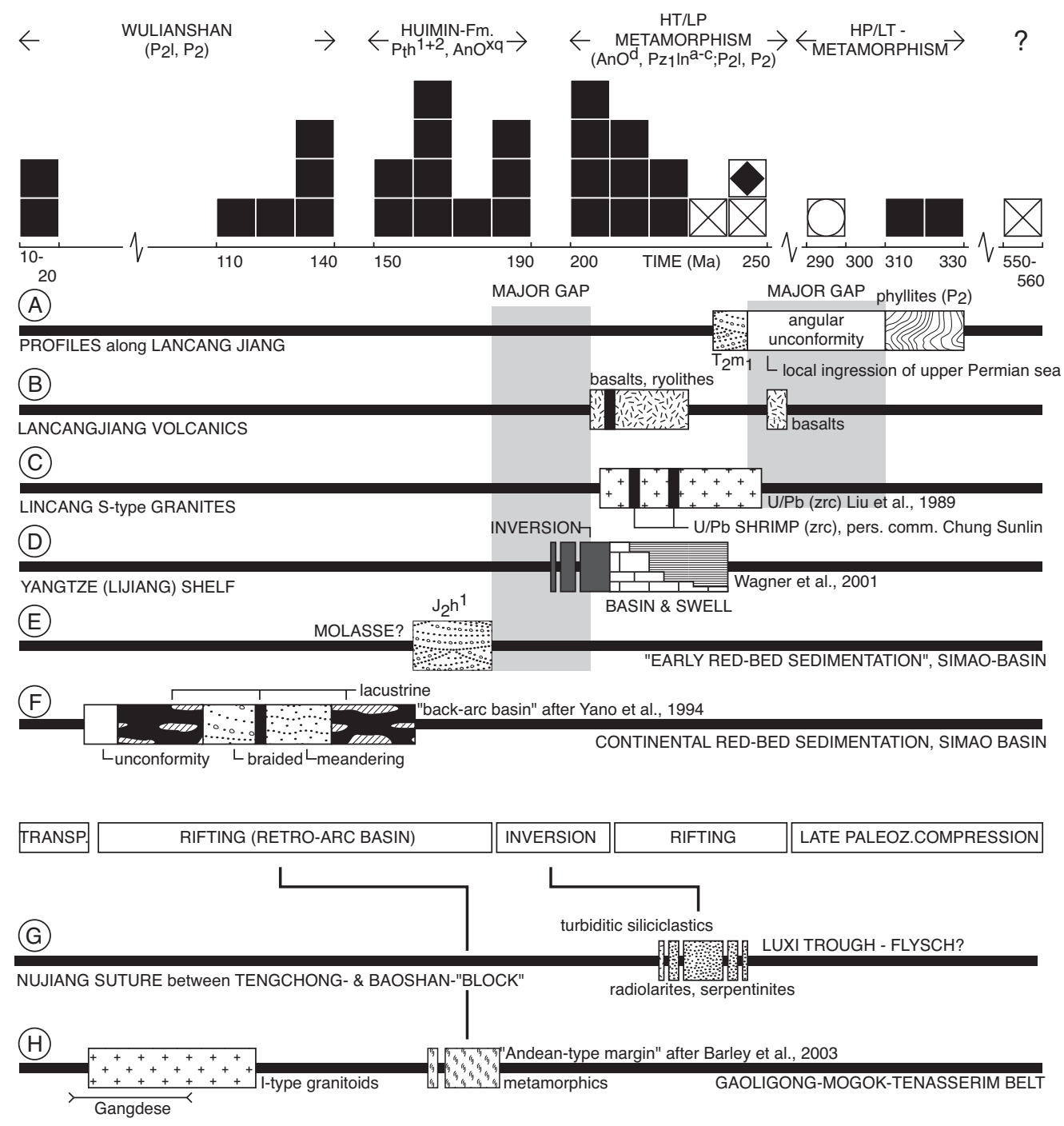

Fig. 3-46: Comparison of the K-Ar geochronological data (histogram on top) with major tectono-stratigraphic, metamorphic and magmatic events along the Lancang River Zone (A to $F$ ) and further to the West $(G$ and $H)$. One box of the histogram is one age - black boxes: K-Ar on mineral fine-fractions, boxes with cross: $\mathrm{K}$-Ar on separated muscovites, box with diamond: $\mathrm{K}-\mathrm{Ar}$ on detrital muscovite and box with circle: Ar-Ar on phengites (cf. Table 3). 


\subsubsection{The Lancang Paired-metamorphic Belts}

Though the occurrence of a pronounced paired-metamorphic belt in southwest Yunnan (Zhang et al., 1993) is a strong argument for the existence of a wide-spanned ocean in the Changning-Menglian Belt (CMB), perceptions developed in our working group are somehow inconsistent with a long-termed island-arc setting in the Lancang River Zone during the Late Paleozoic and Early Mesozoic time. In the following paragraphs a short review and discussion of the arguments for and against a co-genetic high-P/low-T and low-P/high-T belt as being an expression of a Yangtze-vergent subduction zone (Zhong et al., 2000) will be given. Reviewing and discussing the paper by Zhang et al. (1993) there are some facts which cannot be disputed and will not be questioned. The authors are distinguished scholars in their field and therefore the petrological work along with the inferred P/T paths for the two belts are considered as solid facts. Obviously, there are some intricatenesses related to in-depth and unilateral approaches in general, and in west Yunnan particularly being i] the scarce and seemingly unreliable age data presented for the two belts as being co-genetic ii] the poor structural investigations of the two belts available in the early 90 's and iii] the disputable nature and settings of the protolith.

\section{Discussion}

There are apparent inconsistencies and problems that need to be discussed: Firstly, the intrusive bodies of the high-T/low $P$ belt seem to postdate the formation of the blueschist belt violating the fact that paired-metamorphic belts shall be contemporaneous (Miyashiro, 1961, Yardley, 1996).

The assemblage of granitic intrusives, commonly referred to as the Lincang Granite, of the high T/P belt were dated by $\mathrm{Rb}-\mathrm{Sr}$ whole-rock analysis revealing ages between 290 and 279 million years. More reliable $\mathrm{U}-\mathrm{Pb}$ ages on zircons are pointing to younger, Triassic ages between 212 and 254 million years (Liu et al., 1989). A Triassic age will further be supported by ongoing U-Pb-Shrimp studies on the Lincang Granite by Chung Sunlin (University of Taipei, pers. com. 2003). Following the belt to the south, in northern Thailand (Doi Inthanon-Lincang Unit of Chonglakmani et al., 2001), Triassic U-Pb ages are reported by Mickein (1997) for gneisses at Umphang (202 $\pm 3 \mathrm{Ma}$ ), Larn Sang $(197$ +2/-3 Ma, 190 +5/-6 Ma), Mae Sariang (200 +/-3 Ma). Granitoid intrusions being part of the North Thailand Granite Complex show Triassic ages (Cobbing et al., 1986, Mickein, 1997).

For the high-P/low-T belt in Yunnan Zhang et al. (1993) report an Ar-Ar cooling age of 279 million years on crossitic amphiboles. As a single meaningful metamorphic age this result is rather questionable, especially as Zhong et al. (2000) bespeak that the age of 279 million years is in actual fact a selected „step“ within an overall stair case pattern (discordant age spectrum) of the Ar-Ar plots, showing age plateaus at $111 \mathrm{Ma}, 215 \mathrm{Ma}$ and 409 Ma. (cf. Zhong et al., 2000 p. 35, 177, cited from Zhao, 1991). The interpretation of discordant age spectra has been an issue of considerable debate (e.g. Hanson et al., 1975, Foland, 1983, Harrison, 1983). It is now widely accepted that it does not reflect the internal distribution of Ar within mineral grains and is therefore more related to mineralogical heterogeneities, alteration products or minor impurities than to a geological 
event. In this study an attempt to date a typical blueschist form the western Lancang Group by means of the Ar-Ar laser ablation technique (Hodges, 1998) has shown that the potash-content of the glaucophanes (crossites) is too low ( $<0.1 \mathrm{wt} \%)$ to obtain a reliable age (see EMS-Analysis, Table 5 in Appendix). Hence, paragenetic phengites were chosen and obtained a concordant "age spectrum" and a plateau age of $294 \pm 1 \mathrm{Ma}$ (Fig. 3-8). Considering that the closing temperature of amphiboles $\left(450-500^{\circ} \mathrm{C}\right.$; Harrison, $1981)$ is higher than the one for muscovites $\left(350-400^{\circ} \mathrm{C}\right.$; Purdy and Jaeger, 1976), a comparatively older cooling age is expected from the crossites.

In this respect, and in reference to the co-geneity of the belts, it is noteworthy what Yardley (1989) rephrased from Oxburgh and Turcotte (1971): „It follows that when we obtain a date for the „age of high pressure metamorphism“ of old metamorphic rocks formed in a subduction zone setting, what we may be dating is the time at which such a period of steady-state metamorphism ceased, due to changes in plate motions bringing a part of the „conveyor belt" to a stop." cited from Yardley (1996, p.194).

Taking this assumption into account, a change in plate-tectonic motion, or a stop in the evolution of the conveyor belt in the Late Carboniferous, would be inconsistent with the overall convergent regime proposed by Zhang et al. (1993) from the Late Paleozoic (?) to the Late Triassic and against the idea of the Changning-Menglian Belt as being a suture zone of a large Paleo-Tethys (cf. Model B of Chapter 2.1.2.). In spite of these arguments, if the 279 Ma-date from our analysis would indeed document a meaningful age, a change in plate-tectonic processes at that time would have been "surprisingly“ simultaneous with a Late Paleozoic tectono-metamorphic event recorded in the Lancang River area and the western Simao Basin (this study and Feng and Helmcke, 2000). This estimation is corroborated by the new late Carboniferous Ar-Ar age from the phengites (Fig. 3-9).

The protolith of the belts is a matter of debate as well. Though reporting well-bedded flysch deposits from the western Zone (Zone A) of the high-P/low-T belt, Zhang et. al. (1993, cf. Fig. 3-7) presume a passive continental margin protolith. This characterization is somehow puzzling inasmuch as Devonian flysch deposits are generally excluded from passive continental margin sequences, taking an Alpine definition of the term "flysch" into account. Despite the occurrence of flysch-like deposits, the appreciated protolith can be agreed upon and is consistent with perceptions developed further to the east, in the western Simao area (Feng and Helmcke, 2000), and to the south in northern Thailand, where Helmcke et al. (1993) suggested a bathymetrically highly structured continental margin environment for the Upper Devonian / Carboniferous of large parts of northern Thailand. A continuity of certain facies zones or tectono-stratigraphic units was proposed by Chonglakmani et al. (2001) suggesting a regional extent of these zones crossing the boundaries of China, Myanmar, Laos and Thailand (Fig. 2-4). It is interesting to note, that in 1996, Prof. Maruyama and Prof. Liou, who co-authored the publication by Zhang et al. (1993), proposed a genetic classification of the world's blueschist belts, where so-called A- and B-type blueschist belts were related to protoliths of either active continental margin (B-type or Cordilleran) or passive continental margin sequences (A-Type or collisional; Maruyama et al, 1996). Reading the publication, it becomes obvious that the percep- 
tion of the classification scheme was of no influence in 1993. Applying the classification of blueschist belts of Maruyama et al. (1996), the blueschist belt in western Yunnan according to its protolith - would result to be of A-type character, and - as stated in their Table 1, p. 488 - a paired metamorphic belt must be absent. Though I cannot conceive, that the classification scheme developed is applicable to the Sanjiang area, it explicitly excludes a paired-metamorphic belt in the reported depositional environment and thus refutes Zhang et al. (1993)'s earlier appreciation in western Yunnan!

Here, I would like to quote a paragraph from Yardley (1996, p. 194) which illuminates an interesting perspective on high-pressure metamorphism and is somewhat different from Prof. Maruyama and Prof. Liou's perceptions: „Although normal continental crust is too buoyant to be subducted, stretching at continental margins can greatly thin the continental crust. In the Bay of Biscay, the European continental crust thins westward to as little as $6 \mathrm{~km}$; if such thin crust were subsequently to converge with another continent as part of the downgoing plate, it might well be underthrust to considerable depths, where evidence of subduction of continental crust is lacking, blueschists do not necessarily result from subduction of purely oceanic or trench-fill materials, as was implied in the early models of subduction zones; they may still have continental affinities. Forbes, Evans \& Thurston (1984) showed that this was the case for blueschists of the Seward peninsula, Alaska, and argued that the high-pressure metamorphism resulted from overthrusting of unknown material over sediments of continental origin that were already 200 Ma in age."

As pointed out by Zhang et al. (1993), a greenschist-facies overprint was observed from samples of the blueschist belt. Depending on whether this apparently polybaric signature in the blueschist is prograde or retrograde, the observed chloritization is related to the thermal event forming the Lincang Granite intrusions immediately to the east, making the tectonic contact between both zones dispensable. The observation is supported by the fact that style and strike of deformation within the Lancang Group resembles the deformation in the Phyllite Belt along the Lancang River to the east and is mutually recorded as the main deformation phase D1 (Lancang River, Fig. 3-11 and 3-12) and D3 (Lancang Group, Zhong et al. 2000, p. 40). A close relation between the Lincang Granite and greenschist metamorphism in the eastern Lancang Group and western Phyllite Belt has been deduced in the previous chapter and is reflected by the age distribution of the $\mathrm{K}-$ Ar cooling ages.

To sum up the point: If the blueschist belt was overprinted by the thermal event as proposed in earlier chapters, it would violate the requirement of the single units of the paired-metamorphic belt to be isobaric in respect to each other (cf. Yardley, 1996), and conclusively: a co-genetic pair of metamorphic belts must not overprint each other.

Secondly, the architecture of a volcanic-arc setting is a function of the subduction angle and therefore principally controlled by the age and density of the subducted oceanic lithosphere. In almost all arc settings the depth at which dehydration reactions and initial melting begins, is about 100 kilometer or more (i.e. Howell, 1995: p. 42). Though there are considerable variations in dip, areas which are considered to have very steep subduction angles, such as the Northern Mariana arc - being a kind of end-member -, show 
a distance of at least 200 to 250 kilometer (Howell, 1995: his Fig. 2.16) between the trench and the axis of magmatism. Transporting these ideas to southwest Yunnan, a foreland basin of significant width must have been closed without the preservation of any relicts of the fore-arc environment. This is surely possible, but did this really happen and if so, when?

For the time being, there is no sedimentological record of a foreland basin sequence described between the high-P/T and low-P/T belt requiring that basin was completely overthrusted at some time in the Late Paleozoic or Early Mesozoic. Consequently, a complete closure places the high-P/low-T belt on top of the high-T/low-P belt. As field observations have shown, there is no evidence supporting a feature similar to the „Median Tectonic Line“ (Ryoke-/Sambagawa Belt, Japan) between both units. Further, there is neither a publication known to me, where a thrust fault is described nor any geological maps available which depict a continuous reverse fault between the Lancang Group and the Lincang Granite intrusions. To my knowledge, there is no evidence for a reverse fault to the west of the Lincang Granite, but undoubtly, there is a case to make for a normal fault to the west of the Lancang Group (Chapter 3.4.3.).

Thirdly, the S-type character of the coarse-grained peraluminous biotite monzonites

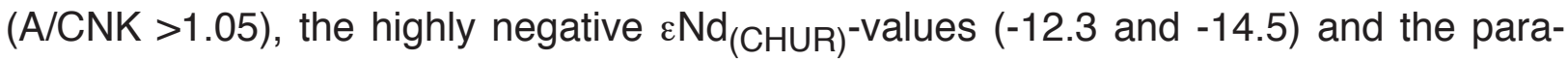
metamorphic, exogenic xenoliths within the granites suggest that the protolith was essentially continental crust without a geochemical signature of mantle origin. Anatexis at mid-crustal levels is further demonstrated by the occurrence of lower-granulite facies rocks and geobarometric investigations that indicate a depth of 12-15 kilometres. Exogenic xenoliths of para-metamorphic nature (biotite, quartz, feldspar, sillimanite, partially cordierite, spinell and sapphire), which are distributed in various sizes (two to 15 centimeters in diameter) throughout the intrusions, show in some cases the same farbric of crenulation cleavage (dominated by biotite) that is recorded in the sericite schists of the Lancang Group of the high-P/low-T belt. Stoping as a principal process in the formation of the xenoliths is possible, though the spots seem to be evenly distributed and can be found almost everywhere the Lincang Granite intrusions crop out. A mid-crustal level is further suggested by observations from Manyan $\left(\mathrm{P}_{\mathrm{t}} \mathrm{h}^{2}\right.$, close to the Burmesian border, Fig. 3-1), where the plutonic body is bordered by leucocratic migmatites and dark massive rocks that might turn out to be restites. This is still rather speculative, but following a small river at km 63 (Rd. Menghai to Manyan) to the North, a gradual decrease from the widely observed typical metamorphic fabric of a megascopic crenulation cleavage to a migmatitic, gneissic fabric can be located. It is obvious that these observation do not speak for a typical contact metamorphism, but for a cross-section through a part of the middle crust that has undergone partial - and possibly - predominantly in-situ(?) melting (cf. Mehnert, 1968, p. 227ff).

A catalysis of the melting processes by adiabatic decompression was nevertheless likely to have taken place as the contemporaneous late-stage bimodal volcanism is undoubtly situated in an extensional setting. Geochemical methods to distinguish between post-orogenic and syn-orogenic, subduction-related plutonism and volcanism are difficult to apply, as Cortesogno et al. (1998), Liew and Hofmann (1988) and Kagami 
et al. (1991) demonstrated for the Late Carboniferous-Permian volcanic sequences of the Variscan orogeny, and Inger (1994) emphasized from examples of the Himalayas and Tibet. Nevertheless, the petrological and geochemical similarity to the Emeishan basalts strongly point to a rift environment for the volcanic suite (Chapter 3.3.2.), and excludes an island-arc setting.

Further, arguments for a post-tectonic setting of the Lancang River bimodal volcanic suite are of structural nature: 1] The volcanism and granite emplacement postdates the main tectono-metamorphic peak, which has been determined to be of Late Paleozoic age (Chapter 3.4 and 3.5.1.). Hence, in respect to the plate-tectonic evolution of the Lancang River Zone, the magmatism must be considered as post-orogenic, since the orogenic activity terminated in the Middle Permian. 2] If the middle Triassic suite was caused by a new syn-orogenic event, unrelated to the Late Paleozoic orogeny, but to the subduction of the Changning Menglian Belt until the Late Triassic, one must expect a significant structural overprint of the Lancang River Zone such as a pervasive deformation of the Lincang Granites. 3] The Middle Jurassic molasse deposits do not show any metamorphic and almost no granitic pebbles shedding light on the exposed source area at that time. 4) There are observations that the Triassic volcanism is intercalated with shallow marine carbonates, which makes an elevated Triassic continental island arc or elevated mountain-belt unlikely. (slumping structures and flakes of pyroclastics / ignimbrites? in carbonates $\mathrm{T}_{3} \mathrm{x} / \mathrm{T}_{3} \mathrm{~b}, \mathrm{~km} 2784 \mathrm{Rd}$. Lincang to Yongping).

Due to the above arguments it can be concluded that the Lancang paired-metamorphic belts were formed by two temporally separate but spatially overlapping events: The Late Carboniferous high-P/low-T belt is related to an east-vergent, Late Paleozoic thrustbelt inverting a Devonian to Carboniferous marginal basin of the Yangtze-Platform. The Upper Permian and Triassic low-P/T belt is caused by a post-orogenic stage of rifting with a distinct similarity to the Emeishan Large Igneous Province. This conclusion has far-reaching consequences on hitherto established plate tectonic models: It implies that no active continental margin accounts for the subduction of the Paleotethys presently believed to be recorded along the Lancang River (Model B - Two-Tethys Ocean Model) or in the Changning-Menglian Belt (Model B: "Archipelagic Ocean Model").

Are there other analogues or other paired-metamorphic belts that are good candidates for a non-co-geneity? As a matter of fact, there are. Recent research in the Variscan belt of Europe (O'Brien, 2000) and even new data from the classical Sambagawa/Ryoke belts of Japan (Brown and Nakajima, 1994, Brown, 1996) support the validity of the above argumentation and show that perceptions on the evolution of even the most „distinguished“ paired-metamorphic belts are changing: „In some older metamorphic belts, high and low pressure facies series may occur, but sometimes the low pressure facies series metamorphism has been superimposed during an evolution of the metamorphic belt that involved an earlier high pressure facies series metamorphism. Thus, the metamorphisms are temporally separate but spatially overlapping, in contrast to paired metamorphic belts where the metamorphisms are regarded as synchronous and spatially adjacent." (Brown and O'Brien, 1997, p. 219). Further, it is interesting to note that Spear (1993) discusses a similar distribution of metamorphic facies for the 
Acadian terrane in New England, USA. Here, a clockwise up to $1 \mathrm{GPa}$ Barrovian P-T-t path is documented to the west of a low-pressure $(0.5 \mathrm{Gpa})$ Buchan counter-clockwise $\mathrm{P}$-T-t path. This peculiarity is not interpreted to document a paired-metamorphic belt, but is attributed to the difference in tectonic setting. For its clarity, I will cite Winter (2001, p. 511) because his description of the Acadian terrane is so strikingly similar to the situation, which I can observe along the Lancang River Zone: "The clockwise path in the west is typical for crustal thickening followed by erosion and cooling. The eastern zone is riddled with numerous synmetamorphic plutons, perhaps because of crustal extension and upwelling mantle, supplying sufficient heat to partially melt the lower crust." But, and this is the decisive difference to Yunnan, the Buchan metamorphism predates the Barrovian metamorphism. Spear (1993, p. 753) writes: "The Buchan metamorphism is early and formed in an extensional basin aided by the emplacement of magmas. The Barrovian metamorphism was late and likely resulted from the emplacement of the Buchan terrane on top of the Connecticut Valley Synclinorium.". Though the features in New England and Yunnan are similar, timing was different!

To account for this difference, it can be concluded that there are (at least) three ways of forming a "paired-metamorphic belt"-like tectonic setting: A] The well-known Sangabawa/Ryoke type belt of Japan, where the high-pressure terrane forms early and the low-pressure terrane forms later as the island arc develops. B) The Acadian-type belt, where the low-pressure terrane forms prior to the formation and juxtaposition of the low-T/P-belt; and C) The Yunnan-type, where the low-P/T belt predates the formation of a rift-related high-T/P belt.

This tectonic setting can, but needs not be related to subduction on both local or large scale. It shall be stressed, that as far as the Lancang River Zone is concerned, the existence of a thermal flux that was subduction-related cannot be ruled out. But the existence of a mature island arc displaying its unique geochemical features can be ruled out. - To account for the above situation, several models, such as flat-slab subduction, crustal delamination, slab-break-off, and slab-window formation are possible plate tectonic scenarios. But bearing in mind that the exploration of the region is still in its infancy and the research of this thesis is restricted to a rather limited area, a preference to any of these models will not be given.

So, why do these belts turn out to be discrete and temporally different events of metamorphism and why were scientist not aware of this issue? I presume it is tightly knotted to the way we deal with and define the term terrane. In the following chapter I will try to convey my ideas. 


\subsubsection{A Note on Terrane Analysis}

The definition of a terrane as being a distinctive tectono-stratigraphic unit is widely appreciated (Howell, 1995). In the light of plate tectonics one must be well aware that the term is not necessarily restricted to a continental fragment that has been accreted to a plate margin. As Monger and Nokleberg (1995) demonstrated for the Canadian Cordillera, a terrane will also form - and this is only one from several other examples when a collage of micro-continents, island-arcs and accretionary wedges becomes overprinted by a new continental island-arc that is related to a subduction zone much farther away. The influenced area, exhibiting magmatism and a thermal overprint, forms a distinctive new disparate terrane within the former collage of fragments.

A terrane or tectono-stratigraphic unit, as I understand it, is the sum of all sedimentary, tectonic and magmatic processes that account for being characteristic of a confined, fault-bounded area. Hence, it is a vague, purely descriptive, static and three-dimensional term, which must not be related to dynamic processes of plate tectonics a priori. Monger and Nokleberg (1995, p. 1133) are well aware of this issue: „The fragments, which form most of the North American suspect terranes, were accreted to the North American craton during early Jurassic (...)." All processes that result in the formation of a terrane, whether it is suspect, exotic or indigenous, when dissolved in space and time, will lead to the perception of how the area was formed and how it interacted with neighbouring units. This is the dynamic approach of plate tectonics in as much as terranes will be identified as accretionary prisms, island arcs, micro-continents, nappes, and so on (confer to further criticism in Sengör and Dewey, 1990).

If dynamic or kinematic processes are described by using the term terrane, it is a major flaw in the perception of the concept of terrane analysis and plate tectonics as well: a continental fragment can drift, rift and accrete, a terrane cannot! The Simao-Block can be regarded as a terrane, but cannot be regarded as a single micro-continent! Paleomagnetic interpretations considering the area between the Lancang River and the Red River treat the Simao Region as a single block or crustal fragment that rifts, drifts and accretes. I presume this is a misconception to do, if one resolves the history of the Simao-Region in space and time (see previous chapters).

The word „terrane“ is clearly used as a non-process-orientated and non-plate tectonic term. Therefore, it is prone to obliterating solutions of various different plate tectonic configurations in space and time. Terrane analysis - in my opinion - is an approach to the theory of plate tectonics and is a straightforward tool to understand it. Its success will entirely depend on the individual's perception of the geological history of the region. In this respect, I would like to quote two statements. The first one is from D.G. Howell (1995) saying: „Enumerating terranes is not as important as the concept that evokes terranes." and, the second one is by N. Humphrey (1992): „... the mere fact that naming something tends to give definiteness to our conception of it, can cut both ways. Once we have a word for something it is easy to suppose ipso facto the thing named is a distinctive entity."

The implementation of the terrane concept of the Canadian/American Cordillera in 
Western Yunnan, which has been so conceptual and stimulating over the last two decades, finally masks the mutual interplay and the interdependency of the proposed „blocks", „massifs" and "terranes " in space and especially in time. This makes the development of an agreeable regional plate-tectonic model a difficult task. It is not the concept by itself that is misleading, it is the wrong plate-tectonic perceptions it has falsely aroused.

Abandoning the hybrid perception of the "blocky" terrane concept in Yunnan is rewarding. For example, the decrease in metamorphic grade from the western side of the Lincang Granite to the eastern part of the Simao Region relates the blueschist-belt (D3 of Zhang et al. 2000, p. 40), the qtz-phyllite belt (D1 of Fig. 3-12: Stereonet 1-7 and Fig. 3-33 and 3-34), the phyllite belt and the folded but unmetamorphosed sequences of the Western Simao basin to a single, large-scale, co-genetic accretionary assemblage. The large-scale wedge-shaped body, with all its stratigraphic and tectonic irregularities, is likely to be an expression of a Late Paleozoic west-dipping A- or B-type subduction zone consuming an Upper Devonian to upper Middle Permian highly structured marginal basin within the widely extended margin of the South China plate. The style of deformation in the wider area of the Lancang River in southwest Yunnan can best be described by Late Paleozoic wedge- and ramp tectonics of upper crustal levels, where continental and possibly oceanic fragments of various sizes of the extended margin become offscraped and incorporated. Hence, here is no need to distinguish between a Lincang or Simao Block. 


\subsubsection{Mountain Building Processes}

Plate tectonic processes in the Late Paleozoic belt can certainly be approximated by Oxburgh and Turcotte (1971) and Sengör and Okurogullari (1991), who both stress the role of accretionary complexes in the growth of continents. Further, and in relation to the Indosinian evolution, one has to mention the Russian „activation concept“ of Staritzkiy et al. (1973), which is on par with the Chinese DIWA-Concept of Chen (2000, recently published in English). Though the ideas of Staritzkiy et al. (1973) were affected by a different global tectonic concept, they describe the stage of the "Indosinian orogeny" as being an expression of crustal movements along deep-seated fractures in the Earth's crust, along which ,previously elevated areas have subsided and previously depressed blocks risen“. This is a "geosynclinist's“ way of saying that the deformation observed is „intracontinental“ or even „within-plate“. Though old-fashioned terminology is used, I am - for the sake of its descriptive quality - willing to cite the phenomenological treatment of Staritzkiy et al. (1973):

„One of the most characteristic features of the Paleozoic geosynclinal cycle not only in the region under consideration, but over the whole peninsula of Indochina, is the lack of a clearly defined orogenic stage, so that the geosynclinal regime ends in a stage of tectonic quiescence. (...) The beginning of the Mesozoic was marked by the onset of the next qualitatively different tectonomagmatic epoch of development of North Vietnam the process of tectonic activation (Diwa), encompassing the Paleozoic folded region of Western Vietnam and the South China platform. (...) By tectonic activation is meant the intensive folded-block movements of considerable extent, even commensurate with geosynclinal contrast, occurring on a rigid basement within regions that have ended their geosynclinal development and have a crust of continental structure (regions of completed folding and platforms). The characteristic features of tectonic activation are: the lack of a geosynclinal stage, a different succession of magmatism and sediment distinct from that of geosynclines and platforms; considerable fluctuations in the thicknesses and composition of the sediments formed, not also across but also along the strikes of the structures; and near surface injections and effusion of magmatic rocks of sharply different petrographic and chemical composition, often localized in one structural formational zone."

Unlike the pre-plate tectonic treatment of Staritzkiy et al. (1973), a modern model, which offers an explanation for the observed variations between a Late Paleozoic and Triassic/Jurassic phase of mountain-building and the interplay of convergence and divergence can be learned from Royden (1993) and especially Royden and Burchfiel (1989), who discuss plate-boundary conditions in the Mediterranean. Their ideas convey a broader view, which assigned to the regional plate-tectonic scenario of Southeast Asia (Helmcke et al., 1993), may give an insight into how these variations are inter-connected with each other. In their view, thrust-belt systems developed at continental subduction boundaries comprise two groups, predominantly differentiated by the presence (i.e. Carpathians) or absence (i.e. Western Alps) of contemporaneous back-arc / retro-arc extension and are casually linked to an advancing or retreating subduction boundary. In the case where the overall convergence is less than the rate of subduction, the transmit- 
ted stress is small and causes a mass excess on the oceanward-side of the retreating slab and a mass deficiency in the overriding plate. This disequilibrium desires to be balanced by a flow of asthenospheric material from the overriding plate towards the slab. The tectonic expression of the retreating subduction boundary in the overriding plate is dominant extension causing a low topography, little erosion, little to no involvement of crystalline basement, a protracted history of flysch sedimentation and rift-, retro-arc- or back-arc-basin formation. In the case where the overall convergence is greater than the rate of subduction, the transmitted stress across the plate-boundary is large, and regional compressive deformation will occur, leading to intense deformation down to midcrustal depth, uplift, high topography and the exposition of metamorphic rocks causing a protracted phase of molasse deposition.

The cyclic repetition of these stages appears to be a characteristic feature of active continental margin orogens (cf. other so-called Cordilleras: Dewey and Lamb, 1996 (Andes) or Monger and Nokleberg, 1995 (Canadian- and US-Cordillera). Research over the next decade will reveal whether the "Two-Tethys-" and "Archipelagic Ocean Model" in Southeast Asia have been overemphasized, and if so, how these perceptions can be incorporated into the Cordilleran view.

Finally, if one accepts this two-fold cyclic behavior, it is interesting to note that continental thickening does not inevitably mean a dramatic initial vertical surface uplift of the mountain in respect to sea-level. Richardson and England (1979) point out, that though intensive crustal thickening occurs, an extensive immediate or significant contemporaneous surface uplift will not occur: „The burial of these rocks by a rapid overthrust mass increases the pressure instantaneously but, owing to the thermal inertia of the rocks, the consequent increase of temperature is sluggish. If the increase in pressure is sufficient, the lower unit may wholly or partly be subjected to eclogite facies conditions in which plagioclase will become unstable due to the reactions, for example: 1) albite in plagioclase $\rightarrow$ jadeite in $\mathrm{cpx}+\mathrm{qtz}, \Delta \mathrm{p}=+17 \%$ 2) anorthite in plagioclase + opx $->\mathrm{cps}+$ kyanite, $\Delta p=+16.7 \%$ 3) anorthite in plagioclase + cpx $->$ MgCa2-garnet + qtz, $\Delta p=+13.7 \%$ “ Further, they point out: „If hydration of the lower crust takes place following overthrusting, the resulting eclogites may be zoisite and glaucophane-bearing; the increase in density remains similar to that in the anhydrous case.“, and they finally conclude: „Rapid thickening of continental crust may move lower crustal material from granulite to eclogite facies, thus greatly reducing its buoyancy; as a result the surface height, even of greatly thickened continental crust, may be close to, or below, sea level." Due to the thermal inertia of the rocks, regional uplift will be interrupted and delayed until the eclogitic part of the crust becomes re-equilibrated or detached. Timing of these events are certainly disputable. Taken the Late Paleozoic orogeny in Yunnan and the late Triassic phase of "deformation“ into account, one might grasp the widely observed difference in a) the structural deformation of the crust (orogeny) and b) the pure surface elevation or relative uplift of the crust/lithosphere.

It is reasonable to speculate, that the Indosinian orogeny in southwest Yunnan is likely to reflect a thermal event that lead to a widespread and moderate surface uplift and is - primarily - related to a change in the bulk density of the crust/lithosphere and thus in 
buoyancy. The perturbed and unstable thermal status of the middle/lower crust and its increase in density was (pre-)arranged by the restoration / re-assembly of the disrupted continental margin with its indigenous continental fragments by a Late Paleozoic orogeny. The exact processes, which resulted in the change of buoyancy remain essentially uncertain, but cases can be made according to various plate-tectonic models following Richardson and England, 1979; Dewey et al., 1993 (eclogite transition and equilibration); Bird, 1979, Houseman et al., 1981, (lithospheric thinning and continental delamination of the eclogitic lower crust); McKenzie, 1978, White and McKenzie, 1989 (lithospheric stretching at rift zones); Hill et al., 1992 (lithospheric thinning by mantle plumes) or Davies and von Blanckenburg, 1995 (slab break-up).

I would like to point out that the widely documented Late Triassic/Early Jurassic unconformity throughout the Doi Inthanon-Lincang Unit - and presumably of bordering areas might basically be unrelated to a continent-continent collision as presently accepted to be the standard model (Metcalfe 1999, 2002, Sengör, 1979, 1985, Hutchison,1989) of the area. From areas disccussed in this thesis, there is concurrent evidence that the missing sediments are merely a feature of surface uplift caused by a) an increasing buoyancy of a thermally re-equilibrating lithosphere (decay of cool lithospheric thermal anomalies) or b) replacement of lithospheric by asthenospheric mantle. In the field, these processes are essentially expressed by Late Triassic/Early Jurassic extension, volcanism, uplift and erosion. Finally, the docking of the Tengchong micro-continent in late Triassic times onto the Cordillera resulted in a weak inversion of the Lancang River Zone and an end in volcanic activity. 


\subsection{Summary of the New Geodynamic Model and Mineral Deposit Potential}

\subsubsection{Devonian - Lower Carboniferous Marginal Basin Evolution (Fig. 3-47, A)}

Stratigraphic analysis has revealed that a near-shore continental rift or back-arc basin with strong bathymetric variation must have existed from the Upper Devonian to the middle Lower Permian along the present Lancang River Zone. The extension phase, which led to the creation of the basin, is related in time and facies to the expanding continental margin of the Yangtze Platform in the Devonian and Lower Carboniferous. During the rifting phase, basic to acid volcanic rocks were extruded in a submarine environment to form small-scale Kuroko-type volcanogenic massive sulfide (VHMS) deposits in a dynamic hydrothermal system. Dapingzhang is a deposit of this type and together with other VHMS deposits such as Sandashan, Yinzishan and a small, abandoned massive sulfide deposit in the vicinity of Xincun forms a belt along the Lancang River. The Dapingzhang VHMS-deposit is being investigated by Prof. B. Lehmann and cand. Geol. R. Artmann from the Technical University of Clausthal, Germany. A concise geochemical and petrological treatment of the evolution of the VHMS-deposits of Dapingzhang and Sandaoshan will soon be published (Lehmann et al., 2004, in preparation). Geochemical analyses of the volcanic rocks favor a continental back-arc setting.

3.6.2. Late Paleozoic Accretionary Wedge Tectonics - "Eo"- or "Pre" Indosinian Stage of High-P/T Metamorphism (Fig. 3-47, B and C)

Characterized by an eastward progressing deformation front, closure of the basin began in the Upper Carboniferous and progressed from the present west to east. This closure was associated with the formation of an accretionary wedge on the west side, in which the volcanogenic massive sulfide deposits were sheared. The stockworks of the Dapingzhang and Sandaoshan deposits are strongly tectonized and lie within the zone of the weakly- or unmetamorphosed accretionary wedge. From this belt to the present east, the deformation increases parallel to the gradual change from greenschist (Phyllite Belt) to lower-blueschist facies (Lancang Group). The closure of the basin led to the exhumation of the blueschist- and greenschist-metamorphosed rocks and the formation of a land area on the western edge of the Yangtze Platform up to the Middle Permian. The mineral potential related to this stage is estimated to be low. However, Kerrich (1999) underlines that 95 percent of all vein-type Au-deposits mined globally occur in greenschist facies rocks related to channelling of hot fluids into shear zone faults (cf. Kerrich 1999, his figure on p. 2101). Potential sites for this type of deposit are restricted to areas, where temperatures between $300-400^{\circ} \mathrm{C}$ were reached (cf. Fig 3-42). From petrological investigations (Zhang et al., 1993), a small stripe to the west of the Lincang Granite (cf. Lancang Group, Chapter Fig. 3-43) complies with these requirements.

3.6.3. Upper Permian-Triassic Post-collisional Rifting - Indosinian Stage of High-T/P Metamorphism (Fig 3-47, D-E)

Late Paleozoic orogenesis was followed by marine ingressions, post-orogenic bimodal rift volcanism and continental sedimentation. The volcanism is an expression of a regional thermal event causing crustal anatexis and the formation of the Lincang Granite. The petrology and geochemistry of the basalts along the Lancang River are identical to the 

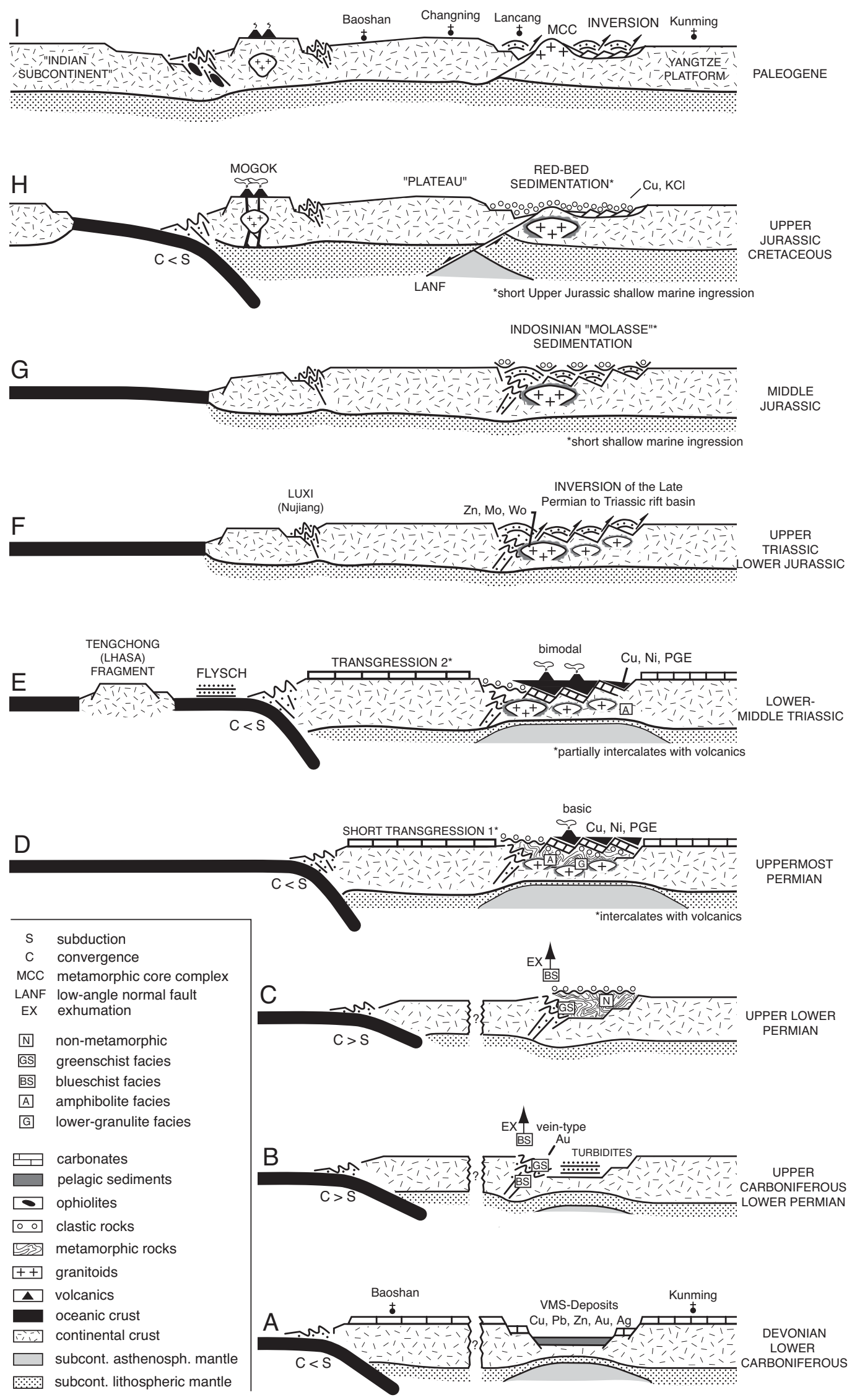

Fig. 3-47: Cartoon depicting the plate tectonic evolution of the Lancang River Zone in southwestern Yunnan. Left out (see question mark) is the evolution of the ChangningMenglian Belt, which geotectonic setting is discussed as a rift or major ocean of the Paleotethys (see Chapter 2.2.4). $\mathrm{C}<\mathrm{S}$ causes extension and $\mathrm{C}>\mathrm{S}$ causes compression along the Lancang River Zone. 
continental flood basalts of the Emeishan Large Igneous Province (LIP), which are proposed to be mantle plume related (Xu et al., 2001, Chung, 1998). Other conceivable models that account for the observed features can be made according to Richardson and England, 1979; Dewey et al., 1993 (eclogite transition and equilibration); Bird, 1979, Houseman et al., 1981, (lithospheric thinning and continental delamination of the eclogitic lower crust); McKenzie, 1978, White and McKenzie, 1989 (lithospheric stretching at rift zones).

A success for the new plate tectonic model is the re-evaluation of the mineral potential between the Permian and the Triassic. The new results exclude a Mesozoic islandarc setting and expectations of finding large scale Au-bearing porphyry copper deposits cannot be met. Nevertheless, a close correlation between the volcanic rocks along the Lancang River and the Emeishan flood basalts (and rhyolites) opens up a new perspective: Ore deposits in relation to large-scale or so-called "failed" continental rifting, such as 1] native $\mathrm{Cu}$ deposits of Keweenaw type (Keweenaw rift, Precambrian, Superior Province, Canada); 2] Ni-Cu, PGE deposits of Norilsk-Talnakh type (Siberian Traps at the Permian/Triassic boundary. cf. Naldrett, 1999; Naldrett and Lightfoot, 1999); The Norilsk-Talnakh-type deposits are mentioned here because the plate tectonic setting of the Siberian Traps at the northern margin of the Siberian Craton has analogies with West Yunnan. The basalts making up the Siberian Traps were extruded like the Emeishan flood basalts at the Permian/Triassic boundary and are similarly associated with the break-up of Pangea. In addition, the rifting, which is associated with the extrusion of continental flood basalts, occurs at the margins of a craton with a similar plate tectonic history to Yunnan (cf. Lightfoot et al., 1990 and Zonenshain, 1990; Naldrett, 1999 and Naldrett and Lightfoot, 1999). 3] Volcanic red-bed Cu-deposits, e.g. Wenyu, Guanfang, Longbohe (see Helmcke and Wagner, 2001, p. 20ff). For an in-depth treatment of other mineral deposits see also Pirajno (2000).

In fact, recent developments in the Emeishan area do support the view that the above mentioned types of deposits represent a realistic potential: 1] A copper deposit of Keweenaw-type has recently been described by the Yunnan Bureau of Geology and Mineral Resources, Kunming (Zhu et al., 2003). The deposit lies outside of our area of investigation at the border to Sichuan and is associated with the Emeishan flood basalts (Fig. 3-31 and 3-48). 2] Song et al. (2003) report on Ni-Cu-(PGE) magmatic sulfide deposits in mafic to ultramafic sills from the Emeishan igneous province to the south of Danba. Though these sulfide deposit were discovered by the Bureau in the 1970's, the relation to the Late Permian basalts of the Dashibao Formation (Emeishan flood basalts, Song et al., 2001; Zhou et al., 2002) was only recently documented (Song et al., 2003). 3] An increased interest in the Late Permian/Triassic volcanic rocks is documented by a contract of work that was signed by the Yunnan Geology and Mineral Resources Co., Ltd. and Southwestern Resources Corp., Canada. The exploration licence of Southwestern Resources Corp. covers part of the Emeishan area and concentrates on a zone in which the Emeishan basalts are eroded and the underlying co-magmatic gabbros are exposed.

In this respect, the southern and central Lancang River Zone has been undervalued 


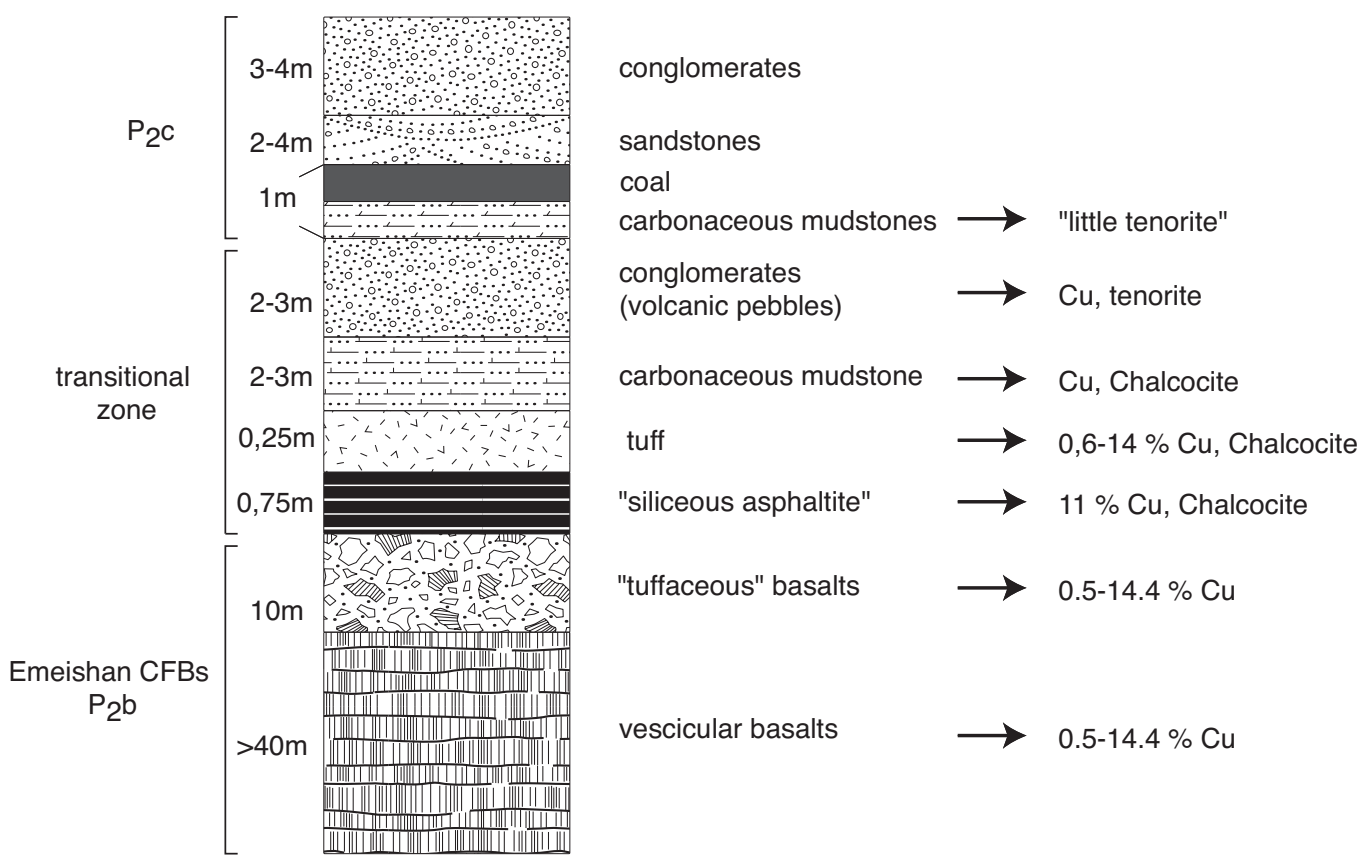

Fig. 3-48: Compiled lithological profile and related mineralization of the newly discovered Keweena-type native Cu-deposit from the Northeast of Yunnan (all data after Zhu et al., 2003). Rock types are literally translated from the Chinese language.

and the relation to the Emeishan Large Igneous Province has not been recognized. Further, and this makes the zone more prospective than the Emeishan area, it exposes deeper levels of the crust. For this reason, the gabbro-peridotite sequences occurring along the Lancang River (e.g. Banpo), which may have been falsely interpreted as ophiolites, should be the focus of future work. These may in fact be mafic intrusions or magmatic feeder conduits (Naldrett et al., 1995), which occur alongside Permo-Triassic basalts in the rift zones. The calculated $\mathrm{T}_{(\mathrm{DM})}$ model age of the Banpo "peridotite" (02/131) plots in the same range of model ages as the Triassic basalts (Fig. 3-20). The gabbro (02/135) has a higher model age. The dates determined so far are still rather contradictory. In addition, the Permo-Triassic basalts reveal low concentrations of $\mathrm{Ni}$, $\mathrm{Cu}$ and $\mathrm{Cr}$ (Fig. 3-48) in comparison to normal MOR basalts and in relation to the Emeishan basalts. This raises the question of whether the low concentrations of $\mathrm{Ni}$ and $\mathrm{Cu}$ are attributable to sulfide differentiation. Although the gabbro at Banpo does not show an abnormal enrichment in $\mathrm{Ni}, \mathrm{Cu}$ and $\mathrm{Cr}$, what is the situation with the other gabbros in the region? How high are the threshold values of the platinum-group elements in these gabbros? Systematic sampling is proposed for the gabbros along the Lancang River Zone, in the transition to the Changning Menglian Belt and in the eastern part of the Simao Basin.

The mineral deposit potential of the Lincang Granite has already been shortly addressed in Chapter 3.3.1., and the intrusions were assigned to the tin granites of the Main Range in Southeast Asia. Some economically less significant wolfram mineralization and polymetallic $\mathrm{Pb}-\mathrm{Zn}-\mathrm{Ag}$ veins are known which are associated with Himalayan deformation along the NNW-SSE striking strike-slip faults (cf. Nan Jiao He deposit in Helmcke and Wagner, 2001). However, the geochemical analyses of the Lincang Granite (01/161, 02/067, 01/160a, B56, B98, B99-2) do not show a significant enrichment in Sn, 


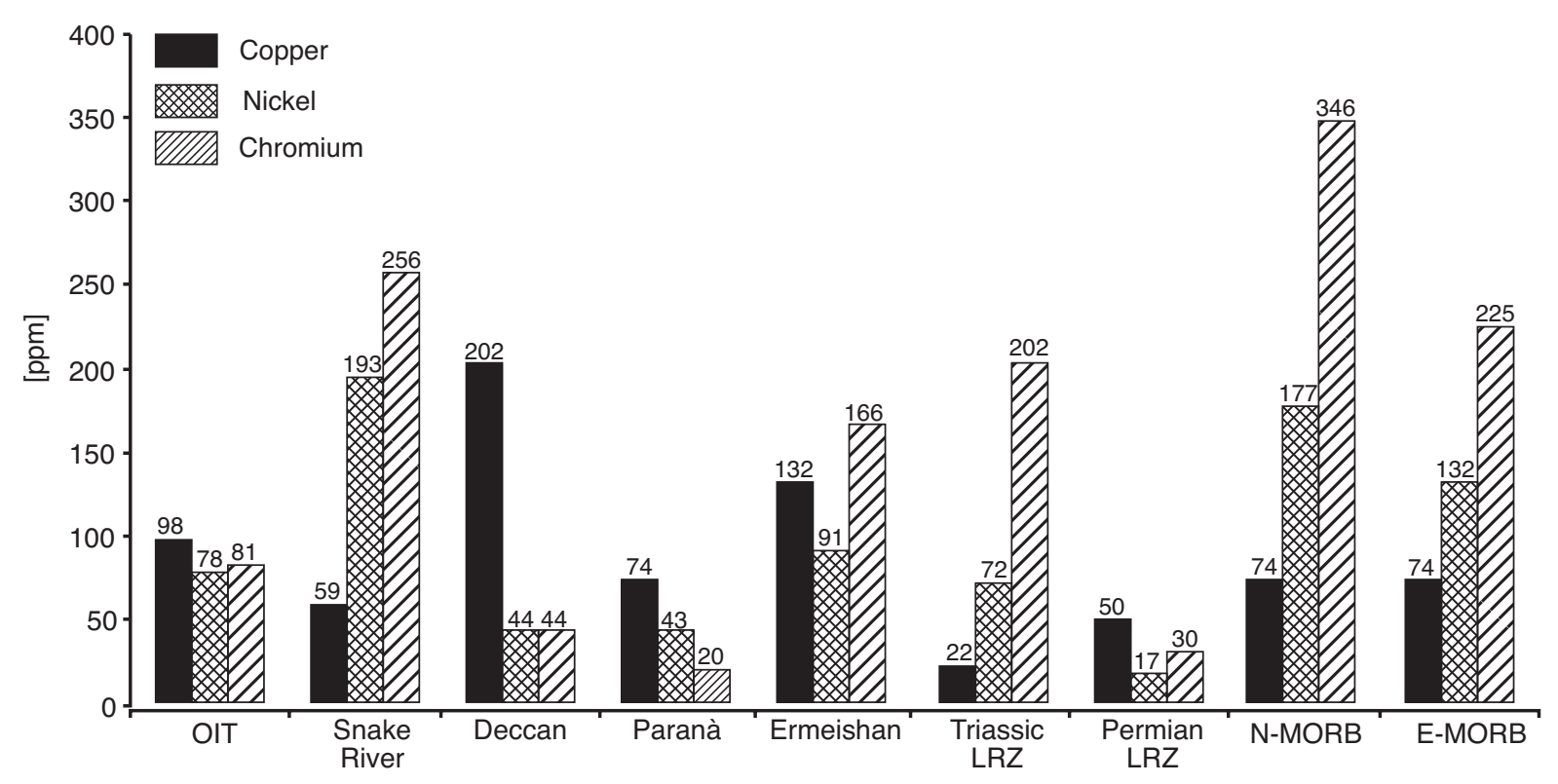

Fig. 3-49: Mean values for $\mathrm{Cr}, \mathrm{Ni}$, and $\mathrm{Cu}$ of Upper Permian and Triassic basaltic rocks along the Lancang River Zone (LRZ, $n=7$ ) compared to typical values of continental flood basalts from Ermeishan (Xu et al., 2001), Snake River, Deccan and Paranà (Thompson et al., 1983). Also shown are typical values for ocean-island tholeiite (OIT, Thompson et al., 1984), enriched-MORB and normal-MORB (Humphris et al., 1985).

W and Mo. Though the Lincang Granite has the chemistry of a prospective tin granite (Fig. 3-50), the similarity to the North Thai Granite Province discourages a high mineral potential. As outlined by Cobbing et al. (1997), the granites of the Northern Thai province are of minor economic importance and include endogeneous vein and skarn replacement scheelite- and fluorite deposits with minor tin and local antimony. There are no major alluvial tin fields. Au-bearing porphyry Cu-deposits in relation to the Lincang Granite can be further excluded.

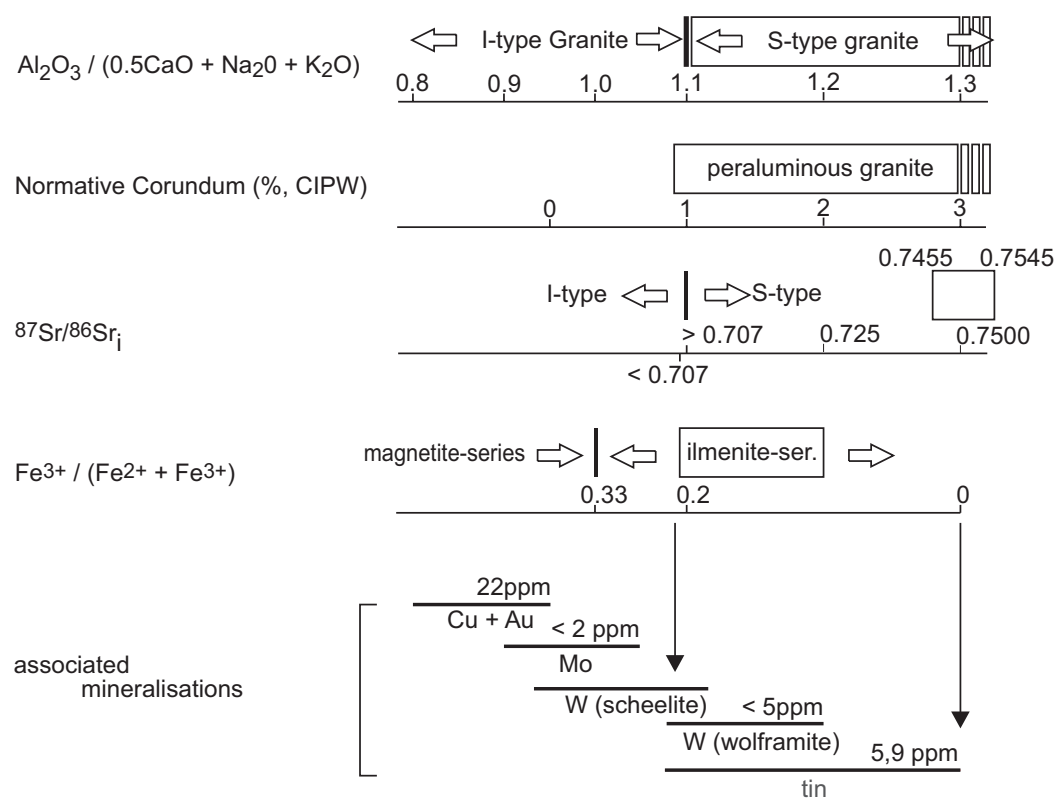

Fig. 3-50: Mineral potential of the Lincang Granites following a classification scheme by Ohmoto (1986). The presented values are average values determined from Table 8. 


\subsubsection{Late Triassic-Early Jurassic Basin Inversion (Fig 3-47, F)}

Weak compression and basin inversion took place beginning in the Upper Triassic along the Lancang River Zone. The cause of this compression is unclear but could be associated with the collision of the Tengchong micro-continent. No mineralizations are known to me, which are related to this event along the Lancang River Zone occurring between the Upper Triassic and Middle Jurassic.

3.6.5. Late Jurassic to Paleogene MCC Evolution and Basin Formation (Fig 3-47, $\mathrm{G}, \mathrm{H}, \mathrm{I})$

A regional extensional phase took place in the area from the Upper Jurassic to the Paleogene, and the exhumation of the Lincang metamorphic core complex controlled the deposition of massive sequences of continental red-beds in the Simao region. The geometry of the basin can best be explained by a retreating plate boundary to the west of the Tenasserim-Mogok belt causing extension and the formation of a retro-arc basin in the hinterland. Extension was accommodated along predisposed anisotropies of the Late Paleozoic accretionary wedge and led to the formation of a west-dipping low-angle normal fault, where progressively cool lithospheric mantle material was replaced by hot asthenospheric mantle causing a plateau-like uplift to the east of the Doi-InthanonLicang unit (Min et al., 2001) and a depression in the Yunxian-Lanpang unit. This perception is in line with the simple shear model of basin formation (Wernicke, 1982) and gives an explanation for the mechanics of low-angle normal faults. In contrast to Yano et al. (1994), who relates the source of the continental red-beds to the emplacement of granites in the Mogok-Tenasserim Belt, I regard the depositional features to be locally controlled by the exhumation of the Doi-Inthanon Lincang Unit and the Lincang Granite. In relation to this stage sediment-hosted stratiform copper or red- bed Cu-deposits evolved and are summarized in Helmcke and Wagner (2001, p. 25).

\subsubsection{Himalayan Adjustment}

If the mechanics forming the Simao Basin are fundamentally correct, the local consequence for western Yunnan is that a Middle Cenozoic inversion of the Simao Basin must have been largely accommodated by the readjustment of allochthons (former extensional allochthons, see sub-point [7] - I in chapter 3.4.3.), which progressively lead to a complex interplay of thrusting, folding, faulting and rotation. That the Middle Cenozoic deformation within the Simao Basin was rather complex is supported by the fact that a consistent vergence of the structures (Wang and Burchfiel, 1997, p. 207) or a penetrative cleavage is lacking (see Leloup et al., 1995, their Fig. 4). According to Wagner (2003) this phase is most important when estimating the mineral potential of West Yunnan. During this period a whole spectrum of mineralization developed as a result of the high fluid flow in the transtensional settings of the India/Asia collision in West Yunnan. Copper and Au-porphyries occur in addition to polymetallic vein mineralization and Au-quartz veins. 


\section{Acknowledgements}

This thesis would not exist but for the support and assistance of many individuals and organizations. Adequately acknowledging all of my colleagues, friends and "xin pengyoumen" from China is a difficult task. But, in any case I am very much indebted to Prof. Dr. Dietrich Helmcke, who provided me with the opportunity to work on an integrated multidisciplinary topic in China. It has been a difficult venture to integrate the results of rather diverse disciplines such as metamorphic petrology, geochemistry, ore-deposit geology, sedimentology and paleontology, and indeed, today, this approach appears to be against the main stream in earth sciences. Regardless of the rapid change to quantification and mathematical modelling, in my personal experience, the last three years have been a real delight, a journey through various schools of geological and philosophical thought. It is this utmost sense of delight, of which I am so grateful to Prof. Helmcke. A few months ago, it was a shock to learn that he had caught a serious illness on a field trip to northern Thailand and China. After fighting for weeks, he passed away on April 1st, 2004.

Furthermore, I would like to acknowledge Prof. Dr. Bernd Lehmann (Clausthal University) and Prof. Dr. Dietrich Bannert (former Bundesanstalt für Geowissenschaften und Rohstoffe (BGR), Hannover, and Marburg University), who both - not only in the field of geology - have exerted a continous influence on me. Prof. Bannert infected me with the virus of working in Southeast Asia and China in as early as the 90's, and encouraged me to leave Münster for Göttingen - a move I never regretted. Prof. Lehmann advised and stimulated me on various parts of my thesis, and finally became my new supervisor.

Starting with the perception of doing field-orientated analysis to solve the evolution of the Lancang River Zone, more and more analytical techniques were necessary to obtain a better picture. Due to a rather limited amount of money for laboratory work, I am very much indebted to colleagues at Göttingen University. Hence, I gratefully acknowledge the technical support by Dr. K. Wemmer, Dr. S. Pawlig, Prof. Dr. H. Ruppert, Prof. B. Hansen, Dr. K. Simon, Dr. A. Kronz, and Dipl.-Geol. A. Hoffmann for their help in supporting the laboratory investigations at the Geoscience Center (GZG), Göttingen University. Furthermore, warm thanks go to Dr. Xifan Zhang and Prof. Dr. Kip Hodges for their support in carrying out the Ar-Ar geochronology at MIT, Cambridge, USA, and Prof. Dr. B. C. Burchfiel for his kind invitation. The research tenure in Göttingen, Germany, and the visit to Cambridge, USA, was funded by the Studienstiftung des deutschen Volkes, Bonn, whom I would like to thank for their trust, continuous encouragement and support. I am especially indebted to Prof. Dr. A. deMeijere (Studienstiftung), who has been a supportive advisor over the last years. Most of the analytical work as well as the field trips were funded by research grant No. 2-1001561 of the Bundesanstalt für Geowissenschaften und Rohstoffe, Hannover. I thank Dr. D. Leifeld and Dr. T. Oberthür for supervising the project as part of the "Hochschulvergabeprojekte" in ore deposit research. As I was fortunate enough to spend two field seasons in Yunnan, I am especially grateful to the Yunnan Bureau of Geology and Mineral Resources (YBGMR), Kunming, for the permission to conduct field work in even the most distant parts of Yunnan. I kindly acknowledge my counterpart Dr. Gang Bao and his staff for the successful collaboration and the energetic support in China. Several "brigades" of field geolo- 
gists, preparing brilliant geological maps in even the most hostile areas, are admired at this point. My friend and driver, Wei Zhang, is very much thanked for enduring my Chinese and keeping up with heavy field work. Dr. Rusha Ingavat Helmcke and Prof. Dr. Qinglai Feng (CUG Wuhan) are thanked for splendid company and scientific assistance. Prof. Dr. P. O'Brien (Potsdam University) is thanked for discussing issues on the formation of paired-metamorphic belts and help in looking at some of the thin sections.

Finally, my deepest thanks go to my family and friends. You have been a constant help. I will promise to compensate for the last few months, where I was either physically or mentally absent. 


\section{References}

Ahrendt, H., Chonglakmani, C., Hansen, B. T., and Helmcke, D. (1993): Geochronological cross section through northern Thailand. - J. SE Asian Earth Sci., v. 8, p. 207 - 217.

Allégre, C. J., Dupré, B., Lambret, B., and Rickard, P. (1981): The subcontinental versus the suboceanic debate I. Lead-neodymium-strontium isotopes in primary alkali basalts from a shield area: the Ahaggra volcanic suite. - Earth Planet. Sci. Lett., v. 52, p. 85-92.

Avouac, J. P., and Tapponier, P. (1993): Kinematic model of active deformation in Central Asia. Geophys. Res. Lett., v. 20, p. 895-898.

Armstrong, J. T. (1995): CITZAF: A package of correction programs for the quantitative electron microbeam x-ray analysis of thick polished materials, thin films, and particles. - Microbeam Analysis, v. 4, p. 177-200.

Ashworth, J. R. (1985): Migmatites. - Blackie, Glasgow, 288p.

Bannert, D., and Helmcke, D. (1981): The evolution of the Asian plate in Burma. - Geol. Rdsch., v. 70, p. 446-458.

Barley, M. E., Pickard, A. L., Zaw, K., Rak., P., and Doyle, M. G. (2003): Jurassic to Miocene magmatism and metamorphism in the Mogok metamorphic belt and the India-Eurasia collision in Myanmar. - Tectonics, v. 22, p. 1-11.

Batchelor, R. A., and Bowden, P. (1985): Petrogenetic interpretation of granitoid rock series using multicationic parameters. - Chem. Geology, v. 48, p. 43-55.

Baum, F., Braun, E. von, Hahn, L., Koch, K. E., Kruse, G., Quarch, H., and Siebenhüner, M. (1982): On the geology of Northern Thailand. - Beil. Geol. Jb., v. 102, 23p.

Bender, F., Bannert, D., Brinckmann, J., Gramann, F., and Helmcke, D. (1981): Geology of Burma 1 : 2000000. - In: Bender, F. (1983): Geology of Burma. - Gebrüder Borntraeger, Berlin, Stuttgart, 293.p.

Bender, F. (1983): Geology of Burma. - Gebrüder Borntraeger. Berlin, Stuttgart, 293p.

Best, M. G. (1982): Igneous and Metamorphic rocks. - W. H. Freeman, San Francisco.

Bien, M. N. (1941): "Red Beds" of Yunnan. - Bull. Geol. Soc. China, v. 21, p. 157-197.

Bird, P. (1979): Continental Delamination and the Colorado Plateau. - J. Geophys. Res., v. 84/B13, p. $7,561-7,571$.

Bird, P. (1991): Lateral Extrusion of Lower Crust From Under High Topography, in the Isostatic Limit. - J. of Geophys. Res., v. 96, p. 10,275-10,286.

Blundy, J. D., and Holland, T. J. B. (1990): Calcic amphibole equilibria and a new amphibole plagioclase geothermometer. - Contrib. Mineral. Petrol., v. 104, p. 208-224.

Bohlen, S. R. (1987): Pressure-Temperature-time paths and a tectonic model for the evolution of granulites. - J. Geol., v. 95, p. 617-632.

Bohlen, S. R. (1991): On the formation of granulites. - J. Metam. Geol., v. 9, p. 223-229.

Bohlen, S. R., and Metzger, K. (1989): Origin of granulite terranes and the formation of the lowermost continental crust. - Science, v. 244, p. 326-329.

Boven, A., Pasteels, P., Punzalan, L. E., Liu, J., Luo, X., Zhang, W., Guo, Z., and Hertogen, J. (2002): ${ }^{40} \mathrm{Ar} /{ }^{39} \mathrm{Ar}-$ geochronological constraints on the age and evolution of the Permo-Triassic Emeishan Volcanic Province, Southwest China. - J. of Asian Earth Sci., v. 20, p. 157-175.

Bullard, E. C., Everett, J. E., and Smith, A. G. (1965): The fit of the continents around the Atlantic. - Phil. Trans. R. Soc. Lond. A, v. 258, p. 41-51.

Bunopas, S., and Vella, P. (1978): Late Palaeozoic and Mesozoic structural evolution of northern Thailand - A Plate Tectonic Model. - In: Nutalaya, P. (Edit.): Proc. of the 3rd Reg. Conf. on Geol. and Min. Res. of SE Asia, Bangkok, p. 133-140.

Brown, M., and Nakajima, T. (1994): High-T - Low-P metamorphism in the Ryoke belt of Japan: Consequences of ridge subduction. - Geol. Soc. Amer. Annual Meeting, Seattle, Washington. Abs. with programs, v. 26/6, A-214. 
Brown, M. (1996): Ridge-trench interaction and the myth of „paired“ metamorphic belts. - 30th Inter. Geol. Cong., Beijing, China, Abstracts, v. 2, p. 582.

Brown, M., and O'Brien, P. J. (1997): Evolution of metamorphic belts: a changing view. - In: Qian, X., You, Z., Jahn, B., and Halls, H. C. (Eds.): Precambrian Geology and Metamorphic Petrology, Proc. 30th Int'l. Geol. Congr., v. 17/2, p. 217-231.

Carey, S. W. (1958): A tectonic approach to continental drift, In: Carey, S.W. (Eds.): Symposium at the University of Tasmania, Hobart, Australia, p. 177-355.

Caridroit, M. (1993): Permian radiolaria from NW Thailand. - Int. Symp. On Biostratigraphy of Mainland Southeast Asia. - Facies \& Palaeontology, Vol. 1, p. 83-95.

Chappell, B. W., and White, A. J. R. (1974): Two contrasting granite types. - Pacific Geology, v. 8, p. 173-174.

Chen, G. (2000): Diwa Theory - Activated Tectonics and Metallogeny. - Central South University Press, Changsha. Hunan Geology Printing Factory of Surveying and Mapping, 405p.

Chen J. (1987): Ages of Granitoids in western Yunnan and discussion on their isotopic datings. Yunnan Geology, v. 6, p. 101-113.

Chen, Y., and Courtillot, V. (1989): Widespread Cenozoic (?) remagnetization in Thailand and its implications for the India-Asia collision. - Earth Plan. Sci. Let., v. 93, p. 113-122.

Chonglakmani, C. (1983): The marine Mesozoic stratigraphy of Thailand. - Proc. of the Workshop on Stratigraphic Correlation of Thailand and Malaysia, v. 1, Hat Thai, Thailand, p. 105-126.

Chonglakmani, C. (1998): The Triassic system of Thailand: implication on geotectonic evolution of Southeast Asia. - 9th Intern. Congress on Geology, Mineral and Energy Resources of Southeast Asia - GEOSEA 98, Kuala Lumpur, Malaysia, p. 48.

Chonglakmani, C., Feng, Q., Meischner, D., Ingavat-Helmcke, R., and Helmcke, D. (2001): Correlation of Tectono-Stratigraphic Units in Northern Thailand with Those of Western Yunnan (China): J. of China Univ. of Geosci., v. 12, p. 207-213.

Chopin, C. (1981): Talc-phengite: a wide-spread assemblage in high grade pelitic blueschists of the western Alps. - J. of Petr., v. 22, p. 628-650.

Chung, S. L., Jahn, B., Wu, G., Lo, C., and Bolin, C. (1998): The Emeishan Flood Basalt in SW China: A Mantle Plume Initiation Model and its Connection with Continental Breakup and Mass Extinction at the Permian-Triassic Boundary. - Mantle Dynamics and Plate Interactions in East Asia, Geodynamics, v. 27, p. 47-58.

Clark, M. K., and Royden, L. H. (2000): Topographic ooze; building the eastern margin of Tibet by lower crustal flow. - Geology, v. 28 (8), p. 703-706.

Cobbing, E. J. Mallic, D. I. J., Pitfield, P. E. J., Teoh, L. H. (1986): The Granites of the Southeast Asian Tin Belt. - J. Geol. Soc. Lond., v. 143, p. 537-550.

Cobbing, E. J., Pitfield, P. E. J., Beckinsale, R.D. (1988): Report on the geology and geochemistry of a selection of Granites from Burma. Southeast Asia Granite Project. - Report No. WC/88/30/R, British Geological Survey \& NERC. p. 1-45.

Cong, B. L., Wu, G. Y., Zhang, Q., and others (1994): Petrotectonic evolution of Paleotethys in western Yunnan, China. - Science in China (Series B), Vol. 37, p. 1016-1024.

Cong B., and Zhai, M. (2000): Metamorphic petrology and metamorphism in western Yunnan. - In Zhong, D. (Ed.): Paleotethysides in west Yunnan, China. - VSP Science Press Beijing, p. 26-38.

Cortesogno, L., Cassinis, G., Dallagiovanna, G., Gaggero, L., Oggiano, G., Ronchi, A., Seno, S., and Vanossi, M. (1998): The Variscan post-collisional volcanism in Late Carboniferous-Permian sequences of Ligurian Alps, Southern Alps and Sardina (Italy): a synthesis. - Lithos, v. 45, p. 305-328.

Cox, K. G., and Hawkesworth, C. J. (1984): Relative contribution of crust and mantle to flood basalt magmatism, Malabaleshwar area, Deccan Traps. - Phil. Trans. R. Soc. Lond., A-310, p. 627641. 
Davies, H. J., and von Blanckenburg, F. (1995): Slab breakoff: A model of lithosphere detachment and its test in the magmatism and deformation of collisional orogens. - Earth Plan. Sci. Let., v. 129 , p. 85-102.

Deer, W. A., Howie, R. A., and Zusman, J. (1992): An introduction to the rock forming minerals. 2nd Edition, Longman Scientific and Technical, Essex, England, 197p.

DePaolo, D. J., and Wasserburg, G. J. (1976): Nd isotopic variations and petrogenetic models. Geophys. Res. Let., 3, p. 249-52.

Dewey, J. F., and others (1988): The tectonic evolution of the Tibetan Plateau. - Phil. Trans. R. Soc. Lond., A-327, p. 379-413.

Dewey, J. F., Cande, S., and Pittman, W. C. (1989): Tectonic evolution of the India / Eurasia Collision Zone. - Ecolgae geol. Helv., v. 82/3, p. 717-734.

Dewey, J. F., Ryan, P. D., and Anderson, T. B. (1993): Orogenic uplift and collapse, crustal thickness, fabrics and metamorphic phase changes: role of eclogites. - In: Richard, H. M., Alabaster, T., Harris, N. B. W., and Neary, C. R. (Eds.), 1993, Magmatic Processes and Plate Tectonics, Geol. Soc. Spec. Pub., v. 76, p. 325-343.

Dewey, J. F., and Lamp, S. H. (1996, Eds.): Geodynamics of the Andes. - Tectonophysics, v. 259, Issue 1-3., 250p.

Dickin, A. P. (1997): Radiogenic Isotope Geochemistry. - Cambridge University Press, 506p.

Dickinson, W. R., and Suczek, C. A. (1979): Plate tectonics and sandstone compositions. - AAPG Bull., 63/12, p. 2,164-2,182.

Dickinson, W. R., Beard, L. S., Brakenridge, G. R., Erjavec, J. L., Ferguson, R. C., Inman, K. F., Knepp, R. A., Lindberg, F. A., and Ryberg, P. T. (1983): Provenance of North American Phanerozoic sandstones in relation to tectonic setting. - Bull. Geol. Soc. Am., 94, p. 222-235.

Dodson, M. H. (1973): Closure Temperature in Cooling Geochronological and Petrological Systems. - Contrib. Mineral. Petrol., v. 40, p. 259-274.

Doglioni, C. (1995): Geological remarks on the relationships between extension and convergent geodynamic settings. - Tectonophysics, v. 252, p. 253-267.

Dunning, G. R., MacDonald, A. S., and Barr, S. M. (1995): Zircon and monazite U/Pb dating of the Doi Inthanon core complex, northern Thailand: implication for extension within the Indosinian Orogen. - Tectonophysics, v. 251, p. 197-213.

Duan and Zhao (1981): ... (imprecise reference in: Fan, C. and Zhang, Y. (1994): The structure and tectonics of western Yunnan. - J. SE Asian Earth Sci., 9/4, p. 355 - 361).

El Bouseily, A. M., and El Sokkary, A. A. (1975): The relation between Rb, Ba, and Sr in granitic rocks. - Chem. Geol., v. 16, p. 207-219.

England, P. C., and Houseman, G. A. (1989): Extension During Continental Convergence, With Application to the Tibetan Plateau. - J. of Geophys. Res., v. 94, p. 17,561-17,579.

Fan, C. (1982): The characteristics of the regional geology of West Yunnan. - Yunnan Geology. 1, p. 323-336. (in Chinese)

Fan, C. (1985): Origin and regional settings on $\mathrm{Pb}, \mathrm{Zn}$, deposits in Laochang, west Yunnan. Yunnan Geology, 1/4, p. 1-16. (in Chinese)

Fan, C., and Zhang, Y. (1993): On the structural pattern of western Yunnan. - Spec. Pub. Yunnan Bureau of Geology and Mineral Resources, 12p.

Fan, C., and Zhang, Y. (1994): The structure and tectonics of western Yunnan. - J. SE Asian Earth Sci., v. 9/4, p. 355-361.

Fang, N., Fan, C., Liu, B., Feng, Q., and others (1994): Late Palaeozoic and Triassic deep-water deposits and tectonic evolution of the Palaeotethys in the Changning-Menglian and Lancangjiang belts, southwestern Yunnan. - J. SE Asian Earth Sci., v. 9/4, p. 363-374.

Fang, N., and others (1998): Paleotethys evolution recorded in the Changning-Menglian Belt, western Yunnan, China. - C. R. Acad. Sci. Paris, Sci. de la Terre et des Planetes, 326, p. 275 - 282.

Fang, N., and Feng, Q. (1996): Devonian to Triassic Tethys in Western Yunnan, China. - China Univ. of Geosci. Press, Wuhan, 135 p. 
Fang, N., and Niu, Y. (2003): Late Paleozoic ultramafic Lavas in Yunnan, SW China, and their Geodynamic Significance. - J. of Petrol., v. 44, p. 141-157.

Fang, W., Van der Voo, R., and Liang, Q. Z. (1989): Devonian Paleomagnetism of Yunnan Province across the Shan Thai - South China suture. - Tectonics, v. 5, p. 939-952.

Fang, Z. (1994): Biogeographic constrains on the rift-drift-accretion history of the Sibumasu block. - J. SE Asian Earth Sci., v. 9/4, p. 375-385.

Feng, Q. (1992): Permian and Triassic radiolarian biostratigraphy in south and southwest China. J. of China Univ. of Geosci., v. 3/1, p. 51-52.

Feng, Q. (2002): Stratigraphy of volcanic rocks in the Changning-Menglian Belt in southwestern Yunnan, China. - J. of Asian Earth Sci., v. 20, p. 657-664.

Feng, Q., Liu, B., Ye, M., and Yang, W. (1996): Age and tectonic setting of the Nanduan Formation and Laba Group, southwestern Yunnan, China. - J. of Strat., 20/3, p. 183-189.

Feng, Q., Zhang, Z., Liu, B., Shen, S., Zhang, W., Zhang, S. (2000): Radiolarian fauna from the Longdonghe Formation at the western margin of the Simao Massif and its geological significance. - J. of Strat., v. 24/2, p. 126-128.

Feng, Q., and Helmcke, D. (2001): Late Palaeozoic Compressional Deformation in the Simao Region, Southern Yunnan, P. R. of China. - Newslet. Strat., v. 38 (2/3), p. 221-231.

Feng, Q., Ingavat-Helmcke, R., Helmcke D., Wagner, B., and Heppe, K. (2001): On the geodynamic evolution of the Simao-Region (southwestern Yunnan, P.R. of China) during Upper Paleozoic and Triassic times). - J. of China Univ. of Geosci., Beijing, Vol. 12, No. 3., p. 185-200.

Feng, Q., Shen, S., Liu, B., Helmcke, D., Qian, X., and Zhang, W. (2001a): Permian Radiolarians, Chert and Basalt from the Daxinshan Formation in Lancangjiang Belt of Southwestern Yunnan, China. - Sci. in China, v. 44, 11p. (in Chinese).

Feng, Q., Ingavat-Helmcke, R., Helmcke, D., Wagner, B., and Heppe, K. (2001): On the geodynamic evolution of the Simao-Region (southwestern Yunnan, P. R. of China) during Upper Paleozoic and Triassic times). - J. of China Univ. of Geosci., Beijing. - Intern. Symp. on the Global Stratotype of the Permian Triassic Boundary and the Paleozoic and Mesozoic Events, Changxing, Zhejiang Province, P.R. of China. August, 10th-13th 2001. - abstract

Ferry, M., and Spear, F. S. (1978): Experimental calibration of the partitioning of $\mathrm{Fe}$ and $\mathrm{Mg}$ between biotite and garnet. - Contrib. Mineral. and Petr., v. 66, p. 113-117.

Foland, K. A. (1983): ${ }^{40} \mathrm{Ar} / 39 \mathrm{Ar}$ incremental heating plateaus for biotites with excess argon. - Isotope Geosci., v. 1, p. 3-21.

Fontaine, H., Suteethorn, V., and Vachard, D. (1994): The Carboniferous Corals of Southeast Asia with new Discoveries in Laos and Thailand. - Proc. of the Int. Symp. on: Stratigraphic Correlation of Southeast Asia, Bangkok, Thailand, p. 25-42.

Fuhrmann, U., Lippolt, H. J., and Hess, J. C. (1987): Examination of some proposed K-Ar standards: ${ }^{40} \mathrm{Ar} /{ }^{39} \mathrm{Ar}$ analyses and conventional K-Ar-data. - Chem. Geol. (Isot. Geosci. Sect.), v. 66, p. 41-51.

Hahn, L. and others (1986): Outline of the Geology and the Mineral Potential of Thailand. - Geol. Jb., B 59, p. 3-49.

Hanson, G. N., Simmons, K. R., and Bence, A. E. (1975): ${ }^{40} \mathrm{Ar} / 39 \mathrm{Ar}$ spectrum ages for biotite, hornblende and muscovite in a contact metamorphic zone. - Geochim. Cosmochim. Acta, 39, p. 1269-1277.

Harrison, T. M. (1981): Diffusion of ${ }^{40} \mathrm{Ar}$ in hornblende. - Contrib. Mineral. Petrol., v. 78, p. 324-331.

Harrison, T. M. (1983): Some observations on the interpretation of (super 40) $\mathrm{Ar} /$ (super 39) Ar age spectra. - Chem. Geol., v. 41/4, p. 319-338.

Hart, S. R. (1964): The petrology and isotopic-mineral age relations of a contact zone in the Front Range Colorado. - J. of Geol., v. 72, p. 493-525.

Hawkesworth, C. J., Mantovani, S. M., Taylor, P. N., and Palacz, Z. (1986): Evidence from the Paraná of South Brazil for a continental contribution to Dupal basalts. - Nature, v. 322, p. 356359. 
He, F. X., and Liu, B. P. (1993): Recognition of ancient oceanic island in Paleotethys, western Yunnan. - J. China Univ. of Geosci., v. 4, p. 23-29.

Heinemeyer, C. (1996): Die „Pebbly Mudstones“ in Yunnan (China) und W-Thailand - Zeugen der permo-karbonischen Vereisung Gondwanas? - unveröffentl. Diplomarbeit, 99p., Univ. Göttingen.

Heinrichs, H., and Herrmann, A. G. (1990): Praktikum der Analytischen Geochemie. - Springer Verlag, $669 \mathrm{p}$.

Helmcke, D., and Lindenberg, H. G. (1983): New data on the „Indosinian“ orogeny from central Thailand. - Geol. Rdsch., v. 72, p. 317 - 328.

Helmcke, D. (1984): The orogenic evolution (Permian - Triassic) of central Thailand. Implications on paleogeographic models for mainland SE-Asia. - Mém. Soc. géol. France, v. 147, p. 83-91.

Helmcke, D. (1985): The Permo-Triassic "Paleotethys" in Mainland Southeast-Asia and adjacent parts of China. - Geol. Rdsch., v. 74, p. 215-228.

Helmcke, D. (1986): Die Alpiden und die Kimmeriden: Die verdoppelte Geschichte der Tethys Discussion. - Geol. Rdsch., v. 75, p. 495-499.

Helmcke, D., Ingavat-Helmcke, R., and Meischner, D. (1993): Spät-variszische Orogenese und Terranes in Südost-Asien. - Göttinger Arbeiten zur Geologie und Paläontologie (WalliserFestschrift), v. 58, p. 29-38.

Helmcke, D. and Wagner, B. (1997): Zwischenbericht November 1997 zum Forschungsauftrag Lagerstättenvorkommen im Norden Yunnans. - Bundesanstalt für Geowissenschaften und Rohstoffe (BGR), Hanover.

Helmcke, D. and Wagner, B. (1998): Zwischenbericht November 1998 zum Forschungsauftrag Lagerstättenvorkommen im Norden Yunnans. - Bundesanstalt für Geowissenschaften und Rohstoffe (BGR), Hanover.

Helmcke, D., Wagner, B., and Heppe, K. (1999): Zwischenbericht 1999 zum Forschungsauftrag Lagerstättenvorkommen im Norden Yunnans. - Bundesanstalt für Geowissenschaften und Rohstoffe (BGR), Hanover.

Helmcke, D., and Wagner, B. (2000): Study on mineral resources related to the plate tectonics of the Middle and Southern Lancang Jiang zone in Yunnan, P. R. of China. - Interim Report, Bundesanstalt für Geowissenschaften und Rohstoffe (BGR), Hanover.

Helmcke, D., and Wagner, B. (2001): Untersuchungen zum Lagerstättenpotential im Zusammenhang mit der plattentektonischen Entwicklung der mittleren und südlichen Lancang Jiang Zone, Yunnan P. R. of China. - Bericht, Bundesanstalt für Geowissenschaften und Rohstoffe (BGR), Hanover.

Helmcke, D., Ingavat-Helmcke, R., and Meischner, D. (1993): Spät-variszische Orogenese und Terranes in Südost-Asien. - Göttinger Arb. Geol. Paläont., v. 58, p. 29-38.

Heppe, K. (2002): Geodynamische Entwicklung Südwest Yunnans: Rahmenbedingungen zur Modellierung der karbonischen VMS-Lagerstätten vom Typ Dapingzhang. - Annual Seminar on Ore Deposits and Mineral Resources, Bundesanstalt für Geowissenschaften und Rohstoffe, Mai, 16th 2002, Hanover, 2p. (extended abstract).

Heppe, K., and Helmcke, D. (2003): Die „Lancang paired metamorphic belts“ - Unklarheiten und Folgewidrigkeiten in der Vorstellung eines mesozoischen Inselbogen-Settings in Südwest Yunnan, China. - Annual Seminar on Ore Deposits and Mineral Resources, Bundesanstalt für Geowissenschaften und Rohstoffe (BGR), May, 27th 2003, Hanover, 2p. (extended abstract).

Hill, R. I., Campbell, Davies, G. F., and Griffith, R. W. (1992): Mantle Plumes and Continental Tectonics. - Nature, v. 256, p. 186-193.

Hodges, K. (1988): ${ }^{40} \mathrm{Ar} /{ }^{39} \mathrm{Ar}$ geochronology using the laser microprobe. - Rev. in Econ. Geol., v. 7, p. 53-72.

Holt, W. E., Ni, J. F., Wallace, T. C., Haines, A. J. (1991): The active tectonics of the eastern Himalayan syntexis and surrounding regions. - J. of Geophys. Res., B, Solid Earth and Planets, v. 96,9 , p. $149,595-14,632$. 
Houseman, G. A., McKenzie, D. P., and Molnar, P. (1981): Convective instability of a thickened boundary layer and its relevance for the thermal evolution of continental convergent belts. - J. of Geophys. Res., v. 86, p. 6115-6132.

Houseman, G. A., and England, P. (1993): Crustal Thickening Versus Lateral Expulsion in the Indian-Asian Continental Collision. J. of Geophys. Res., v. 98, p. 12,233-12,249.

Howell, D. G. (1995): Principles of terrane Analysis. New applications for global tectonics. - 2nd edition, Topics in Earthsciences, 8, Chapman \& Hall, 218p.

Hsü, K. J., and Bernoulli, D. (1978): Genesis of the Tethys and the Mediterranean. - In: Hsü, K.J., and Montadert, L. et al. (Eds.): Initial Reports of the Deep Sea Drilling Project, 42/1, p. 943 - 949.

Hsü, K. J., Guitang, P., and Sengör, A. M. C. (1995): Tectonic Evolution of the Tibetan Plateau: A Working Hypothesis Based on the Archipelago Model of Orogenesis. - Intern. Geol. Rev., v. 37, p. 473-508.

Huang, J., Chen, G., and Chen, B. (1984): Preliminary analysis of the Tethys - Himalayan tectonic domain. - Acta Geol. Sinica, v. 58, p. 1-17. (in Chinese)

Huang, K., and Opdyke, N. D. (1991): Paleomagnetic results from the Upper Carboniferous of the Shan-Thai-Malay block of western Yunnan, China. - Tectonophysics, v. 192, p. 333-344.

Humphrey, N. (1992): A History of the Mind. - Harper Collins Publishers, New York.

Hunziker, J. C., Frey, M., Clauer, N., Dallmeyer, R. D., Friedrichsen, H., Flehmig, W., Hochstrasser, K., Roggwiler, P., and Schwander, H. (1986): The evolution of illite to muscovite: mineralogical and isotopic data from the Glarus Alps, Switzerland. - Contrib. Mineral. Petrol., 92, p. 157-180.

Hutchison, C. S. (1989): Geological evolution of Southeast-Asia. - Oxford University Press, Oxford, $368 p$.

Hynes, A., and Forest, R. C. (1988): Empirical garnet-muscovite geothermometry in low-grade metapelites, Selwyn Range (Canadian Rockys). - J. of met. Geol., v. 6, p. 277-309.

Ingavat-Helmcke, R. \& Helmcke, D. (1994): Permian facies-realms in Thailand. - Proceedings Intern. Symp. on Strat. Corr. of Southeast Asia, Bangkok, p. 100-105.

Ingavat-Helmcke, R. \& Helmcke, D. (1986): Permian Fusulinacean faunas of Thailand - event controlled evolution. - Lecture Notes in Earth Sci., 8, p. 241-248.

Ishihara, S. (1977): The magnetite-series and ilmenite-series granitic rocks. - Mining Geol., 27, p. 293-305.

Jin, X. (1994): Sedimentary and paleogeographic significance of Permo-Carboniferous sequences in Western Yunnan, China. - Ph.D.-thesis. Univ. of Cologne, 136p.

Kagami, H., Ulmer, P., Hansmann, W., Dietrich, V., and Steiger, R. H. (1991): Nd-Sr Isotopic and Geochemical Characteristics of the Southern Adamello (Northern Italy) Intrusives: Implications for Crustal Versus Mantle Origin. - J. of Geophys. Res., v. 96, p. 14,331-14,346.

Inger, S. (1994): Magmagenesis associated with extension in orogenic belts: examples from the Himalaya and Tibet. - Tectonophysics, v. 238, p. 183-197.

Kerrich, R. (1999): Natures's Gold Factory. - Science, v. 284, p. 2101-2102.

Kisch, H. J. (1991): Illite "crystallinity": recommendations on sample preparation, X-ray diffraction settings and inter-laboratory samples. - J. metamorphic Geol. v. 9, p. 665-670.

Krumm, S. (1992): Illitkristallinität als Indikator schwacher Metamorphose - Methodische Untersuchungen, regionale Anwendungen und Vergleiche mit anderen Parametern. - Erlanger geol. Abh., p. 1-17.

Koppers, A. A. P. (2002): ArArCALC; software for (super 40) Ar/ (super 39) Ar age calculations. Computer and Geoscience, v. 28, p. 605-619.

Konishi, K. (1953): New Boultonia and other microfossils from North Thailand. - Trans. Proc. Palaeont. Soc. Japan, n.s., 12, p. 103-110.

Kübler, B. (1967a): La cristallinité de l'illite et les zones tout à fait supérieures du métamorphisme. - Colloque sur les "Etages Tectonique", 18-21 avril 1966, Neuchâtel, p. 105-122. 
Kübler, B. (1967b): Anchimétamorphisme et schistosité. - Bull. Centre Rech Pau SNPA, v. 1, p. 259278.

Kübler, B. (1968): Evaluation quantitative du métamorphisme par la cristallinité de l'illite. - Bull. Centre Rech Pau SNPA, v. 2, p. 385-397.

Lacassin, R., Leloup, P. H., and Tapponnier, P. (1993) Bounds on strain in large Tertiary shear zones of SE Asia from boudinage restoration. - J. Struct. Geol., v. 15, p. 677-692.

Le Bas, M. J., Le Maitre, R. W., Streckeisen, A. and Zanettin, A. (1986): A chemical classification of volcanic rocks based on the total alkali-silica diagram. - J. Petr., v. 27, p. 745-50.

Leloup, P. H., Lacassin, R., Tapponier, P., Schärer, U., Zhong, D., Liu, X., Zhang, L., Ji, S., and Phan, T. T. (1995): The Ailao Shan - Red River shear zone (Yunnan, China), Tertiary transform boundary of Indochina. - Tectonophysics, v. 251, p. 3-84.

Li, D., Zhang Q., and Zhang, L. (1986): Petrochemical and geochemical characteristics of volcanoes in Menglian area, Yunnan and their geological significance. - In: Sun, H., Cheng, H. (Eds.): Studies in Qinhai-Xizang Plateau, special issue of Hengduan Mountains Scientific Expedition, Beijing Science Technology Press, Beijing, p. 137-146. (in Chinese)

Liew, T. C., and McCulloch, M. T. (1985): Genesis of Granitoid batholiths of Peninsular Malaysia and implications for models of crustal evolution: evidence from $\mathrm{Nd}-\mathrm{Sr}$ isotopic and $\mathrm{U}-\mathrm{Pb}$ zircon study. - Geochem. Cosmochim. Acta, v. 49, p. 587-600.

Liew, T. C., and Hofmann, A. W. (1988): Precambrian crustal components, plutonic associations, plate environment of the Hercynian Fold Belt of central Europe: Indications from a $\mathrm{Nd}$ and $\mathrm{Sr}$ isotopic study. - Contrib. to Mineral. Petrol, v. 98, p. 129-138.

Liew, T.C., Page, R.W. (1985): U-Pb zircon dating of granitoid plutons from the West Coast province of Pensinsular Malaysia. - J. Geol. Soc. Lond., v. 142, p. 515-526.

Liu, C., Zhu, J., Xu, X. (1989): The Hercynian collision type granites of West Yunnan and their tectonic significance. - J. of Southeast Asian Earth Sci., v. 3, p. 263-270.

Liu, B., Feng, Q., and Fang, N. (1991): Tectonic evolution of the Paleotethys in Changning Menglian belt and adjacent regions, western Yunnan. - J. China University of Geosci., v. 2, p. 18-28.

Liu, B., and Feng, Q. (1993): Tectonic Evolution of Paleo-Tethys Polyisland-ocean in ChangningMenglian and Lancangjiang Belts, Southwestern Yunnan, China. - J. China Univ. of Geosci., v. 18 , p. 529-539.

Lightfoot, P. C., Naldret, A. J., Gorbachev, N. S., Doherty, W., and Fedorenko, V. A. (1990): Geochemistry of the Siberian Trap of the Noril'sk area, USSR, with implications for the relative contributions of crust and mantle flood basalt magmatism. - Contrib. Mineral. Petrol., v. 104, p. 631-644.

MacDonald, A. S., Barr, S. M., Dunning, G. R., and Yaowanoiyothin, W. (1991): The Doi Inthanon metamorphic core complex: age and significance. - Proc. 7th Reg. Conf. Geology, Mineral and Energy Resources of SE Asia, Bangkok.

MacDonald, A. S., Barr, S. M., Dunning, G. R., and Yaowanoiyothin, W. (1993): The Doi Inthanon metamorphic core complex in NW Thailand: age and tectonic significance. - J. Southeast Asian Earth Sci., v. 8, p. 117-125.

Maniar, P. D., and Piccoli, P. M. (1989): Tectonic discrimination of granitoids. - Geol. Soc. Am. Bull., 101, p. 635-43.

Maruyama, S., Liou, J. G., and Seno, T. (1986): Experimental investigations of blueschists-greenschists transition equilibria: pressure dependence of $\mathrm{Al}_{2} \mathrm{O}_{3}$ contents in sodic amphiboles - $\mathrm{A}$ new geobarometer. - Geol. Soc. of Am. Mem., v. 164, p. 1-16.

Maruyama, S., Liou, J. G., and Terabayashi, M. (1996): Blueschists and Eclogites of the World and Their Exhumation. - Int. Geol. Rev., v. 38, p. 485-594.

Mehnert, K. R. (1968): Migmatites and the Origin of Granitic rocks. - Elsevier, Amsterdam.

McKenzie, D. P. (1978): Some remarks on the sedimentary development of sedimentary basins. Earth Plan. Sci. Let., v. 40, p. 25-32. 
Menzies, M. A., Leeman, W. P., and Hawkesworth, C. J. (1984): Geochemical and isotopic evidence for the origin of continental flood basalts with particular reference to the Snake River Plane, Idaho, U.S.A. - Phil. Trans. R. Soc. Lond., A-310, p. 643-60.

Metcalfe, I. (1988): Origin and assembly of Southeast Asian continental terranes, in AudleyCharles, I., and Hallam, A. (Eds.): Gondwana and Tethys, 37, Geol. Soc. Lond. Spec. Pub., p. 101-118.

Metcalfe, I. (1993): Southeast Asian terranes: Gondwanaland origins and evolution. - In: Finlay, R.H., Unrug, R., Banks, M.R., and Veevers, J. J. (Eds.): Gondwana 8 - Assembly, evolution, and dispersal, Hobart, A. A. Bakema, p. 181-200.

Metcalfe, I. (1995): Gondwana Dispersion and Asian Accretion. - J. of Geol., B 5/6, p. 223-266.

Metcalfe, I. (1996): Pre-Cretaceous evolution of SE Asian terranes, In: Hall, R., and Blundell, D. (Eds.): Tectonic Evolution of Southeast Asia. - Geol. Soc. Spec. Pub., v. 106, p. 97-122.

Metcalfe, I. (1998): Gondwana dispersion and Asian accretion. - Final Results Volume for IGCP Project, v. 321, A. A. Balkema, Rotterdam.

Metcalfe, I. (1999): The Tethys: how many? how old? how deep? how wide? - Intern. Symposium Shallow Tethys. - 1, Chiang Mai, p. 1-15.

Mickein, A. (1997): U/Pb-, Rb/Sr- und K/Ar-Untersuchungen zur metamorphen Entwicklung und Altersstellung des „Präkambriums“ in NW-Thailand. - Göttinger Arbeiten zur Geol. u. Paläont., v. 73, 83p.

Middlemost (1975): The basalt clan. - Earth Sci. Rev., v. 11, p. 337-64.

Min, M., Lin, K., Feng, Q., Chonglakmani, C., Meischner, D., Ingavat-Helmcke, R., and Helmcke, D. (2001): Tracing the disrupted outer margin of the Paleoeurasian continent through the Union of Myanmar. - J. of China Univ. of Geosci., 12/3, p. 201-206.

Mitchell, A. H. G. (1981): Phanerozoic plate boundaries in mainland SE Asia, the Himalayas and Tibet. - J. Geol. Soc., Lond., v. 138, p. 109-122.

Miyashiro, A. (1961): Evolution of metamorphic belts. - J. of Petrol., v. 2, p. 277-311.

Miyashiro, A. (1972): Pressure and temperature metamorphism conditions and tectonic significance of regional and ocean floor metamorphism. - Tectonophysics, v. 13, p. 141-159.

Miyashiro, A. (1973): Metamorphism and Metamorphic Belts. - Wiley-Halstead, New York.

Miyashiro, A. (1978): Nature of alkalic volcanic rock series. - Contr. Mineral. Petrol., v. 66, p. 91104.

Miyashiro, A. (1994): Metamorphic Petrology. - Oxford University Press, New York.

Mo, X., Shen, S., and Zhu, Q. (1988): Volcanics-Ophiolite and Mineralization. - Geological Publishing House, Beijing, 129p. (in Chinese)

Mo, X., Lu, F., and Shen S. (1993): Sanjiang Tethyan volcanism and related mineralization. Geological Publishing House, Beijing. 67p. (in Chinese)

Molnar, P., and Tapponier, P. (1975): Cenozoic Tectonics of Asia: Effects of a Continental Collision. - Science, v. 189, p. 419-426.

Monger, J. W. H., and Nokleberg, W. J. (1995): Evolution of the northen North American Cordillera: generation, fragmentation, displacement and accretion of successive North American plate-margin arcs, In: Coyner, A. R., and Fahey, P. L. (Eds.): Geology and Ore Deposits of the American Cordillera, Vol. Conf. Proc. Vol. III, Reno/Sparks, Geol. Soc. Nevada.

Mouret, C. (1994): Geological History of Northeastern Thailand since the Carboniferous. Relations with Indochina and Carboniferous to Early Cenozoic Evolution Model. - Proc. of the Intern. Symp. on Strat. Correlation of Southeast Asia, Bangkok, Thailand, p. 132-158.

Nakamura, N. (1974): Determination of REE, Ba, Fe, Mg, Na and K in carbonaceous and ordinary chondrites. - Geochim. Cosmochim. Acta., v. 38, p. 757-773.

Naldrett, A. J., Fedorenko, V. A., Lightfood, P. C., Kunilov, V. I., Gorbachev, N. S., Doherty, W., and Johan, Z. (1995): Ni-Cu-PGE deposits of the Noril'sk region, Siberia: their formation and conduits for flood basalt volcanism. - Trans. Inst. Mining Metall., v. 104, B1-86. 
Naldrett, A. J. (1999): World-class Ni-Cu-(PGE) deposits: key factors in their genesis. - Mineralium Deposita, v. 34, p. 227-240.

Naldrett, A. J., and Lightfoot, P. C. (1999): Ni-Cu-(PGE) deposits of the Noril'sk region, Siberia, dynamic processes. - In: Keays, R. R., Lesher, C. M., Lightfoot, P. C., and Farrow, C. E. G., (Eds.): Magmatic ore deposits and their application to mineral exploration. - Washington, D.C., Geological Association of Canada, p. 195-250.

Neumayr, M. (1885): Klimatische Zonen während der Jura und Kreidezeit. - Denkschr. Kais. Akad. Wiss., Wien, v. 47, p. 1-34.

O'Brien, P. J. (2000): The fundamental Variscan Problem: high-temperature metamorphism at different depths and high-pressure metamorphism at different temperatures. - In: Franke, W., Haak, V., Oncken, O., and Tanner, D. (Eds.): Orogenic Processes: Quantification and Modelling in the Variscan Belt. - Geol. Soc. Lond. Spec. Pub., v. 179, p. 369-386.

Ohmoto, H. (1986): Stable isotope geochemistry of ore deposits. - Rev. in Mineral., v. 16 (Stable Isotopes), p. 491-559.

Oxburgh, E. R., and Turcotte, D. L. (1971): Origin of Paired Metamorphic Belts and Crustal Dilation in Sland Arc Regions. - J. of Geophys. Res., v. 76, p. 1315-1327.

Packham, G. (1996): Cenozoic SE Asia: reconstructing its aggregation and reorganisation. - In: Hall, R., and Blundell, D. (Eds.): Tectonic Evolution of Southeast Asia - Geol. Soc. Special Publ., v. 106, p. $123-152$.

Pattison, D. R. M. (1992): Stability of andalusite and sillimanite and the $\mathrm{Al}_{2} \mathrm{SiO}_{5}$ triple point: Constraints from the Ballachulish aureole, Scotland. - J. Geol., v. 100, p. 423-446.

Peacock, M. A. (1931): Classification of igneous rock series. - J. of Geol., v. 39, p. 54-67.

Pearce, J. A. (1982): Trace element characteristics of lavas from destructive plate boundaries. - In: Thorpe, R. S. (Ed.): Andesites; orogenic andesites and related rocks. John Wiley \& Sons, Chichester, United Kingdom, p. 525-548.

Pearce, J. A., Harris, N. B. W., and Tindle, A. G. (1984): Trace element discrimination diagrams for the tectonic interpretation of granitic rocks. - J. of Petrol., v. 25, p. 956 - 983.

Peng, X., and Luo, W. (1982): Discovery and tectonic significance of glaucophane schist from the southern section of the Lancang River in western Yunnan. - Regional Geol. of China, v. 2, p. 6975. (in Chinese with English abstract)

Pirajno, F. (2000): Ore deposits and Mantle Plumes. - Kluwer Academic Publishers, Dordrecht, Boston, London, 545p.

Pitfield, P. E. J. (1988): Report on the geochemistry of the granites of Thailand - South-East Asia Granite Project. - NERC and British Geological Survey, Report No. WC/88/6.

Popper, K. (1994): Logik der Forschung. - 10th Edition, Mohr Siebeck Verlag, Tübingen.

Purdy, J. W., and Jäger, E. (1976): K-Ar Ages on Rock Forming Minerals of the central Alps. - Mem. Ist. Geol. Mineral Univ. Padova, v. 30, 31p.

Ren, J., Zhang, Z., Qin, D., Jiang, C., and Li, Q. (1987): Geotectonic evolution of China. - SpringerVerlag, Berlin - Heidelberg - New York, 203 p.

Renne, P. R., Swisher, C. C., Deino, A. L., Karner, D. B., Owens, T., and DePaolo, D. J. (1998): Intercalibration of standards, absolute ages and uncertainties in ${ }^{40} \mathrm{Ar} /{ }^{39} \mathrm{Ar}$ dating: Chem. Geol. (Isotope Geosciences), v. 145, p. 117-152.

Richardson, S. W., and England, P. C. (1979): Metamorphic consequences of crustal eclogite production in overthrust orogenic zones. - Earth Plan. Sci. Let., v. 42, p. 183-190.

Richter, B., Schmidtke, E., Fuller, M., Harbury, N.A., and Samsudin, A.R. (1999): Paleomagnetism of peninsular Malaysia. - J. of Asian Earth Sci., v. 17, p. 477-519.

Rowley, D. B. (1996): Age of initiation of collision between India and Asia: A review of stratigraphic data. - Earth Plan. Sci. Let., v. 145, p. 1-13.

Royden, H. R. (1993): The tectonic expression of slab pull at continental convergent boundaries. Tectonics, v. 12/2, p. 303-325. 
Royden, L. H., and Burchfiel, B. C. (1989): Are systematic variations in thrust belt style related to plate boundary processes? (The western Alps versus the Carpathians). - Tectonics, 8, 51-61.

Saurin (1933): Observations géologiques entre Yunnanfou et Yuan Yung Ching (Yunnan). - Bull. Soc. Geol. France, v. 5e (t.3), p. 411-473.

Schumacher, E. (1975): Herstellung von 99,9997\% ${ }^{38} \mathrm{Ar}$ für die ${ }^{40} \mathrm{~K} / 40 \mathrm{Ar}$ Geochronologie. Geochron. Chim., v. 24, p. 441-442.

Scotese, C.R., and Golonka, J. (1992): Paleogeographic Atlas. - PALEOMAP Progr. Rep. 20, Dept. of Geol., Univ. Texas at Arlington.

Searle, M. P. (1991): Geology and Tectonics of the Karakoram Mountains. - Chichester, Wiley.

Sengör, A. M. C. (1979): Mid Mesozoic closure of Permo-Triassic Tethys and its implications. Nature, v. 279, p. 590-593.

Sengör, A. M. C. (1981): The evolution of Paleo-Tethys in the Tibetan segment of the Alpides. In: Geological and Ecological Studies of Qinghai - Tibet Plateau. Beijing, Science Press: p. 51-56.

Sengör, A. M. C. (1982): "Edward Suess' relation to the pre-1950 schools of thought on global tectonics." - Geol. Rndsch., v. 71, p. 381-420.

Sengör, A. M. C. (1984): The Cimmeride orogenic system and the tectonics of Eurasia. - Geol. Soc. Am. Spec. Paper, v. 195.

Sengör, A.M.C. (1985): Die Alpiden und die Kimmeriden: Die verdoppelte Geschichte der Tethys. Geol. Rndsch., v. 74, p. 181-213.

Sengör, A. M. C. (1989): The Tethyside Orogenic System: An introduction. - In: Sengör, A. M. C. (Eds.): Tectonic Evolution of the Tethyan Region. - Kluwer Academic Publishers, p. 1-22.

Sengoer, A. M. C. (1998): Die Tethys; vor hundert Jahren und heute; Ein Festvortrag gehalten am 18. November 1993 im Kleinen Festsaal des Hauptgebaeudes der Universitaet Wien. Mitteilungen der Oesterreichischen Geologischen Gesellschaft, v. 89, p. 5-177.

Sengör, A. M. C. and Dewey, J. F. (1990): Terranology: vice or virtue? - Royal Soc. of Lond. Phil. Trns., v. A331, p. 457-77.

Sengör, A. M. C., and Okurogullari, A. H. (1991): The rôle of Accretionary Wedges in the growth of continents: Asiatic examples from Argand to Plate Tectonics. - Ecolgae geol. Helv., v. 84, p. 535597.

Shand, S. J. (1947): Eruptive Rocks. Their Genesis, Composition, Classification, and their Relation to Ore-Deposits. - 3rd Edition, J. Wiley \& Sons, New York, 488p.

Smith, A. B., Briden, J. C., and Dewey, G. E. (1973): Phanerozoic world maps. - Paleontology, Spec. Paper, v. 12, p. 1-42.

Song, X., Mei, F., Zhi, M., Min, S., and Yun, L. (2003): Ni-Cu-(PGE) magmatic sulfide deposits in the Yangliuping area, Permian Emeishan igneous province, SW China. - Mineralium Deposita, v. 38, p. 831-843.

Spear, F. S. (1993): Metamorphic phase equilibria and pressure-temperature-time paths. Mineralogical Society of America Monograph Series, 2nd Edition, 799p.

Spear, F. S., Kohn, M. J., and Cheney, J. T. (1999): P-T paths from anatectic pelites. - Contrib. Mineral. Petrol., v. 134, p. 17-32.

Staritskiy, Y. G., Maymin, Y. S., and Trofimov, V. A. (1973): Tectonic development of North Vietnam. - Int. Geol. Rev., v. 15, p. 1381-1390.

Steiger, R. H. and Jäger, E. (1977): Subcommission on Geochronology: Convention on the use of Decay Constants in Geo- and Cosmochronology. - Earth Planet. Sci. Lett., v. 36, p. 359-362.

Stosch, H. G. (1999): Einführung in die Isotopengeologie. - Online Publication - Institute of Mineralogy and Geochemistry University of Karlsruhe, 241p.

Suess, E. (1893): Are great ocean depths permanent? - Nat. Sci., v. 2, p. 180-187.

Suess, E. (1901): Das Antlitz der Erde. - 3rd Edition, Tempsky, Wien 
Tapponier, P., Peltzer, G., Armijo, R., Le Dain, A.-Y., and Cobbold, P. (1982): Propagating Extrusion tectonics in Asia: new insights from simple experiments with plasticine. - Geology, 10, p. 611 616.

Tapponier, P., Peltzer, G., and Armijo, R. (1986): On the mechanics of the collision between India and Asia. - In: Coward, M. P., and Ries, A. C. (Eds.): Collision Tectonics. - Geol. Soc. Lond. Spec. Pub., v. 19, p. 1154-1157.

Thompson, R. N., Morrison, M. A., Dickin, A. P., Hendry, G. L. (1983): Continental flood basalts... arachnids rule OK? In: Hawkesworth, C. J. and Norry, M. J. (Eds.): Continental basalts and mantle xenoliths. - Nantwich, Shiva, p. 158-185.

Thompson, R. N., Morrison, M. A., Hendry, G. L., and Parry, S. J. (1984): An assessment of the relative roles of crust and mantle in magma genesis: an elemental approach. - Phil. Trans R. Soc. Lond., v. A310, p. 549-90.

Thompson, R. N., Morrison, M. A., and Dickin, A. P. (1986): Two contrasting styles of interaction between basic magmas and continental crust in the British Tertiary Province. - J. Geophys. Res., v. 91 , p. $5,985-5,997$.

Töfke, T., Lumjuan, A., and Helmcke, D. (1993): Triassic syn-orogenic siliciclastics from the area of Mae Sariang (northwestern Thailand). - Intern. Symp. on Biostratigraphy of Mainland Southeast Asia: Facies \& Paleontology, v. 2, p. 391-400.

Toriyama, R., Pitakpaivan K., and Ingavat, R. (1978): The Paleogeographic Characteristics of Fusuline Faunas of the Rat Buri Group in Thailand and its equivalent in Malaysia. - In: Nutalaya, P. (Eds.): Proc. 3rd Conf. on Geol. and Mineral Resources of Southeast Asia, Bangkok, p. 107111.

Turner, F. J. (1981): Metamorphic Petrology: Mineralogical, Field, and Tectonic Aspects. - McGrawHill. New York.

Ueno, K. (1999): Gondwana/Tethys divide in East Asia: solution from Late Palaeozoic Foraminiferal Paleobiogeography. - Intern. Symp. Shallow Tethys, 5, Chiang Mai, p. 45-54.

Ueno, K. (2002): The Permian fusulinoidean faunas of the Sibumasu and Baoshan blocks; their implications for the paleogeographic and paleoclimatologic reconstruction of the Cimmerian continent. - Paleogeography, Paleoclimatology, Paleoecology, v. 193, p. 1-24.

Wagner, B. (1998): Strukturelle Auswertung von LANDSAT-TM(5)-Szenen aus NW-Yunnan (China). - unpublished Diploma-thesis, 55 p., University of Göttingen.

Wagner, B. (2003): GIS-basierte Analyse der känozoischen Geotektonik und Mineralisationsgeschichte an der östlichen Synthaxis des Himalaya (NW-Yunnan, V. R. China). - unpublished Ph.D.-thesis, University of Göttingen, 99p.

Wagner, B., Zhang, D., Bannert, D., Helmcke, D., and Zhang, Y. (2001): Extensional tectonics in Middle and Upper Triassic sediments on the western margin of the Yangtze Platform, Yunnan Province, P. R. of China. - Zbl. Geol. Paläont., Part 1, Issue 1/2, p. 233-244.

Wang, Y. (1983): The characteristics and significance of Carboniferous gravel bed in Tengchong and Baoshan area, western Yunnan. In: Contribution to the Geology of the Qinghai-Xizang Plateau, v. 11, Geological Publishing House Beijing.

Wang, Y. (1997): Geological structures and tectonic settings in the Changning Menglian zone, western Yunnan. - Tethyan Geology, v. 21, p. 31-49. (in Chinese)

Wang, Y., Bannert, D., Helmcke, D., Ingavat-Helmcke, R., Steinbach, V. Duan, J., Zhang, G., and Bei, J. (1997): Contribution to the plate-tectonic interpretation of Sanjiang-Area of Western Yunnan. - Proc. 30th Intern. Geol. Congr., v. 6, p. 105-119.

Wang, E., and Burchfiel, B. C. (1997): Interpretation of Cenozoic Tectonics in the Right-Lateral Accommodation Zone between the Ailaoshan Shear Zone and the Eastern Himalayan Syntaxis. - Int. Geol. Rev., v. 39, p. 191-219.

Wang, X. D., Ueno, K., Mizuno, Y., and Sugiyama, T. (2001): Late Paleozoic faunal, climatic. and geographic changes in the Baoshan block as a Gondwana-derived continental fragment in southwest China. - Paleogeography, Paleoclimatology, Paleoecology, v. 170, p. 197-218. 
Warr, L. N., and Rice, A. H. N. (1994): Interlaboratory standardization and calibration of clay mineral crystallinity and crystallite size data. - J. of Metam. Geol., V. 12, p. 141-152.

Weaver, C. E. (1960): Possible uses of clay minerals in search for oil. - Amer. Ass. Petrol. Geol. Bull., v. 44, p. 1,505-1,518.

Wemmer, K. (1991): K/Ar-Alterdatierungsmöglichkeiten für retrograde Deformationsprozesse im spröden und duktilen Bereich. - Beispiele aus der KTB-Vorbohrung (Oberpfalz) und dem Bereich der Insubrischen Linie (N-Italien). - Göttinger Arb. Geol. Paläont., v. 51, p. 1-61.

Wernicke, B. (1981): Low-angle normal faults in the basin and Range Province: nappe tectonics in an extending orogen. - Nature, v. 291, p. 645-648.

Wernicke, B. (1985): Uniform-sense normal simple shear of the continental lithosphere. - Canadian J. of Earth Sci., v. 22, p. 108-125.

White, A. J. R., and Chappell, B. W. (1983): Granitoid types and their distribution in the Lachland Fold Belt, southeastern Australia. - Geol. Soc. Am. Mem., v. 159, p. 169-81.

White, R. S., and McKenzie, D. P. (1989): Magmatism at rift zones: the generation of volcanic continental margins and flood basalts. - J. of Geophys. Res., v. 94, p. 7,685-7,729.

Wilson, M. (1997): Igneous Petrogenesis - a global tectonic approach. - Chapman \& Hall, 466p.

Winkler, H. G. F. (1976): Petrogenesis of Metamorphic Rocks. - 4th edition, Springer-Verlag, New York, 334p.

Winter, J. D. (2001): An introduction to igneous and metamorphic petrology. - Prentice Hall, New York, 697p.

Wopfner, H. (1996): Gondwana origin of the Baoshan and Tengchong terranes of West Yunnan. In: Hall, R., and Blundell, D. (Eds.): Tectonic Evolution of Southeast Asia. - Geol. Soc. Spec. Pub.,106, p. 539-547.

Wu, J. (1975): The Ailao Mountains-Tengtiao River fracture - a plate subduction zone. Acta Geol. Sinica. (... imprecise reference from Fan, C., and Zhang, Y. (1994): The structure and tectonics of western Yunnan. - J. of Southeast Asian Earth Sci., v. 9, p. 355-361.)

Wu, G. (1991): Development of Jurassic-Quarternary basins in Western Yunnan, China and Thailand: a comparative study. - Scientia Geol. Sinica, v. 4, p. 259-368.

Wu, G. (1996): On pre-Jurassic stratigraphy of West Yunnan, China. - J. of Strat., v. 20, p. 114-122. (in Chinese)

Wu, G. (1999): Sedimentary records of Paleotethysides in Southwest Yunnan, China. - Intern. Symp. Shallow Tethys, 5, Chiang Mai, p. 136-152.

Wu, H., Boulter, C. A., Ke B., Stow, D. A. V., and Wang, Z. (1995) The Changning - Menglian suture Zone. - A segment of the mayor Cathaysian-Gondwana divide in Southeast Asia. Tectonophysics, v. 242, p. 267-280.

Xiong, J. (1984): Variscan Orogeny in Southwestern Sanjiang Folded Belt. - Regional Geol. of China, v. 9, p. 9-16.

Xu, Y., Chung, S., Jahn, B., and Wu, G. (2001): Petrologic and geochemical constraints on the petrogenesis of Permian-Triassic Emeishan flood basalts in southwestern China. - Lithos, 58, p. 145-168.

Xue, X., Xiong, J., Cai, L., Hu, Y., Cheng, D., and Huang, M. (1989): Yunnan metamorphic complexes. - Explanation of the Metamorphic Map of Yunnan Province on the Scale of 1:2,000,000 - Science Technical Publishing House of Yunnan, 98p. (in Chinese with English abstract)

Yang, K., Mo, X. (1993): Late Paleozoic rifting-related volcanic rocks and tectonic evolution in southwestern Yunnan. - Acta Petrologica et Mineralogica Sinica, v. 12/4, p. 297-311. (in Chinese)

Yang, K., Mo, X., Zhu, Q. (1994): Tectonic volcanic belt and Late Paleozoic-Early Mesozoic evolution of southwestern Yunnan, China. - J. of Southeast Asian Earth Sci., v. 10, p. 245-262.

Yano, T., Wu, G., Mingqing, T., and Shaoli, S. (1994): Tectono-sedimentary development of back arc continental basin in Yunnan, southern China. - J. of Southeast Asian Earth Sci., v. 9, No. 1/2, p. 153-166. 
Yardley, B. W. D. (1996): An introduction to metamorphic rocks. - Longman Earth Science Series, Prentice Hall, New York.

YBGMR (1990): Regional geology of Yunnan Province. - Geological Memoirs, Series 1, Number 21, Ministry of Geology and Mineral Resources, Peoples Republic of China, Bureau of Geology and Mineral Resources of Yunnan Province, Geological Publishing House, Beijing, China.

Young, C. C. (1940): Preliminary notes on the Mesozoic mammals of Lufeng, Yunnan. - Bull. Geol. Soc. China, v. 20, p. 93-11.

Yu, Z., Robinson, P., Townsend, A. T., Münker, C., and Crawford, A. J. (1999): Determination of High Field Strength Elements, Rb, Sr, Mo, Sb, Cs, $\mathrm{Tl}$ and $\mathrm{Bi}$ at $\mathrm{ng} \mathrm{g}^{-1}$. Levels in Geological Reference Material by Magnetic Sector ICP-MS after HF/CLO4 High Pressure Digestion. Geostandards Newsletter. - The Journal of Geostandards and Geoanalysis, v. 10, p. 39-50.

Zhai, M., Cong, B., and Zhang R. (1990a): Sm-Nd and Rb-Sr geochronology of metamorphic rocks from SW Yunnan orogenic zones, China. - Acta Petrologica Sinica, v. 4, p. 1-11. (in Chinese)

Zhai, M., Cong, B., and Zhang, R. (1990b): Distinguishing of two volcanic rock series in the Lancang Group, Yunnan Province, SW China and its geological implication. - Sci. in China (Series B), v. 32, p. 968-969.

Zhang, Zh. M., Liou, J. G., and Coleman, R. G. (1984): An outline of the plate tectonics of China. - Geol. Soc. Am. Bull., v. 95, p. 295-312.

Zhang, Q., Li, D. Z., and Zhang, K. W. (1985): Preliminary study on Tongchangjie ophiolite melange from Yun county, Yunnan Province. - Acta Petrologica Sinica, v. 3, p. 1-14. (in Chinese).

Zhang, Q., Zhang, K. W., Li, D. Z., and Wu, H. W. (1988): A preliminary study of Shuanggou ophiolite in Xinping county, Yunnan Province. - Acta Petrologica Sinica, v. 4, p. 37-48. (in Chinese)

Zhang, Q., Zhou, D., Zhao, D., Peng, X., Luo, W., and Liu, X. (1996a): Wilson Cycle of the PaleoTethyan orogenic belt in western Yunnan: record of magmatism and discussion on mantle processes. - Acta Petrologica Sinica, v. 12, p. 17-28.

Zhang, R., Cong, B., Maruyama, S., and Liou, J. G. (1993): Metamorphism and tectonic evolution of the Lancang paired metamorphic belts, southwestern China. - J. metamorphic Geol., v. 11, p. 605-619.

Zhang, S., Mo, X., and Zhu, Q. (1996b): Geochemical characteristics and tectonic settings of Late Paleozoic volcanic rocks in Menglian area, southwestern Yunnan. - Journal of Graduate School, China University of Geosciences, v. 9, p. 391-401.

Zhao, S. (1986): Physical geography of China. - Science Press Beijing, 209p.

Zhao, J. (1991): Characteristics of deformation and metamorphism of Lancang metamorphic belt and tectonic evolution of Paleotethys. Dianxi, unpublished PhD.-thesis, Institute of Geology, Academia Sinica, Beijing. (in Chinese)

Zhong, D., and others (1999): Tectonic evolutional characteristics of the Eastern Paleotethys in Southwest China. - Intern. Symp. Shallow Tethys, 5, Chiang Mai, p. 153-164.

Zhong, D., and others (2000): Paleotethysides in West Yunnan and Sichuan, China. - Beijing and VSP, Utrecht, Science Press, 248p.

Zhou, W., and Lin, W. (1982): The features of the glaucophane schist in the southern part of the Lancangjiang metamorphic belt. - Regional Geol. of China, v. 2, p. 76-85. (in Chinese with English abstract).

Zhou, Z., and Fang, Z. (1990): Depositional Environments of the Dingjiazhai Formation of Yunnan and the genesis of its bottom pebble-bearing layer. - J. of Strat., v. 14, p. 36-43.

Zhou, Z., Fang, Z., Wang, Y., and Xiao, Y. (1999): Restudies on the depositional environments of the Dingjiazhai Formation in Shidian of Yunnan and the genesis of its bottom pebble-bearing layer. - Acta Sedimentologica Sinica, v. 17, p. 691-698.

Zhu B., Hu Y., and Chang, X. (2003): The extreme coupling conditions for native mineralization on large scale in the border area between Yunnan and Guizhou Province China. - Guangzhou Institute of Geochemistry. (report in Chinese) 
Zindler, A. and Hart, S. (1986): Chemical geodynamics. - Ann. Rev. Earth Planet. Sci., v. 14, p. 493571.

Zonenshain, L. P., Kuzmin, M. I., Naptov, L. M. (1990): Geology of the USSR: A plate tectonic synthesis. - AGU Geodynamic Series, Monography 21. 


\section{Appendix}

\section{A. Analytical Techniques}

\section{A - 1. Major- and Trace Elements by XRF and ICPMS}

Thirty-two rock samples of 1-2 kg each were selected for chemical analysis. The samples were crushed, splitted, and about $100 \mathrm{~g}$ of rock chips were powderized in a Planetary Mill "pluverisette5" from Fritsch $\mathrm{GmbH}$, Germany. Acid pressure digestion was performed with a mixture of concentrated, subboilingly distilled $\mathrm{HF} / \mathrm{HClO}_{4}$ in the $\mathrm{TC} 805$ system of PicoTrace (Bovenden, Germany). More details and reagents and sample decomposition are outlined in Yu et al. (1999). Major and trace elements of fifteen samples were analyzed by X-ray fluorescence (XRF) and inductively coupled plasma mass spectrometry (ICPMS) at the Geochemisches Institut, University of Göttingen, Germany. XRF analyses were carried out on a Philips PW 1480 spectrometer. $\mathrm{H}_{2} \mathrm{O}$ was analyzed by Karl Fischer titration, $\mathrm{CO}_{2} / \mathrm{S}$ using an Eltra CS 1000RF infrared absorption spectrometer, and FeO was titrated following Heinrichs and Herrmann (1990). Major element contents presented in Table 7 and 8 are all calculated on a $\mathrm{H}_{2} \mathrm{O}$ - and $\mathrm{CO}_{2}$ - free basis. Rare earth elements (REE), high field strength elements (HFSE), and large ion lithophile elements (LILE) were analyzed using the Renaissance LECO TOF-ICPMS at the Geochemisches Institut, Göttingen. Further, seventeen samples were analyzed by XRF at the RFA-Labor, Bundeanstalt für Geowissenschaften und Rohstoffe (BGR), Germany and the rare-earth elements (REE), high-field-strength elements (HFSE), and large-ionlithophile elements (LILE) were commissioned to Act-Labs, Canada, for ICPMS analysis. For all samples, $\mathrm{H}_{2} \mathrm{O}, \mathrm{CO}_{2}, \mathrm{~S}$, and $\mathrm{FeO}$ were calculated as a mean of three measurements. The reproducibility of the measurements was within a few percent and the accuracy was checked by reference samples.

\section{A - 2. Sm-Nd / Rb-Sr Isotope Geochemistry}

Sr- and $\mathrm{Nd}$ isotopic compositions and concentrations of seventeen powderized samples (Table 11) were analyzed by the conventional isotope dilution method at the Abteilung für Isotopengeologie, University of Göttingen. Approximately $100 \mathrm{mg}$ of the powdered samples were weighed into $30 \mathrm{ml}$ PTFE digestion vessels, spiked with suitable amounts of mixed ${ }^{84} \mathrm{Sr}-{ }^{87} \mathrm{Rb}$ and ${ }^{149} \mathrm{Sm}-{ }^{150} \mathrm{Nd}$ spike solutions and finally dissolved in a mixture of HF-HNO3-HClO4 using a PicoTrace TC 805 Pressure Digestion System (PicoTrace, Bovenden, Germany). For purification, the sample solutions were processed by standard cation-exchange techniques. $\mathrm{Sr}, \mathrm{Sm}$, and $\mathrm{Nd}$ isotopic ratios were determined by thermal ionization mass spectrometry on a ThermoFinnigan Triton spectrometer operating in static mode. About 300 to 500 ng of the purified Sr-, Sm- and Nd-fractions were loaded with $0.5 \mathrm{~N} \mathrm{H}_{3} \mathrm{PO} 4(\mathrm{Sr})$ and $2.5 \mathrm{~N} \mathrm{HCl}(\mathrm{Sm}, \mathrm{Nd})$ on preconditioned Refilaments and arranged in double-filament configuration for measurement. The obtained ${ }^{87} \mathrm{Sr} /{ }^{86} \mathrm{Sr}$ isotope ratios were normalized to an ${ }^{88} \mathrm{Sr} /{ }^{86} \mathrm{Sr}$ ratio of 0.1194 , and the ${ }^{143} \mathrm{Nd} /{ }^{144} \mathrm{Nd}$ isotope ratios to a ${ }^{146} \mathrm{Nd} /{ }^{144} \mathrm{Nd}$ ratio of 0.7219 . Throughout the study, reiterated measurements resulted in an ${ }^{87} \mathrm{Sr} /{ }^{86} \mathrm{Sr}$ ratio of $0.710245 \pm 10(\mathrm{n}=7,2 \sigma)$ for the NBS987 strontium standard, and in a ${ }^{143} \mathrm{Nd} /{ }^{144} \mathrm{Nd}$ isotopic ratio of $0.511845 \pm 3(\mathrm{n}=6$, $2 \sigma)$ for the La Jolla neodymium standard. The total procedure blanks for $\mathrm{Sr}$ and $\mathrm{Nd}$ are 
less than 50pg and are therefore negligible compared to the amounts extracted from the samples. All analytical errors of isotopic ratios are given at the $2 \sigma$ confidence level. $\varepsilon \mathrm{Nd}$ values were calculated after De Paolo and Wasserburg (1976) for $\mathrm{t}=0$, where CHUR has a ${ }^{143} \mathrm{Nd} /{ }^{144} \mathrm{Nd}$ value of 0.512638 . $(\mathrm{Nd}) \mathrm{T}_{\mathrm{DM}}$ model ages [Ma] were calculated in respect to the evolution of the depleted mantle reservoir (with ${ }^{143} \mathrm{Nd} /{ }^{144} \mathrm{Nd}=0.513151$ and ${ }^{147} \mathrm{Sm} /{ }^{144} \mathrm{Nd}=0.214$ ) following Stosch (1999, Equation 43).

\section{A - 3. K-Ar Geochronology and Illite Crystallinity (IC) Measurements}

Phyllites and schists of 2-3 kg were sampled to process the separation of the fine fractions $>2 \mu \mathrm{m}$ and $<0,2 \mu \mathrm{m}$ for $\mathrm{K} / \mathrm{Ar}$ age determinations. The rocks were crushed and ground in a shatter mill (vibration mill) for about $20 \mathrm{sec}$. and split into sizes $>63 \mu \mathrm{m}$ and $<63 \mu \mathrm{m}$. The fractions $>63 \mu \mathrm{m}$ were used to extract the clay fractions $<2 \mu \mathrm{m}$ by settling in Atterberg cylinders. A second $<2 u m$ fraction was gained the same way and used to separate the fractions $<0.63 \mu \mathrm{m}$ using an ultra-centrifuge. In mica- and qtz-mica schist, where large muscovites were observable, the crystals were handpicked under a microscope and prepared for direct K-Ar analysis. In contrast, the fine fractions were examined by XRD for mineralogical composition and determination of illite crystallinity (cf. Table 2 and 3). IC-values have shown to be sensitive indicators of very low grade metamorphism in clastic sediments. Since the beginning of the development of this method by Weaver (1960) and Kübler (1967) many publications have proven the usefulness of IC in many applications. Reviews of the preparation techniques and the interpretation of IC values are given by Kisch (1991) and Krumm (1992). Illite crystallinity, the peak width at half height of the 10-Angstrom peak, was determined using a computer program developed at the University of Göttingen. Digital measurements of IC was carried out by step scan (301 points, $7-10^{\circ}(2 \theta)$, scan step $0.010^{\circ}(2 \theta)$, integration time 4 sec., receiving slit $0.1 \mathrm{~mm}$, automatic divergence slit). All samples have been investigated as duplicates (A and B). The measurements were carried out in the "airy dry" and the "glycolated" status in order to detect expandable layers of smectite type minerals. IC-values are given in $\left(\Delta^{\circ} 2 \theta\right)$. The limits for diagenesis/anchizone and anchizone/epizone are $0.600^{\circ}$ and $0.240^{\circ}\left(\Delta^{\circ} 2 \theta\right)$, respectively. These limits were checked in the inter-laboratory standardization programme of Warr and Rice (1994). - The argon isotopic composition was measured in a pyrex glass extraction and purification line coupled to a VG $1200 \mathrm{C}$ noble gas spectrometer operating in static mode. The amount of radiogenic ${ }^{40} \mathrm{Ar}$ was determined by isotope dilution method using a highly enriched ${ }^{38} \mathrm{Ar}$ spike from Schumacher, Bern (Schumacher, 1975). The spike is calibrated against the biotite standard HD-B1 (Fuhrmann et al., 1987). The age calculations are based on constants recommended by the IUGS quoted in Steiger and Jäger (1977). Potassium was determined in duplicate by flame photometry using an Eppendorf Elex 63/61. The samples were dissolved in a mixture of $\mathrm{HF}$ and $\mathrm{HNO}_{3}$ according to the technique by Heinrichs and Herrmann (1990). $\mathrm{CsCl}$ and $\mathrm{LiCl}$ were added as an ionisation buffer and internal standard respectively . The analytical error for the K/Ar age calculations is given on 95\% confidence level (2s). Details of argon and potassium analysis for the laboratory in Göttingen are given in Wemmer (1991). 


\section{A - 4. Ar-Ar Geochronology}

${ }^{40} \mathrm{Ar} / 39 \mathrm{Ar}$ incremental heating analysis was performed at the Massachusetts Institute of Technology, Cambridge, USA, using the similar procedures described by Hodges (1998). Prior to analysis, the handpicked phengites of sample 02/132 were irradiated in the C5 position of the McMaster University Nuclear Reactor for fifteen hours with a total power of $30 \mathrm{MW}$. The conversion efficiency of ${ }^{39} \mathrm{~K}$ to ${ }^{39} \mathrm{Ar}$ was monitored using Taylor Creek rhyolite with an assumed age of 28.34 Ma (Renne et al., 1998). The sample was incrementally heated in a resistance furnace to the temperatures that were preset. For each temperature increment the heating lasted for 10 minutes. The released gases were purified for another 10 minutes with $\mathrm{Al}-\mathrm{Zr}$ and Fe-Zr-V getters and then admitted to an MAP 215-50 mass spectrometer for Ar isotopic analysis using an electronic multiplier. The final data reduction was conducted with the program ArArCalc (Koppers, 2002). Corrections for neutron-induced interference were made by the factors previously determined using $\mathrm{K}_{2} \mathrm{SO} 4$ and $\mathrm{CaF}_{2}$ salts. The value of the irradiation parameter $\mathrm{J}$ determined from the measurement of the monitor is 0.003858 with uncertainty of less than $0.5 \%$.

\section{A - 5. Electron Microprobe Analysis}

Wavelength dispersive microprobe analyses of eleven amphiboles of sample 02/143 were performed with a JEOL JXA 8900 RL equipped with 5 WDS detectors at the Geochemische Insitut, Göttingen University. For quantitative measurements, $15 \mathrm{kV}$ acceleration voltage, $15 \mathrm{nA}$ beam current on the Faraday cup, defocused beam of $5 \mathrm{~mm}$ and counting times between $15 \mathrm{sec}$ on the peak for $\mathrm{Na}, \mathrm{Mg}, \mathrm{Al}, \mathrm{Si}, \mathrm{Ca}$, and $\mathrm{Fe}$ and 30 sec for $\mathrm{K}, \mathrm{Cr}, \mathrm{Ba}$, and $\mathrm{Mn}$ were chosen. The phi-rho-z matrix correction method for the raw counts was employed (Armstrong, 1995). The following standards were used for the analysis: albite for $\mathrm{Na}, \mathrm{MgO}$ (synthetic) for $\mathrm{Mg}, \mathrm{Al}_{2} \mathrm{O}_{3}$ (synthetic) for $\mathrm{Al}$, wollastonite for $\mathrm{Si}$ and $\mathrm{Ca}$, sanidine for $\mathrm{K}, \mathrm{TiO}_{2}$ (synthetic) for $\mathrm{Ti}_{1} \mathrm{Cr}_{2} \mathrm{O}_{3}$ (synthetic) for $\mathrm{Cr}$, barite $\left(\mathrm{BaSO}_{4}\right.$ ) for $\mathrm{Ba}$, rhodonite for $\mathrm{Mn}$ and hematite for Fe. Detection limit for $\mathrm{K}$ was $300 \mathrm{ppm}$. In order to calculate $\mathrm{Fe}^{2+}$ and $\mathrm{Fe}^{3+}$, the A-site of the amphibole formula was not occupied, whereas $\mathrm{Na}$ and $\mathrm{K}$ is distributed to the $\mathrm{B}$-site (Table 5). 


\section{B. Tables}

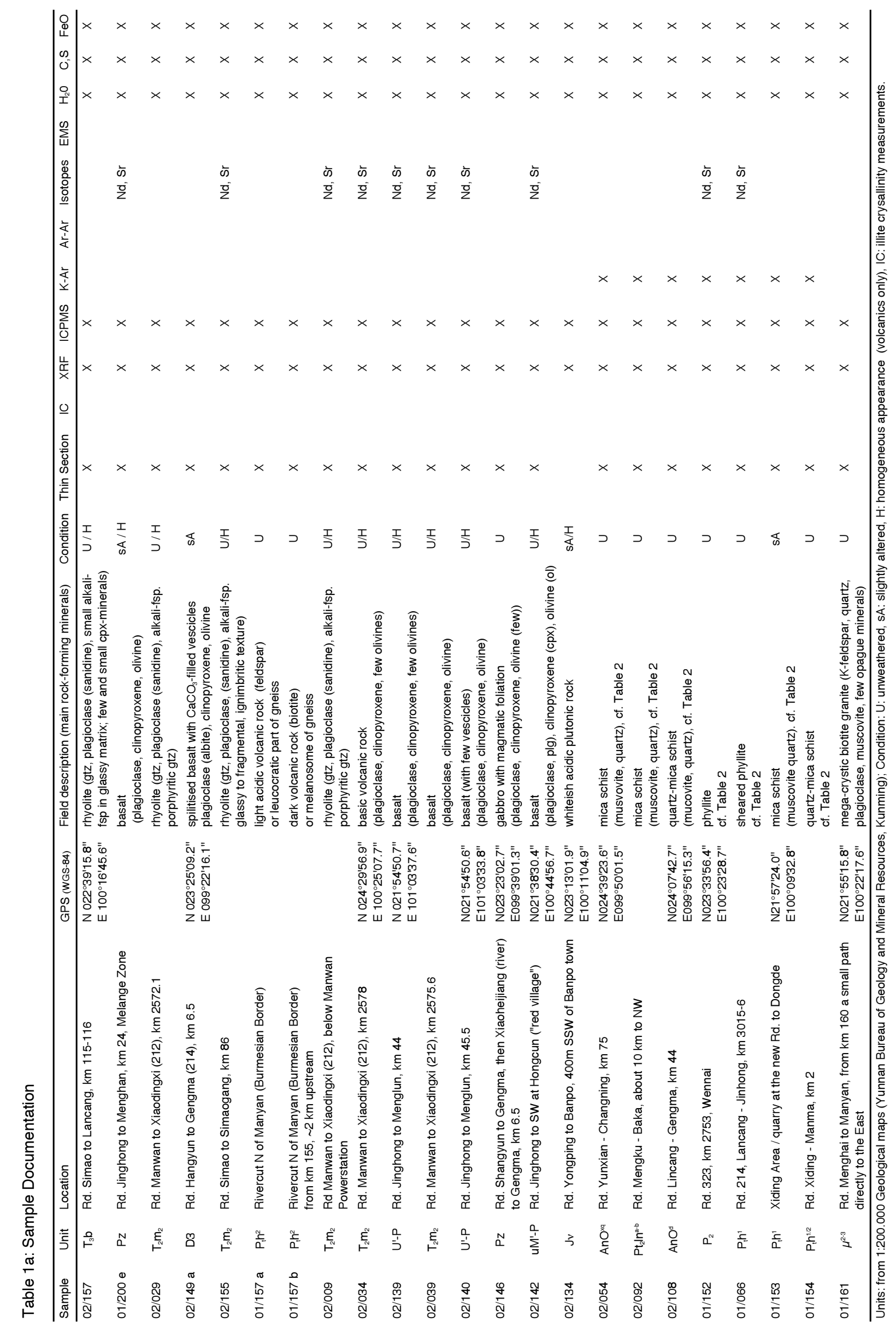




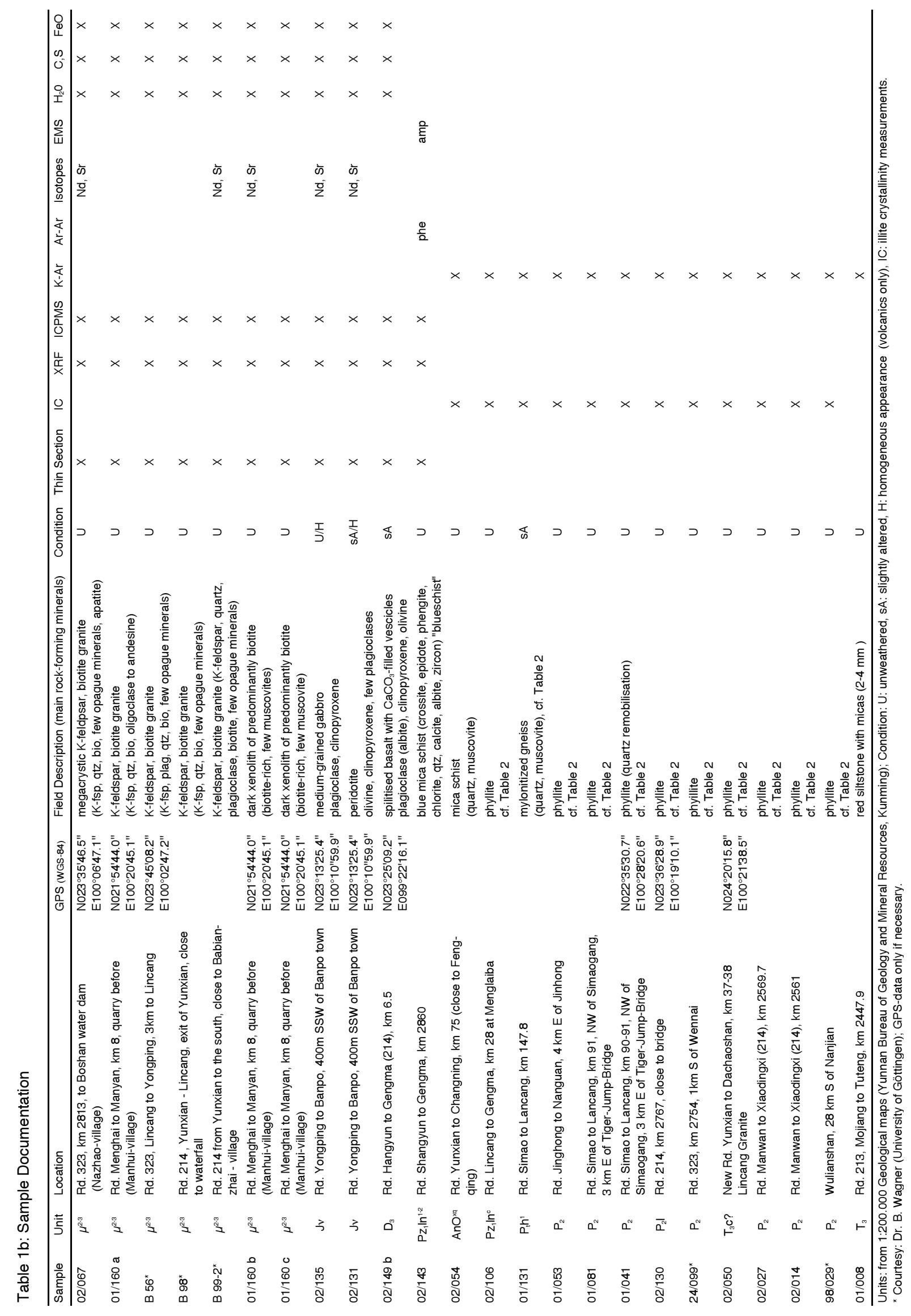


Table 2: Mineralogical composition and illite-crystallinity by X-ray diffractometry of metamorphic rocks from the LRZ.

\begin{tabular}{|c|c|c|c|c|c|c|c|c|c|c|c|c|}
\hline No. & Sample & Location & Rocktype & $\mathrm{Fm}^{\star}$ & Qz & $\begin{array}{l}\text { Illite / } \\
\text { Msc }\end{array}$ & Chl & $A b$ & Kao & $\phi \Delta^{\circ} 2 \theta$ & $\begin{array}{l}\text { Degree of } \\
\text { Metam. }\end{array}$ & $\begin{array}{l}\text { Metam. } \\
\text { Facies }\end{array}$ \\
\hline A & $02 / 054$ & $\begin{array}{l}\text { Rd. Yunxian - Changning } \\
\text { km } 75\end{array}$ & mica-schist & $\mathrm{AnO}^{\times \mathrm{q}}$ & $x$ & $x x$ & O & O & 0 & $\begin{array}{l}0.200 \\
0.200\end{array}$ & $\begin{array}{l}\text { Epizone } \\
\text { Epizone }\end{array}$ & $\begin{array}{l}\text { Green- } \\
\text { schist }\end{array}$ \\
\hline B & $02 / 106$ & $\begin{array}{l}\text { Rd. Lincang - Gengma } \\
\mathrm{km} 28 \text {, Menglaiba }\end{array}$ & phyllite & $P z_{1} \mid n^{c}$ & O & $x x$ & $x$ & O & O & $\begin{array}{l}0.190 \\
0.175\end{array}$ & $\begin{array}{l}\text { Epizone } \\
\text { Epizone }\end{array}$ & $\begin{array}{l}\text { Green- } \\
\text { schist }\end{array}$ \\
\hline C & $01 / 131$ & $\begin{array}{l}\text { Rd. Simao - Lancang } \\
\text { km } 147.8\end{array}$ & mylonitized gneiss & $\mathrm{P}_{\mathrm{t}} \mathrm{h}^{1}$ & $x$ & $x x$ & O & O & $x X$ & $\begin{array}{l}0.210 \\
0.195\end{array}$ & $\begin{array}{l}\text { Epizone } \\
\text { Epizone }\end{array}$ & $\begin{array}{l}\text { Green- } \\
\text { schist }\end{array}$ \\
\hline D & $01 / 066$ & $\begin{array}{l}\text { Rd. 214, Lancang - Jinhong } \\
\text { km 3015-6 }\end{array}$ & mylonitized phyllite & $\mathrm{P}_{\mathrm{t}} \mathrm{h}^{1}$ & $x$ & $\mathrm{x}$ & $x X$ & $(X) ?$ & O & $\begin{array}{l}0.155 \\
0.155\end{array}$ & $\begin{array}{l}\text { Epizone } \\
\text { Epizone }\end{array}$ & $\begin{array}{l}\text { Green- } \\
\text { schist }\end{array}$ \\
\hline E & $01 / 154$ & $\begin{array}{l}\text { Rd. Xiding - Manma } \\
\text { km } 2\end{array}$ & qtz-mica-schist & $\mathrm{P}_{\mathrm{t}} \mathrm{h}^{1 / 2}$ & $x$ & $x x$ & O & O & O & $\begin{array}{l}0.175 \\
0.140\end{array}$ & $\begin{array}{l}\text { Epizone } \\
\text { Epizone }\end{array}$ & $\begin{array}{l}\text { Green- } \\
\text { schist }\end{array}$ \\
\hline $\mathrm{F}$ & $01 / 053$ & $\begin{array}{l}\text { Rd. Jinghong -Nanguan } \\
4 \mathrm{~km} \text { E of Jinhong }\end{array}$ & phyllite & $\mathrm{P}_{2}$ & 0 & $x x$ & $X X$ & 0 & 0 & $\begin{array}{l}0.205 \\
0.180\end{array}$ & $\begin{array}{l}\text { Epizone } \\
\text { Epizone }\end{array}$ & $\begin{array}{l}\text { Green- } \\
\text { schist }\end{array}$ \\
\hline G & $01 / 081$ & $\begin{array}{l}\text { Rd. Simao - Lancang } \\
\text { km 91, NW of Simaogang }\end{array}$ & phyllite & $\mathrm{P}_{2}$ & O & $x x$ & $x$ & O & O & $\begin{array}{l}0.140 \\
0.170\end{array}$ & $\begin{array}{l}\text { Epizone } \\
\text { Epizone }\end{array}$ & $\begin{array}{l}\text { Green- } \\
\text { schist }\end{array}$ \\
\hline $\mathrm{H}$ & $01 / 041$ & $\begin{array}{l}\text { Rd. Simao - Lancang } \\
\text { km 90-91, NW of Simaogang }\end{array}$ & qtz-phyllite & $\mathrm{P}_{2}$ & $(X)$ & $x x$ & $X X$ & O & O & $\begin{array}{l}0.210 \\
0.190\end{array}$ & $\begin{array}{l}\text { Epizone } \\
\text { Epizone }\end{array}$ & $\begin{array}{l}\text { Green- } \\
\text { schist }\end{array}$ \\
\hline I & $02 / 130$ & $\begin{array}{l}\text { Rd. } 214 \\
\text { km } 2767 \text {, close to bridge }\end{array}$ & phyllite & $\mathrm{P}_{2} \mathrm{I}$ & $x$ & $x X$ & $x X$ & 0 & 0 & $\begin{array}{l}0.185 \\
0.185\end{array}$ & $\begin{array}{l}\text { Epizone } \\
\text { Epizone }\end{array}$ & $\begin{array}{l}\text { Green- } \\
\text { schist }\end{array}$ \\
\hline J & $24 / 099$ & $\begin{array}{l}\text { Rd. } 323 \\
\mathrm{~km} 2754,1 \mathrm{~km} \mathrm{~S} \text { of Wennai }\end{array}$ & phyllite & $\mathrm{P}_{2}$ & n.d. ${ }^{\star \star}$ & n.d. & n.d. & n.d. & n.d. & $\begin{array}{l}0.175 \\
0.170\end{array}$ & $\begin{array}{l}\text { Epizone } \\
\text { Epizone }\end{array}$ & $\begin{array}{l}\text { Green- } \\
\text { schist }\end{array}$ \\
\hline K & $02 / 050$ & $\begin{array}{l}\text { Rd. Yunxian - Dachaoshan } \\
\text { E-side of Lincang Granite }\end{array}$ & phyllite & $\mathrm{T}_{3} \mathrm{C}$ & $x$ & $x x$ & $x$ & 0 & 0 & $\begin{array}{l}0.180 \\
0.165\end{array}$ & $\begin{array}{l}\text { Epizone } \\
\text { Epizone }\end{array}$ & $\begin{array}{l}\text { Green- } \\
\text { schist }\end{array}$ \\
\hline L & $02 / 027$ & $\begin{array}{l}\text { Rd. } 214 \\
\text { km 2569.7, S of Manwan }\end{array}$ & phyllite & $\mathrm{P}_{2}$ & $(X)$ & $x x$ & $X X$ & $(X) ?$ & 0 & $\begin{array}{l}0.195 \\
0.190\end{array}$ & $\begin{array}{l}\text { Epizone } \\
\text { Epizone }\end{array}$ & $\begin{array}{l}\text { Green- } \\
\text { schist }\end{array}$ \\
\hline$M$ & $02 / 014$ & $\begin{array}{l}\text { Rd. } 214 \\
\mathrm{~km} 2561 \text {, S of Manwan }\end{array}$ & phyllite & $\mathrm{P}_{2}$ & $(X)$ & $x x$ & $x X$ & $(X)$ & 0 & $\begin{array}{l}0.180 \\
0.215\end{array}$ & $\begin{array}{l}\text { Epizone } \\
\text { Epizone }\end{array}$ & $\begin{array}{l}\text { Green- } \\
\text { schist }\end{array}$ \\
\hline $\mathrm{N}$ & $98 / 029$ & $\begin{array}{l}28 \mathrm{~km} \mathrm{~S} \text { of Nanjian } \\
\text { Wulianshan }\end{array}$ & phyllite & $P_{2}$ & n.d. & n.d. & n.d. & n.d. & 0 & $\begin{array}{l}0.150 \\
0.165\end{array}$ & $\begin{array}{l}\text { Epizone } \\
\text { Epizone }\end{array}$ & $\begin{array}{l}\text { Green- } \\
\text { schist }\end{array}$ \\
\hline
\end{tabular}

* Formation name from geological maps: 1: 200.000 (YBMR, Kunming): $\mathrm{P}_{\mathrm{t}} \mathrm{h}^{2} / \mathrm{P}_{\mathrm{h}} \mathrm{h}^{1}$ (lower/upper Huimin Formation, Lancang Group, Proterozoic): Ptml (Lancang Group); $P z_{1} \mid n^{a-b}$ (lower to middle Lancang Group); $P z_{1} \mid n^{c}$ (upper Lancang Group); AnO (Xiqian-Formation, contin. of Lancang Group on sheet Fengqing); AnO (DatianyakouFormation, Proterozoic); $\mathrm{P}_{2}$ ( upper Permian); $\mathrm{P}_{2}$ (upper Permian), $\mathrm{T}_{3} \mathrm{C}$ (upper of Lancang Group on sheet Fengqing); AnO (Datianyakou-Formation, Proterozoic); $\mathrm{P}_{2} \mathrm{l}$ (upper Permian); $P_{2}$ (upper Permian), $T_{3} C$ (upper Triassic), $T_{3}$ (upper Triassic).

${ }^{\star *}$ not determined (sample $J$ and $N$ from Wagner, 2002) ; XX: major component; X: minor (X): accessory; ?: questionable; O: no component. 
Table 3: K-Ar results on phyllites and schist from the Lancang River Zone.

\begin{tabular}{|c|c|c|c|c|c|c|c|c|c|c|}
\hline Sample No & Rock type & Unit & $\begin{array}{l}\text { Fine Fraction / } \\
\text { Detrital Crystal }\end{array}$ & $\begin{array}{l}\text { Spike } \\
\text { [ No. ] }\end{array}$ & $\begin{array}{c}\mathrm{K}_{2} \mathrm{O} \\
\text { [ wt. \% ] }\end{array}$ & $\begin{array}{c}40 \mathrm{Ar}^{*} \\
{[\mathrm{nl} / \mathrm{g}] \text { STP }}\end{array}$ & $\begin{array}{c}40 \mathrm{Ar}^{\star} \\
{[\%]}\end{array}$ & $\begin{array}{c}\text { Age } \\
{[\mathrm{Ma}]}\end{array}$ & $\begin{array}{c}\text { 2ఠ-Error } \\
{[\mathrm{Ma}]}\end{array}$ & $\begin{array}{c}2 \sigma-E r r o r \\
{[\%]}\end{array}$ \\
\hline \multirow[t]{2}{*}{ 01/066 } & phyllite & $\mathrm{P}_{t} \mathrm{~h}^{1}$ & $<2 \mu \mathrm{m}$ & 2887 & 1.41 & 8.98 & 88.45 & 187.4 & 4.3 & 2.3 \\
\hline & & & $<0.2 \mu \mathrm{m}$ & 2865 & 1.30 & 7.62 & 58.54 & 173.2 & 6.2 & 3.6 \\
\hline \multirow[t]{2}{*}{$01 / 131$} & gneiss & $\mathrm{P}_{t} \mathrm{~h}^{1}$ & $<2 \mu \mathrm{m}$ & 2884 & 3.58 & 19.55 & 86.12 & 161.8 & 3.8 & 2.3 \\
\hline & & & $<0.2 \mu \mathrm{m}$ & 2855 & 5.11 & 23.37 & 87.14 & 136.5 & 3.2 & 2.3 \\
\hline \multirow[t]{2}{*}{$01 / 154$} & quartz-mica schist & $\mathrm{P}_{t} \mathrm{~h}^{1 / 2}$ & $<2 \mu \mathrm{m}$ & 2889 & 8.35 & 46.62 & 96.62 & 165.3 & 3.5 & 2.1 \\
\hline & & & $<0.2 \mu \mathrm{m}$ & 2857 & 6.76 & 35.60 & 94.33 & 156.3 & 3.4 & 2.2 \\
\hline \multirow[t]{2}{*}{ 01/041 } & phyllite & $\mathrm{P}_{2}$ & $<2 \mu \mathrm{m}$ & 2891 & 4.32 & 32.65 & 92.22 & 220.4 & 4.8 & 2.2 \\
\hline & & & $<0.2 \mu \mathrm{m}$ & 2862 & 3.79 & 27.29 & 90.92 & 210.5 & 4.8 & 2.3 \\
\hline \multirow[t]{2}{*}{ 01/053 } & phyllite & $\mathrm{P}_{2}$ & $<2 \mu \mathrm{m}$ & 2893 & 3.70 & 25.33 & 94.03 & 200.7 & 4.9 & 2.4 \\
\hline & & & $<0.2 \mu \mathrm{m}$ & 2860 & 2.88 & 18.02 & 92.33 & 184.3 & 6.2 & 3.4 \\
\hline \multirow[t]{2}{*}{$01 / 153^{\star}$} & mica schist & $\mathrm{P}_{\mathrm{t}} \mathrm{h}^{1}$ & $<2 \mu \mathrm{m}$ & 2998 & 2.82 & 6.79 & 69.54 & 73.2 & 2.1 & 2.9 \\
\hline & & & $<0.2 \mu \mathrm{m}$ & 2874 & 2.61 & 5.53 & 62.82 & 64.6 & 2.1 & 3.3 \\
\hline \multirow[t]{2}{*}{ 01/081 } & phyllite & $P_{2}$ & $<2 \mu \mathrm{m}$ & 2897 & 6.20 & 45.71 & 93.34 & 215.2 & 4.6 & 2.1 \\
\hline & & & $<0.2 \mu \mathrm{m}$ & 2880 & 4.61 & 32.14 & 91.70 & 204.2 & 4.8 & 2.4 \\
\hline \multirow[t]{2}{*}{ 02/014 } & phyllite & $\mathrm{P}_{2}$ & $<2 \mu \mathrm{m}$ & 3090 & 4.12 & 22.76 & 87.47 & 163.6 & 4.3 & 2.6 \\
\hline & & & $<0.2 \mu \mathrm{m}$ & 3058 & 3.85 & 19.66 & 99.01 & 151.8 & 3.1 & 2.0 \\
\hline \multirow[t]{2}{*}{$02 / 027$} & phyllite & $\mathrm{P}_{2}$ & $<2 \mu \mathrm{m}$ & 3087 & 4.99 & 22.74 & 82.37 & 136.1 & 3.3 & 2.4 \\
\hline & & & $<0.2 \mu \mathrm{m}$ & 3060 & 4.65 & 18.01 & 83.98 & 116.3 & 3.2 & 2.8 \\
\hline \multirow[t]{2}{*}{ 02/050 } & phyllite & $\mathrm{T}_{3} \mathrm{C} ?$ & $<2 \mu \mathrm{m}$ & 3091 & 5.58 & 25.80 & 85.21 & 138.0 & 3.2 & 2.3 \\
\hline & & $\left(\mathrm{P}_{2}\right) !$ & $<0.2 \mu \mathrm{m}$ & 3062 & 5.73 & 23.75 & 80.58 & 124.1 & 3.9 & 3.1 \\
\hline \multirow[t]{2}{*}{ 02/054 } & mica schist & $A n O^{\times a}$ & $<2 \mu \mathrm{m}$ & 3097 & 5.38 & 34.22 & 97.39 & 187.2 & 3.9 & 2.1 \\
\hline & & & $<0.2 \mu \mathrm{m}$ & 3064 & 5.30 & 29.86 & 93.49 & 166.8 & 4.5 & 2.7 \\
\hline \multirow[t]{2}{*}{$02 / 106$} & phyllite & $P_{z}^{1} \mid n^{c}$ & $<2 \mu \mathrm{m}$ & 3077 & 7.31 & 55.50 & 97.75 & 221.3 & 4.5 & 2.0 \\
\hline & & & $<0.2 \mu \mathrm{m}$ & 3067 & 4.87 & 34.93 & 93.85 & 209.7 & 4.5 & 2.1 \\
\hline \multirow[t]{2}{*}{$02 / 130$} & phyllite & $\mathrm{P}_{2} \mathrm{I}$ & $<2 \mu \mathrm{m}$ & 3094 & 5.01 & 36.61 & 88.59 & 210.7 & 5.6 & 2.7 \\
\hline & & & $<0.2 \mu \mathrm{m}$ & 3069 & 4.70 & 32.88 & 95.19 & 204.8 & 4.7 & 2.3 \\
\hline \multirow[t]{2}{*}{ Wagner $^{*}$} & phyllite & $\mathrm{P}_{2}$ & $<2 \mu \mathrm{m}$ & 2627 & 5.79 & 67.08 & 93.56 & 327.8 & 7.1 & 2.2 \\
\hline & & & $<0.2 \mu \mathrm{m}$ & 2629 & 5.16 & 56.45 & 88.94 & 311 & 7 & 2.3 \\
\hline 01/008 & red siltstone & $\mathrm{T}_{3}$ & detr. muscovite & 2886 & 10.16 & 86.27 & 98.44 & 245.8 & 5.0 & 2.0 \\
\hline 02/092 & mica schist & $P z_{1} \mid n^{a-b}$ & detr. muscovite & 3066 & 10.67 & 84.92 & 98.50 & 231.3 & 4.7 & 2.0 \\
\hline $02 / 108$ & quartz-mica schist & $\mathrm{P}_{2}$ & detr. muscovite & 3068 & 9.88 & 81.81 & 99.35 & 240.1 & 5.5 & 2.3 \\
\hline $02 / 152$ & phyllite & $\mathrm{P}_{2}$ & detr. muscovite & 3047 & 9.75 & 204.11 & 98.19 & 554.5 & 12.8 & 2.3 \\
\hline
\end{tabular}

* sample from Feng et al. (2001)

\begin{tabular}{llllr}
\hline $\begin{array}{l}\text { Information } \\
\text { on Analysis: }\end{array}$ & \multicolumn{3}{c}{ Laboratory: Dr. K. Wemmer / Abteilung für Geochronologie } \\
University of Göttingen
\end{tabular}


Table 4: K/Ar-ages of metamorphic rocks from the Lancang-River-Zone, Yunnan

\begin{tabular}{|c|c|c|c|c|c|c|c|c|}
\hline No. & Sample & Location & $\begin{array}{l}\text { Coordinates } \\
\text { (WGS84) }\end{array}$ & Rocktype & $\mathrm{Fm}^{\star}$ & Fraction & $\begin{array}{l}\text { Age } \\
{[\mathrm{Ma}]}\end{array}$ & $\begin{array}{c}\text { 2s-Error } \\
{[\mathrm{Ma}]}\end{array}$ \\
\hline \multirow[t]{2}{*}{ A } & $02 / 054$ & Rd. Yunxian - Changning & N02439'23.6" & mica-schist & $\mathrm{AnO}^{\times \mathrm{a}}$ & $<2 \mu \mathrm{m}$ & 187.2 & 3.9 \\
\hline & & $\mathrm{km} 75$ & E09950'01.5" & & & $<0.2 \mu \mathrm{m}$ & 166.8 & 4.5 \\
\hline \multirow[t]{2}{*}{ B } & $02 / 106$ & Rd. Lincang - Gengma & N0235ํ'22.6" & phyllite & $P z_{1} \mid n^{c}$ & $<2 \mu \mathrm{m}$ & 221.3 & 4.5 \\
\hline & & $\mathrm{km} 28$, Menglaiba & E09955'02.9" & & & $<0.2 \mu \mathrm{m}$ & 209.7 & 4.5 \\
\hline \multirow[t]{2}{*}{ c } & $01 / 131$ & Rd. Simao - Lancang & n.d. .* & mylonitized gneiss & $\mathrm{P}_{\mathrm{t}} \mathrm{h}^{1}$ & $<2 \mu \mathrm{m}$ & 161.8 & 3.8 \\
\hline & & $\mathrm{km} 147.8$ & n.d. & & & $<0.2 \mu \mathrm{m}$ & 136.5 & 3.2 \\
\hline \multirow[t]{2}{*}{$\mathrm{D}$} & $01 / 066$ & Rd. 214, Lancang - Jinhong & n.d. & sheared phyllite & $P_{t} h^{1}$ & $<2 \mu \mathrm{m}$ & 187.4 & 4.3 \\
\hline & & km 3015-6 & n.d. & & & $<0.2 \mu \mathrm{m}$ & 173.2 & 6.2 \\
\hline \multirow[t]{2}{*}{ E } & $01 / 154$ & Rd. Xiding - Manma & n.d. & qtz-mica-schist & $\mathrm{P}_{\mathrm{t}} \mathrm{h}^{1 / 2}$ & $<2 \mu \mathrm{m}$ & 165.3 & 3.5 \\
\hline & & $\mathrm{km} 2$ & n.d. & & & $<0.2 \mu \mathrm{m}$ & 156.3 & 3.4 \\
\hline \multirow[t]{2}{*}{$\mathrm{F}$} & $01 / 053$ & Rd. Jinghong -Nanguan & n.d. & phyllite & $\mathrm{P}_{2}$ & $<2 \mu \mathrm{m}$ & 200.7 & 4.9 \\
\hline & & $4 \mathrm{~km} E$ of Jinhong & n.d. & & & $<0.2 \mu \mathrm{m}$ & 184.3 & 6.2 \\
\hline \multirow[t]{2}{*}{ G } & $01 / 081$ & Rd. Simao - Lancang & n.d. & phyllite & $\mathrm{P}_{2}$ & $<2 \mu \mathrm{m}$ & 215.2 & 4.6 \\
\hline & & km 91, NW of Simaogang & n.d. & & & $<0.2 \mu \mathrm{m}$ & 204.2 & 4.8 \\
\hline \multirow[t]{2}{*}{$\mathrm{H}$} & $01 / 041$ & Rd. Simao - Lancang & N022 35 '30.7" & qtz-phyllite & $\mathrm{P}_{2}$ & $<2 \mu \mathrm{m}$ & 220.4 & 4.8 \\
\hline & & km 90-91, NW of Simaogang & $\mathrm{E} 100^{\circ} 28^{\prime} 20.6^{\prime \prime}$ & & & $<0.2 \mu \mathrm{m}$ & 210.5 & 4.8 \\
\hline \multirow[t]{2}{*}{ I } & $02 / 130$ & Rd. 214 & N0233'ㄹ․ 28 " & phyllite & $\mathrm{P}_{2} \mathrm{l}$ & $<2 \mu \mathrm{m}$ & 210.7 & 5.6 \\
\hline & & $\mathrm{km} 2767$, close to bridge & E10019'10.0" & & & $<0.2 \mu \mathrm{m}$ & 204.8 & 4.7 \\
\hline \multirow[t]{2}{*}{$\mathrm{J}$} & $24 / 099$ & Rd. 323 & N023ํ5'00.4" & phyllite & $\mathrm{P}_{2}$ & $<2 \mu \mathrm{m}$ & 327.8 & 7.1 \\
\hline & & 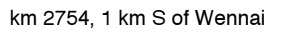 & E100²3'30.3" & & & $<0.2 \mu \mathrm{m}$ & 311 & 7 \\
\hline \multirow[t]{2}{*}{ K } & $02 / 050$ & Rd. Yunxian - Dachaoshan & 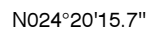 & phyllite & $\mathrm{T}_{3} \mathrm{C}$ & $<2 \mu \mathrm{m}$ & 138.0 & 3.2 \\
\hline & & E-side of Lincang Granite & E100²1'38.5" & & & $<0.2 \mu \mathrm{m}$ & 124.1 & 3.9 \\
\hline \multirow[t]{2}{*}{ L } & $02 / 027$ & Rd. 214 & n.d. & phyllite & $\mathrm{P}_{2}$ & $<2 \mu \mathrm{m}$ & 136.1 & 3.3 \\
\hline & & $\mathrm{km}$ 2569.7, S of Manwan & n.d. & & & $<0.2 \mu \mathrm{m}$ & 116.3 & 3.2 \\
\hline \multirow[t]{2}{*}{ M } & $02 / 014$ & Rd. 214 & N0243ㄴ'08.2" & phyllite & $\mathrm{P}_{2}$ & $<2 \mu \mathrm{m}$ & 163.6 & 4.3 \\
\hline & & $\mathrm{km} 2561$, S of Manwan & E100²9'14.6" & & & $<0.2 \mu \mathrm{m}$ & 151.8 & 3.1 \\
\hline \multirow[t]{2}{*}{ N } & $98 / 029$ & $28 \mathrm{~km} \mathrm{~S}$ of Nanjian & 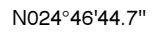 & phyllite & $\mathrm{P}_{2}$ & $<2 \mu \mathrm{m}$ & 17.4 & 1 \\
\hline & & Wuliang-Shan & E100³1'09.6" & & & $<0.2 \mu \mathrm{m}$ & 17.8 & 0.9 \\
\hline \multirow[t]{2}{*}{0} & $02 / 108$ & Rd. Lincang - Gengma & N024ㅇำ'42.7" & gtz-mica-schist & $\mathrm{AnO}^{\mathrm{d}}$ & detr. msc. & 240.1 & 5.5 \\
\hline & & $\mathrm{km} 44$ & E09956'15.3" & & & & & \\
\hline$P$ & 02/092 & $\begin{array}{l}\text { Rd. Mengku - Baka } \\
\text { about } 10 \mathrm{~km} \text { to NW }\end{array}$ & $\begin{array}{l}\text { n.d. } \\
\text { n.d. }\end{array}$ & mica-schist & $P z_{1} \mid n^{a-b}$ & detr. msc. & 231.3 & 4.7 \\
\hline \multirow[t]{2}{*}{ Q } & $02 / 152$ & Rd. 323 & N0233'ㄷ‥ & phyllite & $\mathrm{P}_{2}$ & detr. msc. & 554.5 & 12.8 \\
\hline & & km 2753, Wennai & $\mathrm{E} 100^{\circ} 23^{\prime} 28.7^{\prime \prime}$ & & & & & \\
\hline \multirow[t]{2}{*}{$\mathrm{R}$} & $01 / 008$ & Rd. 213 & n.d. & mudstone & $\mathrm{T}_{3}$ & detr. msc. & 245.8 & 5.0 \\
\hline & & $3 \mathrm{~km} \mathrm{~W}$ of Anding, $\mathrm{km} 2448$ & n.d. & & & & & \\
\hline
\end{tabular}

* Formation name from geological maps: 1: 200.000 (YBMR, Kunming): $\mathrm{P}_{\mathrm{t}} \mathrm{h}^{2} / \mathrm{P}_{\mathrm{t}} \mathrm{h}^{1}$ (lower/upper Huimin-Formation, Lancang Group, Proterozoic): Ptml (Lancang Group); $P z_{1} \mid n^{a-b}$ (lower to middle Lancang Group); $P z_{1} \mid I^{c}$ (upper Lancang Group); AnO ${ }^{\times q}$ (Xiqian-Formation, contin. of Lancang Group on sheet Fengqing); $A_{n} O^{d}$ (Datianyakou-Formation, Proterozoic); $P_{2} l$ (upper Permian); $P_{2}$ (upper Permian), $\mathrm{T}_{3} \mathrm{C}$ (upper Triassic), $T_{3}$ (upper Triassic).

${ }^{\star *}$ not determined. 
Table 5: EMS-Analysis of sodic amphiboles from $02 / 143$ of the high-P/T belt.

\begin{tabular}{|c|c|c|c|c|c|c|c|c|c|c|c|}
\hline & $143-1$ & $\begin{array}{l}143-2 \\
\text { core }\end{array}$ & $\begin{array}{c}143-2 \\
\text { rim }\end{array}$ & $\begin{array}{c}143-3 \\
\text { core }\end{array}$ & $\begin{array}{c}143-3 \\
\text { rim }\end{array}$ & $\begin{array}{c}143-4 \\
\text { core }\end{array}$ & $\begin{array}{c}143-4 \\
\text { rim }\end{array}$ & $\begin{array}{c}143-5 \\
\text { core }\end{array}$ & $\begin{array}{c}143-5 \\
\text { rim }\end{array}$ & $\begin{array}{l}143-6 \\
\text { core }\end{array}$ & $\begin{array}{c}143-6 \\
\text { rim }\end{array}$ \\
\hline $\mathrm{SiO}_{2}$ & 55.66 & 55.36 & 55.65 & 56.02 & 55.69 & 55.89 & 55.39 & 55.86 & 54.91 & 55.99 & 55.44 \\
\hline $\mathrm{Na}_{2} \mathrm{O}$ & 6.67 & 6.34 & 6.58 & 6.70 & 6.57 & 6.41 & 6.17 & 6.56 & 3.51 & 6.74 & 6.77 \\
\hline $\mathrm{TiO}_{2}$ & 0.01 & 0.02 & 0.05 & 0.09 & 0.00 & 0.06 & 0.03 & 0.06 & 0.05 & 0.19 & 0.00 \\
\hline $\mathrm{K}_{2} \mathrm{O}$ & 0.01 & 0.03 & 0.01 & 0.00 & 0.02 & 0.00 & 0.03 & 0.02 & 0.03 & 0.01 & 0.02 \\
\hline $\mathrm{FeO}^{\star}$ & 17.80 & 15.99 & 18.98 & 16.60 & 19.54 & 16.50 & 18.59 & 16.44 & 16.75 & 16.15 & 19.59 \\
\hline $\mathrm{Al}_{2} \mathrm{O}_{3}$ & 5.18 & 5.80 & 3.68 & 5.77 & 4.22 & 5.75 & 3.54 & 5.74 & 1.73 & 6.54 & 3.92 \\
\hline $\mathrm{MgO}$ & 9.68 & 9.96 & 9.62 & 9.88 & 8.88 & 9.89 & 10.06 & 9.88 & 12.92 & 9.43 & 9.13 \\
\hline $\mathrm{Cr}_{2} \mathrm{O}_{3}$ & 0.00 & 0.23 & 0.04 & 0.07 & 0.08 & 0.05 & 0.07 & 0.05 & 0.03 & 0.02 & 0.00 \\
\hline $\mathrm{CaO}$ & 0.53 & 1.28 & 0.84 & 0.74 & 0.57 & 1.10 & 1.59 & 0.92 & 6.15 & 0.77 & 0.60 \\
\hline $\mathrm{MnO}$ & 0.07 & 0.08 & 0.21 & 0.07 & 0.05 & 0.15 & 0.13 & 0.04 & 0.26 & 0.10 & 0.10 \\
\hline $\mathrm{BaO}$ & 0.01 & 0.00 & 0.02 & 0.00 & 0.01 & 0.00 & 0.03 & 0.00 & 0.00 & 0.00 & 0.03 \\
\hline Total & 95.63 & 95.08 & 95.69 & 95.94 & 95.63 & 95.79 & 95.63 & 95.56 & 96.34 & 95.94 & 95.61 \\
\hline $\mathrm{Si}$ & 7.99 & 7.97 & 8.01 & 7.98 & 8.04 & 7.99 & 7.99 & 7.99 & 7.95 & 7.98 & 8.00 \\
\hline $\mathrm{Na}$ & 1.85 & 1.77 & 1.84 & 1.85 & 1.84 & 1.78 & 1.73 & 1.82 & 0.98 & 1.86 & 1.89 \\
\hline $\mathrm{Ti}$ & 0.00 & 0.00 & 0.01 & 0.01 & 0.00 & 0.01 & 0.00 & 0.01 & 0.00 & 0.02 & 0.00 \\
\hline K & 0.00 & 0.00 & 0.00 & 0.00 & 0.00 & 0.00 & 0.01 & 0.00 & 0.01 & 0.00 & 0.00 \\
\hline $\mathrm{Fe}^{2+}$ & 1.16 & 1.18 & 1.09 & 1.12 & 1.25 & 1.18 & 1.14 & 1.14 & 1.36 & 1.21 & 1.14 \\
\hline $\mathrm{Fe}^{3+}$ & 0.98 & 0.75 & 1.20 & 0.85 & 1.11 & 0.79 & 1.11 & 0.83 & 0.67 & 0.72 & 1.22 \\
\hline Al & 0.88 & 0.99 & 0.62 & 0.97 & 0.72 & 0.97 & 0.60 & 0.97 & 0.30 & 1.10 & 0.67 \\
\hline $\mathrm{Mg}$ & 2.07 & 2.14 & 2.06 & 2.10 & 1.91 & 2.11 & 2.17 & 2.11 & 2.79 & 2.00 & 1.96 \\
\hline $\mathrm{Cr}$ & 0.00 & 0.03 & 0.00 & 0.01 & 0.01 & 0.01 & 0.01 & 0.01 & 0.00 & 0.00 & 0.00 \\
\hline $\mathrm{Ca}$ & 0.08 & 0.20 & 0.13 & 0.11 & 0.09 & 0.17 & 0.25 & 0.14 & 0.95 & 0.12 & 0.09 \\
\hline $\mathrm{Mn}$ & 0.01 & 0.01 & 0.03 & 0.01 & 0.01 & 0.02 & 0.02 & 0.00 & 0.03 & 0.01 & 0.01 \\
\hline $\mathrm{Ba}$ & 0.00 & 0.00 & 0.00 & 0.00 & 0.00 & 0.00 & 0.00 & 0.00 & 0.00 & 0.00 & 0.00 \\
\hline Total & 15.02 & 15.03 & 14.99 & 15.02 & 14.97 & 15.01 & 15.01 & 15.01 & 15.05 & 15.02 & 15.00 \\
\hline
\end{tabular}

${ }^{\star} \mathrm{FeO}$, total iron as $\mathrm{FeO}, \mathrm{A}$-site of the amphibole formula is not occupied in order to calculate $\mathrm{Fe}^{2+}, \mathrm{Fe}^{3+}$,

whereas $\mathrm{Na}$ and $\mathrm{K}$ is distributed to the $\mathrm{B}$ position; Analysed at the Geochemisches Institut, Göttingen University 


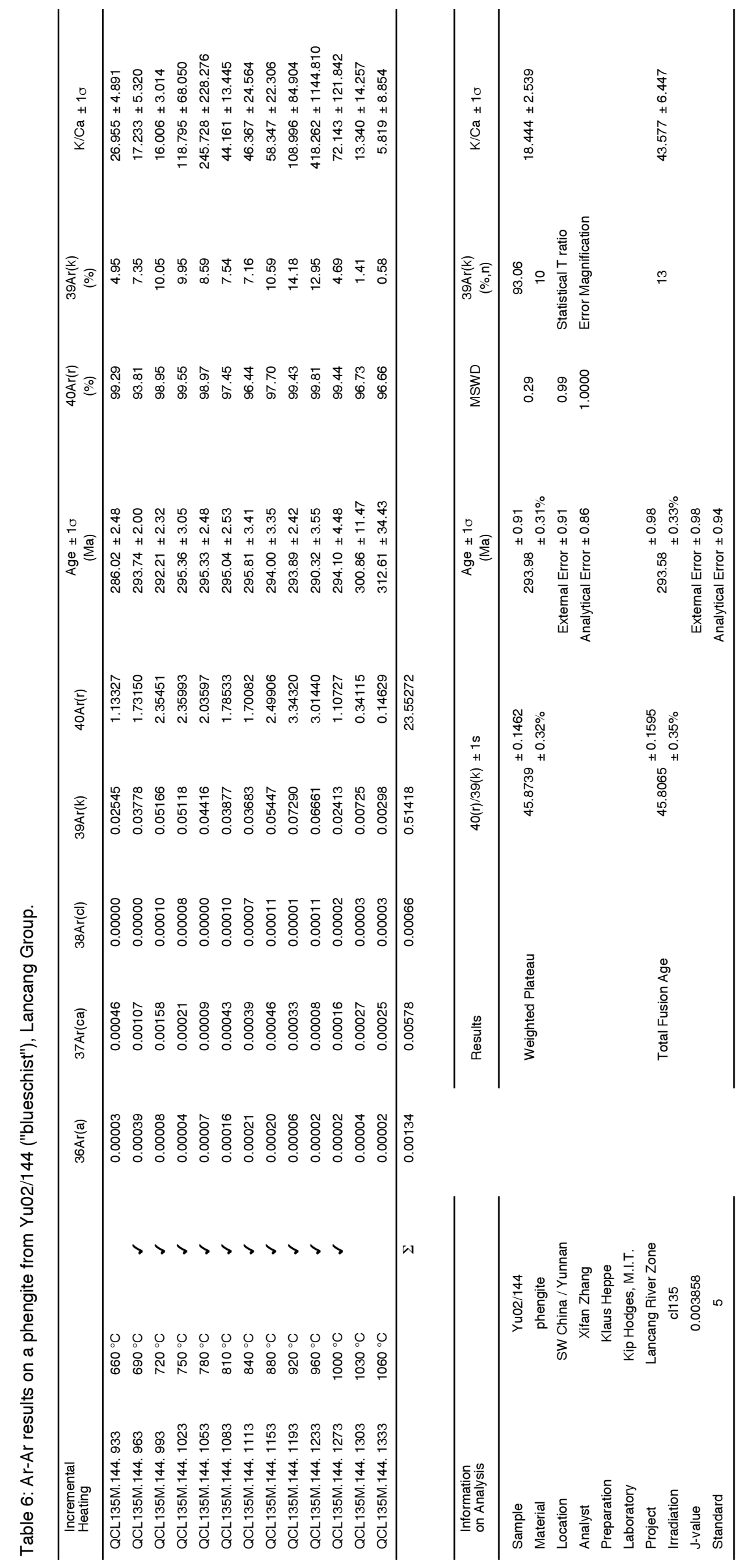


Table 7: X-ray fluorescence data of magmatic rocks from the Lancang River Zone, Yunnan Province, P.R. of China.

\begin{tabular}{|c|c|c|c|c|c|c|c|c|c|c|c|c|c|c|c|}
\hline $\begin{array}{l}\text { Sample No. } \\
\text { Unit } \\
\text { Rock type }\end{array}$ & $\begin{array}{c}02 / 157 \\
\mathrm{~T}_{3} \mathrm{~b} \\
\mathrm{RHY}\end{array}$ & $\begin{array}{c}01 / 200 e \\
P z \\
B A\end{array}$ & $\begin{array}{c}02 / 029 \\
\mathrm{~T}_{2} \mathrm{~m}_{2} \\
\mathrm{RHY}\end{array}$ & $\begin{array}{c}02 / 149 a \\
D_{3} \\
\text { T-B ? }\end{array}$ & $\begin{array}{c}02 / 155 \\
\mathrm{~T}_{2} \mathrm{~m}_{2} \\
\mathrm{RHY}\end{array}$ & $\begin{array}{c}01 / 157 a \\
\mathrm{P}_{\mathrm{t}} \mathrm{h}^{2} \\
\mathrm{RHY}\end{array}$ & $\begin{array}{c}01 / 157 b \\
P_{t} h^{2} \\
A-B A\end{array}$ & $\begin{array}{c}02 / 009 \\
\mathrm{~T}_{2} \mathrm{~m}_{2} \\
\mathrm{RHY}\end{array}$ & $\begin{array}{c}02 / 034 \\
\mathrm{~T}_{2} \mathrm{~m}_{2} \\
\mathrm{~A}-\mathrm{BA}\end{array}$ & $\begin{array}{c}02 / 139 \\
\text { U'-P } \\
\text { BA }\end{array}$ & $\begin{array}{c}02 / 039 \\
\mathrm{~T}_{2} \mathrm{~m}_{2} \\
\mathrm{HAW}\end{array}$ & $\begin{array}{c}02 / 140 \\
\text { U'-P } \\
\text { A-BA }\end{array}$ & $\begin{array}{c}02 / 146 \\
\mathrm{Pz} \\
\mathrm{GA}\end{array}$ & $\begin{array}{c}02 / 142 \\
\text { uM'-P } \\
\text { BA-AN }\end{array}$ & $\begin{array}{c}02 / 134 \\
J v \\
M G\end{array}$ \\
\hline \multicolumn{16}{|l|}{ [wt\%] } \\
\hline $\mathrm{SiO}_{2}$ & 72.50 & 47.40 & 69.20 & 41.20 & 74.30 & 72.50 & 48.40 & 74.30 & 48.30 & 49.60 & 48.10 & 47.90 & 48.50 & 51.20 & 73.90 \\
\hline $\mathrm{TiO}_{2}$ & 0.29 & 3.01 & 0.44 & 3.16 & 0.38 & 0.29 & 2.27 & 0.23 & 1.80 & 2.20 & 2.03 & 2.36 & 1.15 & 1.49 & 0.05 \\
\hline $\mathrm{Al}_{2} \mathrm{O}_{3}$ & 12.40 & 13.50 & 15.70 & 12.70 & 12.90 & 12.40 & 16.00 & 13.20 & 15.60 & 13.50 & 15.20 & 13.30 & 15.80 & 15.20 & 15.60 \\
\hline FeOtit & 1.22 & 11.74 & 2.77 & 10.37 & 0.17 & 1.72 & 7.94 & 1.00 & 6.59 & 10.52 & 6.39 & 7.42 & 4.72 & 7.69 & 0.15 \\
\hline $\mathrm{Fe}_{2} \mathrm{O}_{3}$ calc & 1.53 & 3.16 & 0.01 & -0.03 & 2.54 & 0.99 & 3.04 & 1.04 & 5.55 & 2.73 & 5.16 & 7.17 & 4.75 & 2.51 & 0.62 \\
\hline $\mathrm{MnO}$ & 0.10 & 0.21 & 0.02 & 0.09 & 0.04 & 0.10 & 0.20 & 0.06 & 0.24 & 0.25 & 0.20 & 0.24 & 0.16 & 0.17 & 0.006 \\
\hline $\mathrm{MgO}$ & 0.94 & 5.97 & 0.08 & 3.76 & 0.28 & 0.94 & 6.33 & 0.43 & 3.18 & 4.51 & 6.01 & 4.03 & 6.53 & 4.18 & 0.32 \\
\hline $\mathrm{CaO}$ & 2.87 & 6.13 & 0.12 & 10.57 & 0.20 & 2.87 & 7.99 & 0.48 & 9.86 & 9.17 & 7.01 & 8.26 & 11.84 & 8.30 & 0.17 \\
\hline $\mathrm{Na}_{2} \mathrm{O}$ & 3.79 & 2.23 & 5.14 & 0.70 & 3.63 & 3.80 & 4.02 & 3.63 & 4.53 & 2.86 & 4.49 & 3.55 & 3.20 & 4.36 & 3.75 \\
\hline $\mathrm{K}_{2} \mathrm{O}$ & 2.47 & 0.05 & 4.91 & 6.50 & 4.67 & 2.47 & 0.63 & 4.12 & 0.14 & 0.67 & 0.70 & 0.56 & 0.66 & 0.27 & 3.40 \\
\hline $\mathrm{P}_{2} \mathrm{O}_{5}$ & 0.05 & 0.37 & 0.07 & 0.62 & 0.04 & 0.05 & 0.38 & 0.06 & 0.70 & 0.30 & 0.66 & 0.25 & 0.09 & 0.26 & 0.01 \\
\hline$\sum \mathrm{H}_{2} \mathrm{O}$ & 1.06 & 5.07 & 0.91 & 4.22 & 0.76 & 1.61 & 2.01 & 1.23 & 2.81 & 2.39 & 3.61 & 2.94 & 2.09 & 3.63 & 1.94 \\
\hline $\mathrm{CO}_{2}$ & 0.56 & 1.71 & 0.06 & 7.13 & 0.04 & 0.07 & 0.06 & 0.12 & 0.05 & 1.00 & 0.16 & 1.67 & 0.21 & 0.75 & 0.07 \\
\hline Total & 99.8 & 100.5 & 99.4 & 101.0 & 100.0 & 99.8 & 99.3 & 99.9 & 99.4 & 99.7 & 99.7 & 99.7 & 99.7 & 100.0 & 100.0 \\
\hline Mg\# & n.d. & 47.6 & n.d. & 39.3 & n.d. & n.d. & 58.7 & n.d. & 46.2 & 43.3 & 62.6 & 49.2 & n.d. & 49.2 & n.d. \\
\hline $\mathrm{Fe}_{2} \mathrm{O}_{3} \mathrm{t}(\mathrm{XRF})$ & 2.89 & 16.16 & 3.09 & 11.53 & 2.73 & 2.90 & 11.86 & 2.15 & 12.87 & 14.40 & 12.26 & 15.42 & 10.00 & 11.06 & 0.79 \\
\hline \multicolumn{16}{|l|}{ volatile-fre } \\
\hline $\mathrm{SiO}_{2}$ & 73.86 & 50.56 & 70.29 & 45.96 & 74.93 & 73.88 & 49.79 & 75.40 & 50.06 & 51.50 & 50.13 & 50.40 & 49.80 & 53.54 & 75.43 \\
\hline $\mathrm{TiO}_{2}$ & 0.29 & 3.21 & 0.45 & 3.52 & 0.38 & 0.29 & 2.34 & 0.23 & 1.86 & 2.29 & 2.12 & 2.48 & 1.18 & 1.56 & 0.05 \\
\hline $\mathrm{Al}_{2} \mathrm{O}_{3}$ & 12.63 & 14.40 & 15.95 & 14.17 & 13.01 & 12.64 & 16.46 & 13.40 & 16.17 & 14.02 & 15.84 & 13.99 & 16.22 & 15.89 & 15.92 \\
\hline $\mathrm{FeO}$ & 1.24 & 12.52 & 2.81 & 11.57 & 0.17 & 1.75 & 8.17 & 1.01 & 6.83 & 10.92 & 6.66 & 7.81 & 4.85 & 8.04 & 0.15 \\
\hline $\mathrm{Fe}_{2} \mathrm{O}_{3}$ & 1.56 & 3.37 & 0.01 & -0.03 & 2.56 & 1.01 & 3.13 & 1.06 & 5.75 & 2.83 & 5.38 & 7.54 & 4.88 & 2.62 & 0.63 \\
\hline $\mathrm{MnO}$ & 0.10 & 0.22 & 0.02 & 0.10 & 0.04 & 0.10 & 0.21 & 0.06 & 0.25 & 0.25 & 0.21 & 0.25 & 0.16 & 0.18 & 0.01 \\
\hline $\mathrm{MgO}$ & 0.96 & 6.37 & 0.08 & 4.19 & 0.28 & 0.96 & 6.51 & 0.44 & 3.30 & 4.68 & 6.26 & 4.24 & 6.71 & 4.37 & 0.33 \\
\hline $\mathrm{CaO}$ & 2.92 & 6.54 & 0.12 & 11.79 & 0.20 & 2.92 & 8.22 & 0.49 & 10.22 & 9.52 & 7.31 & 8.69 & 12.16 & 8.68 & 0.17 \\
\hline $\mathrm{Na}_{2} \mathrm{O}$ & 3.86 & 2.38 & 5.22 & 0.78 & 3.66 & 3.87 & 4.14 & 3.68 & 4.69 & 2.97 & 4.68 & 3.74 & 3.29 & 4.56 & 3.83 \\
\hline $\mathrm{K}_{2} \mathrm{O}$ & 2.52 & 0.05 & 4.99 & 7.25 & 4.71 & 2.52 & 0.65 & 4.18 & 0.15 & 0.70 & 0.73 & 0.59 & 0.68 & 0.28 & 3.47 \\
\hline $\mathrm{P}_{2} \mathrm{O}$ & 0.05 & 0.39 & 0.07 & 0.69 & 0.04 & 0.05 & 0.39 & 0.06 & 0.73 & 0.31 & 0.69 & 0.27 & 0.09 & 0.27 & 0.01 \\
\hline Total & 100 & 100 & 100 & 100 & 100 & 100 & 100 & 100 & 100 & 100 & 100 & 100 & 100 & 100 & 100 \\
\hline \multicolumn{16}{|l|}{ [ppm } \\
\hline $\mathrm{Sc}$ & 3 & 40 & 12 & 24 & 6 & 5 & 33 & 6 & 25 & 31 & 28 & 46 & 40 & 29 & 3 \\
\hline v & 29 & 466 & 15 & 209 & 20 & 31 & 302 & 22 & 246 & 310 & 188 & 377 & 261 & 364 & 9 \\
\hline $\mathrm{Cr}$ & 13 & 127 & 8 & 325 & 11 & 13 & 71 & 7 & 206 & 33 & 198 & 32 & 255 & 24 & 8 \\
\hline Co & 13 & 45 & 3 & 71 & 5 & 11 & 32 & 3 & 32 & 42 & 38 & 44 & 44 & 29 & 2 \\
\hline $\mathrm{Ni}$ & 8 & 71 & 0 & 149 & 4 & 7 & 45 & 4 & 68 & 14 & 82 & 23 & 81 & 13 & 5 \\
\hline $\mathrm{Cu}$ & 23 & 46 & 33 & 67 & 4 & 22 & 63 & 8 & 29 & 19 & 15 & 52 & 55 & 80 & 2 \\
\hline $\mathrm{Zn}$ & 34 & 107 & 17 & 206 & 38 & 33 & 98 & 63 & 110 & 127 & 162 & 131 & 68 & 84 & 23 \\
\hline $\mathrm{Ga}$ & 12 & 20 & 17 & 22 & 18 & 13 & 20 & 17 & 23 & 19 & 19 & 20 & 13 & 22 & 20 \\
\hline $\mathrm{Rb}$ & 40 & $<4$ & 117 & 79 & 154 & 36 & 17 & 164 & 4 & 9 & 15 & 11 & 14 & 5 & 147 \\
\hline $\mathrm{Sr}$ & 197 & 146 & 373 & 108 & 111 & 197 & 266 & 124 & 431 & 240 & 230 & 300 & 194 & 275 & 106 \\
\hline $\mathrm{Zr}$ & 155 & 251 & 419 & 272 & 398 & 154 & 190 & 172 & 245 & 195 & 214 & 179 & 75 & 150 & 44 \\
\hline $\mathrm{Nb}$ & 7 & 26 & 28 & 49 & 16 & 6 & 27 & 25 & 25 & 7 & 22 & 8 & 4 & 5 & 9 \\
\hline $\mathrm{Ba}$ & 773 & 53 & 1282 & 953 & 515 & 785 & 269 & 718 & 71 & 157 & 152 & 270 & 95 & 66 & 375 \\
\hline $\mathrm{Pb}$ & 8 & 6 & 24 & 6 & 11 & 2 & 6 & 13 & 37 & 5 & 13 & 4 & 3 & 4 & 6 \\
\hline $\mathrm{Y}$ & 22 & 50 & 39 & 29 & 54 & 24 & 34 & 39 & 41 & 46 & 34 & 44 & 26 & 36 & 10 \\
\hline
\end{tabular}

Rock type: RHY: rhyolithe, BA: basalt, T-B: tephri-basanite, A-BA: alkali basalt, HAW: Hawaiite, GA: gabbro, BA-AN: basaltic andesite, MG: Monzogranite $\Sigma \mathrm{H}_{2} \mathrm{O}$ : by Karl-Fischer Titration, mean of three determinations

$\mathrm{CO}_{2}$ : determination as $\mathrm{TC}$ at $1200^{\circ} \mathrm{C}$, mean of three determinations

n.d.: not determined 
Table 8: X-ray fluorescence data of metamorphic and magmatic rocks along the Lancang River Zone, Yunnan Province, P.R. of China.

\begin{tabular}{|c|c|c|c|c|c|c|c|c|c|c|c|c|c|c|c|c|c|c|}
\hline $\begin{array}{l}\text { Sample No. } \\
\text { Unit } \\
\text { Rock type }\end{array}$ & $\begin{array}{l}02 / 054 \\
\mathrm{AnO}^{\times q} \\
\mathrm{SCH}^{\star}\end{array}$ & $\begin{array}{l}02 / 092 \\
\mathrm{P}_{2} 2 \mathrm{In}^{\mathrm{a}-b} \\
\mathrm{SCH}^{\star}\end{array}$ & $\begin{array}{c}02 / 108 \\
\mathrm{AnO}^{\mathrm{d}} \\
\mathrm{SCH}^{\star}\end{array}$ & $\begin{array}{c}01 / 152 \\
\mathrm{P}_{2} \\
\mathrm{SCH}\end{array}$ & $\begin{array}{c}01 / 066 \\
\mathrm{P}_{\mathrm{t}} \mathrm{h}^{1} \\
\mathrm{SCH}\end{array}$ & $\begin{array}{c}01 / 153 \\
\mathrm{P}_{\mathrm{t}} \mathrm{h}^{1} \\
\mathrm{SCH}\end{array}$ & $\begin{array}{c}01 / 154 \\
P_{t} h^{2} \\
G N\end{array}$ & $\begin{array}{c}01 / 161 \\
\mu^{2 \cdot 3} \\
\mathrm{GD}\end{array}$ & $\begin{array}{c}02 / 067 \\
\mu^{2 \cdot 3} \\
M G\end{array}$ & $\begin{array}{c}01 / 160 \mathrm{a} \\
\mu^{2-3} \\
\mathrm{MG}\end{array}$ & $\begin{array}{l}\text { B } 56 \\
\mu^{2 \cdot 3} \\
\text { GD }\end{array}$ & $\begin{array}{c}\text { B 98 } \\
\mu^{2 \cdot 3} \\
M G\end{array}$ & $\begin{array}{c}\text { B 99-2 } \\
\mu^{2-3} \\
\text { MG }\end{array}$ & $\begin{array}{c}01 / 160 \mathrm{~b} \\
\mu^{2-3} \\
\mathrm{XE}\end{array}$ & $\begin{array}{c}01 / 160 \mathrm{c} \\
\mu^{2-3} \\
\mathrm{XE}\end{array}$ & $\begin{array}{c}02 / 135 \\
J v \\
\mathrm{GA}\end{array}$ & $\begin{array}{c}02 / 131 \\
J v \\
\mathrm{PE}\end{array}$ & $\begin{array}{c}02 / 149 \mathrm{~b} \\
\mathrm{D}_{3} \\
\mathrm{~T}-\mathrm{B}\end{array}$ \\
\hline \multicolumn{19}{|l|}{ [wt\%] } \\
\hline $\mathrm{SiO}_{2}$ & 96.32 & 81.89 & 70.46 & 67.61 & 54.16 & 65.73 & 78.62 & 69.30 & 70.31 & 68.06 & 69.16 & 67.01 & 68.82 & 57.71 & 52.27 & 52.28 & 37.04 & 40.81 \\
\hline $\mathrm{TiO}_{2}$ & 0.07 & 0.42 & 0.56 & 0.66 & 0.92 & 0.47 & 0.18 & 0.68 & 0.46 & 0.75 & 0.57 & 0.57 & 0.61 & 1.4 & 2.01 & 0.76 & 0.06 & 3.07 \\
\hline $\mathrm{Al}_{2} \mathrm{O}_{3}$ & 1.91 & 9.74 & 14.2 & 14.2 & 15.9 & 14.3 & 12.1 & 13.2 & 13.4 & 13.8 & 15.5 & 14.5 & 13.8 & 15.5 & 15.6 & 16.8 & 1.96 & 12.7 \\
\hline FeOtit & 0.21 & 0.86 & 2.71 & 3.47 & 3.4 & 2.97 & 0.14 & 3.73 & 2.98 & 4.03 & 2.64 & 3.64 & 2.88 & 7.28 & 8.11 & 5.77 & 3.55 & 10.4 \\
\hline $\mathrm{Fe}_{2} \mathrm{O}_{3} \mathrm{calc}$ & 0.11 & 0.5 & 1.44 & 0.32 & 5.29 & 0.92 & 2.25 & 1.16 & 0.84 & 0.58 & 0.84 & 0.56 & 1.02 & 1.22 & 2.49 & 3.2 & 9.45 & -0.46 \\
\hline $\mathrm{MnO}$ & 0.01 & 0.02 & 0.09 & 0.06 & 0.14 & 0.07 & 0.01 & 0.06 & 0.07 & 0.05 & 0.05 & 0.08 & 0.06 & 0.12 & 0.13 & 0.21 & 0.13 & 0.09 \\
\hline $\mathrm{MgO}$ & 0.14 & 0.82 & 1.74 & 2.15 & 6.12 & 2.77 & 0.29 & 2.16 & 2.03 & 2.35 & 1.26 & 2.24 & 2.25 & 5.4 & 5.53 & 4.98 & 34.9 & 3.7 \\
\hline $\mathrm{CaO}$ & 0.01 & 0.02 & 0.2 & 2.19 & 5.13 & 4.33 & 0.04 & 1.05 & 2.06 & 1.46 & 2.35 & 3.19 & 2.19 & 2.06 & 3.03 & 5.29 & 0.08 & 10.1 \\
\hline $\mathrm{Na}_{2} \mathrm{O}$ & 0.03 & 0.03 & 0.92 & 2.21 & 3.33 & 3.54 & 0.4 & 2.2 & 1.7 & 2.68 & 3.38 & 2.35 & 2.26 & 2.27 & 1.22 & 6.16 & 0.01 & 0.6 \\
\hline $\mathrm{K}_{2} \mathrm{O}$ & 0.62 & 3.48 & 3.85 & 4.25 & 0.48 & 2.94 & 3.85 & 1.92 & 4.36 & 3.27 & 2.61 & 3.68 & 3.93 & 3.11 & 2.73 & 0.33 & 0.02 & 6.02 \\
\hline $\mathrm{P}_{2} \mathrm{O}_{5}$ & 0.01 & 0.02 & 0.12 & 0.2 & 0.27 & 0.11 & 0.02 & 0.1 & 0.15 & 0.08 & 0.14 & 0.19 & 0.17 & 0.2 & 0.23 & 0.15 & 0.01 & 0.61 \\
\hline$\sum \mathrm{H}_{2} \mathrm{O}$ & 0.48 & 1.91 & 3.29 & 1.20 & 4.68 & 0.93 & 3.38 & 2.91 & 0.93 & 1.72 & 0.81 & 0.74 & 1.18 & 1.45 & 4.72 & 2.34 & 12.26 & 4.22 \\
\hline $\mathrm{CO}_{2}$ & n.d. & n.d. & n.d. & 0.37 & 0.06 & 0.07 & 0.01 & 0.87 & 0.03 & 0.40 & 0.02 & 0.35 & 0.21 & 0.18 & 1.13 & 0.70 & 0.08 & 7.13 \\
\hline Total & 99.9 & 99.7 & 99.5 & 98.9 & 99.9 & 99.2 & 101.3 & 99.3 & 99.3 & 99.2 & 99.3 & 99.1 & 99.4 & 97.9 & 99.2 & 98.9 & 99.5 & 98.9 \\
\hline Mg\# & n.d. & n.d. & n.d. & n.d. & n.d. & n.d. & n.d. & n.d. & n.d. & n.d. & n.d. & n.d. & n.d. & n.d. & n.d. & n.d. & 94.6 & 38.9 \\
\hline $\mathrm{Fe}_{2} \mathrm{O}_{3} \mathrm{t}(\mathrm{XRF})$ & 0.34 & 1.46 & 4.45 & 4.18 & 9.07 & 4.22 & 2.41 & 5.31 & 4.15 & 5.06 & 3.77 & 4.61 & 4.22 & 9.31 & 11.5 & 9.61 & 13.4 & 11.1 \\
\hline \multicolumn{19}{|l|}{ volatile-free } \\
\hline $\mathrm{SiO}_{2}$ & 96.88 & 83.73 & 73.22 & 69.46 & 56.93 & 66.97 & 80.34 & 72.55 & 71.48 & 70.11 & 70.22 & 68.34 & 70.25 & 59.98 & 56.02 & 54.51 & 42.49 & 46.59 \\
\hline $\mathrm{TiO}_{2}$ & 0.07 & 0.43 & 0.58 & 0.67 & 0.97 & 0.48 & 0.18 & 0.71 & 0.47 & 0.77 & 0.58 & 0.58 & 0.63 & 1.46 & 2.16 & 0.79 & 0.06 & 3.50 \\
\hline $\mathrm{Al}_{2} \mathrm{O}_{3}$ & 1.92 & 9.96 & 14.70 & 14.62 & 16.70 & 14.57 & 12.33 & 13.78 & 13.63 & 14.18 & 15.72 & 14.83 & 14.07 & 16.06 & 16.68 & 17.50 & 2.25 & 14.53 \\
\hline $\mathrm{FeO}$ & 0.21 & 0.88 & 2.82 & 3.56 & 3.57 & 3.03 & 0.14 & 3.90 & 3.03 & 4.15 & 2.68 & 3.71 & 2.94 & 7.57 & 8.69 & 6.02 & 4.07 & 11.84 \\
\hline $\mathrm{Fe}_{2} \mathrm{O}_{3}$ & 0.11 & 0.51 & 1.50 & 0.33 & 5.56 & 0.94 & 2.30 & 1.21 & 0.85 & 0.60 & 0.85 & 0.57 & 1.04 & 1.27 & 2.67 & 3.34 & 10.84 & -0.53 \\
\hline $\mathrm{MnO}$ & 0.01 & 0.02 & 0.09 & 0.07 & 0.15 & 0.08 & 0.01 & 0.07 & 0.07 & 0.06 & 0.05 & 0.08 & 0.06 & 0.12 & 0.14 & 0.22 & 0.15 & 0.10 \\
\hline $\mathrm{MgO}$ & 0.14 & 0.84 & 1.81 & 2.21 & 6.43 & 2.82 & 0.30 & 2.26 & 2.06 & 2.42 & 1.28 & 2.28 & 2.30 & 5.61 & 5.93 & 5.19 & 40.01 & 4.22 \\
\hline $\mathrm{CaO}$ & 0.01 & 0.02 & 0.21 & 2.25 & 5.39 & 4.41 & 0.04 & 1.10 & 2.09 & 1.50 & 2.39 & 3.25 & 2.24 & 2.14 & 3.25 & 5.52 & 0.09 & 11.48 \\
\hline $\mathrm{Na}_{2} \mathrm{O}$ & 0.03 & 0.03 & 0.96 & 2.27 & 3.50 & 3.61 & 0.41 & 2.30 & 1.73 & 2.76 & 3.43 & 2.40 & 2.31 & 2.36 & 1.31 & 6.42 & 0.01 & 0.68 \\
\hline $\mathrm{K}_{2} \mathrm{O}$ & 0.62 & 3.56 & 4.00 & 4.36 & 0.51 & 3.00 & 3.93 & 2.01 & 4.43 & 3.36 & 2.65 & 3.76 & 4.01 & 3.23 & 2.92 & 0.34 & 0.03 & 6.87 \\
\hline $\mathrm{P}_{2} \mathrm{O}_{5}$ & 0.01 & 0.02 & 0.12 & 0.20 & 0.28 & 0.11 & 0.02 & 0.11 & 0.15 & 0.09 & 0.14 & 0.19 & 0.17 & 0.21 & 0.25 & 0.16 & 0.01 & 0.70 \\
\hline Total & 100 & 100 & 100 & 100 & 100 & 100 & 100 & 100 & 100 & 100 & 100 & 100 & 100 & 100 & 100 & 100 & 100 & 100 \\
\hline \multicolumn{19}{|l|}{$[\mathrm{ppm}]$} \\
\hline (As) & $<2$ & 6 & 17 & 5 & 3 & 30 & 12 & 5 & $<2$ & 22 & 3 & 14 & 5 & 4 & $<2$ & 5 & 5 & 4 \\
\hline $\mathrm{Ba}$ & 181 & 475 & 645 & 1224 & 223 & 652 & 463 & 2137 & 903 & 785 & 368 & 903 & 849 & 461 & 442 & 72 & 5 & 875 \\
\hline $\mathrm{Bi}$ & $<3$ & $<3$ & $<3$ & $<3$ & $<3$ & 4 & $<3$ & $<3$ & $<3$ & $<3$ & $<3$ & 4 & $<3$ & $<3$ & $<3$ & $<3$ & $<3$ & $<3$ \\
\hline $\mathrm{Ce}$ & $<20$ & 73 & 107 & 106 & 73 & 78 & 137 & 94 & 86 & 127 & 70 & 85 & 81 & 61 & 94 & $<20$ & $<20$ & 93 \\
\hline Co & $<3$ & 6 & 15 & $<3$ & 46 & 8 & $<3$ & 18 & 10 & 14 & 10 & 9 & 9 & 31 & 38 & 29 & 135 & 62 \\
\hline $\mathrm{Cr}$ & 43 & 36 & 89 & 45 & 250 & 76 & 11 & 64 & 49 & 53 & 20 & 53 & 65 & 182 & 163 & 61 & 3051 & 292 \\
\hline Cs & $<5$ & 8 & 10 & 15 & 6 & 8 & 10 & 13 & 12 & 11 & 10 & 20 & 13 & 16 & 15 & 9 & $<5$ & 8 \\
\hline $\mathrm{Cu}$ & $<10$ & $<10$ & 24 & $<10$ & 33 & $<10$ & $<10$ & 13 & 69 & 22 & $<10$ & 18 & 13 & $<10$ & 38 & 52 & 10 & 46 \\
\hline $\mathrm{Ga}$ & 6 & 14 & 22 & 19 & 18 & 15 & 21 & 19 & 19 & 19 & 22 & 21 & 17 & 22 & 28 & 17 & $<3$ & 22 \\
\hline $\mathrm{Hf}$ & $<5$ & 12 & $<5$ & 8 & $<5$ & $<5$ & $<5$ & $<5$ & $<5$ & 7 & $<5$ & $<5$ & $<5$ & $<5$ & $<5$ & $<5$ & $<5$ & 6 \\
\hline La & 20 & $<20$ & 61 & 67 & $<20$ & 26 & 79 & 54 & 162 & 72 & 29 & 65 & 50 & $<20$ & 75 & $<20$ & $<20$ & 41 \\
\hline Mo & $<2$ & 3 & $<2$ & $<2$ & $<2$ & $<2$ & $<2$ & 3 & $<2$ & $<2$ & 3 & $<2$ & $<2$ & $<2$ & $<2$ & $<2$ & $<2$ & $<2$ \\
\hline $\mathrm{Nb}$ & 2 & 8 & 13 & 15 & 11 & 6 & 22 & 13 & 6 & 15 & 13 & 14 & 12 & 21 & 23 & 6 & 5 & 37 \\
\hline $\mathrm{Nd}$ & $<28$ & $<28$ & 42 & 33 & $<28$ & $<28$ & 92 & 75 & 40 & 39 & 42 & 37 & 59 & $<28$ & 75 & $<28$ & $<28$ & 78 \\
\hline $\mathrm{Ni}$ & 194 & $<3$ & 109 & 17 & 54 & 13 & $<3$ & 26 & 21 & 39 & $<3$ & 9 & 22 & 50 & 54 & 11 & 1213 & 137 \\
\hline \multicolumn{19}{|l|}{$\mathrm{ppm}$} \\
\hline $\mathrm{Pb}$ & $<4$ & $<4$ & 31 & 41 & 15 & $<4$ & $<4$ & 6 & 41 & 26 & 17 & 15 & 35 & 6 & 6 & 6 & $<4$ & $<4$ \\
\hline $\mathrm{Pr}$ & $<30$ & $<30$ & $<30$ & 40 & $<30$ & $<30$ & $<30$ & $<30$ & $<30$ & $<30$ & $<30$ & $<30$ & 39 & $<30$ & $<30$ & $<30$ & $<30$ & $<30$ \\
\hline $\mathrm{Rb}$ & 34 & 122 & 166 & 192 & 27 & 87 & 121 & 105 & 175 & 153 & 148 & 158 & 186 & 202 & 184 & 16 & 9 & 74 \\
\hline $\mathrm{Sb}$ & $<5$ & 6 & $<5$ & $<5$ & $<5$ & $<5$ & 7 & $<5$ & $<5$ & $<5$ & $<5$ & $<5$ & $<5$ & $<5$ & $<5$ & $<5$ & $<5$ & $<5$ \\
\hline Sc & 3 & 6 & 13 & 12 & 34 & 16 & 5 & 15 & 9 & 10 & 12 & 13 & 12 & 26 & 39 & 35 & 9 & 23 \\
\hline $\mathrm{Sm}$ & $<22$ & $<22$ & $<22$ & 35 & 35 & $<22$ & $<22$ & $<22$ & $<22$ & $<22$ & 27 & $<22$ & $<22$ & $<22$ & 47 & $<22$ & $<22$ & $<22$ \\
\hline Sn & 4 & 3 & $<2$ & 6 & $<2$ & 2 & 7 & 4 & 10 & 5 & 5 & 6 & 5 & 7 & 6 & $<2$ & $<2$ & 5 \\
\hline $\mathrm{Sr}$ & $<2$ & 5 & 37 & 182 & 207 & 233 & 5 & 132 & 120 & 279 & 107 & 185 & 128 & 200 & 141 & 221 & $<2$ & 96 \\
\hline $\mathrm{Ta}$ & $<5$ & $<5$ & $<5$ & $<5$ & $<5$ & $<5$ & $<5$ & $<5$ & 6 & $<5$ & 7 & $<5$ & 6 & $<5$ & $<5$ & $<5$ & $<5$ & 7 \\
\hline Th & 35 & 43 & 49 & 57 & 40 & 37 & 54 & 51 & 50 & 59 & 62 & 48 & 62 & 47 & 40 & 31 & 32 & 32 \\
\hline U & $<3$ & 6 & 7 & 10 & 7 & 11 & 6 & 8 & 7 & 3 & 11 & 8 & 9 & 7 & $<3$ & $<3$ & 4 & 6 \\
\hline V & 21 & 31 & 77 & 90 & 234 & 91 & 12 & 104 & 57 & 89 & 62 & 89 & 75 & 198 & 329 & 224 & 47 & 202 \\
\hline W & $<5$ & $<5$ & $<5$ & $<5$ & $<5$ & $<5$ & $<5$ & $<5$ & $<5$ & $<5$ & $<5$ & $<5$ & $<5$ & $<5$ & $<5$ & $<5$ & 8 & $<5$ \\
\hline$Y$ & $<3$ & 22 & 20 & 27 & 24 & 37 & 29 & 31 & 20 & 9 & 35 & 24 & 30 & 28 & 54 & 17 & $<3$ & 24 \\
\hline $\mathrm{Zn}$ & 12 & 27 & 78 & 58 & 97 & 38 & 23 & 33 & 64 & 66 & 67 & 56 & 58 & 131 & 147 & 99 & 63 & 207 \\
\hline $\mathrm{Zr}$ & 4 & 475 & 269 & 201 & 120 & 90 & 160 & 233 & 146 & 215 & 196 & 143 & 193 & 136 & 138 & 16 & $<3$ & 238 \\
\hline
\end{tabular}

Rock type: SCH: schist, GN: gneiss, GD: granodiorite, MG: monzogranite, XE: xenolith, GA: gabbro, PE: peridodite, T-B: tephri-basanite n.d.: not determined 
Table 9: ICP-MS data of magmatic rocks from the Lancang River Zone, Yunnan Province, P.R. of China.

\begin{tabular}{|c|c|c|c|c|c|c|c|c|c|c|c|c|c|c|}
\hline $\begin{array}{l}\text { Sample No. } \\
\text { Unit } \\
\text { Rock type }\end{array}$ & $\begin{array}{c}02 / 157 \\
\mathrm{~T}_{3} \mathrm{~b} \\
\mathrm{RHY}\end{array}$ & $\begin{array}{c}01 / 200 e \\
P z \\
B A\end{array}$ & $\begin{array}{l}\text { 02/029 } \\
\mathrm{T}_{2} \mathrm{~m}_{2} \\
\mathrm{RHY}\end{array}$ & $\begin{array}{c}02 / 149 \mathrm{a} \\
\mathrm{D}_{3} \\
\text { T-B ? }\end{array}$ & $\begin{array}{c}02 / 155 \\
\mathrm{~T}_{2} \mathrm{~m}_{2} \\
\mathrm{RHY}\end{array}$ & $\begin{array}{c}01 / 157 a \\
\mathrm{P}_{\mathrm{t}} \mathrm{h}_{2} \\
\mathrm{RHY}\end{array}$ & $\begin{array}{c}01 / 157 b \\
P_{t} h^{2} \\
A-B A\end{array}$ & $\begin{array}{c}02 / 009 \\
\mathrm{~T}_{2} \mathrm{~m}_{2} \\
\mathrm{RHY}\end{array}$ & $\begin{array}{c}02 / 034 \\
\mathrm{~T}_{2} \mathrm{M}_{2} \\
\mathrm{~A}-\mathrm{BA}\end{array}$ & $\begin{array}{c}02 / 139 \\
\text { U'-P } \\
\text { BA }\end{array}$ & $\begin{array}{l}02 / 039 \\
\mathrm{~T}_{2} \mathrm{~m}_{2} \\
\text { HAW }\end{array}$ & $\begin{array}{c}02 / 140 \\
\text { U'-P } \\
\text { A-BA }\end{array}$ & $\begin{array}{c}02 / 146 \\
\mathrm{Pz} \\
\mathrm{GA}\end{array}$ & $\begin{array}{c}02 / 142 \\
\text { uM'-P } \\
\text { BA-AN }\end{array}$ \\
\hline \multicolumn{15}{|l|}{ [ppm] } \\
\hline Li & $<27.7$ & $<3.9$ & $<31.8$ & $<5.9$ & $<28.3$ & $<31.9$ & $<19.9$ & $<13.9$ & $<11.3$ & $<15.1$ & 13.3 & $<5.0$ & $<19.0$ & $<21.0$ \\
\hline $\mathrm{Be}$ & 1.3 & 3.0 & 2.0 & 2.9 & 2.5 & 0.8 & 2.8 & 6.3 & 6.2 & 3.9 & 5.3 & 3.7 & $<1.5$ & 4.5 \\
\hline Sc & 40.3 & 52.2 & 15.6 & 34.5 & 14.4 & 8.6 & 48.9 & 16.4 & 30.7 & 58.0 & 41.6 & 67.0 & 54.0 & 52.3 \\
\hline $\mathrm{Rb}$ & 16.4 & 2.5 & 124 & 105 & 163 & 43.1 & 18.9 & 238 & 4.2 & 14.4 & 20.3 & 13.9 & 16.8 & 8.1 \\
\hline $\mathrm{Sr}$ & 255.6 & 164 & 374 & 130 & 110 & 196 & 267 & 164 & 448 & 300 & 265 & 357 & 218 & 336 \\
\hline Y & 24.1 & 53.6 & 38.3 & 35.5 & 54.2 & 21.0 & 34.6 & 48.8 & 40.9 & 57.2 & 36.0 & 51.5 & 31.2 & 42.6 \\
\hline $\mathrm{Zr}$ & 79.5 & 242 & 401 & 356 & 311 & 143 & 171 & 120 & 254 & 242 & 255 & 206 & 26.2 & 180 \\
\hline $\begin{array}{l}\mathrm{Nb} \\
{[\mathrm{ppm}]}\end{array}$ & 16.0 & 27.9 & 28.3 & 61.0 & 13.5 & 4.6 & 27.0 & 35.2 & 27.2 & 9.1 & 22.9 & 6.3 & 1.2 & 6.9 \\
\hline Mo & 0.04 & 0.10 & 0.08 & 0.08 & 0.06 & 0.26 & 0.09 & 0.11 & 0.09 & 0.10 & 0.07 & 0.06 & 0.03 & 0.09 \\
\hline $\mathrm{Cd}$ & 0.2 & 0.31 & 0.44 & 0.57 & 0.36 & 0.18 & 0.39 & 0.81 & 0.60 & 0.45 & 0.39 & 0.33 & 0.18 & 0.38 \\
\hline Sn & 1.3 & 7.7 & 2.6 & 3.0 & 3.2 & 0.65 & 1.6 & 5.1 & 1.6 & 1.8 & 1.9 & 2.0 & 0.90 & 1.7 \\
\hline $\mathrm{Sb}$ & 0.3 & 2.6 & 6.0 & 0.21 & 2.1 & 0.5 & 0.13 & 2.6 & 0.87 & 0.26 & 0.79 & 0.17 & 0.14 & 0.50 \\
\hline Cs & 0.9 & 1.6 & 3.6 & 3.4 & 1.7 & 0.4 & 1.7 & 8.0 & 0.32 & 3.0 & 1.0 & 1.5 & 0.65 & 1.1 \\
\hline $\mathrm{Ba}$ & 69.9 & 37.1 & 1197 & 1069 & 491 & 741 & 246 & 900 & 52.0 & 166 & 146 & 285 & 89.8 & 58.2 \\
\hline La & 14.9 & 26.7 & 92.1 & 46.0 & 30.7 & 15.8 & 24.4 & 60.8 & 45.6 & 17.5 & 32.1 & 13.1 & 2.7 & 16.6 \\
\hline $\mathrm{Ce}$ & 27.2 & 50.8 & 71.5 & 83.2 & 73.4 & 28.0 & 42.0 & 106 & 84.4 & 35.8 & 64.1 & 28.6 & 7.8 & 32.9 \\
\hline $\mathrm{Pr}$ & 3.4 & 7.0 & 23.7 & 11.1 & 8.1 & 2.9 & 5.3 & 13.9 & 11.9 & 5.2 & 8.7 & 4.3 & 1.3 & 4.5 \\
\hline $\mathrm{Nd}$ & 14.5 & 31.1 & 83.3 & 44.8 & 31.2 & 11.0 & 22.1 & 48.8 & 48.0 & 24.7 & 36.1 & 20.6 & 7.5 & 20.7 \\
\hline Sm & 3.8 & 8.3 & 15.7 & 10.5 & 7.4 & 2.7 & 5.7 & 10.1 & 9.9 & 7.2 & 7.9 & 6.4 & 3.0 & 5.8 \\
\hline Eu & 1.2 & 2.4 & 3.6 & 3.8 & 1.2 & 1.2 & 1.9 & 2.0 & 2.7 & 2.3 & 2.3 & 2.3 & 1.1 & 1.9 \\
\hline Gd & 4.2 & 9.4 & 14.1 & 10.6 & 8.3 & 2.9 & 6.1 & 10.5 & 10.3 & 8.3 & 8.2 & 7.4 & 3.7 & 6.4 \\
\hline $\mathrm{Tb}$ & 0.7 & 1.5 & 1.7 & 1.5 & 1.4 & 0.5 & 1.0 & 1.5 & 1.4 & 1.4 & 1.2 & 1.3 & 0.74 & 1.1 \\
\hline Dy & 3.8 & 8.7 & 7.3 & 6.8 & 8.2 & 2.8 & 5.3 & 7.6 & 6.6 & 8.6 & 5.9 & 7.9 & 4.7 & 6.3 \\
\hline Ho & 0.8 & 1.7 & 1.3 & 1.2 & 1.8 & 0.6 & 1.1 & 1.5 & 1.3 & 1.8 & 1.2 & 1.7 & 1.0 & 1.4 \\
\hline Er & 2.2 & 4.9 & 3.6 & 3.0 & 5.4 & 1.9 & 3.1 & 4.4 & 3.4 & 5.4 & 3.2 & 4.8 & 3.0 & 3.9 \\
\hline $\mathrm{Tm}$ & 0.3 & 0.70 & 0.56 & 0.41 & 0.83 & 0.34 & 0.46 & 0.67 & 0.50 & 0.78 & 0.47 & 0.72 & 0.46 & 0.58 \\
\hline $\mathrm{Yb}$ & 1.9 & 4.4 & 3.8 & 2.4 & 5.6 & 2.3 & 2.8 & 4.5 & 3.2 & 5.2 & 2.9 & 4.7 & 2.9 & 3.8 \\
\hline Lu & 0.3 & 0.66 & 0.61 & 0.37 & 0.86 & 0.41 & 0.44 & 0.69 & 0.49 & 0.81 & 0.47 & 0.73 & 0.47 & 0.61 \\
\hline $\mathrm{Hf}$ & 1.8 & 5.4 & 8.8 & 7.6 & 8.0 & 3.6 & 3.5 & 4.3 & 4.9 & 5.2 & 4.9 & 4.6 & 1.1 & 4.1 \\
\hline $\mathrm{Ta}$ & 0.9 & 1.5 & 1.5 & 3.1 & 1.0 & 0.5 & 1.8 & 2.4 & 1.3 & 0.61 & 1.2 & 0.49 & 0.23 & 0.51 \\
\hline W & 0.5 & 2.0 & 2.0 & 1.1 & 2.5 & 0.7 & 0.48 & 7.8 & 1.4 & 4.4 & 5.4 & 7.0 & 7.7 & 9.2 \\
\hline $\mathrm{TI}$ & 0.1 & 0.05 & 0.78 & 0.22 & 0.53 & 0.20 & 0.11 & 1.17 & 0.08 & 0.09 & 0.15 & 0.15 & 0.11 & 0.09 \\
\hline $\mathrm{Pb}$ & 1.7 & 2.7 & 22.5 & 3.0 & 9.6 & 3.6 & 2.6 & 11.9 & 31.5 & 3.3 & 8.1 & 3.0 & 1.5 & 3.6 \\
\hline $\mathrm{Bi}$ & 0.0 & 0.36 & 0.21 & 0.05 & 0.12 & 0.21 & 0.04 & 0.34 & 0.28 & 0.05 & 0.09 & 0.06 & 0.03 & 0.07 \\
\hline Th & 1.5 & 2.5 & 29.8 & 3.9 & 14.5 & 4.7 & 2.3 & 25.4 & 3.6 & 1.9 & 2.7 & 1.6 & 0.39 & 2.5 \\
\hline U & 0.3 & 0.65 & 4.6 & 1.6 & 3.2 & 1.5 & 0.5 & 4.5 & 1.2 & 0.70 & 0.70 & 0.50 & 0.22 & 0.71 \\
\hline $\mathrm{Nb} / \mathrm{Ta}$ & 17.9 & 18.3 & 19.1 & 19.9 & 13.9 & 9.9 & 15.4 & 14.8 & 21.0 & 14.8 & 19.5 & 12.8 & 5.4 & 13.4 \\
\hline $\mathrm{Zr} / \mathrm{Hf}$ & 43.6 & 44.8 & 45.8 & 47.1 & 38.8 & 39.5 & 48.2 & 27.8 & 52.0 & 46.1 & 51.9 & 44.6 & 24.5 & 43.4 \\
\hline $\mathrm{Th} / \mathrm{Yb}$ & 0.77 & 0.56 & 7.9 & 1.7 & 2.6 & 2.0 & 0.82 & 5.7 & 1.1 & 0.37 & 0.91 & 0.34 & 0.13 & 0.65 \\
\hline $\mathrm{Ta} / \mathrm{Yb}$ & 0.46 & 0.35 & 0.39 & 1.3 & 0.17 & 0.20 & 0.63 & 0.53 & 0.41 & 0.12 & 0.40 & 0.10 & 0.08 & 0.13 \\
\hline $\mathrm{Nb} / \mathrm{Ta}$ & 17.9 & 18.3 & 19.1 & 19.9 & 13.9 & 9.9 & 15.4 & 14.8 & 21.0 & 14.8 & 19.5 & 12.8 & 5.4 & 13.4 \\
\hline $\mathrm{La} / \mathrm{Yb}$ & 7.7 & 6.1 & 24.4 & 19.3 & 5.4 & 6.8 & 8.7 & 13.6 & 14.3 & 3.4 & 10.9 & 2.8 & 0.93 & 4.4 \\
\hline $\mathrm{Nb} / \mathrm{Th}$ & 10.8 & 11.4 & 0.9 & 15.5 & 0.9 & 0.97 & 11.8 & 1.4 & 7.6 & 4.7 & 8.6 & 3.9 & 3.2 & 2.8 \\
\hline $\mathrm{Ce} / \mathrm{Pb}$ & 16.3 & 19.0 & 3.2 & 28.0 & 7.6 & 7.8 & 16.3 & 8.9 & 2.7 & 11.0 & 7.9 & 9.4 & 5.3 & 9.1 \\
\hline $\mathrm{Zr} / \mathrm{Nb}$ & 5.0 & 8.7 & 14.2 & 5.8 & 23.1 & 31.3 & 6.3 & 3.4 & 9.3 & 26.7 & 11.1 & 32.8 & 21.3 & 26.2 \\
\hline
\end{tabular}

Rock type: RHY: rhyolite, BA: basalt, T-B: tephri-basanite, A-BA: alkali basalt, HAW: Hawaiite, GA: gabbro, BA-AN: basaltic andesite, MG: Monzogranite Analysis by TOF-ICP-MS, Geochemisches Institut, University of Göttingen. 
Table 10: ICP-MS data of metamorphic and magmatic rocks along the Lancang River Zone, Yunnan Province, P.R. of China.

\begin{tabular}{|c|c|c|c|c|c|c|c|c|c|c|c|c|c|c|c|c|c|c|}
\hline $\begin{array}{l}\text { Sample No. } \\
\text { Unit } \\
\text { Rock type }\end{array}$ & $\begin{array}{l}02 / 054 \\
\mathrm{AnO}^{\times 9}\end{array}$ & $\begin{array}{l}02 / 092 \\
\mathrm{Pt}_{2} / \mathrm{n}^{\mathrm{a}-\mathrm{b}}\end{array}$ & $\begin{array}{c}02 / 108 \\
\mathrm{AnO}^{d}\end{array}$ & $\begin{array}{c}01 / 152 \\
P_{2}\end{array}$ & $\begin{array}{c}\text { 01/066 } \\
\mathrm{P}_{\mathrm{t}} \mathrm{h}^{1}\end{array}$ & $\begin{array}{c}01 / 153 \\
P_{t} h^{1}\end{array}$ & $\begin{array}{c}01 / 154 \\
\mathrm{P}_{\mathrm{t}} \mathrm{h}^{2}\end{array}$ & $\begin{array}{c}01 / 161 \\
\mu^{2 \cdot 3}\end{array}$ & $\begin{array}{c}02 / 067 \\
\mu^{2 \cdot 3}\end{array}$ & $\begin{array}{c}01 / 160 a \\
\mu^{2 \cdot 3}\end{array}$ & $\begin{array}{l}\text { B } 56 \\
\mu^{2 \cdot 3}\end{array}$ & $\begin{array}{l}\text { B } 98 \\
\mu^{2 \cdot 3}\end{array}$ & $\begin{array}{c}\text { B 99-2 } \\
\mu^{2 \cdot 3}\end{array}$ & $\begin{array}{c}01 / 160 \mathrm{~b} \\
\mu^{2-3}\end{array}$ & $\begin{array}{c}01 / 160 \mathrm{c} \\
\mu^{2 \cdot 3}\end{array}$ & $\begin{array}{c}02 / 135 \\
J v\end{array}$ & $\begin{array}{c}02 / 131 \\
J v\end{array}$ & $\begin{array}{c}02 / 149 \mathrm{~b} \\
\mathrm{D}_{3} \\
\mathrm{~T}-\mathrm{B}\end{array}$ \\
\hline 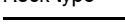 & & יו & & (1) & th & th t & Uiv & 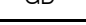 & & & . & & & & & & & \\
\hline \multicolumn{19}{|l|}{ [ppm] } \\
\hline $\mathrm{Li}$ & 1.5 & 8.7 & 12.6 & 24.4 & 30.8 & 2.1 & 9.1 & 41.4 & 26.5 & 32.4 & 19.4 & 18.1 & 5.8 & 79.0 & 75.3 & 31.3 & 1.3 & 28.9 \\
\hline $\mathrm{Be}$ & 0.4 & 1.8 & 3.0 & 3.4 & 1.5 & 1.8 & 1.8 & 1.9 & 1.3 & 1.0 & 1.8 & 3.0 & 0.3 & 1.3 & 2.9 & 0.4 & $<0.1$ & 1.2 \\
\hline V & 16 & 23 & 71 & 80 & 223 & 102 & 4 & 92 & 60 & 71 & 57 & 79 & 22 & 186 & 297 & 239 & 40 & 162 \\
\hline Co & 0.7 & 2.5 & 17.8 & 11.5 & 47.4 & 14.6 & 2.1 & 14.4 & 13.2 & 15.4 & 7.8 & 11.5 & 6.6 & 29.6 & 37.7 & 30.2 & 158 & 69.5 \\
\hline $\mathrm{Ni}$ & 217 & 13.5 & 138 & 25.6 & 70.5 & 31.6 & 7.5 & 41.2 & 39.0 & 49.6 & 13.9 & 20.0 & 2.7 & 65.4 & 64.4 & 27.5 & 1,380 & 161 \\
\hline $\mathrm{Cu}$ & 10.0 & 7.2 & 31.5 & 7.2 & 47.0 & 7.6 & 3.1 & 16.0 & 78.8 & 29.3 & 9.3 & 23.1 & 1.3 & 15.1 & 42.3 & 70.0 & 17.6 & 49.3 \\
\hline $\mathrm{Ga}^{\star}$ & 3.3 & 12.7 & 20.2 & 19.1 & 19.4 & 19.9 & 19.5 & 18.3 & 16.9 & 18.2 & 22.4 & 19.7 & 7.3 & 23.7 & 28.1 & 16.2 & 2.3 & 17.4 \\
\hline $\mathrm{Ge}$ & $<0.1$ & 0.6 & 0.5 & 0.2 & 0.5 & 0.2 & 0.5 & 0.2 & 0.2 & 0.2 & 0.4 & 0.1 & 0.1 & 0.5 & 0.7 & 0.1 & 0.1 & 0.4 \\
\hline $\mathrm{Se}$ & 0.6 & 0.8 & 1.6 & 1.0 & 1.3 & 1.5 & 0.9 & 0.5 & 1.3 & 0.8 & 1.2 & 0.7 & 0.5 & 0.9 & 1.6 & 0.8 & 0.4 & 1.3 \\
\hline $\mathrm{Rb}$ & 32.0 & 105 & 92.9 & 96.6 & 18.9 & 43.1 & 130 & 32.4 & 101 & 61.8 & 63.2 & 87.4 & 1.8 & 73.6 & 84.0 & 2.6 & 0.2 & 45.0 \\
\hline $\mathrm{Sr}$ & 8.0 & 8.5 & 40.4 & 187 & 246 & 299 & 6.5 & 146 & 130 & 303 & 106 & 183 & 28.3 & 214 & 157 & 255 & 2.3 & 110 \\
\hline Y & 2.8 & 4.6 & 6.1 & 17.0 & 26.8 & 29.1 & 20.6 & 9.6 & 11.3 & 8.3 & 14.4 & 16.3 & 7.0 & 17.4 & 32.8 & 17.7 & $<0.1$ & 27.3 \\
\hline $\mathrm{Zr}^{\star}$ & 6 & 51 & 28 & 20 & 55 & 32 & 48 & 18 & 4 & 22 & 53 & 3 & 41 & 17 & 14 & 24 & 2 & 244 \\
\hline $\mathrm{Nb}$ & 1.3 & 3.2 & 12.6 & 14.0 & 9.2 & 8.0 & 22.0 & 15.9 & 10.7 & 15.1 & 13.5 & 12.1 & 1.1 & 17.0 & 17.1 & 2.0 & $<0.1$ & 24.7 \\
\hline $\mathrm{Ag}$ & 0.06 & $<0.05$ & 0.30 & 0.07 & $<0.05$ & $<0.05$ & $<0.05$ & 0.10 & 0.08 & $<0.05$ & 0.32 & $<0.05$ & $<0.05$ & $<0.05$ & $<0.05$ & $<0.05$ & $<0.05$ & 0.26 \\
\hline $\mathrm{Cd}$ & $<0.1$ & $<0.1$ & $<0.1$ & 0.1 & 0.2 & $<0.1$ & $<0.1$ & $<0.1$ & 0.2 & 0.1 & 0.1 & $<0.1$ & $<0.1$ & 0.1 & 0.5 & $<0.1$ & $<0.1$ & 0.3 \\
\hline $\mathrm{Sn}^{*}$ & $<1$ & $<1$ & 2 & 3 & 1 & 3 & 2 & 2 & 6 & 3 & 3 & 3 & $<1$ & 3 & 3 & $<1$ & $<1$ & 1 \\
\hline Cs & 0.94 & 6.58 & 6.28 & 12.3 & 2.56 & 1.63 & 5.24 & 7.15 & 7.88 & 6.10 & 9.63 & 18.3 & 0.42 & 8.98 & 11.3 & 1.12 & 1.19 & 3.20 \\
\hline $\mathrm{La}^{\star}$ & 5.1 & 14.6 & 30.8 & 32.3 & 25.2 & 20.7 & 58.7 & 25.5 & 20.4 & 37.0 & 22.6 & 18.0 & 2.5 & 18.7 & 28.8 & 4.5 & 0.7 & 38.0 \\
\hline $\mathrm{Ce}^{*}$ & 13.4 & 35.5 & 73.1 & 79.6 & 54.5 & 45.6 & 136 & 61.9 & 52.7 & 90.2 & 62.0 & 46.6 & 6.6 & 46.4 & 69.6 & 11.9 & 1.1 & 80.8 \\
\hline $\mathrm{Pr}^{\star}$ & 1.1 & 4.4 & 8.3 & 8.1 & 6.4 & 5.9 & 14.7 & 7.3 & 6.2 & 10.7 & 7.7 & 4.7 & 0.9 & 5.7 & 9.0 & 1.7 & 0.1 & 9.9 \\
\hline $\mathrm{Nd}^{\star}$ & 3.9 & 18.0 & 31.6 & 30.7 & 25.5 & 23.3 & 54.7 & 27.7 & 24.3 & 41.2 & 30.6 & 18.0 & 4.0 & 23.5 & 36.6 & 8.5 & 0.4 & 41.7 \\
\hline $\mathrm{Sm}^{\star}$ & 0.7 & 3.8 & 6.1 & 6.2 & 6.2 & 5.7 & 11.2 & 5.7 & 5.1 & 8.3 & 7.6 & 4.0 & 1.1 & 5.6 & 9.4 & 2.6 & $<0.1$ & 9.9 \\
\hline $\mathrm{Eu}^{\star}$ & 0.14 & 0.74 & 0.98 & 1.00 & 1.49 & 0.80 & 1.08 & 0.95 & 1.04 & 1.14 & 0.95 & 0.78 & 0.31 & 0.89 & 1.18 & 1.08 & 0.05 & 2.95 \\
\hline $\mathrm{Gd}^{\star}$ & 0.6 & 3.0 & 4.2 & 5.2 & 6.4 & 5.9 & 8.6 & 4.9 & 4.6 & 6.3 & 6.8 & 4.0 & 1.3 & 5.5 & 9.6 & 3.6 & 0.1 & 10.1 \\
\hline $\mathrm{Tb}^{\star}$ & $<0.1$ & 0.4 & 0.5 & 0.7 & 0.9 & 1.0 & 0.9 & 0.6 & 0.6 & 0.6 & 0.9 & 0.6 & 0.2 & 0.8 & 1.3 & 0.5 & $<0.1$ & 1.3 \\
\hline $\mathrm{Dy}^{*}$ & 0.5 & 1.6 & 2.0 & 3.8 & 5.3 & 5.7 & 4.7 & 3.0 & 3.1 & 2.7 & 4.5 & 3.4 & 1.6 & 4.4 & 7.2 & 3.4 & 0.2 & 6.5 \\
\hline $\mathrm{Ho}^{*}$ & $<0.1$ & 0.3 & 0.3 & 0.7 & 1.0 & 1.2 & 0.8 & 0.5 & 0.5 & 0.4 & 0.8 & 0.7 & 0.4 & 0.9 & 1.4 & 0.7 & $<0.1$ & 1.1 \\
\hline $\mathrm{Er}^{\star}$ & 0.3 & 0.8 & 0.8 & 2.0 & 2.9 & 3.7 & 2.5 & 1.2 & 1.4 & 1.0 & 1.9 & 2.0 & 1.1 & 2.3 & 4.1 & 2.2 & 0.1 & 2.9 \\
\hline $\mathrm{Tm}^{\star}$ & $<0.1$ & 0.1 & 0.1 & 0.3 & 0.4 & 0.5 & 0.3 & 0.2 & 0.2 & 0.1 & 0.2 & 0.3 & 0.2 & 0.3 & 0.6 & 0.3 & $<0.1$ & 0.4 \\
\hline $\mathrm{Yb}^{\star}$ & 0.3 & 0.9 & 0.6 & 1.6 & 2.3 & 3.7 & 2.0 & 0.9 & 0.9 & 0.5 & 1.5 & 1.8 & 1.2 & 2.2 & 3.9 & 2.2 & 0.1 & 2.1 \\
\hline $\mathrm{Lu}^{\star}$ & $<0.1$ & 0.2 & $<0.1$ & 0.2 & 0.3 & 0.5 & 0.3 & $<0.1$ & $<0.1$ & $<0.1$ & 0.2 & 0.2 & 0.2 & 0.3 & 0.5 & 0.3 & $<0.1$ & 0.2 \\
\hline $\mathrm{Hf}^{*}$ & 0.1 & 1.3 & 0.7 & 0.7 & 1.5 & 1.1 & 1.8 & 0.5 & 0.1 & 0.9 & 1.5 & $<0.1$ & 1.1 & 0.6 & 0.5 & 0.9 & $<0.1$ & 5.7 \\
\hline $\mathrm{Ta}^{\star}$ & $<0.1$ & $<0.1$ & 1.0 & 1.3 & 0.7 & 0.8 & 1.2 & 1.4 & 1.1 & 1.7 & 1.4 & 1.4 & $<0.1$ & 1.4 & 1.4 & $<0.1$ & $<0.1$ & 0.8 \\
\hline TI & 0.22 & 0.72 & 0.87 & 1.37 & 0.11 & 0.47 & 0.92 & 0.51 & 1.13 & 1.04 & 0.88 & 1.07 & $<0.05$ & 1.48 & 1.27 & $<0.05$ & 0.80 & 0.24 \\
\hline $\mathrm{Pb}$ & 4.1 & 10.7 & 42.7 & 49.2 & 20.4 & 4.0 & 7.0 & 7.5 & 49.3 & 30.2 & 23.7 & 26.5 & 0.7 & 13.0 & 10.7 & 12.6 & 0.9 & 4.7 \\
\hline $\mathrm{Bi}$ & 0.14 & 0.32 & 0.72 & 0.24 & 0.29 & 0.19 & 0.12 & 0.29 & 0.61 & 1.83 & 1.15 & 0.45 & 0.04 & 0.34 & 0.79 & 0.05 & 0.07 & 0.06 \\
\hline $\mathrm{Th}^{\star}$ & 2.2 & 8.6 & 11.2 & 16.2 & 10.7 & 7.4 & 23.1 & 12.0 & 10.9 & 19.0 & 20.2 & 9.9 & 0.8 & 7.7 & 10.1 & 0.2 & 0.1 & 3.9 \\
\hline U & 0.7 & 1.5 & 1.5 & 3.1 & 2.2 & 3.6 & 2.0 & 3.5 & 4.3 & 2.9 & 7.9 & 3.9 & 0.5 & 2.6 & 2.0 & $<0.1$ & $<0.1$ & 1.8 \\
\hline $\mathrm{Nb} / \mathrm{Ta}$ & $>13.5$ & $>31.8$ & 13.0 & 11.2 & 13.0 & 10.0 & 18.6 & 11.5 & 9.4 & 9.0 & 10.0 & 8.4 & $>10.6$ & 12.3 & 12.5 & $>20.1$ & 1.0 & 31.4 \\
\hline $\mathrm{Zr} / \mathrm{Hf}$ & 43.4 & 38.4 & 40.4 & 28.6 & 36.5 & 27.7 & 27.5 & 34.5 & 40.0 & 24.9 & 35.5 & $>31.3$ & 36.5 & 27.4 & 30.1 & 28.4 & $>16.7$ & 42.7 \\
\hline $\mathrm{Th} / \mathrm{Yb}$ & 6.6 & 9.4 & 17.9 & 9.9 & 4.6 & 2.0 & 11.3 & 12.8 & 12.1 & 39.7 & 13.3 & 5.4 & 0.61 & 3.6 & 2.6 & 0.09 & 1.0 & 1.8 \\
\hline $\mathrm{Ta} / \mathrm{Yb}$ & $>0.3$ & $>0.1$ & 1.5 & 0.8 & 0.30 & 0.22 & 0.58 & 1.5 & 1.3 & 3.5 & 0.89 & 0.79 & $>0.1$ & 0.64 & 0.35 & $>0.1$ & $>1.0$ & 0.37 \\
\hline $\mathrm{La} / \mathrm{Yb}$ & 15.0 & 16.1 & 49.0 & 19.7 & 10.8 & 5.6 & 28.7 & 27.0 & 22.6 & 77.5 & 14.9 & 9.9 & 2.0 & 8.6 & 7.5 & 2.0 & 6.5 & 17.8 \\
\hline $\mathrm{Nb} / \mathrm{Th}$ & 0.60 & 0.37 & 1.1 & 0.87 & 0.86 & 1.1 & 1.0 & 1.3 & 1.0 & 0.80 & 0.67 & 1.2 & 1.4 & 2.2 & 1.7 & 10.4 & $>1.0$ & 6.3 \\
\hline $\mathrm{Ce} / \mathrm{Pb}$ & 3.3 & 3.3 & 1.7 & 1.6 & 2.7 & 11.4 & 19.6 & 8.3 & 1.1 & 3.0 & 2.6 & 1.8 & 10.0 & 3.6 & 6.5 & 0.95 & 1.2 & 17.1 \\
\hline $\mathrm{Zr} / \mathrm{Nb}$ & 4.4 & 16.1 & 2.3 & 1.4 & 5.9 & 4.0 & 2.2 & 1.2 & 0.42 & 1.5 & 3.9 & 0.26 & 38.3 & 0.97 & 0.85 & 12.09 & $>16.7$ & 9.9 \\
\hline
\end{tabular}

Rock type: SCH: schist, GN: gneiss, GD: granodiorite, MG: monzogranite, XE: xenolith, GA: gabbro, PE: peridotite, T-B: tephri-basanite

* element concentrations may not be total due to inability to completely dissolve very resistant minerals like zircon, monazite, xenotime, and sphene.

Analysis by Activation Laboratories Ltd., Canada. 


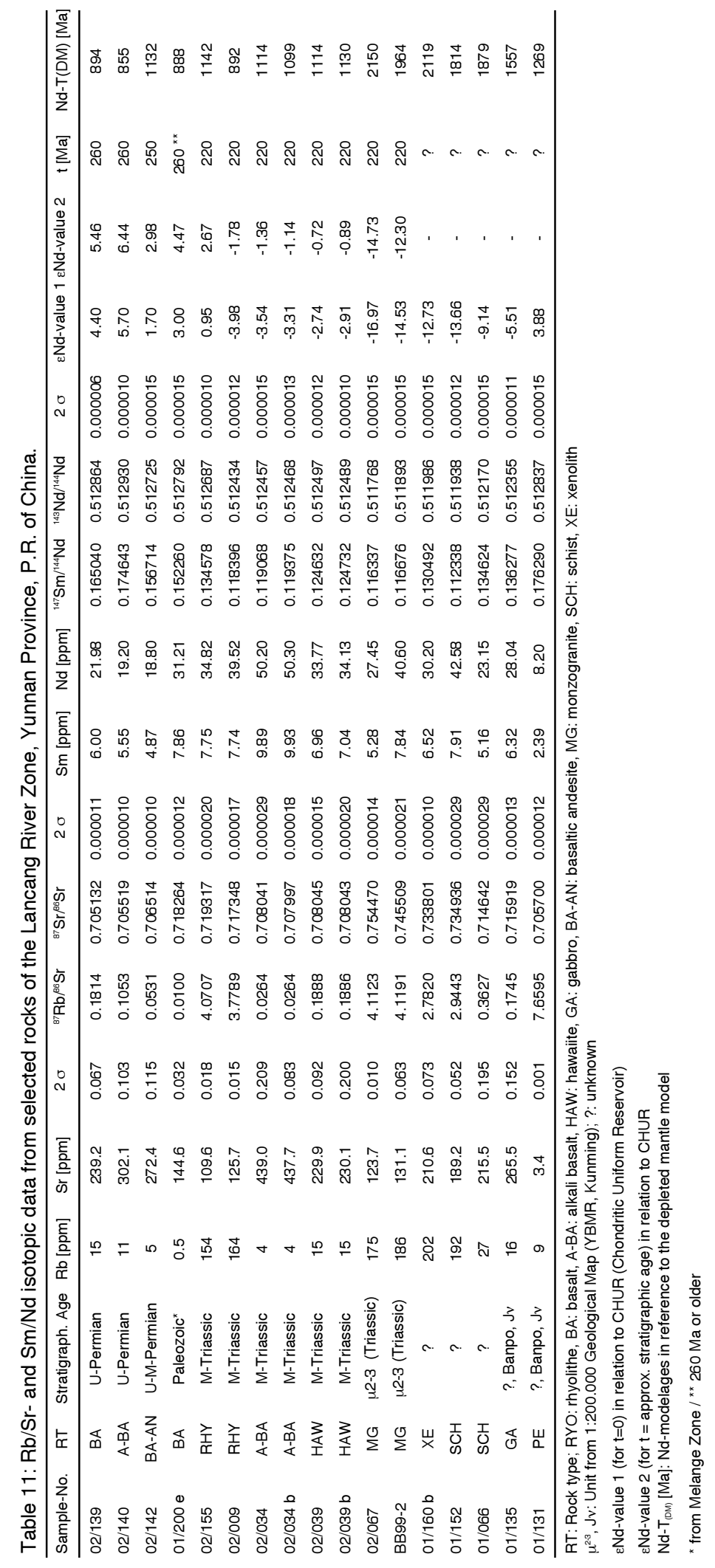


Table 12: IR-spectrometric determination* of the total content in sulfur and carbon.

\begin{tabular}{|c|c|c|c|c|}
\hline Sample-No. & $\mathrm{C}$ in \% & $S$ in $\%$ & $C$ in ppm & $S$ in $p p m$ \\
\hline $01 / 160 b$ & 0.0482 & 0.0867 & 482 & 867 \\
\hline $01 / 160 a$ & 0.1071 & 0.1784 & 1071 & 1784 \\
\hline $01 / 160 c$ & 0.3022 & 0.4388 & 3022 & 4388 \\
\hline $02 / 152$ & 0.0985 & 0.0347 & 985 & 347 \\
\hline $02 / 131$ & 0.0204 & 0.0124 & 204 & 124 \\
\hline $02 / 134$ & 0.0184 & 0.0009 & 184 & 9 \\
\hline $02 / 135$ & 0.1883 & 0.0776 & 1883 & 776 \\
\hline $02 / 167$ & 0.0089 & 0.0967 & 89 & 967 \\
\hline $01 / 161$ & 0.2327 & 0.3660 & 2327 & 3660 \\
\hline $01 / 154$ & 0.0034 & 0.0012 & 34 & 12 \\
\hline $02 / 066$ & 0.0154 & 0.0044 & 154 & 44 \\
\hline $02 / 157$ & 0.1501 & 0.2688 & 1501 & 2688 \\
\hline $02 / 140$ & 0.4476 & 0.0079 & 4476 & 79 \\
\hline $02 / 155$ & 0.0109 & 0.0004 & 109 & 4 \\
\hline $01 / 200 e$ & 0.4562 & 0.0077 & 4562 & 77 \\
\hline 01/157a & 0.0188 & 0.0362 & 188 & 362 \\
\hline $01 / 157 b$ & 0.0169 & 0.1566 & 169 & 1566 \\
\hline $01 / 023$ & 0.0158 & 0.0008 & 158 & 8 \\
\hline $02 / 146$ & 0.0572 & 0.0004 & 572 & 4 \\
\hline $02 / 139$ & 0.2674 & 0.0016 & 2674 & 16 \\
\hline $02 / 034$ & 0.0143 & 0.0013 & 143 & 13 \\
\hline $02 / 039$ & 0.0427 & 0.0000 & 427 & 0 \\
\hline $02 / 142$ & 0.2016 & 0.2109 & 2016 & 2109 \\
\hline $02 / 149$ & 1.9056 & 0.0637 & 19056 & 637 \\
\hline $01 / 153$ & 0.0196 & 0.0590 & 196 & 590 \\
\hline $02 / 009$ & 0.0308 & 0.0399 & 308 & 399 \\
\hline $02 / 139$ & 0.2962 & 0.0029 & 2962 & 29 \\
\hline BB56-00 & 0.0063 & 0.0670 & 63 & 670 \\
\hline BB99-2 & 0.0556 & 0.1111 & 556 & 1111 \\
\hline B-98 & 0.0938 & 0.0448 & 938 & 448 \\
\hline
\end{tabular}

*by Eltra CS 1000RF, mean of three determinations 


\section{Stereonets}
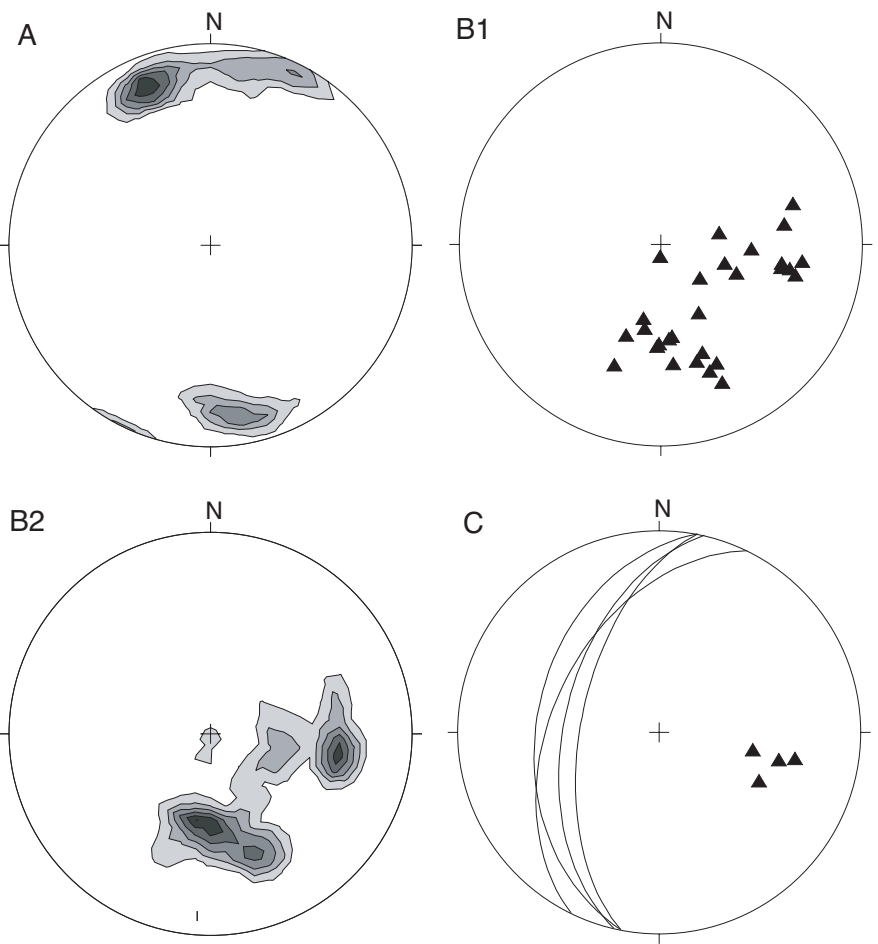

Stereonet 1: Quartz-mica and mica schists of the Lancang Group; New road from Lincang to Gengma, $\mathrm{km} 20$ to 34. A: density-plot of fold-hinges (lineaments, $n=33$, max. at $340 / 18$, contours at: $3,6,9,12$, and 15); B1 and B2 polepoints and density-plot of sf1 $(n=28$, max. at 190/54, contours at: $3,6,9,12,15,18)$, and C: polepoint and planes of horsetails showing an easterly movement of the hangingwall. Equal area projection; lower hemisphere. 

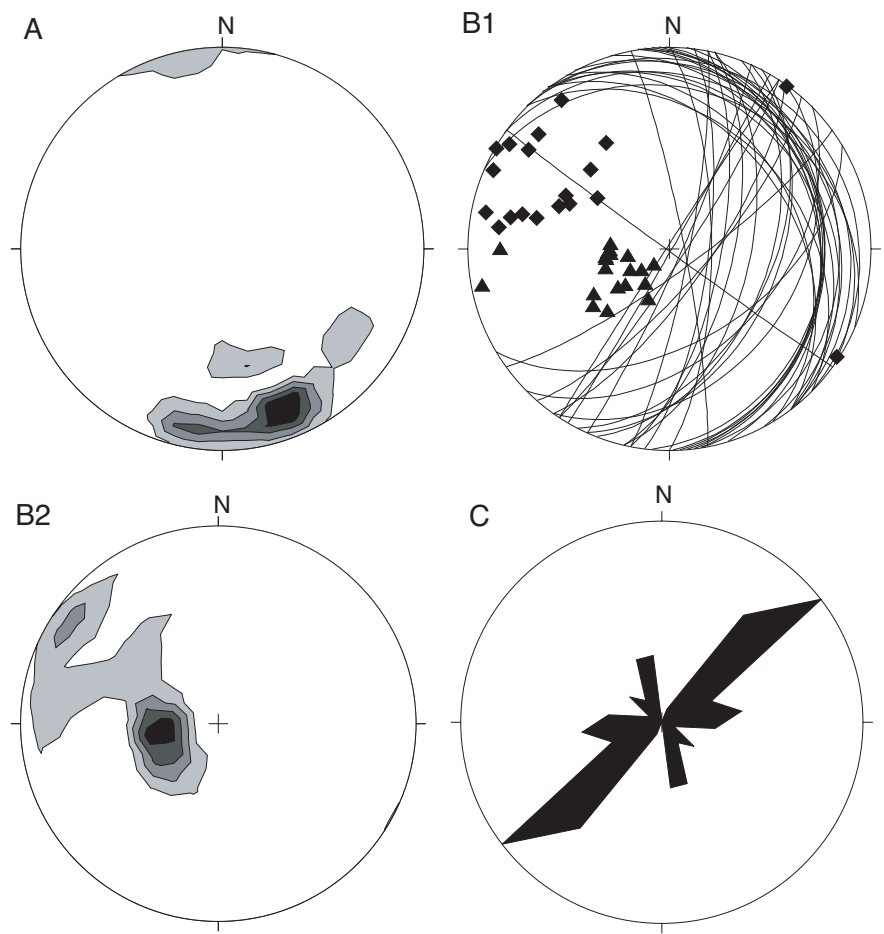

Stereonet 2: Quartz-mica schists and mica schists of the Lancang Group (PzIna-c); Road from Mengku to Baka, km 10. A: density-plot of fold-hinges (lineaments, $n=16$, max. at 158/10, contours at: 3, 6, 9, and 12); B1 and B2 polepoints and density-plot of sf1 $(n=29)$, max. at 270/70, contours at: 3, 6, 9, and 12). Equal area projection; lower hemisphere. C: rose diagram of joints ( $n=56$, largest petal: 12 values, strike direction: $15^{\circ}$ classes). 

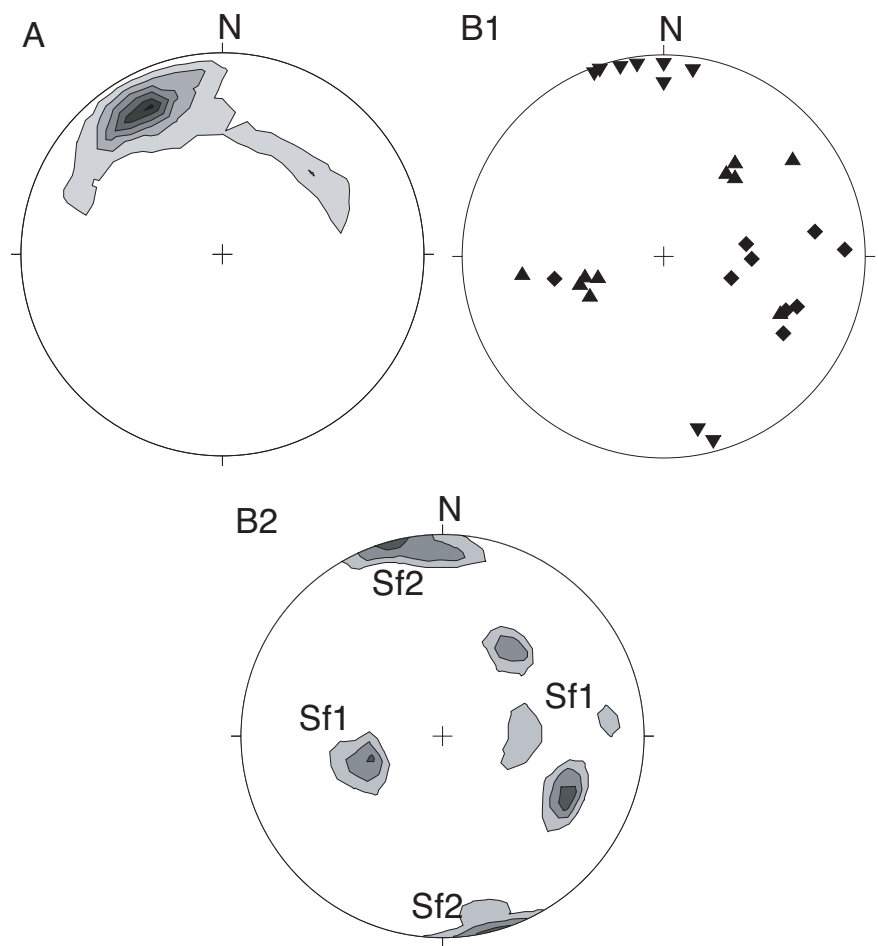

Stereonet 3: Quartz-mica schists and mica schists of the Lancang Group (AnOd); Road from Yunxian to Baka, km 63 to 67. A: density-plot of fold-hinges (lineaments, $n=55$, max. at 334/20, contours at: 3, 6, 9, 12, 15, and 18); B1 and B2 polepoints and density-plot of sf1 and sf2? ( $n=28$, contours at: 3,6 , and 9). Equal area projection; lower hemisphere. 

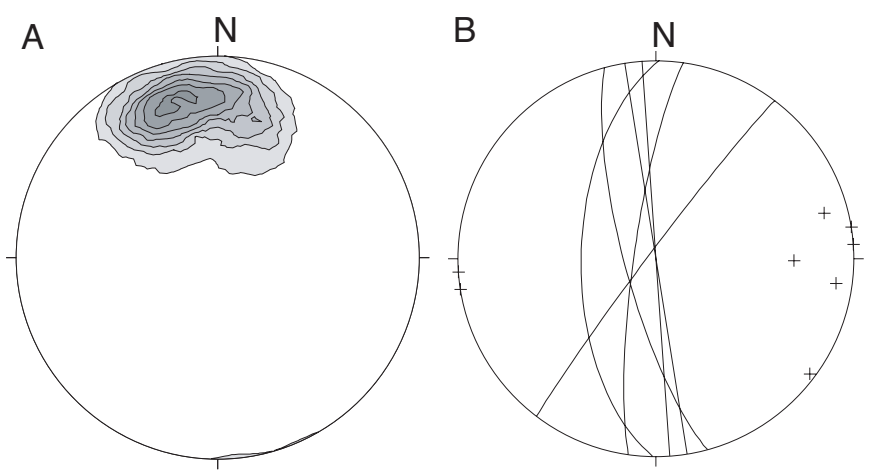

Stereonet 4: Quartz-phyllites of the Phyllite Belt (" $\mathrm{P}_{2}$ "); Road Jinghong to Nanguang, $\mathrm{km}$ 2. A: density-plot of fold-hinges (lineaments, $n=39$, max. at 344/24, contours at: 1.8, 3.6, 5.4, 7.2, 9, 10.8, and 12.6); B: polepoints and planes of kink-bands $(n=6)$. Equal area projection; lower hemisphere. Folding: predominantly upright, few W-vergent- and rare E-vergent folds; disharmonic folding seems to be controlled by the remobilization of quartz.

A

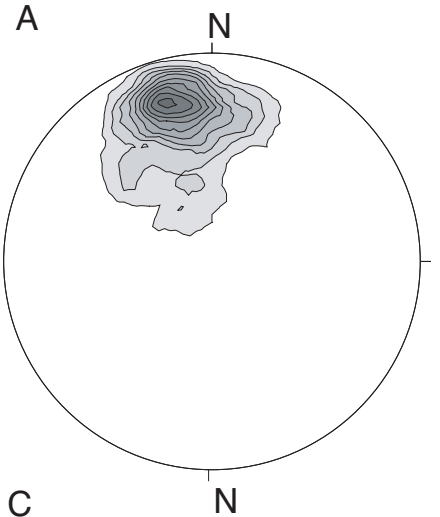

C

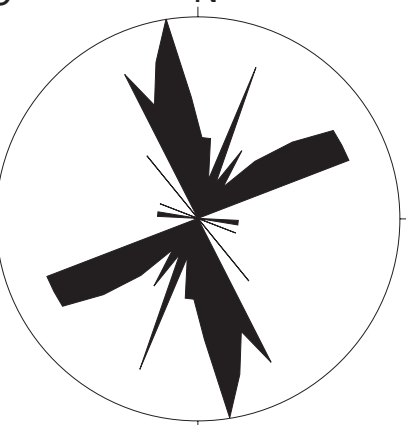

B

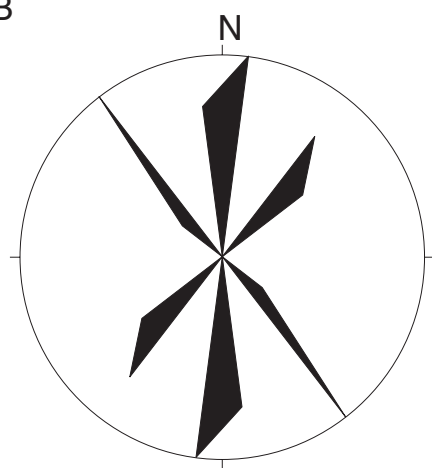

D

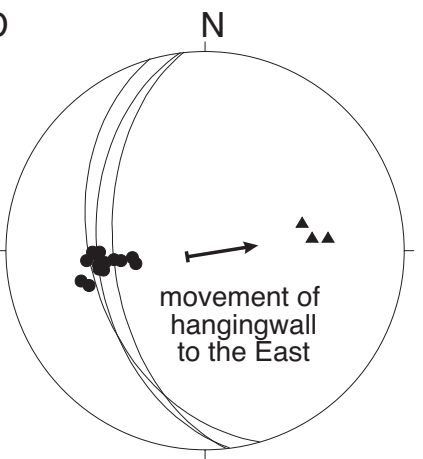

Stereonet 5: Phyllites of the Phyllite Belt $\left(P_{2} \mid\right)$; Road Jinghong to Nanguang, $\mathrm{km} \mathrm{4-6.} \mathrm{A:} \mathrm{density-plot} \mathrm{of} \mathrm{fold-}$ hinges (lineaments, $n=79$, max. at $344 / 21$, contours at: 1.8, 3.6, 5.4, 7.2, 9, 10.8, 12.6, 14.4, 16.2, and 18.0). Equal area projection; lower hemisphere. B: rosediagram of joints within $\mathrm{P}_{2} \mathrm{l}(\mathrm{n}=17)$. C: rose-diagram of joints from an intrusive within $P_{2} \mid(n=54)$. D: polepoints and planes of a fault (triangles) and orientation of slickensides (lineaments, filled circles). Folding: predominantly isoclinal upright, rarely E-vergent. 

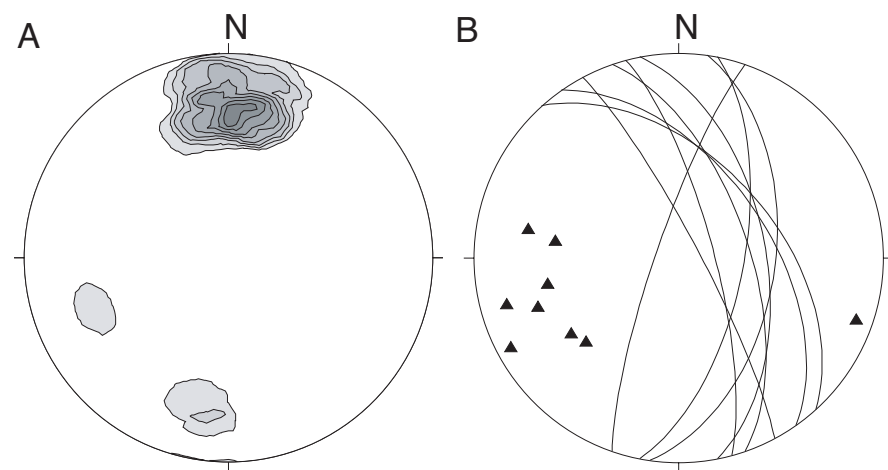

Stereonet 6: weakly metamorphosed rocks to the east of the Phyllite Belt $\left(\mathrm{P}_{2} \mathrm{l}\right)$; Road Jinghong to Nanguang, $\mathrm{km}$ 14-15. Density-plot of fold-hinges (lineaments, $\mathrm{n}=30$, max. at 003/30, contours at: 1.8, 3.6, 5.4, 7.2, 9, $10.8,12.6$, and 14.4). Equal area projection; lower hemisphere. B: pole-points and planes of bedding (ss).

A

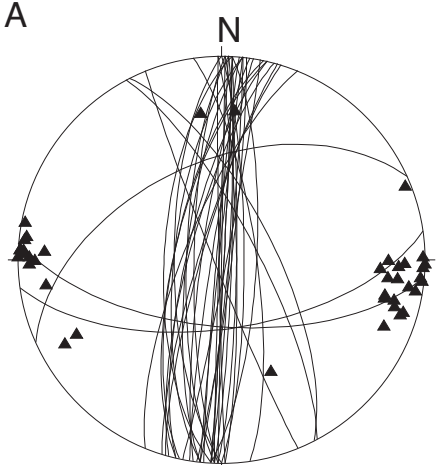

C

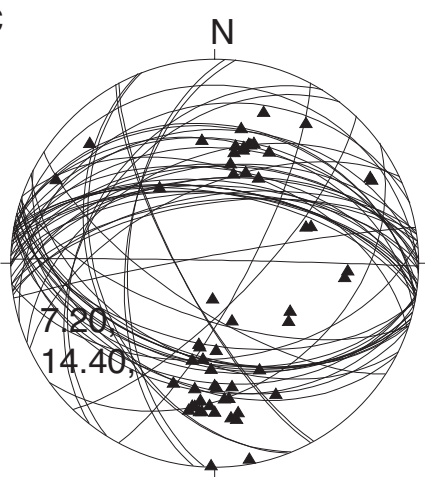

B
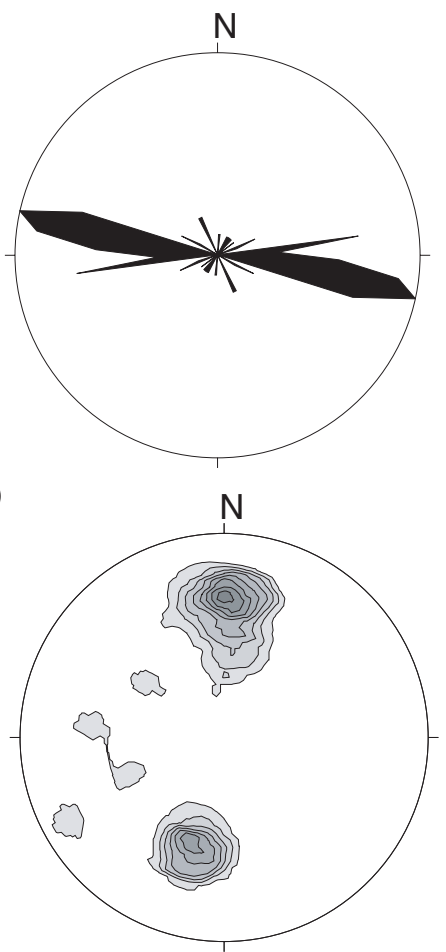

Stereonets 7: weakly metamorphosed rocks to the east of the Phyllite Belt $\left(\mathrm{P}_{2} \mathrm{l}\right)$; Road Jinghong to Nanguang, $\mathrm{km}$ 15.8. A: pole-points and planes of sf1 $(n=38)$. Equal area projection; lower hemisphere. B: rose-diagram of joints within $\mathrm{P}_{2} \mathrm{l}(\mathrm{n}=59)$. C: pole-points and planes of $B$ in an equal area lower hemisphere projection, upper hemisphere. D: Density plot of $\mathrm{C}$ in an equal area projection, lower hemisphere. Note: Although the orientation of the cleavage (sf) is in line with the E-W compression recorded in earlier profiles, jointing must have been younger. 

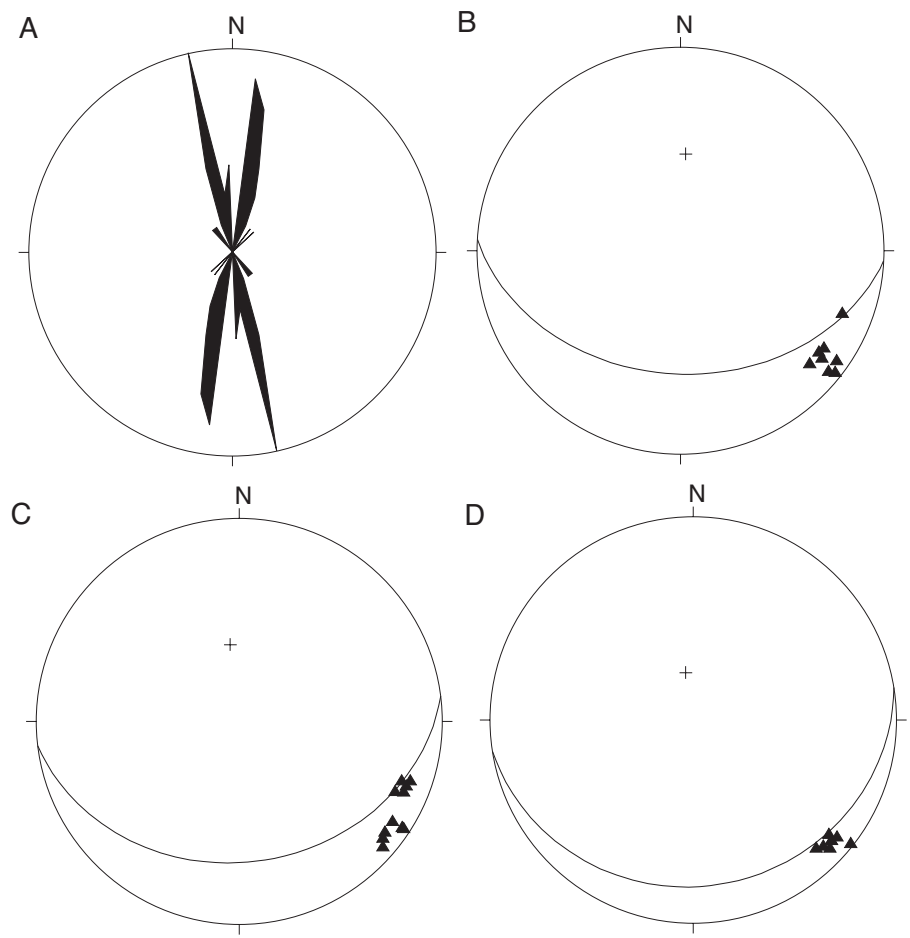

E

F

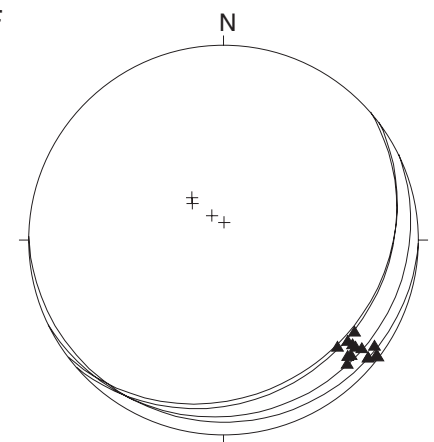

Stereonet 8: Melange Zone; Road Jinghong to Nanguang, km 24. A: Rose-diagram of west-dipping, lens-shaped slices within the Melange Zone $(n=38$; largest pedal 7 values, strike direction: $5^{\circ}$ classes). B, $C$, D, and $E$ show pole-points and planes of thrusts (crosses) and accompanying slickensides (triangles). All slickensides revealed a movement of the hanging wall to easterly and southeasterly directions. (Further data can be received on request). 
Mesozoic: Upper Cretaceous: mudstone intercalated with siltstone and marl lenses (continental red-beds)

$\mathrm{K}_{2}$

Lower Cretaceous: red sandstones, siltstone, marl, conglomerates, Cu-mineralization (continental red-

$\mathrm{K}_{1}$ beds), cf. Chapter 3.4.3

Upper Jurassic: red clastic rocks intercalated with marl lenses (continental red-beds)

Middle Jurassic: mudstone, siltstone, marl (continental red-beds), few limestones, cf. Chapter 3.4.3

$J_{3}$

$J_{2}, J_{2} s, J_{2} h^{1}, J_{2} h^{2}$

Upper Triassic: sandstone, slates, cherts, locally intercalated with limestones, basalts, phyllites Middle Triassic, carbonate and clastic rocks intercalated with volcanic rocks, cf. Chapter 3.3.2, 3.4.1

$T_{3}, T_{3} x, T_{3} s c^{1}, T_{3} C$

$\mathrm{T}_{2}, \mathrm{~T}_{2} \mathrm{~m}_{1}, \mathrm{~T}_{2} \mathrm{~m}_{2}, \mathrm{~T}_{2} \mathrm{~m}$

Lincang Granite, cf, Chapter 3.3.1

$\mu^{2-3}$

Paleozoic: Upper Permian: basalt, carbonate rocks, clastic $(\mathrm{Pz})$ rocks, cherts, limestone, completely revised unit, $\mathrm{P}_{2}, \mathrm{P}_{2} \mathrm{l}$ see lithological profiles of Chapter 3.4.1, 3.5.1

Lower Carboniferous: limestones, clastic rocks, $\quad \mathrm{C}_{1}, \mathrm{Cnn}_{1}$ volcanic rocks ( $\mathrm{Cnn}_{1}$ : Nanduan Formation)

Upper Devonian: carbonate rocks, shales, $\mathrm{D}_{3}$ volcanic rocks

Proterozoic: Lancang Group; (blue-)schists, meta-sandstones and siltstones with meta-basic volcanic rocks

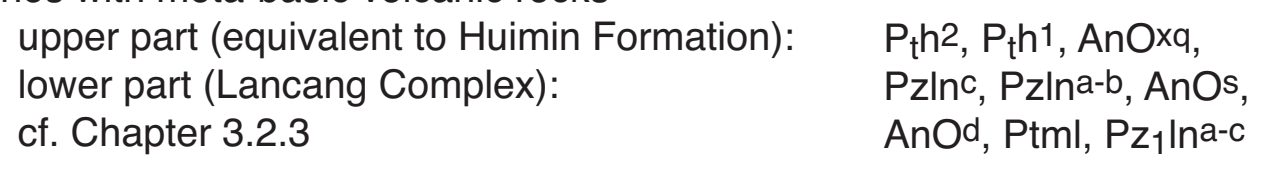

Chongshan Group: migmatites, gneisses and marbles Ptch cf. 3.2.1

Ptdm

Damenglong Group: migmatized schists, gneisses, amphibolites and marbles, cf. 3.2.1 


\begin{tabular}{|c|c|}
\hline BGR & Bundesanstalt für Geowissenschaften und Rohstoffe \\
\hline cf. & confer to \\
\hline CFB & Continental Flood Basalt \\
\hline CIPW & Cross, Iddings, Pirsson and Washington (petrologists) \\
\hline CMB & Changning Menglian Belt \\
\hline CUGW & China University of Geosciences Wuhan \\
\hline CHUR & Chondrite Uniform Reservoir \\
\hline $\mathrm{Cz}$ & Thickness of the Continental Crust \\
\hline $\mathrm{DM}$ & Depleted Mantle \\
\hline$E$ & East \\
\hline e.g. & for example (exempli gratia) \\
\hline $\mathrm{GPa}$ & Giga Pascal \\
\hline GZG & Geowissenschaftliches Zentrum der Universität Göttingen \\
\hline HFSE & High Field Strength Elements \\
\hline IC & Illite Crystallinity \\
\hline ICPMS & Iductively Coupled Plasma Mass Spectronomy \\
\hline IS & Transitional I- and S-type \\
\hline LANF & Low-Angle Normal Fault \\
\hline LILE & Large Ion Lithophile Elements \\
\hline LIP & Large Igneous Province \\
\hline LREE & Light Rare Earth Elements \\
\hline LRZ & Lancang River Zone \\
\hline lz & Thickness of the Lithosphere \\
\hline $\mathrm{Ma}$ & Million Years (Annum) \\
\hline MCC & Metamorphic Core Complex \\
\hline M.I.T. & Massachussetts Institute of Technology \\
\hline MORB & Mid-Ocean-Ridge Basalt (E: Enriched, N: Normal) \\
\hline $\mathrm{N}$ & North \\
\hline NRW & North Rhine Westphalia \\
\hline OIB & Ocean-Island Basalt \\
\hline OIT & Ocean-Island Tholeiite \\
\hline $\mathrm{P}$ & Pressure \\
\hline $\mathrm{Pa}$ & Pascal \\
\hline PGE & Platinum Group Elements \\
\hline ppm & parts per million \\
\hline $\mathrm{P} / \mathrm{T}-\mathrm{t}$ & Pressure / Temperature - time \\
\hline REE & Rare Earth Elements \\
\hline S & South \\
\hline SEDEX & Sedimentary-exhalative \\
\hline S.S. & sensu stricto \\
\hline $\mathrm{T}$ & Temperature \\
\hline TAS & Total Alkali Silica \\
\hline $\mathrm{TC}$ & Total Carbon \\
\hline TU & Technical University \\
\hline VHMS & Volcanic-Hosted Massive Sulfide \\
\hline W & West \\
\hline$w t \%$ & weight percent \\
\hline YBGMR & Yunnan Bureau of Geology and Mineral Resources \\
\hline $\mathrm{XRF}$ & X-ray fluorescence \\
\hline
\end{tabular}


Name:

Geburtstag:

Geburtsort:

Nationalität:

Abitur:

Studium:

Promotion:

Stipendien:

10. Mai 2004
Klaus Heppe

29. August 1972

Warstein (NRW)

deutsch

Städtisches Gymnasium Rüthen (NRW)

WS 93/94 bis SS 98 Diplom-Geologie / Paläontologie Westfälische Wilhelms-Universität Münster Vordiplom: 10/11/1995

WS 96/97 und SS 97 Akademisches Jahr im Ausland Anglia Polytechnic University Cambridge, United Kingdom Bachelor of Science: 10/07/97

WS 98/99 bis WS 99/00 Diplom-Geologie / Paläontologie Georg-August-Universität Göttingen Diplom: 11/01/00

04/01 bis 06/04 Georg-August-Universität Göttingen Projekt der Technischen Zusammenarbeit (TZ) des BMWA vergeben im Rahmen der Hochschulvergabeprojekte der Bundesanstalt für Geowissenschaften und Rohstoffe (BGR), Hannover

04/00 bis 03/01 Ostasienstipendium der DaimlerChrysler AG

04/01 bis 04/04 Promotionsstipendium der Studienstiftung des deutschen Volkes

07/02 bis 10/02 Auslandsstipendium der Studienstiftung des deutschen Volkes, M.I.T., Cambridge, USA 